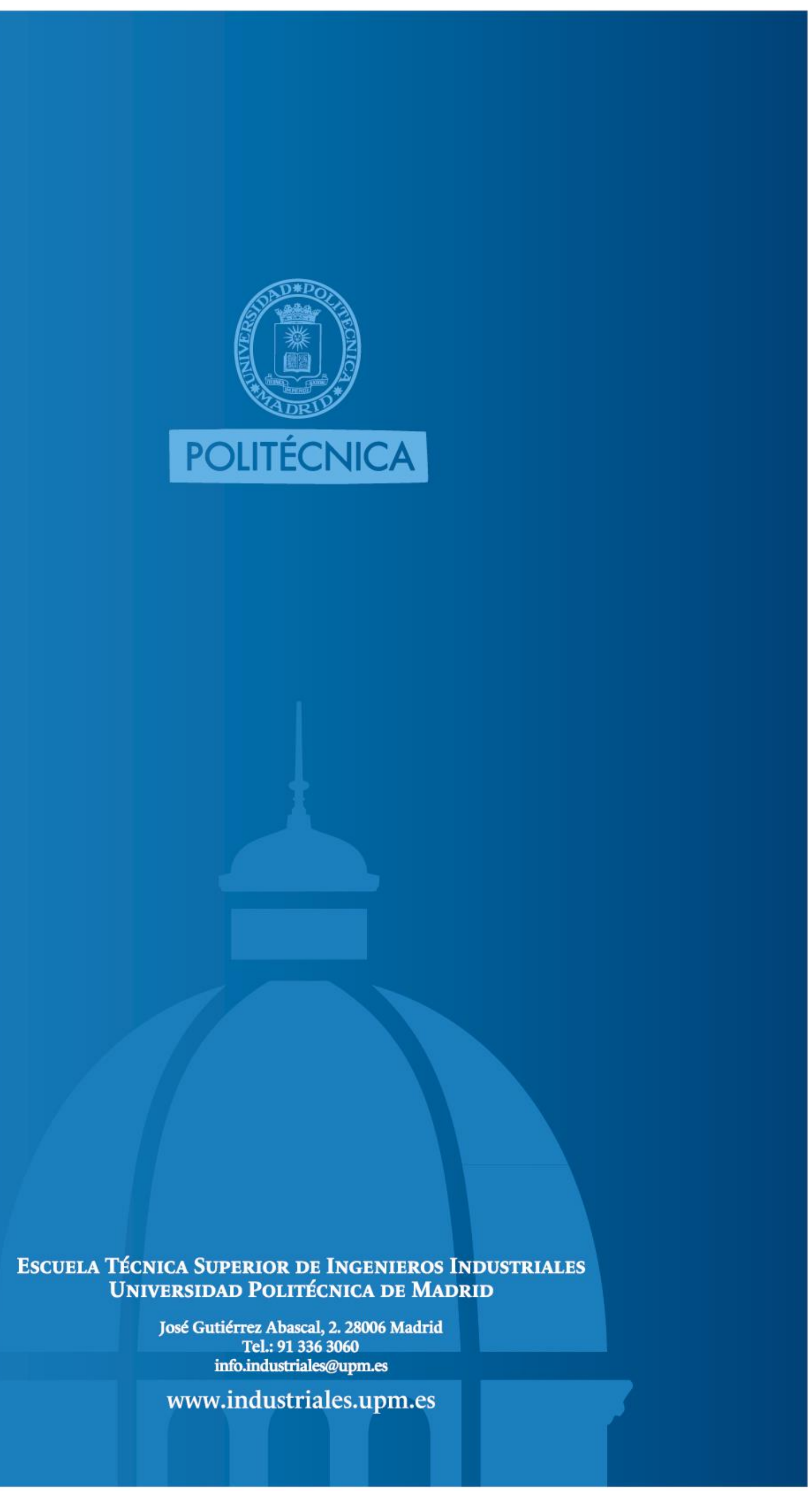

CONTRIBUTIONS IN THE DESIGN AND OPTIMIZATION OF UNREGULATED LLC CONVERTERS WITHHIGH CONVERSION RATIO AND HIGH OUTPUT CURRENT

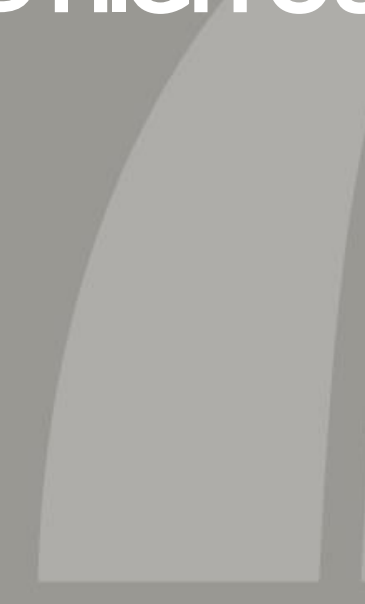

TESIS DOCTORAL PARA LA OBTENCIÓN DEL TÍTULO DE DOCTOR

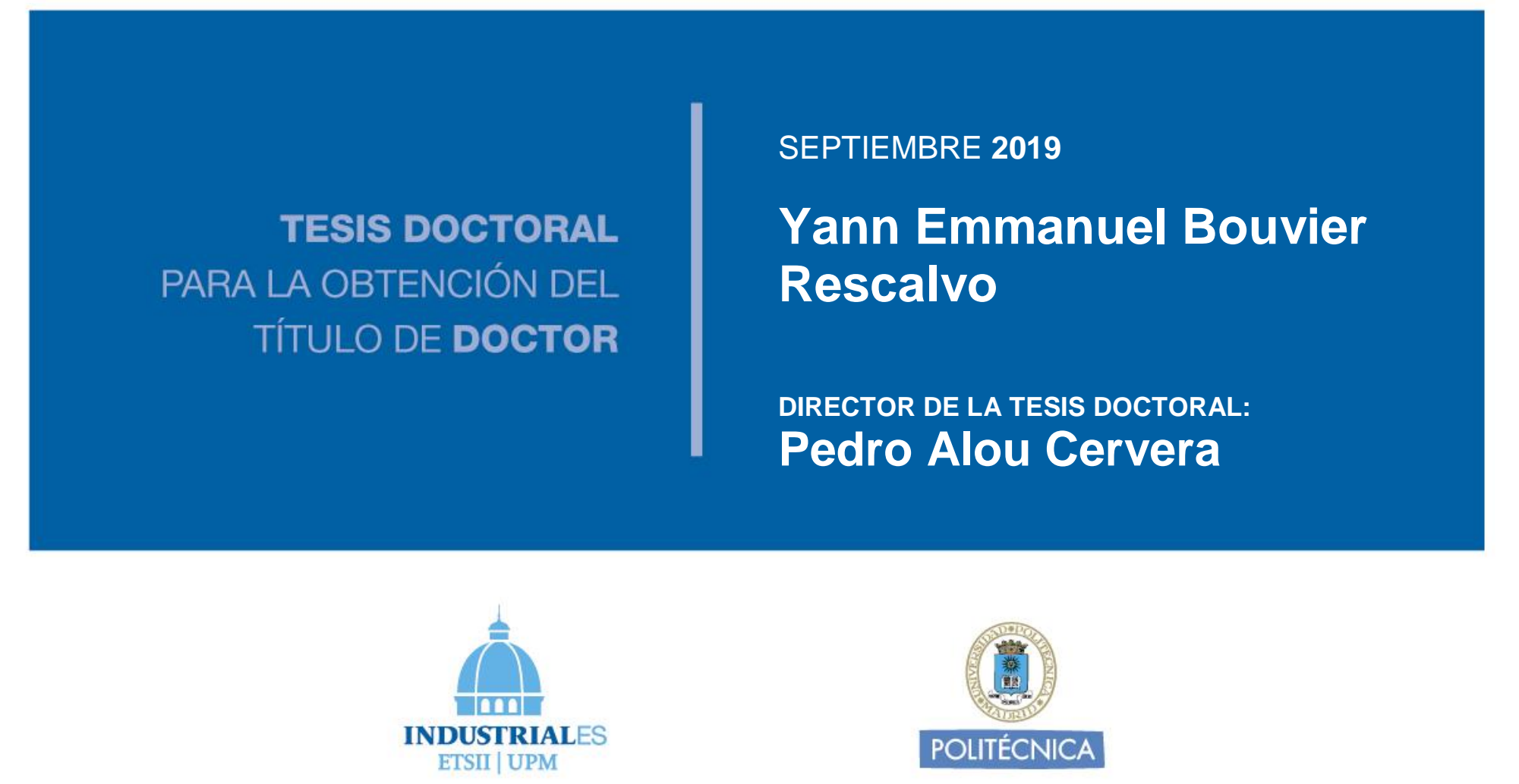




\author{
DEPARTAMENTO DE AUTOMÁTICA, INGENIERÍA \\ ELECTRÓNICA E INFORMATICA INDUSTRIAL \\ ESCUELA TÉCNICA SUPERIOR DE INGENIEROS \\ INDUSTRIALES \\ CENTRO DE ELECTRÓNICA INDUSTRIAL
}

\title{
Contributions in the design and optimization of unregulated LLC converters with high conversion ratio and high output current
}

\section{TESIS DOCTORAL}

Autor: Yann Emmanuel Bouvier Rescalvo

Ingeniero Industrial y Máster en Electrónica Industrial por la Universidad Politécnica de Madrid

Director: Pedro Alou Cervera

Doctor Ingeniero Industrial por la Universidad Politécnica de Madrid 



\section{Tribunal}

Tribunal nombrado por el Mgfco. y Excmo. Sr. Rector de la Universidad Politécnica de Madrid, el día de de 2018.

Presidente: Dr. José Antonio Cobos Márquez

Vocales: $\quad$ Dr. Javier Sebastian Zuñiga

Dr. Zhe Zhang

Dr. Antonio Lázaro Blanco

Secretario: Dr. Miroslav Vasić

Suplentes: Dr. Cristina Fernández Herrero

Dr. Pablo Zumel Vaquero

Realizado el acto de lectura y defensa de la Tesis el día de de 2019 en la Escuela Técnica Superior de Ingenieros Industriales de la Universidad Politécnica de Madrid.

Calificación:

EL PRESIDENTE

LOS VOCALES

EL SECRETARIO 

"Il faut imaginer Sisyphe heureux"

-Albert Camus 1942 



\section{Acknowledgements}

It has been a long journey since the start of my research work at the Centro de Electrónica Industrial (CEI). It is finally coming to an end, and I can already see some light at the end of the tunnel. This research work has been exhausting yet thrilling. I encourage any aspiring Ph.D. students reading this to keep the hard work but also remember to take care of yourselves.

I would like to express my sincere gratitude to my tutor: Professor Pedro Alou. For all his wisdom, diligence, and professionalism during our research work. I would also like to mention Professors Jesús A. Oliver and Miroslav Vasić, for all their help in the projects and the research that I have participated in during my stay in the CEI laboratory. The work ethic that I learned from them has influenced me and will benefit me for the rest of my career.

This research work could not have been done without the help of the people for the AIR project. From Indra, Fernando Arévalo and Jorge Carmena, but also, a special thanks to Gonzalo Moreno for the help in gathering the necessary data, and his generosity with his time. To my research project colleague Uros Borovic, I am thankful for having the opportunity to work alongside a brilliant student and researcher.

During my short but intense research stay in Denmark at DTU, I learned and experienced a different way of working, and a beautiful country. I would like to thank my tutor Professor Ziwei Ouyang for his time, guidance and knowledge, and Kevin Mañez for his generosity by lending me his prototype for research. Of course, a warm thank you to Henriette and María Mira for their help and friendliness, during the whole stay.

My gratitude also goes to the rest of professors and staff from CEI. Especially Oscar García, without his help I would not have started my journey in CEI. Of course, the long work hours would not have been the same without the support from friends and coworkers: Nico, Branislav, Vladan, Mónica, María, Mavi, Aledo, Mora, Álvaro, Fer, A $\nu \tau \rho \varepsilon \alpha \varsigma$, 李诚，史丽金金, and 赵思思. Thank you for teaching me a little bit about each of your country's culture and languages. 
A los miembros de Kaizen, Pablo, Trayad, Laura y Ricardo, por hacerme olvidar mis problemas una vez por semana. Tampoco hubiese podido aguantar con la presión que ha supuesto este trabajo sin mi pasión por la música. Agradezco a todos los miembros de Lymon RF, Carlota, Asier y Diego todos los buenos momentos y el disfrute de los ensayos y conciertos.

A Guillermo y Diego. No podría haber acabado esta tesis sin vuestra ayuda. En esta tesis no solo está mi sangre y sudor pero también el vuestro.

À mes parents et mon frère, Marc, Vicenta et Ael. Merci pour vos encouragements et le soutien moral pendant cette periode difficile de ma vie. L'éducation que vous m'avez fourni à fait de moi la personne que je suis maintenant. Grosse bises.

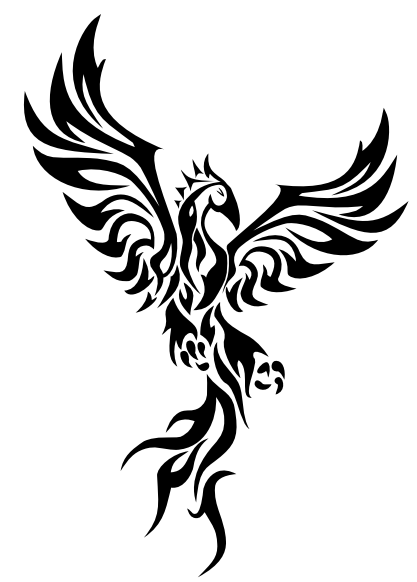





\begin{abstract}
In the last two decades, the awareness of global environmental issues has accelerated the need for more efficient and cost-effective systems, especially in the field of transportation, that represents $25 \%$ of all $\mathrm{CO}_{2}$ emissions in Europe. To provide solutions to this issue, new power converter solutions are developed with new topologies, materials, and control methods to increase their efficiency and power density. The series resonant LLC converter topology has gathered significant attention in the state of the art. It achieves soft switching with ease and therefore, has improved efficiency compared with other topologies. A great benefit of the LLC converter is also the magnetic integration, as the two inductors can be merged into a single component, increasing the power density of the converter. However, with the increase in power and the restrictive specifications of modern transportation systems, new design challenges arise. This Ph.D. dissertation focuses on the contribution in the design and optimization of the unregulated LLC converter with a high conversion ratio and high output current.

In Chapter 2, an overview of the state of the art is provided. The basic topologies of isolated DC-DC converters are reviewed and briefly compared in the context of high current and high conversion ratio applications. Then, topologies are briefly reviewed. The isolated LLC converter is highlighted as a good candidate for high efficiency and power density.

The operation of the isolated LLC full-bridge is reviewed in more detail in Chapter 3. The different operation modes and frequency modes are briefly explained and reviewed. Using analytical calculations, it has been found that the optimal operation mode of the LLC converter is located at the resonant frequency. Additionally, the LLC converter operating at resonant frequency displays a constant gain and can be used for DC transformer applications. The traditional approach to estimate the voltage gain is the first harmonic approximation (FHA). This method presents a mismatch with the real converter in applications with high parasitics, like high conversion and high output current applications. In this chapter, modified models, including parasitics are analyzed and compared with the traditional FHA method. These models have a substantial impact on the design of unregulated LLC
\end{abstract}


converters that can be used as DC transformers. In these unregulated converters the mismatches and error of the traditional FHA method cannot be corrected by the control loop. Additionally, the resonant current models are analyzed, using the same time-based models as the voltage gain models.

In Chapter 4, the zero voltage switching (ZVS) transition is analyzed considering the particularities of LLC converters, where the resonant inductor creates a variable turn-off current. This has to be considered in order to assess the ZVS capabilities of a LLC design. In this context, the traditional approach of considering a constant turn-off current is accurate enough. A charge-based method is proposed to estimate the ZVS range of the LLC converter with accuracy. High magnetizing inductance transformers minimize circulating currents and improve the efficiency. However, with low magnetizing currents, the ZVS capabilities of the LLC is reduced. Auxiliary circuits can be used to solve this issue while maintaining the benefits of a high magnetizing transformer. This chapter ends with a review and performance comparison of different auxiliary circuits used to improve the ZVS capabilities of full-bridge converters.

In Chapter 5, a design and optimization method of the LLC full-bridge for high output current and high conversion ratio with full ZVS range is presented. State of the art models are used to model the power losses, volume, and temperatures. They are reviewed in section 5.2. Because power converters are complex systems with multiple design variables. A multi-objective optimization method can be used to determine the best design solutions. The Pareto front analysis is used to identify the design solutions with the best efficiency and power density trade-off. The results of this multi-objective optimization are presented and analyzed.

In Chapter 6, a $10 \mathrm{~kW}$ unregulated LLC prototype with a single inductor ZVS auxiliary circuit and a two series/parallel transformer configuration is presented. The prototype specifications follow aircraft standards as part of a project from the European Cleansky initiative. The performance of the converter is measured at different output powers. The behavior of the converter is shown with and without an auxiliary circuit to verify the efficiency improvement.

In the last chapter, a summary of all the conclusions reached with this research work is presented. The different contributions are highlighted. To finish, a brief vision of the possible future lines of work is provided. 



\section{Resumen}

En las dos últimas décadas, el incrementado en la consciencia de los problemas globales del medio ambiente ha incrementado la necesidad de sistemas energéticamente eficientes y económicos, especialmente en el ámbito del transporte, que representa el $25 \%$ de las emisiones de $\mathrm{CO}_{2}$ en Europa. Para dar solución a estos problemas, nuevos convertidores electrónicos de potencia están siendo desarrollados con nuevas topologías, materiales y métodos de control para mejorar su rendimiento y densidad de potencia. La topología del convertidor serie resonante LLC, de creciente interés en el estado del arte, tiene un rendimiento alto, gracias al uso de conmutación suave de los transistores. Otro beneficio de la topología LLC es la integración magnética, concepto por el cual se pueden fusionar varios componentes magnéticos en uno solo. En el caso del convertidor LLC se pueden integrar las dos bobinas resonantes dentro del transformador, incrementando la densidad de potencia del convertidor. Sin embargo, utilizando altas potencias y con las especificaciones restrictivas de los sistemas de transporte modernos, surgen nuevos desafíos en el diseño de estos convertidores. Esta tesis doctoral se centra en las contribuciones al diseño y optimización de convertidores LLC no regulados de alta relación de tensiones y alta corriente de salida.

En el capítulo 2, se da una visión de conjunto del estado del arte. Las topologías de convertidores $\mathrm{CC} / \mathrm{CC}$ aislados son repasadas y brevemente comparadas entre ellas en el contexto de los convertidores de alta relación de tensiones y alta corriente de salida. A continuación, las topologías resonantes son introducidas, de las cuales el convertidor LLC surge como un buen candidato para aplicaciones con alto requisitos en rendimiento y densidad de potencia.

La operación del convertidor LLC de puente completo es repasada en más detalle en el capítulo 3. Los distintos modos de operación y modos de frecuencia son brevemente explicados. Utilizando ecuaciones analíticas, se encuentra que el máximo rendimiento se consigue con la operación a frecuencia de resonancia. Por otra parte, el convertidor LLC exhibe una ganancia en tensión constante cuando opera a frecuencia de resonancia y puede ser usado para aplicaciones de transformador de continua (DC transformer). Tradicionalmente, se usa la aproximación por 
primer armónico (FHA) para estimar la ganancia en tensión del convertidor LLC. Sin embargo, este método presenta cierta discrepancia con respecto a la ganancia real del convertidor, cuando este presenta elementos parásitos, como la resistencia parasita del tanque resonante. En este capítulo, modelos modificados para incluir estos parásitos son analizados y comparados con el método tradicional (FHA). Estos modelos tienen un impacto substancial en el diseño de convertidores LLC no regulados, donde no existen lazos de control para corregir las pequeñas discrepancias de los modelos tradicionales. Al final del capítulo, los modelos de corriente son brevemente analizados utilizando modelos similares a los modelos de ganancia en tensión, considerando los elementos parásitos.

En el capítulo 4, la transición de la conmutación a cero tensión (ZVS) es analizada considerando las particularidades de los convertidores LLC, donde la bobina serie del tanque resonante crea una corriente de apagado variable. Esta corriente variable debe ser considerada para evaluar la capacidad para conseguir ZVS en diversos diseños de convertidor LLC. En este contexto, la aproximación tradicional de corriente constante no es suficientemente precisa y un método basado en la carga total de la corriente de apagado es propuesto y analizado con mayor precisión para estimar el comportamiento de la conmutación ZVS. Los transformadores con alta inductancia magnetizante minimizan las corrientes circulantes. Sin embargo, con corrientes circulantes reducidas también se reduce la capacidad del convertidor para conseguir ZVS. Los circuitos auxiliares se pueden usar como solución a este problema manteniendo los beneficios de un transformador con alta inductancia magnetizante. Este capítulo finaliza con un repaso de los distintos circuitos auxiliares existentes en el estado del arte para conseguir una conmutación ZVS en convertidores LLC de puente completo.

En el capítulo 5, se presenta un método de diseño y optimización de convertidores LLC de puente completo con alta relación de tensiones y alta corriente de salida. Se usan modelos del estado del arte para el cálculo de perdidas, volúmenes y temperaturas de operación. El diseño de convertidores electrónicos de potencia es un problema complejo de muchas variables. Por lo tanto, se un método de optimización multivariable llamado análisis por frente de Pareto para identificar los diseños con mejor compromiso entre rendimiento y densidad de potencia. 
En el capítulo 6, se presenta un prototipo de $10 \mathrm{~kW}$ de convertidor LLC no regulado con circuito auxiliar de una sola bobina con configuración serie/paralelo de dos transformadores. El prototipo sigue las especificaciones de los estándares de aviónica, como parte de un proyecto adjunto a la iniciativa europea Cleansky. Medidas y resultados del convertidor son presentados a distintas potencias de salida. El comportamiento del convertidor con y sin circuito auxiliar es presentado para verificar la mejora que supone para el rendimiento.

En el último capitulo, se presenta un resumen de las conclusiones de este trabajo de investigación, destacando las contribuciones originales, finalizando con un breve resumen de las posibles líneas futuras. 



\section{Contents}

1 Introduction $\quad 1$

1.1 Motivation . . . . . . . . . . . . . . . . . 1

1.2 Organization of the dissertation . . . . . . . . . . 2

2 Study of the state of the art $\quad 5$

2.1 Isolated DC-DC Converters for high conversion ratio and high output

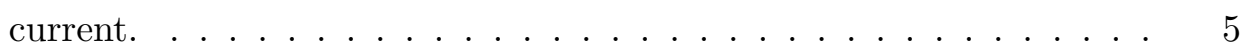

2.2 Resonant Converters . . . . . . . . . . . . . . . . . 10

3 Isolated LLC Full-Bridge at Resonant Frequency: Operation and $\begin{array}{ll}\text { Modelling } & 15\end{array}$

3.1 Normalization in isolated LLC converters . . . . . . . . . . . . 15

3.2 Operating principle . . . . . . . . . . . . . . . . . 18

3.2.1 Switching frequency operation modes . . . . . . . . . . 21

3.2.2 Unregulated LLC converter operating at resonant frequency . 23

3.3 Voltage gain models . . . . . . . . . . . . . . . . . . . . 24

3.3.1 First harmonic approximation model (FHA) . . . . . . . . . . 24

3.3.2 Series resistance modified First harmonic approximation model (SR-FHA) . . . . . . . . . . . . . 25

3.3.3 Distributed Impedance FHA model (DI-FHA) _ . . . . . 27

3.3.4 Time-based simulation models: (SR-TB and DI-TB) . . . . 29

3.3 .5 Comparison of models . . . . . . . . . . . . . . 30

3.4 Resonant current models . . . . . . . . . . . . . . . . . . . . 33

3.4.1 Series resistance and current distortion . . . . . . . . . . 34

3.4.2 Comparison between SR-TB and DI-TB current models . . . 35

3.5 Chapter summary . . . . . . . . . . . . . . . . . . 36

4 Zero Voltage Switching Analysis in LLC Converters and $\begin{array}{ll}\text { Auxiliary Circuits } & 37\end{array}$

4.1 ZVS Basics . . . . . . . . . . . . . . . . . . 38 
4.2 ZVS transition analysis: conventional method and limitations for LLC converters . . . . . . . . . . . . . . . . . . 44 41

4.3 Charge-based ZVS analysis for LLC converters . . . . . . . . . . 43

4.4 ZVS auxiliary circuits: analysis, design and comparison . . . . . . 45

4.4.1 Auxiliary circuits classification . . . . . . . . . . . . 45

4.4.2 Design of auxiliary circuits . . . . . . . . . . . 46

4.4.3 Comparison of ZVS auxiliary circuits . . . . . . . . . . 54

4.5 Chapter summary . . . . . . . . . . . . . . . . . . . . . 59

5 Design and Optimization $\quad 61$

5.1 Problem statement: Multiobjective-optimization . . . . . . . . . 61

5.2 Modeling of losses, volume and temperatures . . . . . . . . . . 62

5.2 .1 Power loss models . . . . . . . . . . . . . . . . . . 63

5.2 .2 Volume estimation . . . . . . . . . . . . . . . 70

5.2.3 Thermal modeling of magnetic components . . . . . . . . . . 74

5.3 Design of LLC operating at resonant frequency with high conversion ratio and high output current . . . . . . . . . . . . . . 80

5.3 .1 Parameter design . . . . . . . . . . . . . . . 80

5.3 .2 Transistor design . . . . . . . . . . . . . . . . . 85

5.3.3 Magnetic component design . . . . . . . . . . . . . . . 88

5.3.4 Series-Parallel Configuration _... . . . . . . . . . . . 93

5.4 Multi-objective optimization: Pareto front analysis . . . . . . . . . 97

5.4.1 Data calculation algorithm for LLC converters operating at resonant frequency . . . . . . . . . . . . . . 97

5.4.2 Multi-objective optimization results and conclusions . . . . . 99

5.5 Chapter summary . . . . . . . . . . . . . . . . . . . . 104

$\begin{array}{llr}6 & \text { Experimental validation } & 107\end{array}$

6.1 Construction of prototype . . . . . . . . . . . . . . 107

6.1.1 More electric aircraft philosophy . . . . . . . . . . . . . 107

6.1.2 Transistors . . . . . . . . . . . . . . . . . . . . 112

6.1.3 Magnetic components . . . . . . . . . . . . . . . 113

6.1 .4 Capacitors . . . . . . . . . . . . . . . . . . 114

6.1 .5 Heat-sink . . . . . . . . . . . . . . . . . . . 115 
6.1 .6 Drivers . . . . . . . . . . . . . . 116

6.1 .7 Control board . . . . . . . . . . . . . . . . 116

6.2 Experimental results . . . . . . . . . . . . . . . . . . 116

6.2 .1 Voltage gain verification . . . . . . . . . . . . . . 119

6.2.2 ZVS transition experimental results and auxiliary circuit . . . 120

6.2.3 Performance at different loads . . . . . . . . . . . . . . . . . 124

6.2.4 Experimental results: conclusions . . . . . . . . . . . . . . 127

7 Conclusion and future work $\quad 129$

7.1 Conclusion and contributions . . . . . . . . . . . . . . . . 129

7.2 Future work . . . . . . . . . . . . . . . . . . 131

7.3 Diffusion of the results . . . . . . . . . . . . . . . . . 132

$\begin{array}{ll}\text { Bibliography } & 135\end{array}$ 



\section{List of Figures}

Fig. 1.1 Number of IEEE publications related to LLC converters over the years. Source - IEEE . . . . . . . . . . . . . . . . 2

Fig. 2.1 Flyback converter . . . . . . . . . . . . . . . 6

Fig. 2.2 Forward converter . . . . . . . . . . . . . . . 6

Fig. 2.3 Double ended inverter configurations . . . . . . . . . . . 8

Fig. 2.4 Double ended rectifier configurations . . . . . . . . . . 8

Fig. 2.5 Double ended synchronous rectifier configurations . . . . . . . 9

Fig. 2.6 Resonant converter structure . . . . . . . . . . . . . . . . . 10

Fig. 2.7 LLC converter output power for IEEE publications from 2012

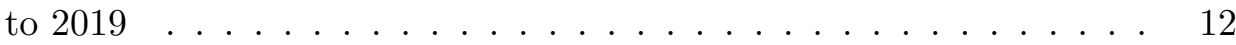

Fig. 2.8 Efficiency over Voltage Gain $\left(\frac{V_{\text {OUT }}}{V_{I N}}\right) \ldots \ldots \ldots \ldots$

Fig. 2.9 Efficiency over output power for LLC converter from IEEE publications from 2012 to 2019, distinguishing the input inverter structure . . . . . . . . . . . . . . . . .

Fig. 2.10 Efficiency over output power for LLC converter from IEEE publications from 2012 to 2019, distinguishing the output rectifier structure . . . . . . . . . . . . . . . . . . 13

Fig. 3.1 Isolated LLC converter with diode bridge . . . . . . . . . . . . . 16

Fig. 3.2 LLC circuit with full-bridge inverter and full-bridge diode rectifier 18

Fig. 3.3 LLC circuit with full-bridge inverter and full-bridge diode rectifier 19

Fig. 3.4 Positive powering state . . . . . . . . . . . . . . . . 20

Fig. 3.5 Negative powering state . . . . . . . . . . . . . . . . 20

Fig. 3.6 Positive freewheeling state . . . . . . . . . . . . . . . 20

Fig. 3.7 Negative freewheeling state _ . . . . . . . . . . . . . . . . 21

Fig. 3.8 LLC converter switching frequency modes: below resonance (left), at resonance (center) and above resonance (right) . . . . . . .

Fig. 3.9 LLC converter total power losses normalized over the peak output power $\left(P_{\text {Loss }} / P_{\text {Out }}\right)$ at $m=10.5$ and at $m=215 \ldots \ldots$. 
Fig. 3.10 LLC circuit transformation using FHA . . . . . . . . . . . 24

Fig. 3.11 FHA (hacer un zoom y mostar la zona de $\mathrm{M}=1$ y $\mathrm{fn}=1 \ldots 26$

Fig. 3.12 FHA equivalent circuit with series resistance (SR-FHA) . . . 26

Fig. 3.13 Transformer model and normalized transformer model referred to primary values. . . . . . . . . . . . . . . 27

Fig. 3.14 Transformer models considering coupling factor $k \ldots \ldots 27$

Fig. 3.15 Distributed transformer model with additional external parasitic impedances. All secondary impedances are referred to primary side. 28

Fig. 3.16 FHA Equivalent circuit with distributed impedances (DI-FHA) 28

Fig. 3.17 Time-based equivalent circuit with series resistance (RS-TB) . . 30

Fig. 3.18 Time-based equivalent circuit with Distributed impedances

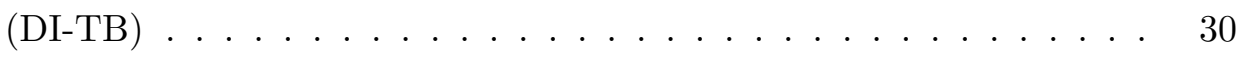

Fig. 3.19 Comparison of the voltage gain $M$ from SR-FHA and SR-TB models at low inductance ratio $m=10.5 \ldots \ldots \ldots$

Fig. 3.20 Comparison of the voltage gain $M$ from SR-FHA and SR-TB models at high inductance ratio $m=215 \ldots \ldots . \ldots 31$

Fig. 3.21 Comparison of the voltage gain $M$ from DI-FHA and DI-TB models at low inductance ratio $m=10.5 \ldots \ldots . \ldots 32$

Fig. 3.22 Comparison of the voltage gain $M$ from DI-FHA and DI-TB models at high inductance ratio $m=215 \ldots \ldots$. . . . . . . 32

Fig. 3.23 Comparison of rms current for FHA and TB models . . . . . . 34

Fig. 3.24 Resonance damping . . . . . . . . . . . . . . . . . . . . . . . 34

Fig. 3.25 Current distortion . . . . . . . . . . . . . . . . . 34

Fig. 3.26 SR-TB cambiar a puente de mosfets en primary . . . . . . . 35

Fig. 3.27 DI-TB cambiar a puente de mosfets en primary . . . . . . . . 35

Fig. 3.28 Instantaneous resonant current comparison for RS-TB and DI-TB models, at $m=10.5$ and $m=215$ at $10 k W \ldots \ldots$

Fig. 4.1 LLC converter voltage gain $M$ over the normalized frequency $f_{n}$ with the ZVS and ZCS operating regions . . . . . . . . . 37

Fig. 4.2 MOSFET with parasitic diode and $C_{O S S}$ capacitance . . . . . 39

Fig. 4.3 MOSFET totem pole structure: a) Low-side turn-off, high-side turn-on b) High-side turn-off, Low-side turn-on . . . . . . . . . . . . 39 
Fig. $\quad 4.4$ Output capacitance $C_{\text {oss }}$ of a Coolmos MOSFET device IPW65R037C6 in function of $V_{d s} \ldots \ldots \ldots \ldots$

Fig. $\quad 4.5$ Equivalent output capacitance of a transistor leg with IPW65R037C6 devices, as depicted in Figure 4.6 . . . . . . . . . . 40

Fig. 4.6 Transistor leg with a single inductor, ZVS transition model . . 40

Fig. 4.7 Discharge of the output capacitance with variable Capacitance (red dotted line) and equivalent Capacitance models (blue solid line) $\quad 40$

Fig. 4.8 Single inductor . . . . . . . . . . . . . . . . . . . . . . . . . 41

Fig. 4.9 LLC resonant network . . . . . . . . . . . . . . . . . . . 42

Fig. 4.10 Distributed LLC model resonant network . . . . . . . . . . . . 43

Fig. 4.11 LLC converter current during the transition below resonance (left), at resonance (center) and above resonance (right), for two different inductance ratios: $m=10.5$ (center row) and $m=215$

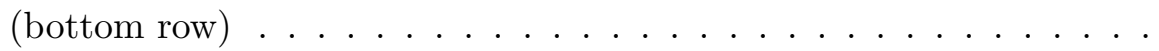

Fig. 4.12 Two auxiliary circuit structure for Full-bridge: Between nodes A and $\mathrm{B}$ the rest of the full-bridge is connected . . . . . . . . .

Fig. 4.13 Single "leg to leg" auxiliary circuit structure for Full-bridge: Between nodes A and B the rest of the full-bridge is connected . . . 46

Fig. 4.14 Auxiliary circuits, A: Single inductor passive circuit, B: two inductors with auxiliary capacitor leg circuit, C: LCL resonant circuit, D: Single inductor active circuit . . . . . . . . . . . . . . 47

Fig. 4.15 Single inductor passive circuit . . . . . . . . . . . . . . . 48

Fig. 4.16 Single inductor passive circuit waveforms . . . . . . . . . . . . . 49

Fig. 4.17 Maximum auxiliary inductance ratio $m_{x}$ for different at different frequencies and output powers . . . . . . . . . . . . . 50

Fig. 4.18 Two inductors with auxiliary capacitor leg circuit . . . . . . . . 51

Fig. 4.19 Two inductors with auxiliary capacitor leg circuit waveforms . . 51

Fig. 4.20 LCL resonant auxiliary circuit . . . . . . . . . . . . . . . . 52

Fig. 4.21 LCL resonant circuit waveforms . . . . . . . . . . . . . 53

Fig. 4.22 Single inductor active auxiliary circuit f . . . . . . . . . 53

Fig. 4.23 Single inductor active auxiliary circuit: simulated waveforms . . 54 
Fig. 4.24 Comparison of power losses for the four different auxiliary circuit designs. The losses of the switches are dividided into switching losses

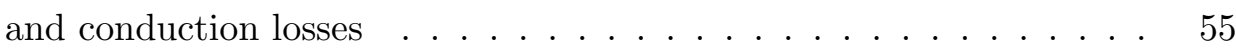

Fig. 4.25 Comparison of Volume for the four different auxiliary circuit designs . . . . . . . . . . . . . . . . 55

Fig. 4.26 Comparison of MOSFET currents with the different auxiliary circuit solutions . . . . . . . . . . . . . . . .

Fig. 4.27 Comparison of power losses for each auxiliary circuit design with extra primary bridge conduction losses, because of the current distortion from Figure $4.26 \ldots \ldots \ldots \ldots$

Fig. 5.1 Pareto front data calculation algorithm . . . . . . . . . . . . 62

Fig. 5.2 Temperature effect on Drain/Source resistance from Infineon Si MOSFET IPW65R037C6 . . . . . . . . . . . . . . 64

Fig. $\quad 5.3$ Switching loss estimation from data-sheet. Source SCTH9065G2V-7 . . . . . . . . . . . . . . 65

Fig. 5.4 High frequency effects: Skin effect and Proximity effect . . . . . 67

Fig. 5.5 Power loss in function of flux density $B$ at different frequencies for material 3C95. Source: Ferroxcube $[1] \ldots \ldots$. . . . . . . 68

Fig. 5.6 Capacitor model with parasitic ESL and ESR . . . . . . . . . 69

Fig. 5.7 Planar transformer . . . . . . . . . . . . . . . . . . 71

Fig. 5.8 Planar transformer with heat-sink . . . . . . . . . . . 71

Fig. 5.9 Prototype breakdown of power losses . . . . . . . . . . 72

Fig. 5.10 Film capacitor data-sheet: Volume estimation . . . . . . . . . 73

Fig. 5.11 Multilayer ceramic capacitor data-sheet: Volume estimation . . 73

Fig. 5.12 Simple thermal electric equivalent model . . . . . . . . . . . 74

Fig. 5.13 Decoupled thermal electric equivalent model . . . . . . . . . 75

Fig. 5.14 Coupled thermal electric equivalent model . . . . . . . . . . 76

Fig. 5.15 Transformer design A . . . . . . . . . . . . . . . . . 77

Fig. 5.16 Transformer design B . . . . . . . . . . . . . . . . 77

Fig. 5.17 Transformer design C . . . . . . . . . . . . . . . 77

Fig. 5.18 Thermal Resistance: FEA calculations (diamonds), Curve Fitting from equations 5.325 .335 .345 .35 (dotted line) . . . . . 77 
Fig. 5.19 Thermal runaway effect . . . . . . . . . . . . . . . . . . 79

Fig. 5.20 LLC resonant network . . . . . . . . . . . . . . . 80

Fig. 5.21 Voltage gain for different inductance ratios . . . . . . . . . . . 83

Fig. 5.22 LLC full-bridge converter: Parallel inductor voltage . . . . . . . 83

Fig. 5.23 Parallel inductor $L_{m}$ : Voltage and current . . . . . . . . . . . 84

Fig. 5.24 LLC full-bridge converter: Parallel inductor voltage . . . . . . . 85

Fig. 5.25 ZVS current . . . . . . . . . . . . . . . . . 86

Fig. 5.26 Power Losses of different technologies . . . . . . . . . . . . 87

Fig. 5.27 Junction Temperature of the different transistor technologies. . 87

Fig. 5.28 LLC converter with high conversion ratio and high output power 90

Fig. 5.29 Core/winding power loss trade-of in function of the transformer secondary number of turns . . . . . . . . . . . . . . . . . 92

Fig. $\quad 5.30$ Core and winding temperatures in function of different transformer sizes, scaled with the effective area . . . . . . . . . 94

Fig. 5.31 Optimal secondary number of turns for different transformer sizes, scaled with the effective area . . . . . . . . . . . . 94

Fig. 5.32 Series/parallel configuration, $\mathrm{SP}=1$ and $\mathrm{SP}=2 \ldots \ldots 9$

Fig. 5.33 Series/parallel configuration arbitrary number of series parallel

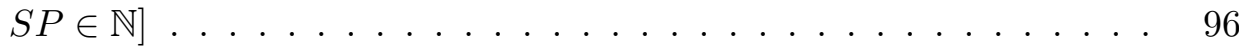

Fig. 5.34 Pareto front data calculation algorithm . . . . . . . . . . . 100

Fig. 5.35 Pareto results for different transistor technologies and Series/Parallel configurations . . . . . . . . . . . . . . . . 102

Fig. $\quad 5.36$ Pareto results for different transistor technologies and Series/Parallel configurations . . . . . . . . . . . . . . 102

Fig. $\quad 5.37$ Pareto results for different transistor technologies and Series/Parallel configurations . . . . . . . . . . . . . . . . . 103

Fig. 5.38 Capacitor design space results . . . . . . . . . . . . . . . . 103

Fig. 6.1 Aircraft isolated rectifier: Passive solution . . . . . . . . . . . . 108

Fig. 6.2 Aircraft isolated rectifier: Active solution . . . . . . . . . . . . 108

Fig. 6.3 System redundancy. a) Normal operation. b) Overload operation 109

Fig. $\quad 6.4$ Prototype: $10 k W$ LLC converter operating at constant frequency with series parallel configuration . . . . . . . . . . . . 111 
Fig. 6.5 LLC converter operating at constant frequency with series parallel configuration . . . . . . . . . . . . . . . . . 111

Fig. 6.6 Transformer with heat-sink . . . . . . . . . . . . . 113

Fig. 6.7 Auxiliary inductor . . . . . . . . . . . . . . . 114

Fig. 6.8 Volume breakdown of the prototype . . . . . . . . . . . 117

Fig. 6.9 Experimental results: Efficiency at different output powers with auxiliary circuit . . . . . . . . . . . . . 117

Fig. 6.10 Prototype breakdown of power losses . . . . . . . . . . . . . 118

Fig. 6.11 Prototype detailed breakdown of power losses . . . . . . . . . 118

Fig. 6.12 Voltage Gain Estimation and experimental results . . . . . . . . 120

Fig. 6.13 ZVS transition experimental measurement set-up . . . . . . . . 121

Fig. 6.14 ZVS transition experimental results of the $m=215$ LLC converter with auxiliary circuit at $500 \mathrm{~W}$. Low-side MOSFET Drain/source voltage (Ch1 in blue, 100V/div), auxiliary circuit current (Ch2 in cyan, 5A/div), low-side MOSFET Gate/Source voltage (Ch3 in magenta, 25V/div), resonant current (Ch4 in green,

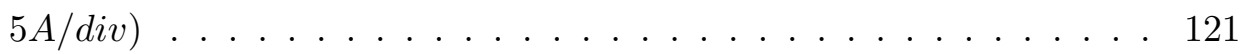

Fig. 6.15 ZVS transition experimental results of the $m=215$ LLC converter with auxiliary circuit at $5 \mathrm{~kW}$. Low-side MOSFET Drain/source voltage (Ch1 in blue, 100V/div), auxiliary circuit current (Ch2 in cyan, 5A/div), low-side MOSFET Gate/Source voltage (Ch3 in magenta, 25V/div), resonant current (Ch4 in green,

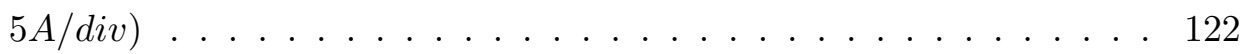

Fig. 6.16 ZVS transition experimental results of the $m=215$ LLC converter with auxiliary circuit at $10 \mathrm{~kW}$. Low-side MOSFET Drain/source voltage (Ch1 in blue, 100V/div), auxiliary circuit current (Ch2 in cyan, 5A/div), low-side MOSFET Gate/Source voltage (Ch3 in magenta, 25V/div), resonant current (Ch4 in green,

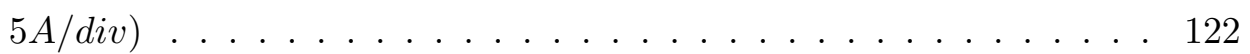


Fig. 6.17 ZVS transition experimental results of the $m=215$ LLC converter without auxiliary circuit at $5 \mathrm{~kW}$. Low-side MOSFET Drain/source voltage (Ch1 in blue, 100V/div), Low-side MOSFET Gate/Source voltage (Ch3 in magenta, $25 \mathrm{~V} /$ div), Resonant current

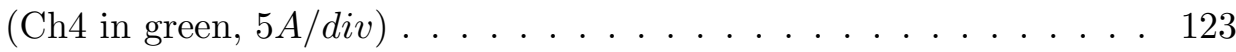

Fig. 6.18 Experimental results of $m=215$ LLC converter without auxiliary circuit at $5 \mathrm{~kW}$. Low-side MOSFET Drain/source voltage (Ch1 in blue, 100V/div), Low-side MOSFET Gate/Source voltage (Ch3 in magenta, 25V/div), Resonant current (Ch4 in green, 5A/div) 123

Fig. 6.19 Experimental results: Comparison of efficiency at different output powers with and without auxiliary circuit . . . . . . . . 125

Fig. 6.20 Experimental results at $5 k W$, with auxiliary circuit . Input bridge voltage, between middle points ( $\mathrm{Ch} 1$ in blue, $250 \mathrm{~V} /$ div), input resonant current (Ch2 in cyan, 10A/div), Secondary resonant current A (Ch3 in magenta, 10A/div), Secondary resonant current B (R1 in black, $10 A /$ div $\ldots \ldots \ldots \ldots \ldots \ldots \ldots$

Fig. 6.21 Experimental results at $10 \mathrm{~kW}$, with auxiliary circuit . Input bridge voltage, between middle points (Ch1 in blue, $250 \mathrm{~V} /$ div), input resonant current (Ch2 in cyan, 10A/div), Secondary resonant current A (Ch3 in magenta, 10A/div), Secondary resonant current B (R1 in black, $10 A /$ div $\ldots \ldots \ldots \ldots \ldots \ldots \ldots$ 



\section{List of Tables}

Table 2.1 Isolated DC-DC converter topologies . . . . . . . . . . 5

Table 3.1 Electrical parameter bases . . . . . . . . . . . . 16

Table 4.1 Auxiliary capacitors comparison . . . . . . . . . . . . . 56

Table 4.2 Auxiliary circuits complexity comparison . . . . . . . . . . 58

Table 5.1 Transformer design parameters . . . . . . . . . . . 76

Table 5.2 Transistor technology comparison . . . . . . . . . . . 85

Table 5.3 LLC converter specifications for high voltage ratio and high output current . . . . . . . . . . . . . . . . . . 91

Table 6.1 Isolated DC/DC specifications for AIR system . . . . . . . . . 109

Table 6.2 List of prototype components . . . . . . . . . . . . . . . 110

Table 6.3 Prototype normalized parameters . . . . . . . . . . . . 116

Table 6.4 Prototype parameters . . . . . . . . . . . . . . . . 116 

Chapter 1

\section{Introduction}

\subsection{Motivation}

Since the creation of the power electronics field, the efficiency of power converters has been improving, as better topologies, materials, and control methodologies are developed. Recent global environmental issues have accelerated the need for more efficient and cost-effective power systems. The transportation field consumes large amounts of energy and represents $25 \%$ of all $\mathrm{CO}_{2}$ emissions in Europe [2]. Electrification is used in this field to increase the efficiency and reduce the energy consumption. Recent examples of electrification in transports are the increased development of the electrical car, or the More Electrical Aircraft (MEA) philosophy, which is the modern tendency of substituting pneumatical, hidraulical and mechanical systems by electric and electronic counterparts with higher efficiency. These electronic systems have usually higher power densities and have a reduced weight. With this reduction in weight the energy compsumption can further be decreased.

To increase the power density of the high power converters, new technologies and optimized topologies are required. Also, high efficiency is desired, so that less voluminous heat-sinks are required to dissipate the losses [3]. Considering this, soft switching topologies have two main advantages to improve the power density. They can increase the switching frequency with reduced switching losses, reducing the size of the magnetic components, and because of the reduced losses the heat-sinks can be minimized. Nevertheless, with smaller magnetic components, the heat dissipation capability of the magnetic components is reduced. Accurate power loss and thermal models are required to push the design to their power density limits.

This work focuses on the contributions in the design and optimization of a particular soft switched converter: the LLC converter. The optimization process 


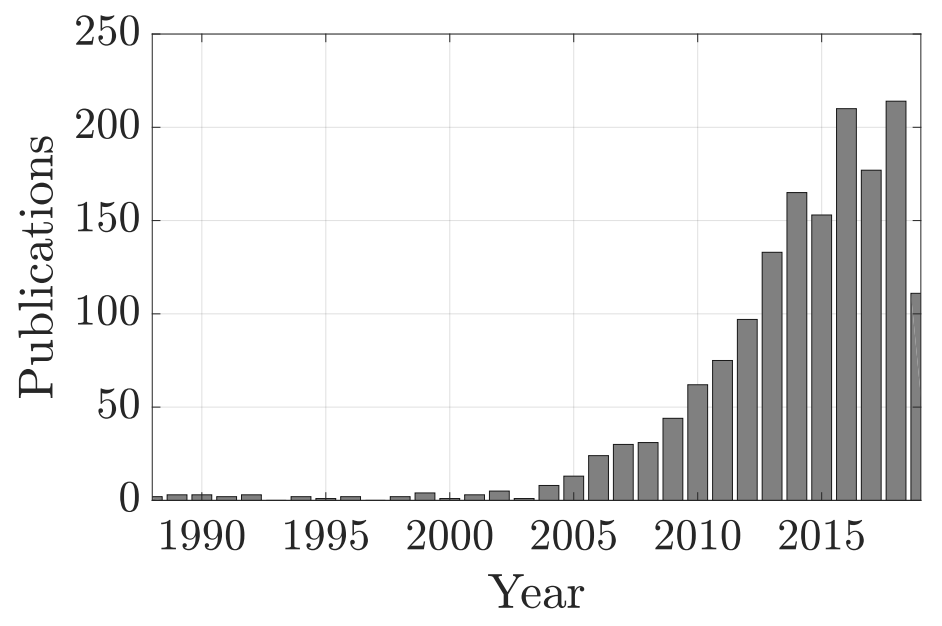

Figure 1.1: Number of IEEE publications related to LLC converters over the years. Source - IEEE

seeks to increase the efficiency and power density to the state of the art limits. The design and optimization are presented for high voltage gain and high output current applications, which are typical in modern transportation systems. The LLC converter is a topology with increasing popularity in the state of the art, as Figure 1.1 shows. The IEEE publications related to LLC converters have reached more than 200 entries per year in recent years.

\subsection{Organization of the dissertation}

The objective of this dissertation is to propose a three-phase single-stage isolated active rectifier topology under the demanding More Electric Aircraft initiative.

After this Introduction chapter, the work of this dissertation is developed by the following chapters:

In Chapter 2 a summary of the state of the art in isolated DC-DC converters for high output current and high voltage ratio is done. Additionally, a review of different auxiliary circuits to achieve ZVS is done.

Chapter 3 introduces the voltage and current gain models for the LLC converter. Two different modifications based on the traditional First Harmonic 


\subsection{Organization of the dissertation}

Approximation (FHA) are presented and compared with Time-Based (TB) simulation to assess their accuracy.

Chapter 4 addresses the ZVS transition analysis. The conventional method based on turn-off current has limited accuracy for variable turn-off current topologies like the LLC converter. Finally a comparison in terms of volume, losses and complexity of 4 different type of auxiliary circuit is presented.

Chapter $\mathbf{5}$ is dedicated to the design and optimization of LLC converters operating at resonant frequency, for high voltage ratio and high output current. The models used to design and optimized are presented. Then the LLC parameter optimization is proposed followed by the review of the design of each main component: transistors and magnetic component. Finally, the chapter ends with the description of the multi-objetive algorithm and the analysis of the results achieved with it.

In Chapter 6, the construction of a $10 \mathrm{~kW}$ prototype for aircraft application is described. Experimental results of the prototype performance are presented. The performance of the prototype with and without auxiliary circuit is measured and compared.

Finally, in Chapter 7, a summary of the work and contribution of this dissertation is presented. A vision of the future work is also given. 

Chapter 2

\section{Study of the state of the art}

In this chapter a review on the state of the art is presented. First, the basic topologies for isolated DC-DC converters are reviewed. Their benefits and drawbacks related to high conversion ratio and high output current will be discussed. Secondly, a brief review of resonant topologies is presented and the LLC is highlighted as a good candidate for high conversion ratio and high output current. The different inverter and rectifier structures for the LLC will be discussed.

\subsection{Isolated DC-DC Converters for high conversion ratio and high output current.}

There are multiple topologies available for isolated DC-DC conversion. They are all based in one of the fundamental topologies:

- Flyback

- Forward

- Push-pull

- Half-bridge

- Full-bridge

All of these topologies include a transformer to create isolation. However, the transformer utilization is different in each topology, as depicted in Table 2.1.

Table 2.1: Isolated DC-DC converter topologies

\begin{tabular}{|c|c|c|}
\hline Coupled Inductor & \multicolumn{2}{|c|}{ Transformer } \\
\hline Single ended & Single ended & Double ended \\
\hline & & Push Pull \\
Flyback & Forward & $\begin{array}{c}\text { Half-Bridge } \\
\text { Full-Bridge }\end{array}$ \\
\hline
\end{tabular}




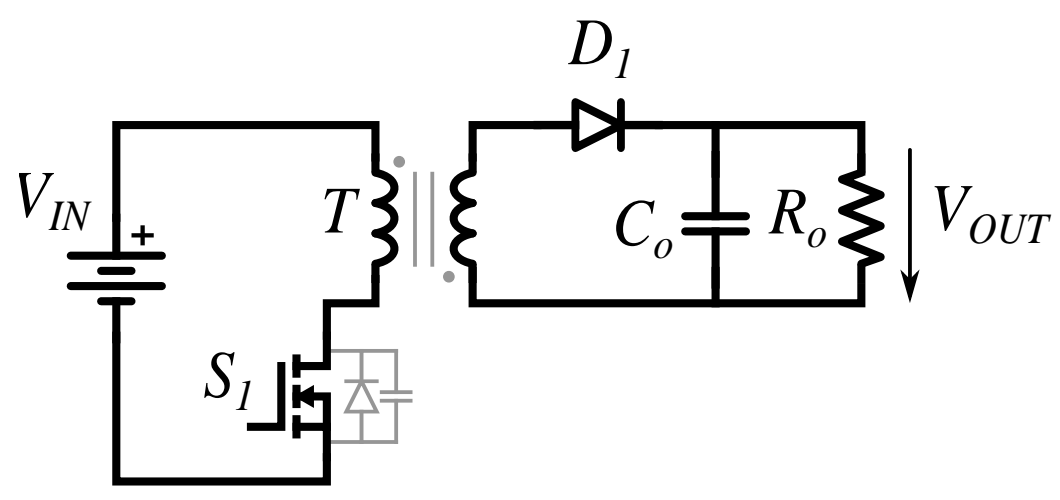

Figure 2.1: Flyback converter

The Flyback converter uses its transformer as a coupled inductor. The energy is stored in one cycle and then released in the next cycle. There is not a continuous flow of power from input to output. As a consequence, Flyback transformers are voluminous and this issue is intensified in high power applications, in which it is not a desirable topology. Nevertheless, the Flyback converter has only one switching device, as illustrated in Figure 2.1. This reduces the complexity and cost of the system. Therefore, it is still a good choice for low power and low cost applications.

The next topology is the Forward converter. Similar to the Flyback it has only one switch in the input side, as depicted in Figure 2.2.

It utilizes the transformer with continuous power flow and therefore it can be optimized to generate a minimum amount of circulating magnetizing current. However, it is still a single ended topology, and utilizes only the first quadrant of the hysteresis cycle of the magnetic material. Because of this, a path is required for the demagnetization of the core and this issue is solved typically with an auxiliary

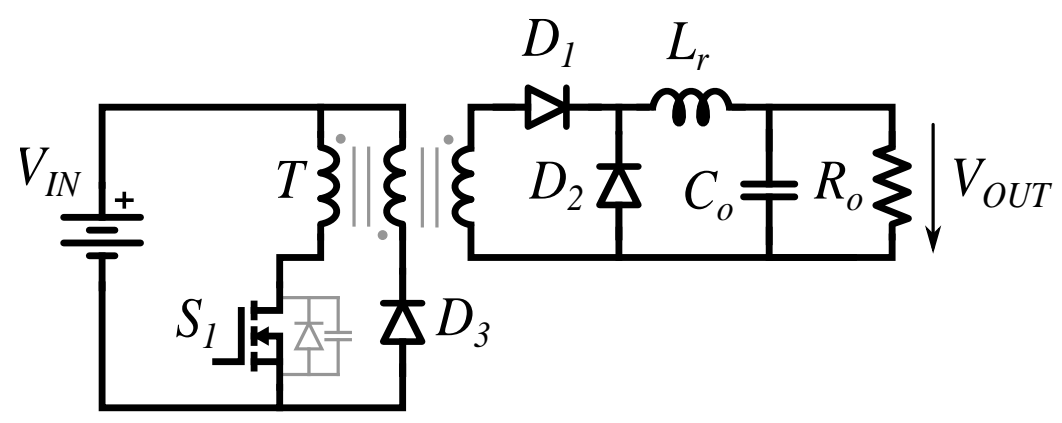

Figure 2.2: Forward converter 


\subsection{Isolated DC-DC Converters for high conversion ratio and high output current.}

winding. The transformer design is more complex and the power density of this component is reduced. Therefore, the Forward topology is not desired in high power or high current applications were the transformer design is critical.

The next family of topologies include double ended transformer core utilization. They are the Push-Pull, the Half-Bridge and the Full-Bridge. These names are based on the type of inverter used in the primary side of the transformer. However, they can include different secondary rectifiers. They have higher number of switching devices but they achieve optimized transformer design as they can utilize the magnetic component to its fullest potential.

In a generalized categorization of these topologies we can include both the inverter side and the rectifier side. Based on the traditional topologies, as depicted in Figure 2.3 and Figure 2.4.

The push-pull structure is equivalent to the center tapped rectifier, as shown in Figure $2.3 \mathrm{a}$ ) and Figure $2.4 \mathrm{a}$ ). On the other hand, the half-bridge structure becomes the voltage doubler rectifier, as depicted in Figure $2.3 \mathrm{~b}$ ) and Figure $2.4 \mathrm{~b}$ ). Finally, the full-bridge inverter structure is mirrored as the full-bridge rectifier, as illustrated in Figure $2.3 \mathrm{~d}$ ) and Figure $2.4 \mathrm{~d}$ ). A secondary type of half-bridge structure is also possible, using inductors instead of capacitors, as illustrated in Figure $2.3 \mathrm{c}$ ) and Figure $2.4 \mathrm{c}$ ). In its rectifier version, it is typically called current doubler, and in its inverter form it is called L type Half-bridge citeLtypeHB.

The rectifier structures of Figure 2.4 use diodes. In high current application it is desirable to substitute these devices with synchronous transistors to improve the efficiency. These synchronous rectifier structures are shown in Figure 2.4.

Both half-bridge configurations and the push-pull/center-tapped configurations, in their inverter and rectifier structure, have the advantage of only having two switches or diodes. This increases the reliability of the system and robustness to failures. However, when compared to the full-bridge structure. either the voltage rating is bigger or the current rating of the transformer is bigger for the same specification. In a full-bridge structure with four switches, always two of them are conducting in series with one another. However, the voltage rating is equal to the input voltage and better devices can be chosen for the same output power. A more detailed review on this structures will be given in the next section, considering the 


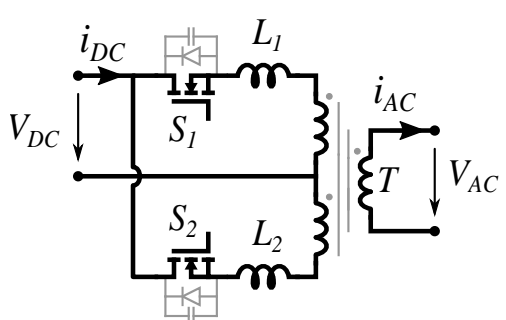

a)

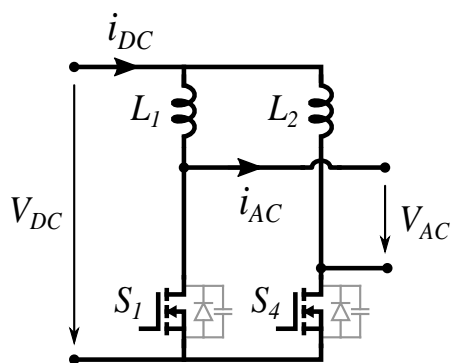

c)

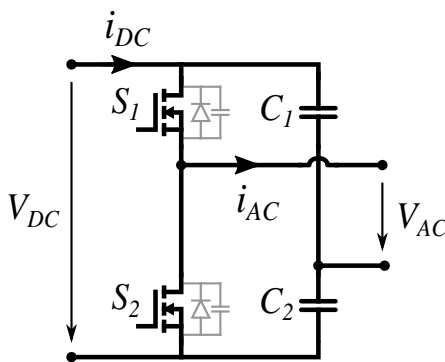

b)

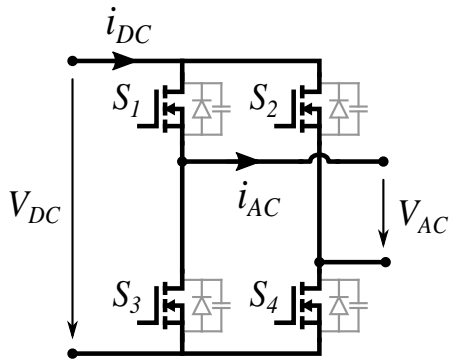

d)

Figure 2.3: Double ended inverter configurations

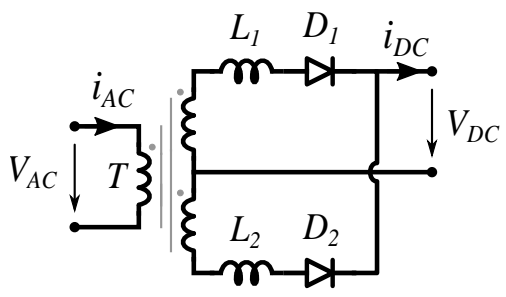

a)

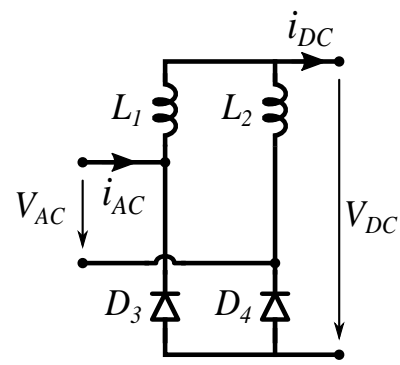

c)

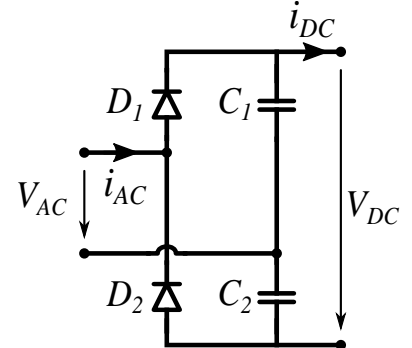

b)

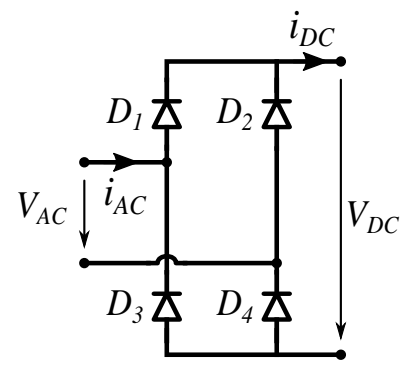

d)

Figure 2.4: Double ended rectifier configurations 
2.1. Isolated DC-DC Converters for high conversion ratio and high output current.

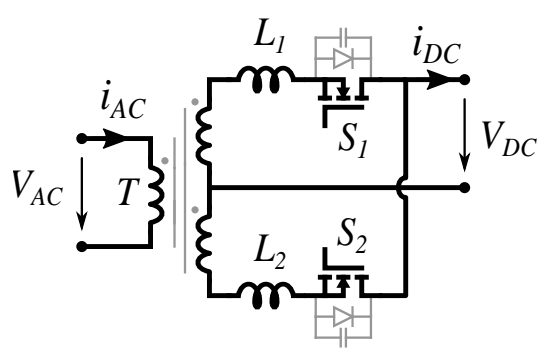

a)

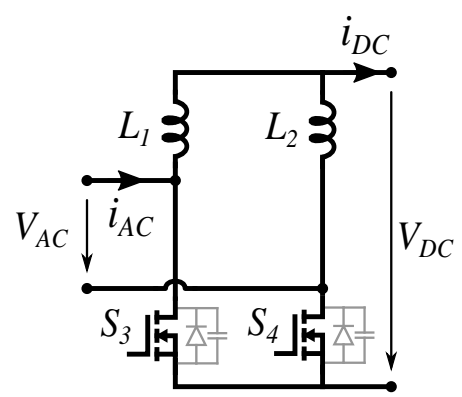

c)

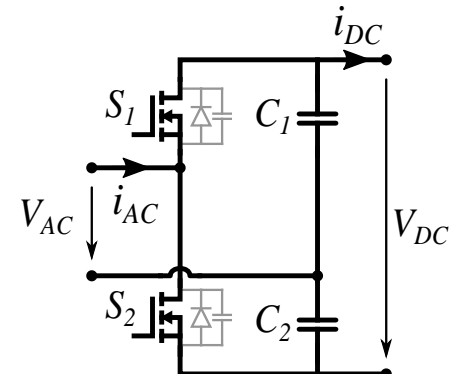

b)

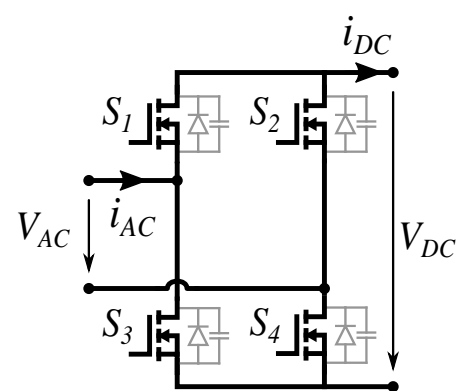

d)

Figure 2.5: Double ended synchronous rectifier configurations 
particularities of resonant converters and the high conversion ratio and high output current.

\subsection{Resonant Converters}

Resonant converters have been used for decades in the field of power electronics. In the early 80's, the basic resonant converter structure are analyzed: the series and the parallel resonant converters [4]. In these converters the resonance is achieved with only two components, a capacitor and an inductor. The series resonant, while achieving good efficiency with soft-switching, is not capable of voltage regulation [5] while the parallel resonant converter can achieve regulation [6]. These types of converters were used for high power applications, as in [7], were $10 \mathrm{~kW}$ are reached.

In the next decade, converters with three resonant elements are analyzed [8]. The additional component can help reduce the disadvantages of one of the two-element resonant converter. In the case of the series resonant, a parallel inductor can be included to help with the voltage regulation. The LLC converter is created in this way and achieves better efficiency than the regular PWM converters as presented in [9]. The same soft switching benefits as in the series resonant converter are still possible in the LLC converter while allowing voltage regulation and ZVS capabilities to the primary switches.

Another advantage of the LLC converter is the magnetic integration that can be achieved. The series and the parallel inductor of this topology can be integrated into a single component in isolated DC-DC converters, using a single transformer. The magnetizing inductance will act as the parallel inductor and the leakage inductance of the transformer will form the series resonant inductor. Magnetic components are bulky and therefore, are responsible for the power density of a converter. Using magnetic integration the power density of an LLC converter can be greatly increased.

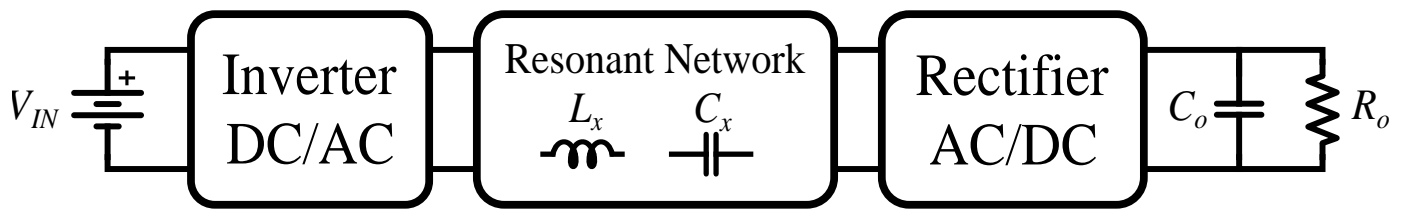

Figure 2.6: Resonant converter structure 
A DC/DC resonant converter can be analyzed as the combination of three main stages. An inverter structure, a resonant network and a rectifier structure, as depicted in Figure 2.6.

In the case of the LLC converter the resonant network will be composed of a series tank LC and a parallel inductor. Different inverter and rectifier structures can be used. Considering high current applications, the single ended topologies Flyback and Forward converters can be discarded. The double ended inverters and rectifiers configuration can be seen in Figure 2.3, Figure 2.4, and Figure 2.5. Considering the resonant tank of the LLC converter, the push-pull inverter can also be discarded as it would require two separate resonant tanks for each transistor path. The L-type half-bridge and the current doubler configurations are know for their benefits in high current applications. However, they require two additional inductors that cannot be integrated in the resonant tank. These configurations are not adequate for high power density requirements. Therefore, the considered inverters are the the half-bridge and the full-bridge, while the considered rectifiers are the center-tapped, the half-bridge and full-bridge.

Figure 2.7 depicts the output power of the LLC converters in IEEE publications from 2012 to 2019 . It can be noted that the maximum output power has been increasing over the years. Considering high step down converters and high power converters will lead to a high output current, which is the focus of this thesis. The output voltage of this type of converters is low in comparison to the input voltage and with a high output power, the output current will also by high. Additionally, it can also be noted in the Figure that the full-bridge configuration is generally used at higher output power than the half-bridge. As explained before, the full-bridge transformer is more optimized and has a better design than the half-bridge transformer for the same power.

In Figure 2.8, the efficiency over the voltage gain is shown for the same IEEE publications from 2012 to 2019. Only step down voltage ratios are considered, with voltage gains ranging from 1 to 0.01 . It can be noted that the efficiency drops with the increase of the step down in gain. This can be explained by the transformer design, in which a high turns ratio can complicate the design and increase the high frequency effects. While half-bridge converter are used at lower voltage gains than 


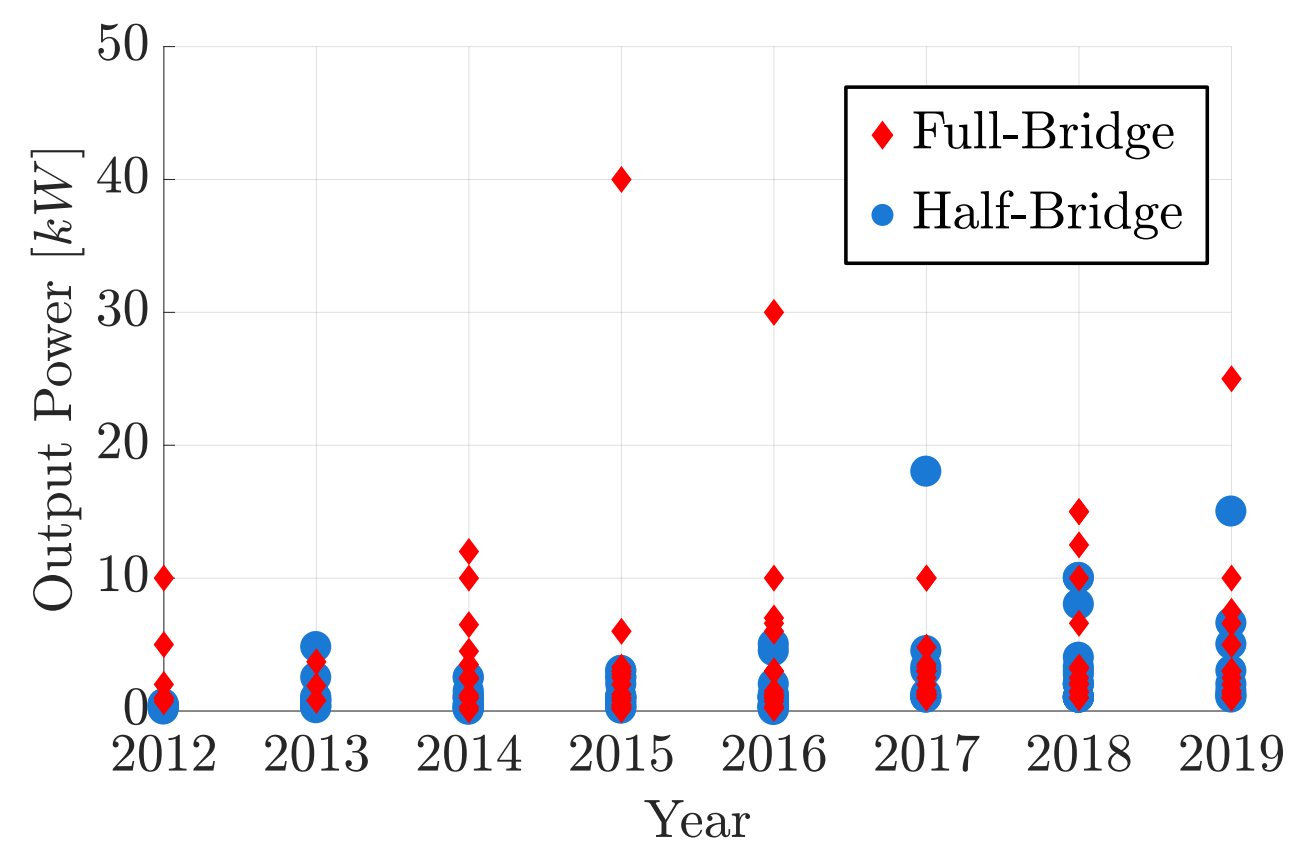

Figure 2.7: LLC converter output power for IEEE publications from 2012 to 2019

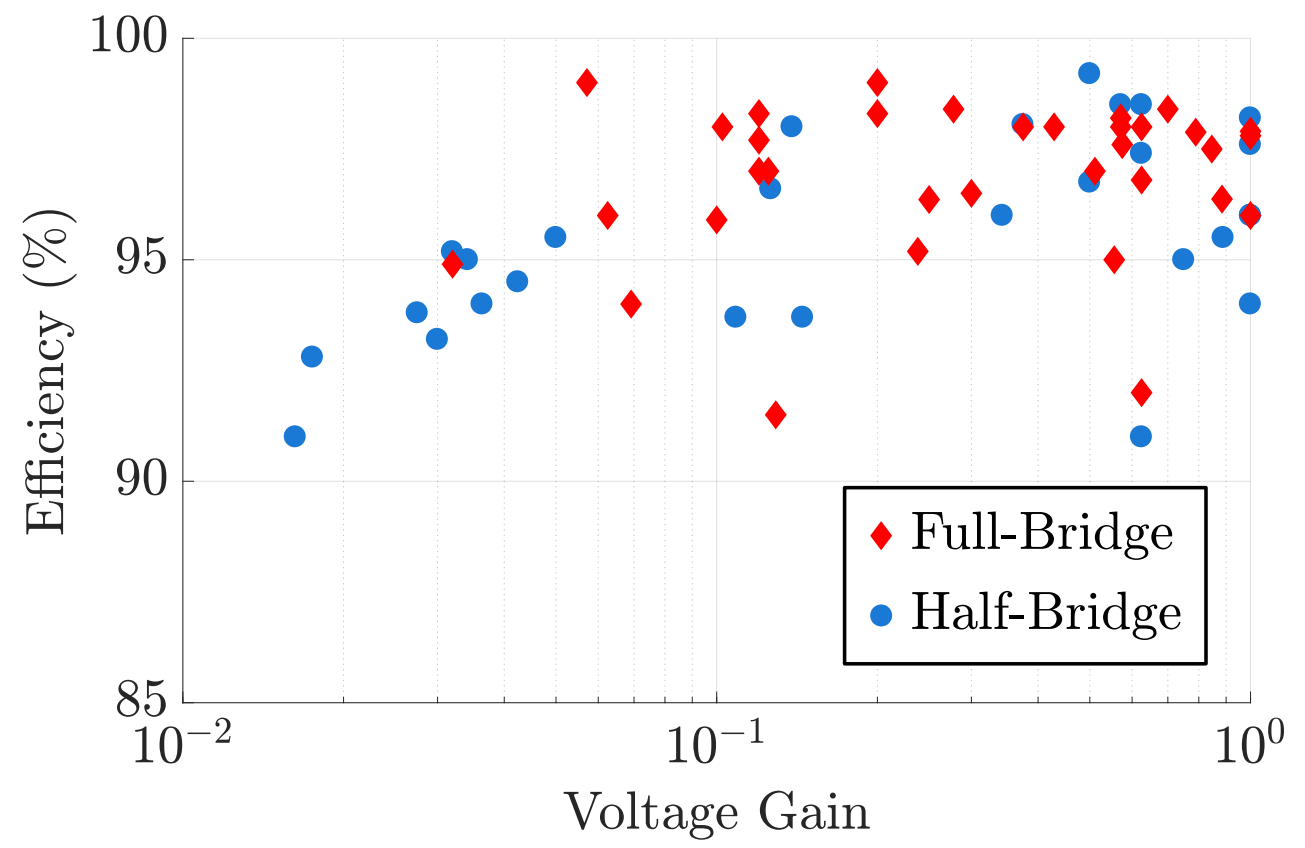

Figure 2.8: Efficiency over Voltage Gain $\left(\frac{V_{O U T}}{V_{I N}}\right)$ 


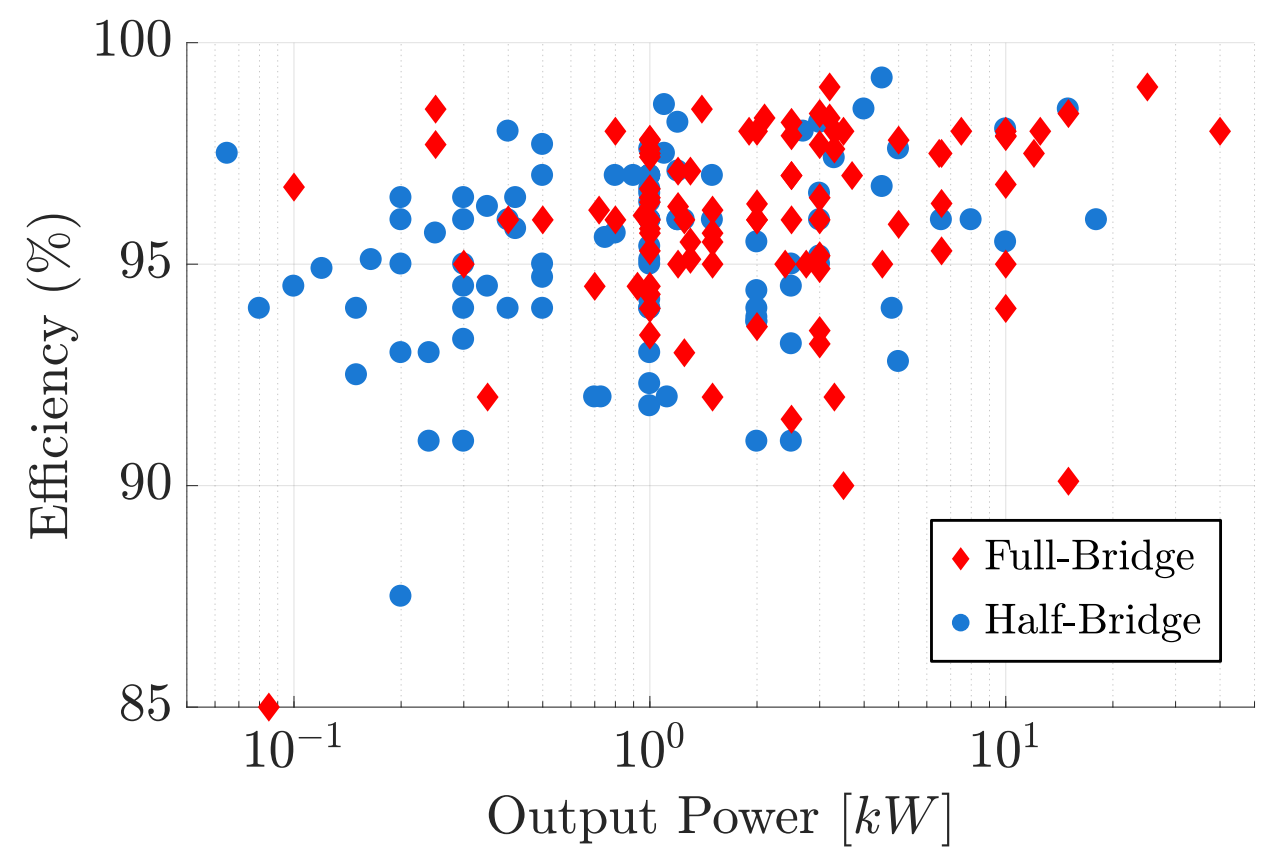

Figure 2.9: Efficiency over output power for LLC converter from IEEE publications from 2012 to 2019, distinguishing the input inverter structure

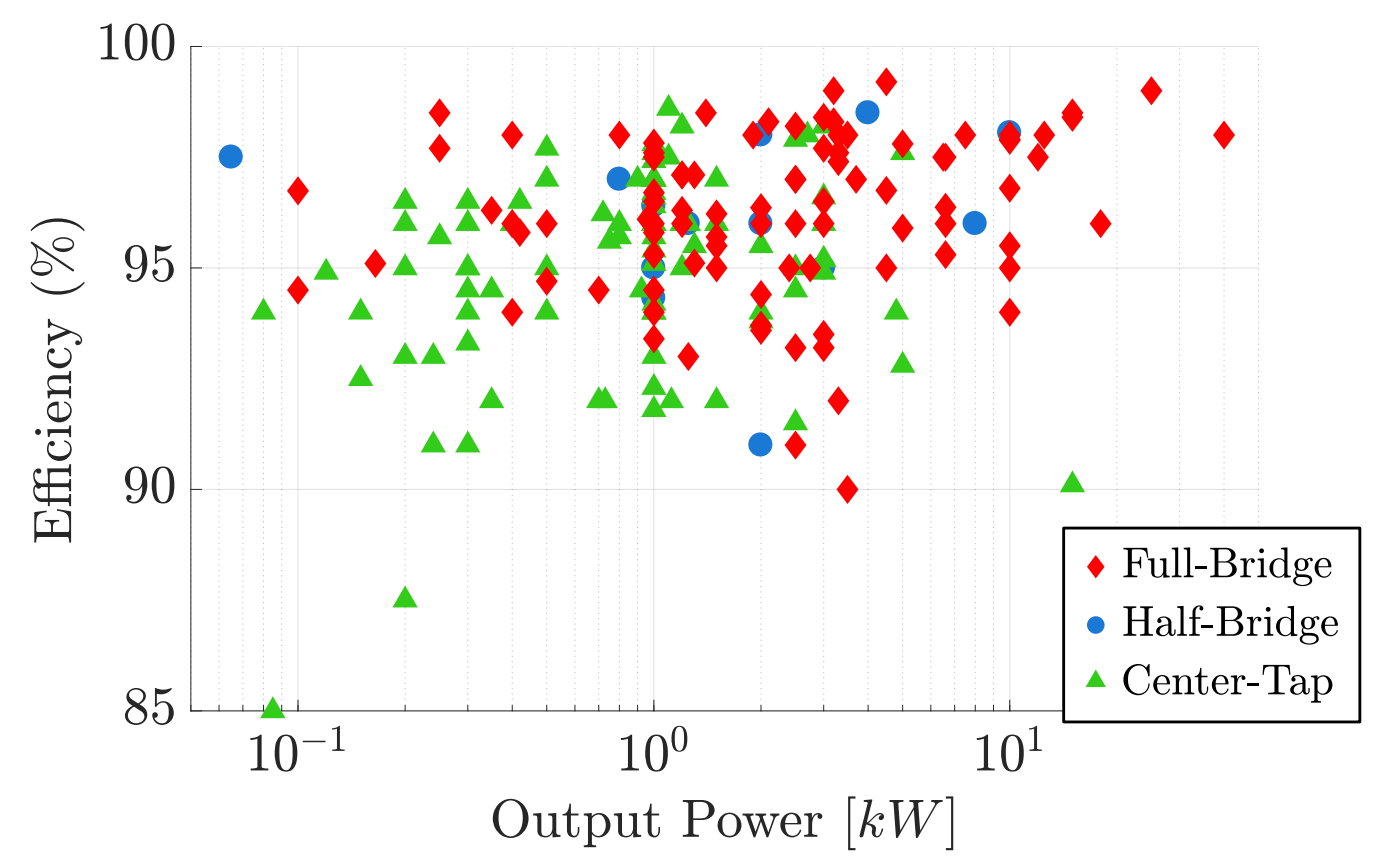

Figure 2.10: Efficiency over output power for LLC converter from IEEE publications from 2012 to 2019, distinguishing the output rectifier structure 
the full-bridge, it can be noted that the full-bridge converter generally achieves a higher efficiency, even at a moderate step down like 0.6, as illustrated in Figure 2.8.

Figure 2.9 and Figure 2.10 depicts the efficiency over the output power of the same LLC converters from 2012 to 2019, showing the different inverter and rectifier configurations used. A higher density of full-bridge publications can be found at higher output powers for both the inverter and rectifier configurations. At lower power, the half-bridge configuration with center-tapped rectifier is the most common topology. High output power converters generally show a slighlty higher efficiency, this can be explained by the thermal issues that arise in high power converters, where a higher efficiency is usually mandatory for the temperatures to remain moderate.

Because of all these reasons, this thesis is going to focus on the design considerations for full-bridge LLC converters. 
Chapter 3

\section{Isolated LLC Full-Bridge at Resonant Frequency: Operation and Modelling}

In this chapter, the operation of the isolated LLC full-bridge will be reviewed, demonstrating that the optimal operation mode of the LLC converter is at resonant frequency. Subsequently, different voltage gain and current gain models will be analyzed and compared. Modified models that consider parasitic effects are proposed. These have a strong impact on the design of unregulated converters, where the feedback loop can not correct the the mismatches caused by these parasitics.

\subsection{Normalization in isolated LLC converters}

The concept of normalization needs to be recalled, as it is commonly used in LLC converters [10]. It is convenient as it considerably simplifies and generalizes the analysis. In the process of normalization, parameters are divided by their bases to get dimensionless parameters. The bases can be selected arbitrarily, though selecting specific values can create relevant parameters that give more insight into the design process. For example, in the case of LLC converters, the base for frequency normalization is chosen to be the series tank resonant frequency $f_{r}$. The normalized frequency is then defined as $f_{n}=\frac{f}{f_{r}}$. With this base, concepts like operation below resonance, above resonance and at resonance can be summarized mathematically as $\left(f_{n}<1\right),\left(f_{n}>1\right)$ and $\left(f_{n}=1\right)$ respectively. However, some dimensionless parameters come from ratios of parameters with the same units. For example, a common parameter in power converters is the voltage gain from input to output, 
defined as:

$$
G=\frac{V_{O U T}}{V_{I N}}
$$

This parameter can be understood as a normalized output voltage, with a base of $V_{I N}$. However, in the context of power converters, it is usually called voltage gain.

Figure 3.1 depicts a simplified circuit of the isolated LLC converter, with a full-bridge inverter and a full-bridge diode rectifier.

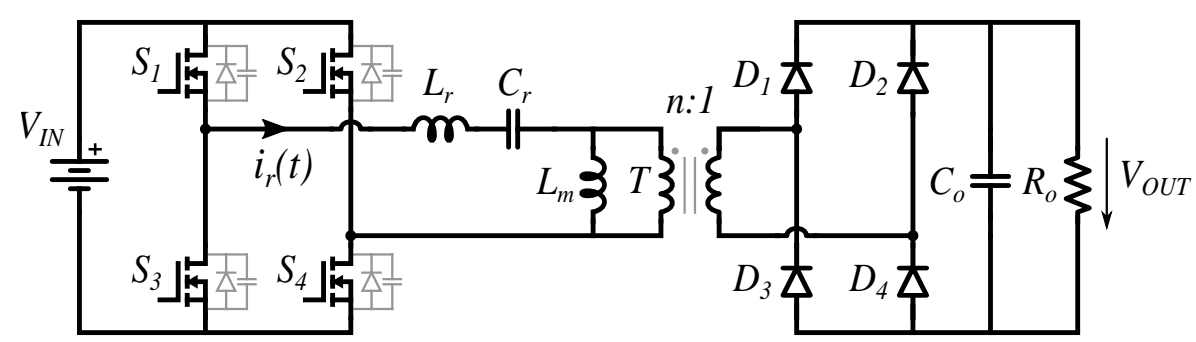

Figure 3.1: Isolated LLC converter with diode bridge

The behavior of this converter is characterized by seven parameters: the series inductance $L_{r}$, the series resonant capacitance $C_{r}$, the parallel inductance $L_{m}$, the output load resistance $R_{o}$, the input voltage $V_{I N}$ and the output voltage $V_{O U T}$, and the transformer turns ratio $n$. With these, the bases for the electrical units can be defined, as summarized in Table 3.1 .

\begin{tabular}{c|c|c|c}
\hline \hline Voltage & Current & Impedance & Frequency \\
\hline \hline$n V_{O U T}$ & $\frac{V_{O U T}}{Z_{r}}$ & $Z_{r}=\sqrt{\frac{L_{r}}{C_{r}}}$ & $f_{r}=\frac{1}{2 \pi \sqrt{L_{r} C_{r}}}$ \\
\hline
\end{tabular}

Table 3.1: Electrical parameter bases

Considering LLC designs, the following dimensionless parameters are usually used in the literature. They are defined as follows:

- Normalized frequency $f_{n}$ : defined as the ratio between the switching frequency of the LLC converter $f_{s}$ and the series resonant frequency $f_{r}$ :

$$
f_{n}=\frac{f_{s}}{f_{r}}=2 \pi f_{s} \sqrt{L_{r} \cdot C_{r}}
$$




\subsection{Normalization in isolated LLC converters}

- Voltage gain $M$ : it was defined in (3.1). When a transformer is present with a non-unity turns ratio, the voltage gain can be normalized considering the turns ratio $n$. The normalized voltage gain is then defined with the extra parameter, as follows:

$$
M=\frac{n \cdot V_{O U T}}{V_{I N}}
$$

- Inductance ratio $m$, which accounts for the relationship between the series inductance $L_{r}$ and the parallel inductance $L_{m}$ of the LLC converter. The analytical equation for $m$ is as follows:

$$
m=\frac{L_{m}+L_{r}}{L_{r}}
$$

- Load quality factor $Q$ : In Physics and Engineering, the quality factor describes the damping of a harmonic resonator. It is usually defined as a ratio between the energy dissipated and the energy stored in each cycle of the resonance. However, in terms of $L C$ electrical resonance, the quality factor can be also be defined as a ratio of electrical impedances. In the context of isolated LLC converters, the load quality factor is defined as:

$$
Q=\frac{1}{R_{o}^{*}} \sqrt{\frac{L_{r}}{C_{r}}}
$$

where $R_{o}^{*}$ is the AC equivalent load resistance, defined as follows:

$$
R_{o}^{*}=\frac{8}{\pi^{2}} n^{2} \frac{V_{O U T}^{2}}{P_{O U T}}
$$

This equivalent load resistance is derived from the first harmonic approximation and will be explained in section 3.3.1, where the first harmonic approximation is analyzed and explained in detail.

Along the following sections and chapters, new dimensionless parameters may be introduced, as new parameters are introduced to account for parasitic behavior and different configurations. 


\subsection{Operating principle}

The LLC full-bridge with full-bridge diode rectifier is depicted in Figure 3.2. It consists of a resonant converter where the inverter and rectifier structure are full-bridge type.

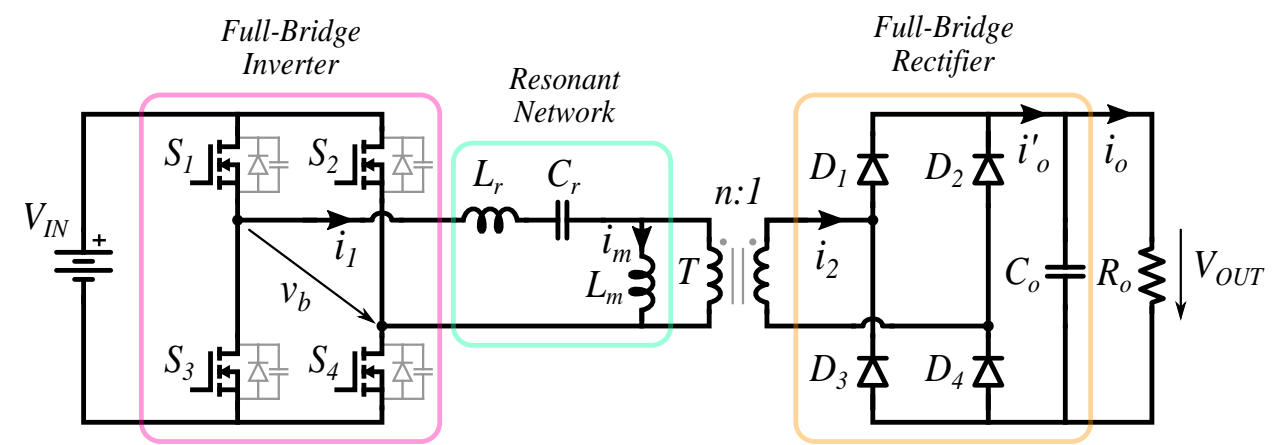

Figure 3.2: LLC circuit with full-bridge inverter and full-bridge diode rectifier

The resonant network of the LLC consists of a series resonant tank $L_{r} / C_{r}$ and a parallel inductor connected after the series tank. This resonant network is excited by the square voltage waveform created in the input full-bridge, as illustrated in Figure 3.3. An AC Voltage is required to meet the Volt-second balance in the transformer and avoid saturation of the magnetic material. This AC current is then rectified in the output diode bridge.

With the square voltage of the input bridge, the series resonant tank $L_{r} / C_{r}$ generates a sinusoidal waveform. Additionally, the parallel inductor $L_{m}$ generates a triangular current waveform, as the voltage applied to it is the square voltage waveform of the secondary output bridge. The AC current is then rectified by the output bridge and filtered by the output capacitor to create a DC current at the output load.

Considering the switching states and the power flow in the LLC converter, two different types of operating states can be defined: the powering states and the freewheeling state. These are explained in the following subsections.

\subsubsection{LLC converter operating states}

Powering states The power state with positive current is depicted in Figure 3.4. In this operation mode, the voltages applied in the input and output bridge share 


\subsection{Operating principle}
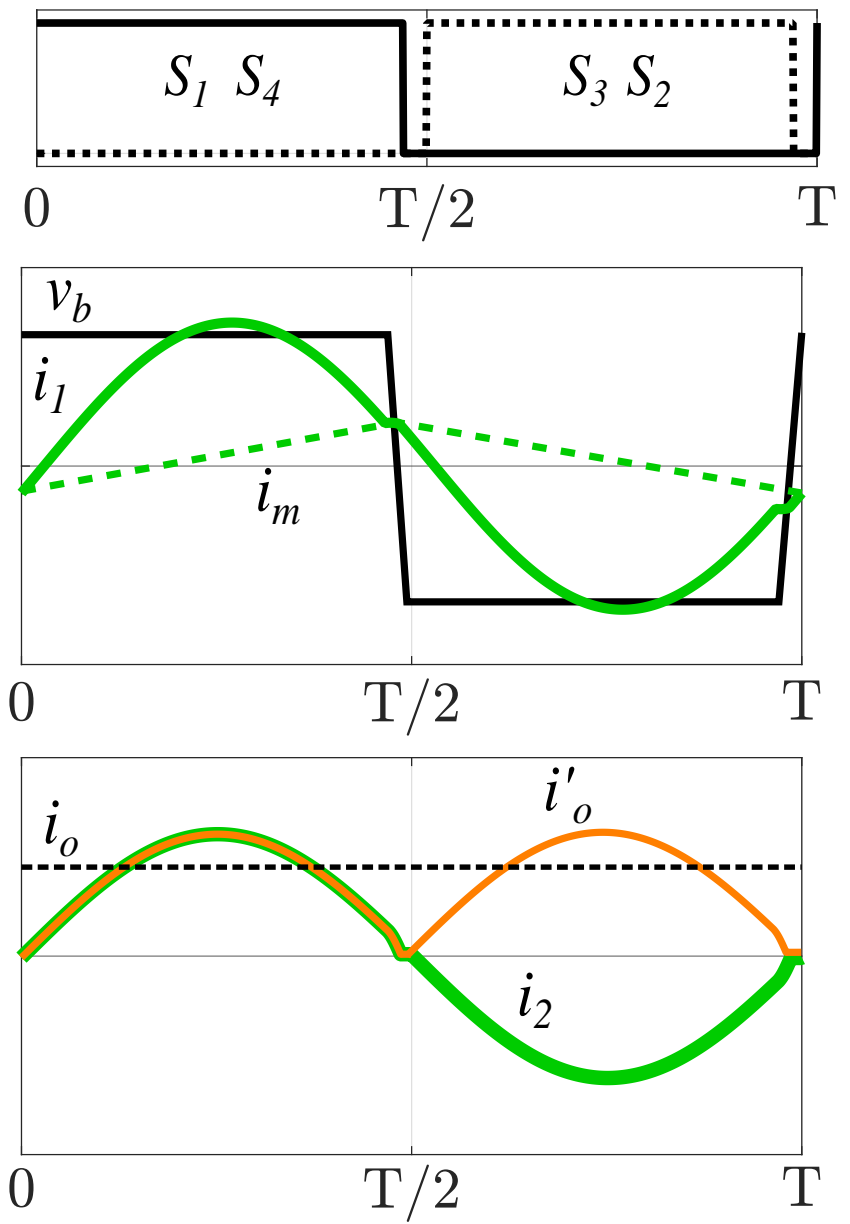

Time

Figure 3.3: LLC circuit with full-bridge inverter and full-bridge diode rectifier

a positive sign. Switches $S_{1}$ and $S_{4}$ conduct in the input bridge and diodes $D_{1}$ and $D_{4}$ in the output bridge. The current delivered to the output bridge is the input current minus the magnetizing current (multiplied by the turns ratio $n$ ). In this operation mode, power is transferred from input to output.

A second power delivery operation is also possible with inverted polarity, where the opposite switches $S_{2}$ and $S_{3}$ conducts, as well as diodes $D_{2}$ and $D_{3}$. In this mode, the current sign is reversed, and so are the voltages applied to the bridges. This negative current powering state is illustrated in 3.5 


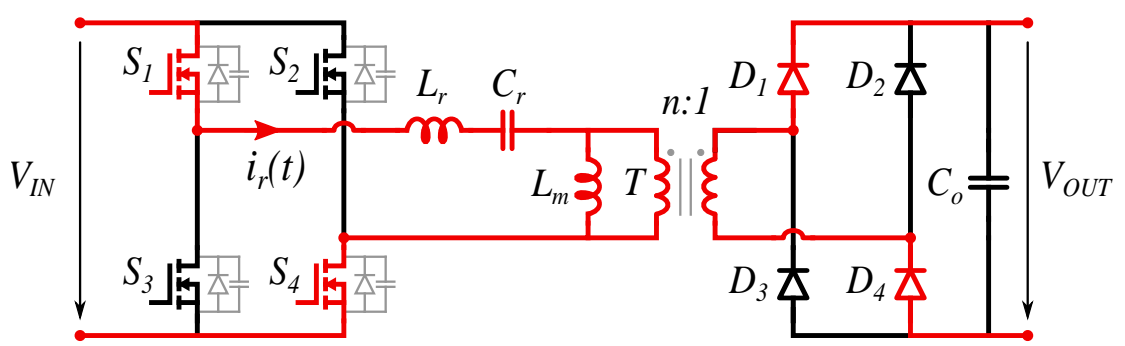

Figure 3.4: Positive powering state

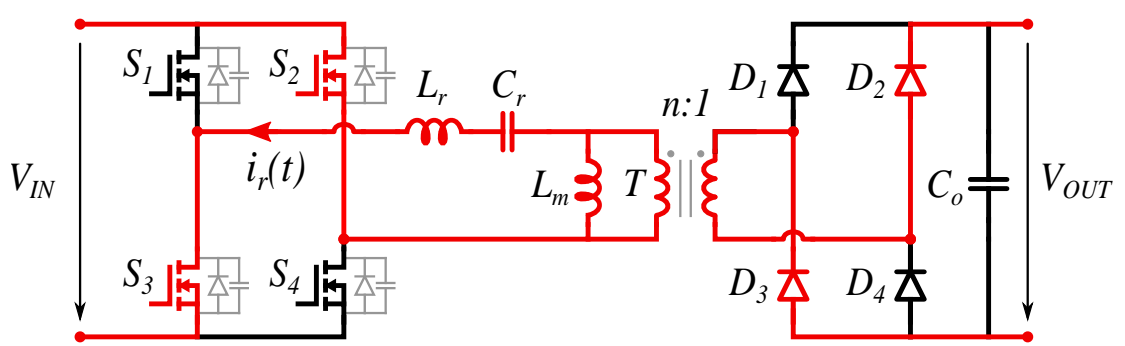

Figure 3.5: Negative powering state

Freewheeling states A freewheeling state follows a power delivery operation, when the input current reaches parallel inductor current. In this case, no power is delivered to the load. All output bridges diodes are blocking $V_{O U T} / 2$, as depicted in Figure 3.6. Therefore, the output current and secondary transformer current is zero, and the input current consists only of circulating current.

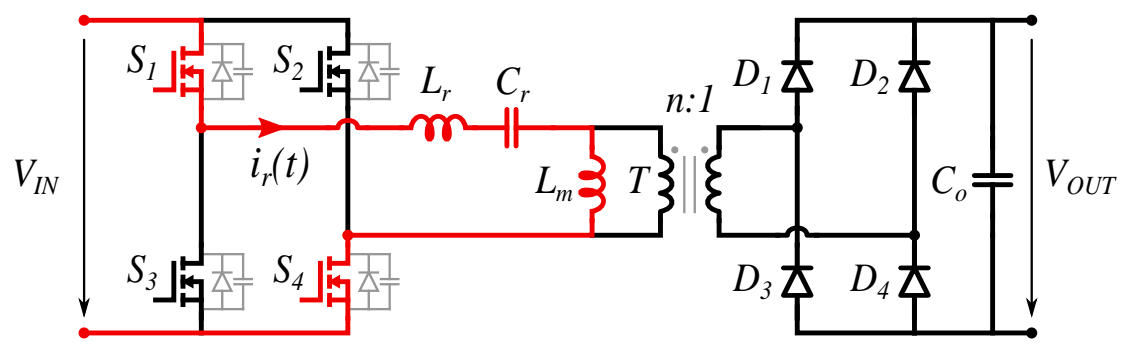

Figure 3.6: Positive freewheeling state

The second freewheeling state is illustrated in Figure 3.7. In this freewheeling state, the resonant current $i_{r}(t)$ is negative, as is the voltage applied to the resonant network.

More detailed models of the LLC converters modes can be found in the literature $[11,12]$. These models consider different stages of freewheeling and resonant states. 


\subsection{Operating principle}

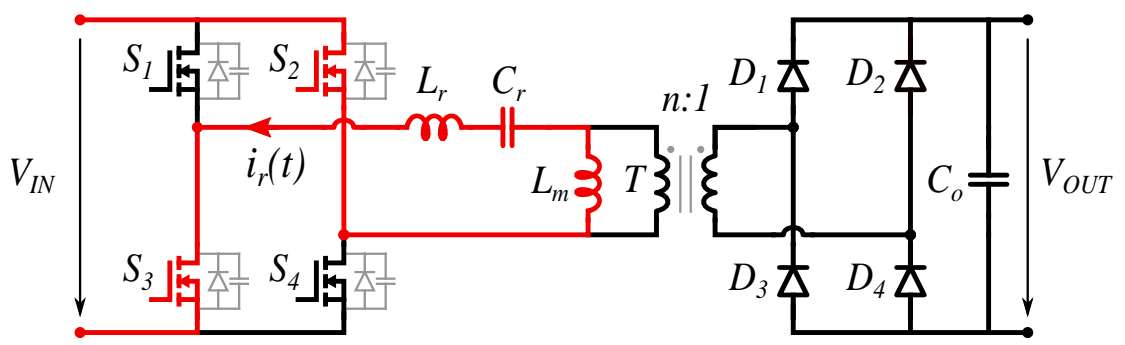

Figure 3.7: Negative freewheeling state

In These modes, the models distinguish the cases where the parallel inductor resonates or not.

\subsubsection{Switching frequency operation modes}

Depending on the value of the switching frequency, the converter operates with a different combination of powering states and freewheeling states, that were explained in the previous subsections. They are the following.

- Below resonance $\left(f_{n}<1\right)$ : where the switching frequency is below the resonant frequency

- At resonance $\left(f_{n}=1\right)$ : where the switching frequency is equal to the resonant frequency

- Above resonance $\left(f_{n}>1\right)$ : where the switching frequency is higher than the resonant frequency.

The transistor signals, bridge voltages and resonant current are summarized in Figure 3.8 at the different frequency mode of operations.

The operation below resonance includes a large portion of freewheeling operation, while operations at resonance and above resonance only consists of power delivery operation with freewheeling only during the dead-time transition, as illustrated in Figure 3.8.

Operation below resonance is characterized by high values of RMS currents because more time is spent operating in freewheeling mode. Therefore, the power is delivered in a smaller portion of the period. Additionally, during the freewheeling mode, the circulating currents are dominant, further increasing the input RMS currents. As a result, conduction losses are dominant in below resonance operation. 

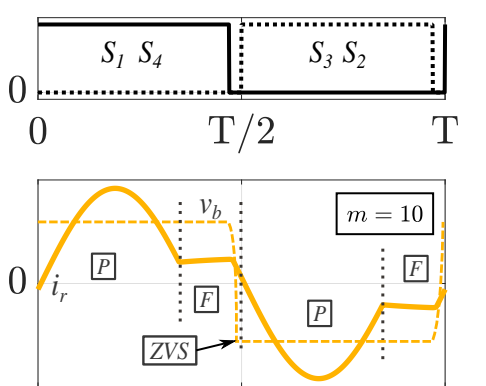

0

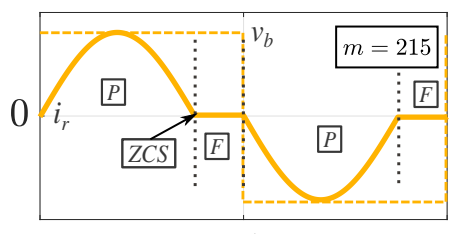

0

$\mathrm{T} / 2$

T 0

T 0

Time
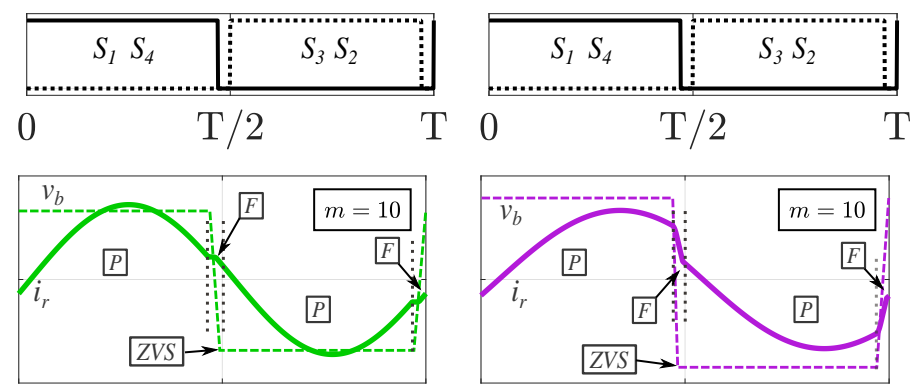

$\mathrm{T} / 2$

T 0
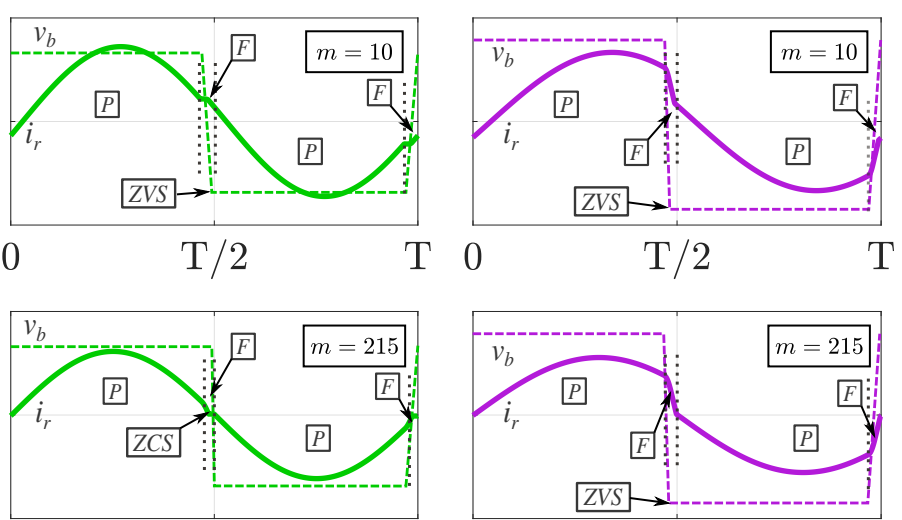

$\mathrm{T} / 2$

Time

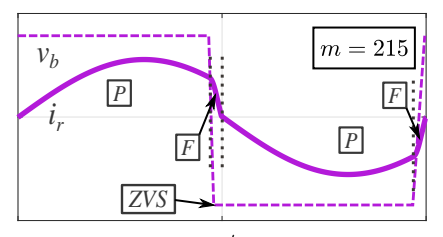

T 0

$\mathrm{T} / 2$

Time

Figure 3.8: LLC converter switching frequency modes: below resonance (left), at resonance (center) and above resonance (right)

On the other hand, operation above resonance has less freewheeling, limited only to the dead-time transition. Because of this, the RMS currents are lower. However, the resonant current is interrupted before reaching zero. This increases the turn-off current in both primary and secondary devices. With this turn-off current, ZVS is achieved. However, ZCS is not. Therefore, the switching losses in the transistors and diodes are higher.

Finally, the operation at resonant frequency combines the benefits of the previous operations without their disadvantages. It only operates in freewheeling during the dead-time transition but allows the resonant to reach zero during the switching transition. This allows for soft switching, reducing switching losses, while conduction losses remain low.

As explained previously, the freewheeling operation is defined by parallel inductor current, also called circulating current, because it does not deliver power to the output. This circulating current is affected by the inductance ratio $m$. The 


\subsection{Operating principle}

higher the inductance ratio $m$, the higher the parallel inductance $L_{m}$ and the lower the circulating current.

A comparison of the LLC converter power losses at different frequency modes and for high $m=215$ and low $m=10.5$ inductance ratio is presented in Figure 3.9.
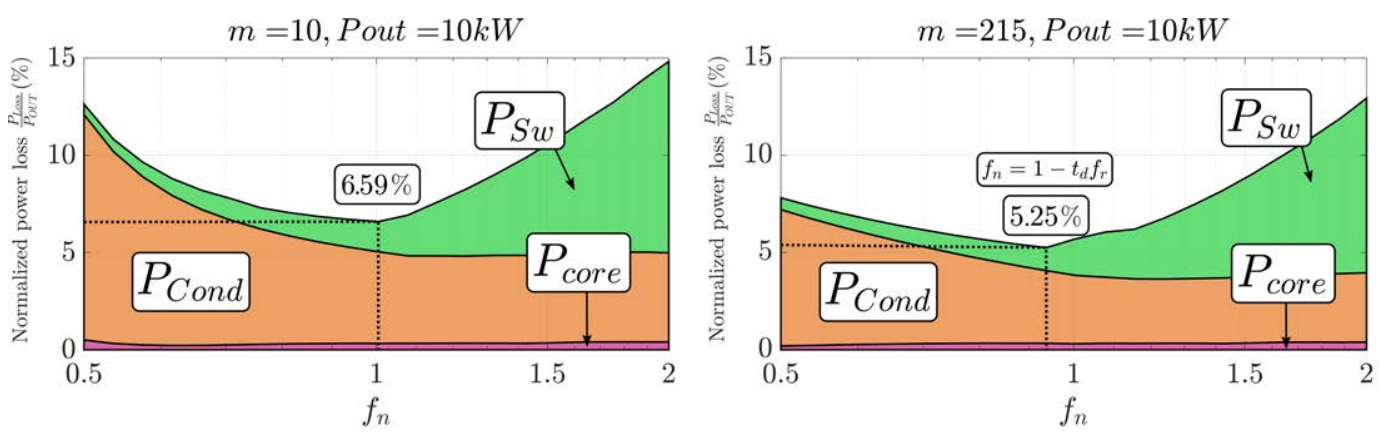

Figure 3.9: LLC converter total power losses normalized over the peak output power $\left(P_{\text {Loss }} / P_{\text {Out }}\right)$ at $m=10.5$ and at $m=215$

As it was explained previously, the conduction losses are dominant in operation below resonance and switching losses are dominant above resonance. The minimum losses are achieved exactly at resonance for the low inductance case $m=10.5$, while at $m=215$ the minimum losses are achieved at $f_{n}=1-t_{d} / f_{r}$, where $t_{d}$ is the dead-time of the transistors. The high inductance ratio has fewer losses at the minimum, with $5,25 \%$ compared with $6.59 \%$ for the low inductance ratio case. In conclusion, operation at resonant frequency is the most efficient operation mode.

\subsubsection{Unregulated LLC converter operating at resonant frequency}

As explained in the previous section, the efficiency achieved operating at resonant frequency is the highest of all other operation modes. Additionally, the voltage gain of the LLC converter operating at resonant frequency is almost load-independent. These two characteristics of the operation at resonant frequency make this operation mode a good candidate for constant gain converters, also called DCX or DC transformer $[13,14]$. This type of converter is required in applications where isolation is required and the voltage needs to be adapted. Since the normalized voltage gain of this operation mode is close to constant and equal to 1 , for all load conditions. No regulation is required. However, in high current and high voltage ratio converters, if considering the effect of different parasitics in the power circuit, the gain can no 
longer be considered constant for all loads. Detailed models are needed to account for these parasitics because the traditional models are not accurate enough. In the literature we can find several modifications for the traditional models to overcome these inaccuracies [15-17]. These are especially critical in unregulated converter, where the control feedback loop is not implemented and the errors in the estimated gain cannot be corrected.

\subsection{Voltage gain models}

In this section, different analytical voltage gain models are going to be analyzed and compared to check their accuracy against time-based simulations, which are accurate but time-consuming. All the analytical models are all derived from the traditional approach of the First Harmonic Approximation (FHA) [18].

\subsubsection{First harmonic approximation model (FHA)}

The FHA is a method to analyze the voltage gain of resonant converters. It consists in considering only the first harmonic of the input square voltage excitation. All higher harmonics are neglected. The Typical DC/DC resonant converter consists of three stages: an inverter $(\mathrm{DC} / \mathrm{AC})$, a resonant network $(\mathrm{AC})$ and a rectifier (AC/DC), as depicted in Figure 3.10.

$D C / A C$

$A C / D C$

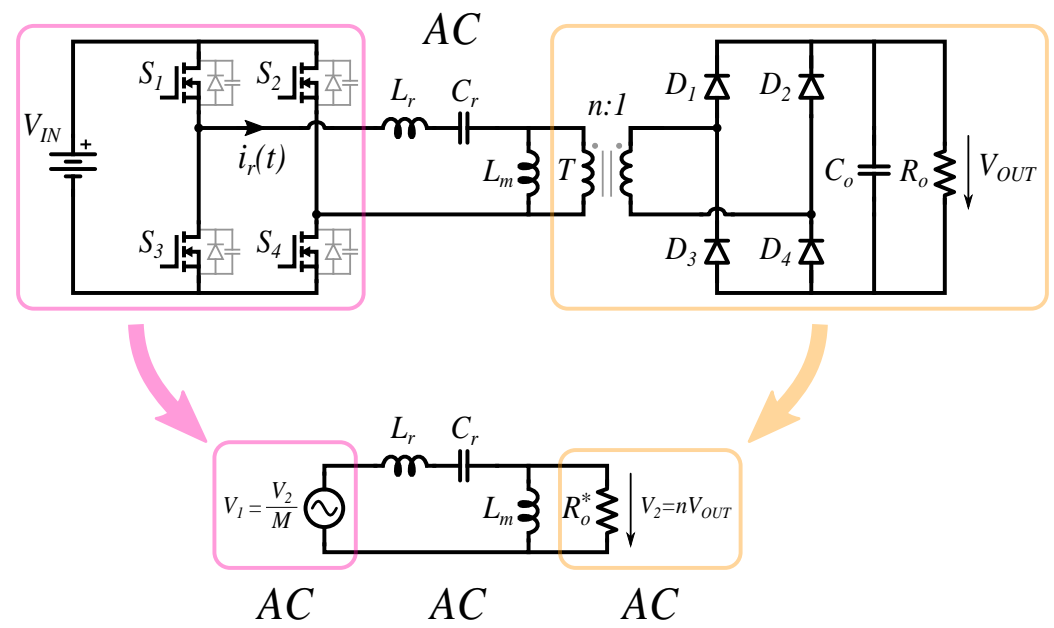

Figure 3.10: LLC circuit transformation using FHA 


\subsection{Voltage gain models}

Using the FHA, the circuit is modified and analyzed purely in AC. A sinusoidal voltage source substitutes the inverter and the ideal transformer,the rectifier, the output filter and the load resistor are substituted by an equivalent AC load resistor. This equivalent $\mathrm{AC}$ load resistance is defined for full-bridge type rectifiers as:

$$
R_{o}^{*}=\frac{8}{\pi^{2}} n^{2} \frac{V_{O U T}^{2}}{P_{O U T}}
$$

This equation is obtained by assuming that the equivalent $\mathrm{AC}$ resistance dissipates the same power as output resistance.

This thesis focuses on full-bridge type inverters and rectifier, however, the conclusions are also valid for different inverters and rectifiers types. Although, the definition of the equivalent resistance or the voltage gain may change.

The FHA can be used for preliminary designs. However, it does not consider any parasitic. The effect of parasitic can create mismatches between the models and the real converter behavior. Feedback loops usually correct These mismatches, but, in unregulated LLC converters, there is no feedback loop to correct the gain. Therefore it has to be considered in the design calculations with higher accuracy to ensure design margins. In the next sections, two different modified FHA are going to be proposed to increase the accuracy when considering parasitics.

\subsubsection{Series resistance modified First harmonic approximation model (SR-FHA)}

The regular FHA does not consider the voltage drop effect with increasing output load. This means that the gain at $f_{n}=1$ is exactly $M=1$, as depicted in Figure 3.11 .

In real converters, all components have a parasitic resistance between the input and the output. Therefore a voltage drop exists between input and output depending on the load. To consider this load-dependent voltage drop a series resistance can be added to the FHA circuit, as depicted in Figure 3.12

The series resonant tank $\left(L_{r}-C_{r}\right)$ acts as a filter for the harmonics of the square waveform of the input bridge. However, with the addition of the series resistance, the filtering behavior of the tank is damped. When adding the resistance to the FHA model, the assumption that the higher harmonics are negligible is no longer 

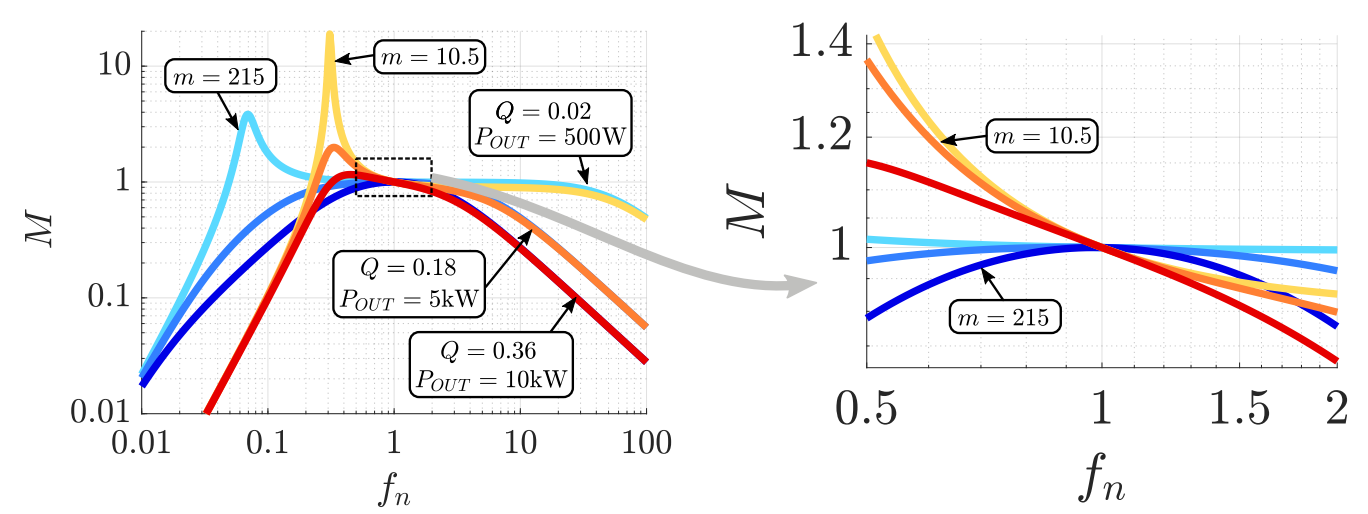

Figure 3.11: FHA (hacer un zoom y mostar la zona de $\mathrm{M}=1$ y $\mathrm{fn}=1$

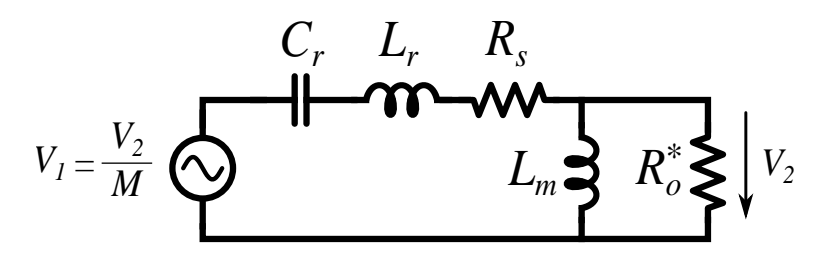

Figure 3.12: FHA equivalent circuit with series resistance (SR-FHA)

valid, as it will be shown later. This is especially true when operating far from resonance, either above or below. This will be analyzed in the comparison section.

The analytical equation of this modified FHA model from Figure3.12 is the following:

$$
M_{R S}=\frac{1}{\sqrt{\left(1+\frac{1}{m-1}\left(1-\frac{1}{f_{n}^{2}}\right)-\frac{Q}{Q_{s}}\right)^{2}+Q^{2}\left(f_{n}-\frac{1}{f_{n}}-\frac{1}{f_{n}^{2}}\left(\frac{1}{(m-1) \cdot Q \cdot Q_{s}}\right)\right)^{2}}}
$$

It requires an additional dimensionless parameter, the series tank quality factor, defined as follows:

$$
Q_{s}=\frac{1}{R_{s}} \sqrt{\frac{L_{r}}{C_{r}}}
$$

Where $R_{s}$ is the total series resistance from input voltage source to output voltage source. This resistance includes the transformer resistance, the series resonant network elements and the resistances of the input and output bridge switches. The RS-FHA model with a high quality factor $Q_{s}$ will be closer to the traditional FHA approach. 


\subsection{Voltage gain models}

\subsubsection{Distributed Impedance FHA model (DI-FHA)}

The resonant network of the LLC converter includes two inductors, a series inductor $L_{r}$ and a parallel inductor $L_{m}$. In isolated LLC converters, these two inductors can usually be integrated into a single magnetic component. The transformer magnetizing inductance acts as the parallel inductor, and the leakage acts as the series resonant inductor, as illustrated in Figure 3.13.

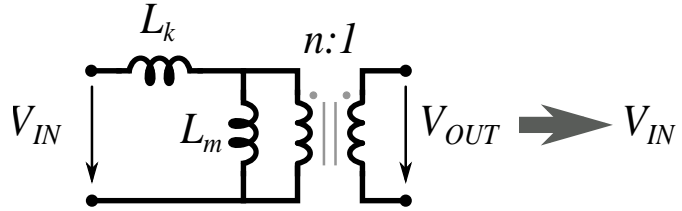

a)

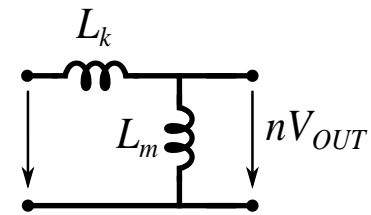

b)

Figure 3.13: Transformer model and normalized transformer model referred to primary values.

However, this model is only accurate for perfectly coupled transformers. Considering real coupling, there are two possible models, as shown in Figure 3.13.

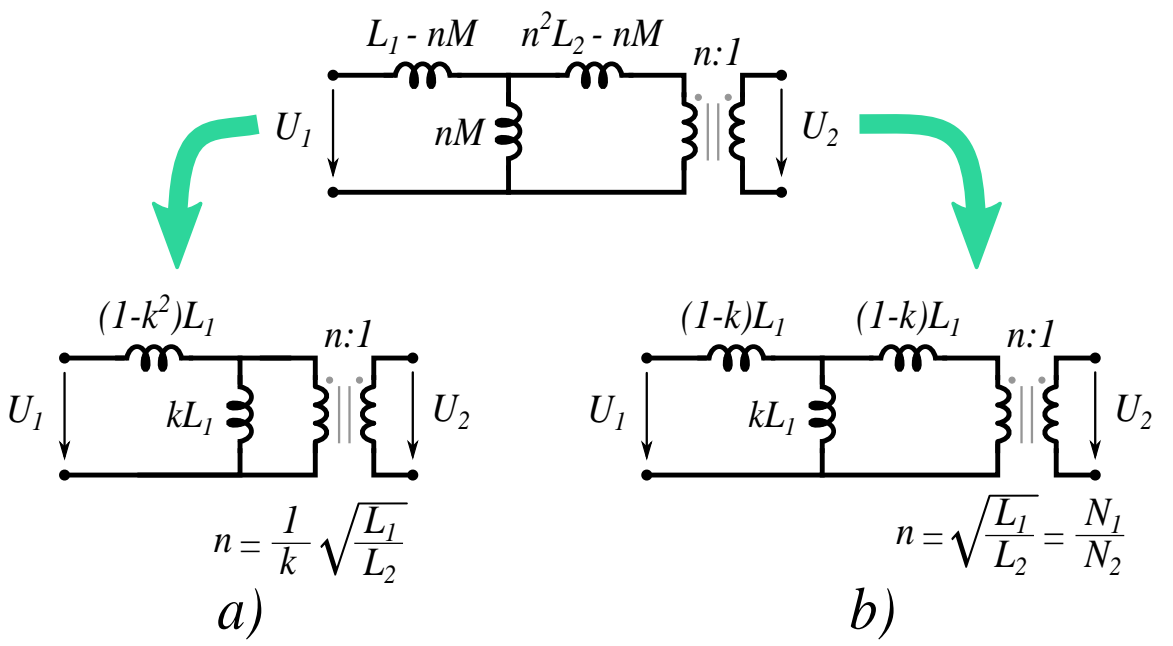

Figure 3.14: Transformer models considering coupling factor $k$

In the transformer model depicted in Figure 3.14 a), where all the leakage inductance is lumped into primary side, the turns ratio of the ideal transformer is not the real turns ratio of the transformer, in order for the model to be accurate. 
To keep the ideal transformer turns ratio equal to the real turns ratio, the distributed model has to be used.

With this model, all of the secondary impedances can be referred to primary side by multiplying by the turns ratio squared.

Using this transformer model and including the parasitics from the terminals and PCB stray inductances, the resonant network depicted in Figure 3.14 is obtained. All values from secondary side are referred to the primary side.

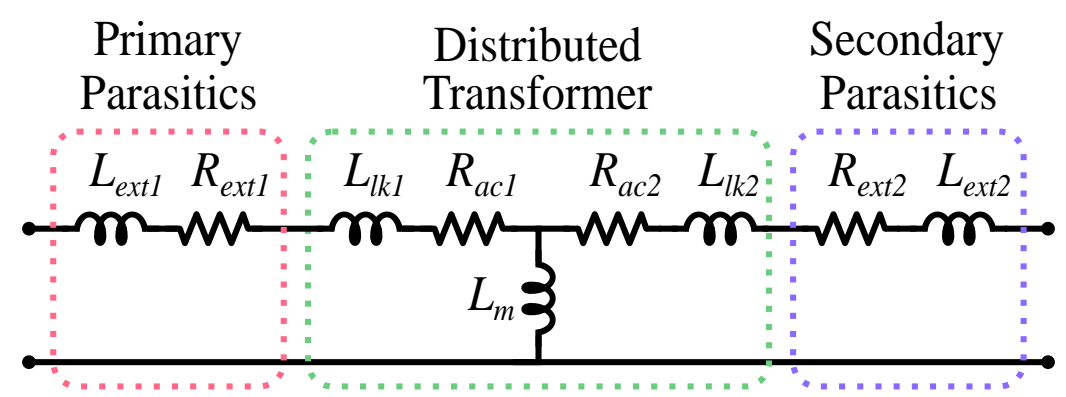

Figure 3.15: Distributed transformer model with additional external parasitic impedances. All secondary impedances are referred to primary side.

The FHA model can be applied with to modified resonant network. Lumping all the series impedances together, the equivalent circuit obtained is the one in Figure 3.16 .

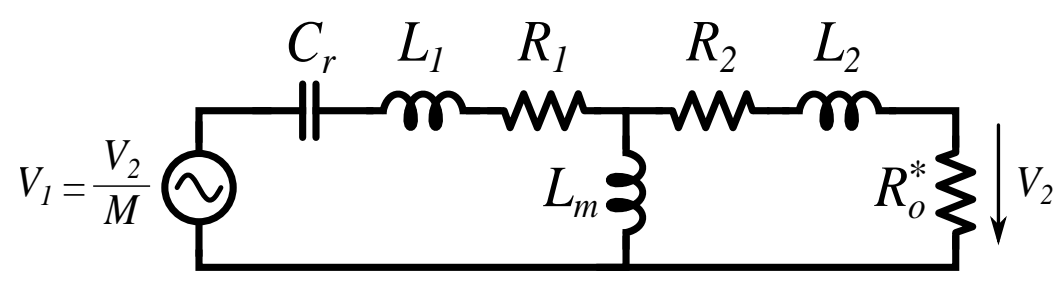

Figure 3.16: FHA Equivalent circuit with distributed impedances (DI-FHA)

Two additional dimensionless parameters are required to account for the distribution of resistance between input and output side; the distributed resistance ratio, $\rho$, with the following relationship to the resistances:

$$
R_{1}=\rho \cdot R_{s} \quad R_{2}=(1-\rho) \cdot R_{s}
$$

And the distributed inductance ratio, $\lambda$ : 


$$
L_{1}=\lambda \cdot L_{r} \quad L_{2}=(1-\lambda) \cdot L_{r}
$$

The analytical solution for the gain of the Figure 3.16 circuit can be derived using these parameters. The solution is cumbersome. However, it can be rearranged similarly as equation (3.8):

$M=\frac{1}{\sqrt{\left(1+\frac{1}{m-1}\left(1-\frac{1+A_{1}}{f_{n}^{2}}\right)-\frac{Q}{Q_{s}}+A_{2}\right)^{2}+Q^{2}\left(\left(1+B_{1}\right) f_{n}-\frac{1+B_{2}}{f_{n}}-\frac{1}{f_{n}^{2}}\left(\frac{1}{(m-1) \cdot Q \cdot Q_{s}}\right)\right)^{2}}}$

The terms $A_{1}, A_{2}, B_{1} B_{2}$ are defined separately, for the sake of simplicity and for the equation to be more manageable:

$$
\begin{gathered}
A_{1}=(1-\rho) \frac{Q}{Q_{s}} \\
A_{2}=\frac{1}{m-1}(\rho(1-\lambda)+(1-\rho) \lambda) \frac{Q}{Q_{s}}-(1-\lambda) \\
B_{1}=\frac{1-\lambda}{m-1} \\
A_{1}=\frac{1}{m-1}\left(1-\lambda+\frac{\rho(1-\rho)}{Q_{s}^{2}}-\frac{1-\rho}{Q \cdot Q_{s}}\right)
\end{gathered}
$$

It can be noted that all parameters have a factor of $1 /(m-1)$, except for $A_{1}$, which already has the factor of $1 /(m-1)$ included in equation (3.12). This shows that the parameters are negligible at high values of inductance ratio $m$.

The comparison results will be presented in section 3.3.5.

\subsubsection{Time-based simulation models: (SR-TB and DI-TB)}

In order to compare the different FHA models, an estimation of the real gain of the LLC converter including parasitics is needed. For this, the simulation approach is accurate though time-consuming, if considering all the parasitics that where previously introduced. In these simulations, the inverter and rectifier are modeled accurately, as depicted in Figure 3.17 and Figure 3.18 


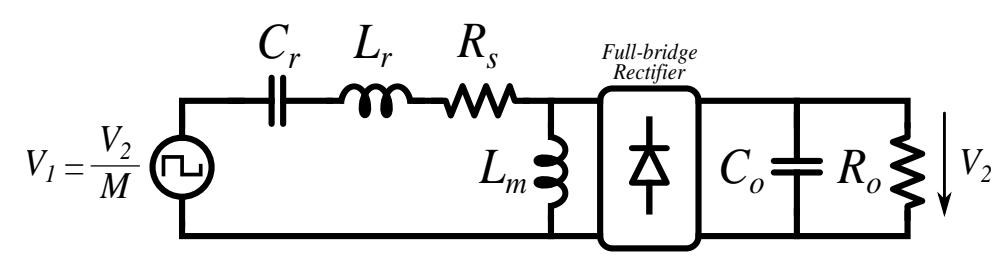

Figure 3.17: Time-based equivalent circuit with series resistance (RS-TB)

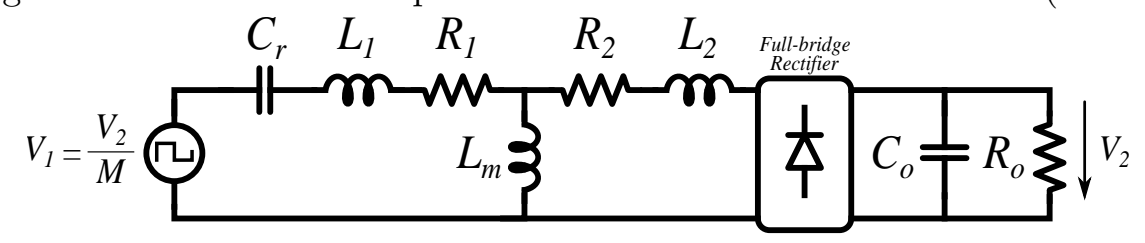

Figure 3.18: Time-based equivalent circuit with Distributed impedances (DI-TB)

Two different time-based models will be considered to compare with the two modified FHA. The series resistance time-based model (SR-TB) and the distributed impedance time-based model (DI-TB). The equivalent circuits of these two models are depicted in 3.17 and 3.18 .

\subsubsection{Comparison of models}

To compare the models, three different output loads are chosen, to highlight the behavior of the converter at light load $500 \mathrm{~W}$, medium load $5 \mathrm{~kW}$ and full load $10 \mathrm{~kW}$. Two different inductance ratios are considered, for low inductance ratio $m=10$ and for high ratio $m=215$. Finally, the frequency range of frequencies is selected to be from $f_{n}=0.5$ to $f_{n}=2$. As operation close to resonance is the main focus of this chapter.

Figure 3.19 illustrates the numerical comparison between the SR-FHA and SR-TB models for low inductance ratio and in Figure 3.20 for high inductance ratio. A good match between the analytical model and the time-based model is only achieved within the frequency range $0.75<f_{n}<1.1$. Outside this range, the harmonic harmonics are not negligible, and the assumptions of the FHA approach are not valid. Therefore the model is not accurate enough. The relative error increases with the output power.

The comparison of the DI-FHA and DI-TB models is depicted in Figure 3.21 for low inductance ratio $(m=10)$ and in Figure 3.22 for high inductance ratio $(m=215)$. As explained in the previous section, the distributed model is not 


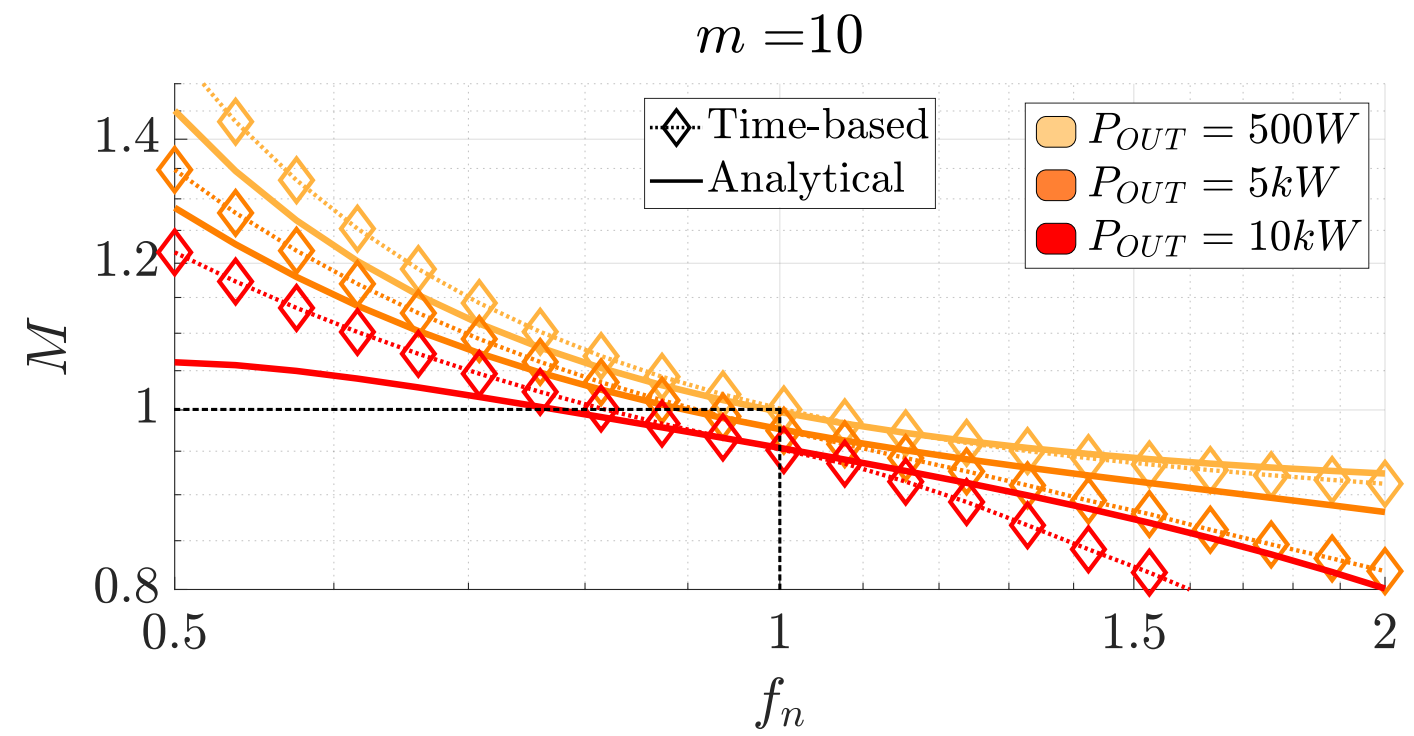

Figure 3.19: Comparison of the voltage gain $M$ from SR-FHA and SR-TB models at low inductance ratio $m=10.5$

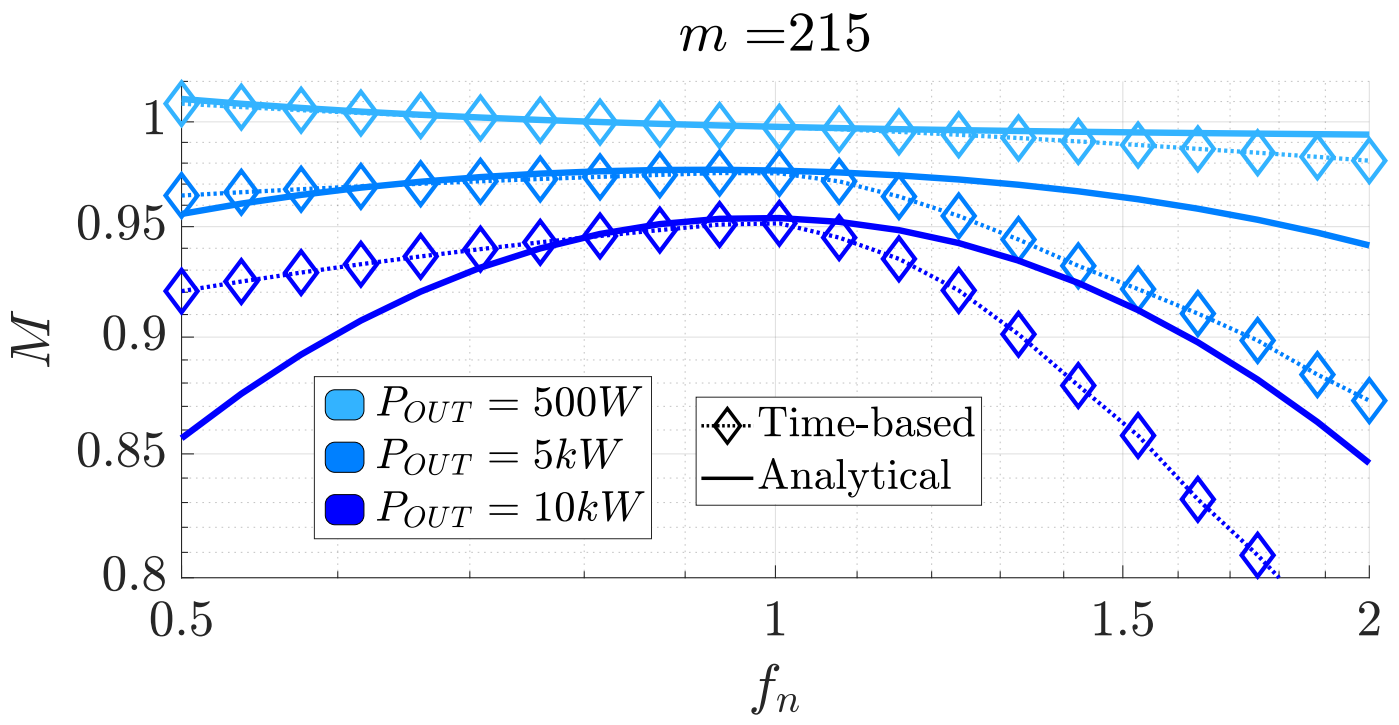

Figure 3.20: Comparison of the voltage gain $M$ from SR-FHA and SR-TB models at high inductance ratio $m=215$ 


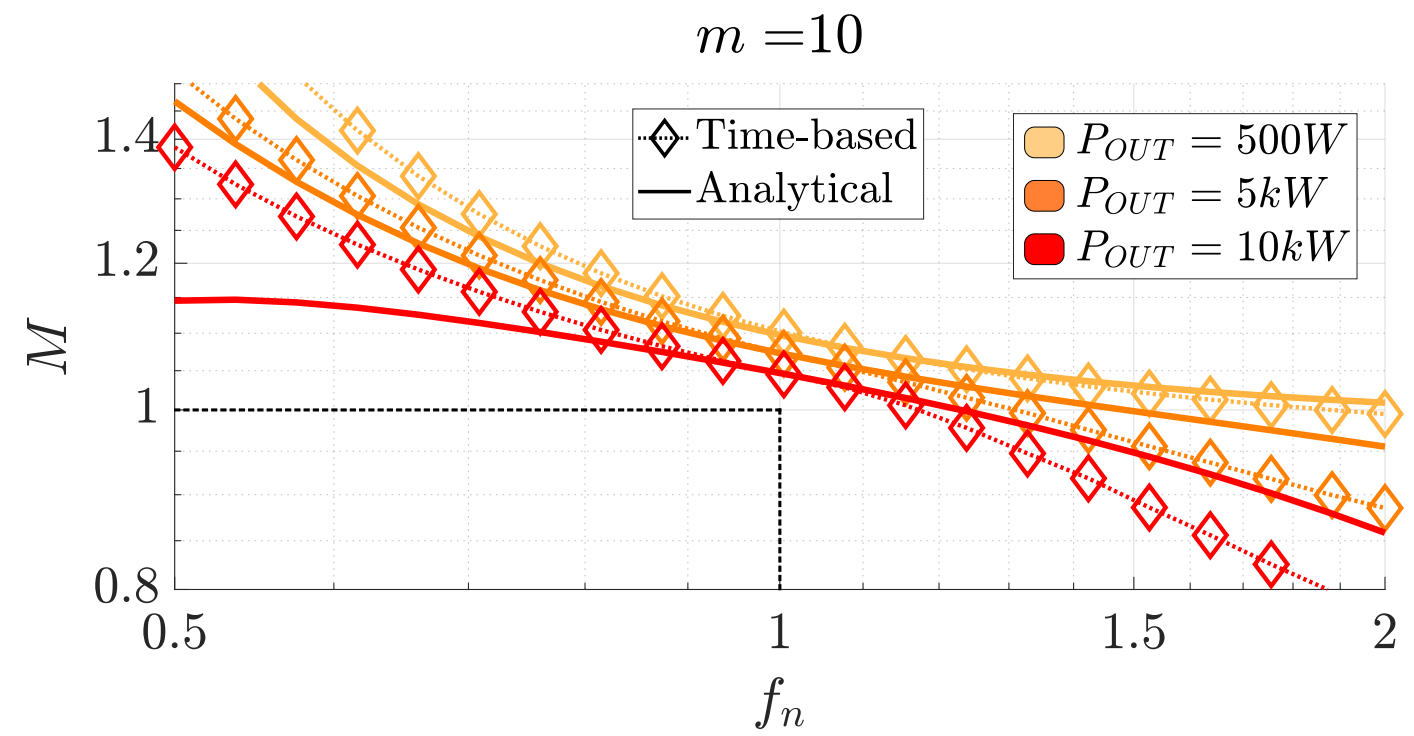

Figure 3.21: Comparison of the voltage gain $M$ from DI-FHA and DI-TB models at low inductance ratio $m=10.5$

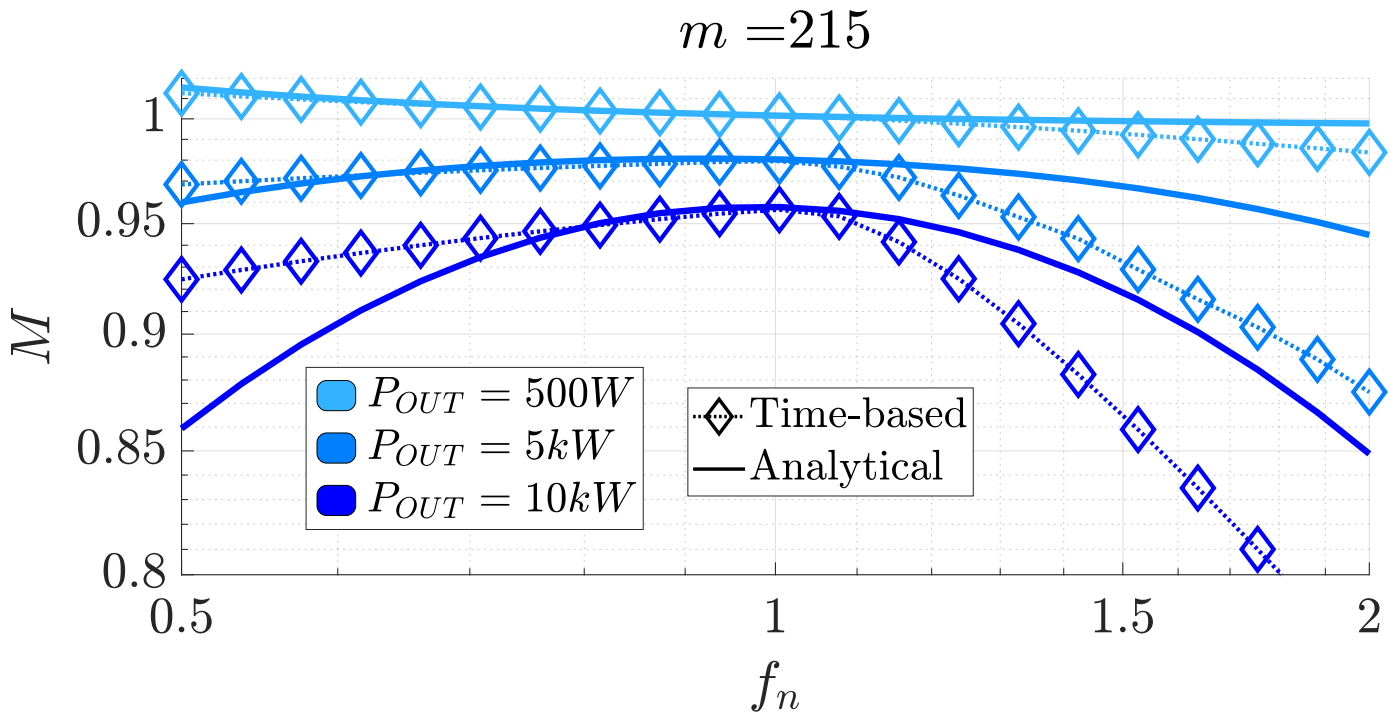

Figure 3.22: Comparison of the voltage gain $M$ from DI-FHA and DI-TB models at high inductance ratio $m=215$ 


\subsection{Resonant current models}

relevant at high inductance ratio, where the more simple model SR-FHA is accurate enough. This can be observed in Figure 3.20 and Figure 3.22, where the numerical values of the voltage gain are identical for both models. On the other hand, at low inductance ratio, the voltage gain $10 \%$ increases $10 \%$ at the resonant frequency, and the DI-FHA models account for this. However, the distributed model is also only valid between $f_{n}=0.75$ and $f_{n}=1.1$ approximately.

In conclusion, for LLC converters operating close to resonance and with high inductance ratio, the series resistance FHA model (SR-FHA) has better accuracy than the traditional FHA by considering the load-dependent voltage drop. However, for the low inductance ratio case, the RS-FHA is not accurate enough, and the distributed impedance model DI-FHA is more accurate.

\subsection{Resonant current models}

In the previous sections, the voltage gain models have been discussed, where the FHA approach is not entirely accurate but with low parasitics and for preliminary designs is accurate enough. However, considering the current, the FHA incurs in much error. Figure 3.23 shows the relative error of the current using the FHA compared with the current of the time-based simulation. The FHA circuit is a purely AC circuit with only one harmonic and linear. Therefore, the current is also purely sinusoidal. However, in an LLC circuit, the diode rectifier introduces non-linearities, and the two different inductors of the LLC network resonate at different frequencies. It can be seen in Figure 3.23, that the relative error in the estimated RMS current is high when operating far from resonance.

In operation at resonant frequency, even if the error is moderate, the FHA current model is not accurate enough when dealing with instantaneous current, as illustrated in Figure 3.23. The instantaneous current is needed for ZVS analysis, where the current during the transition is required to be modeled accurately to define if the ZVS condition is achieved or not. Because of this, time-based simulations will be used instead of FHA models to estimate currents for the remainder of this thesis. 


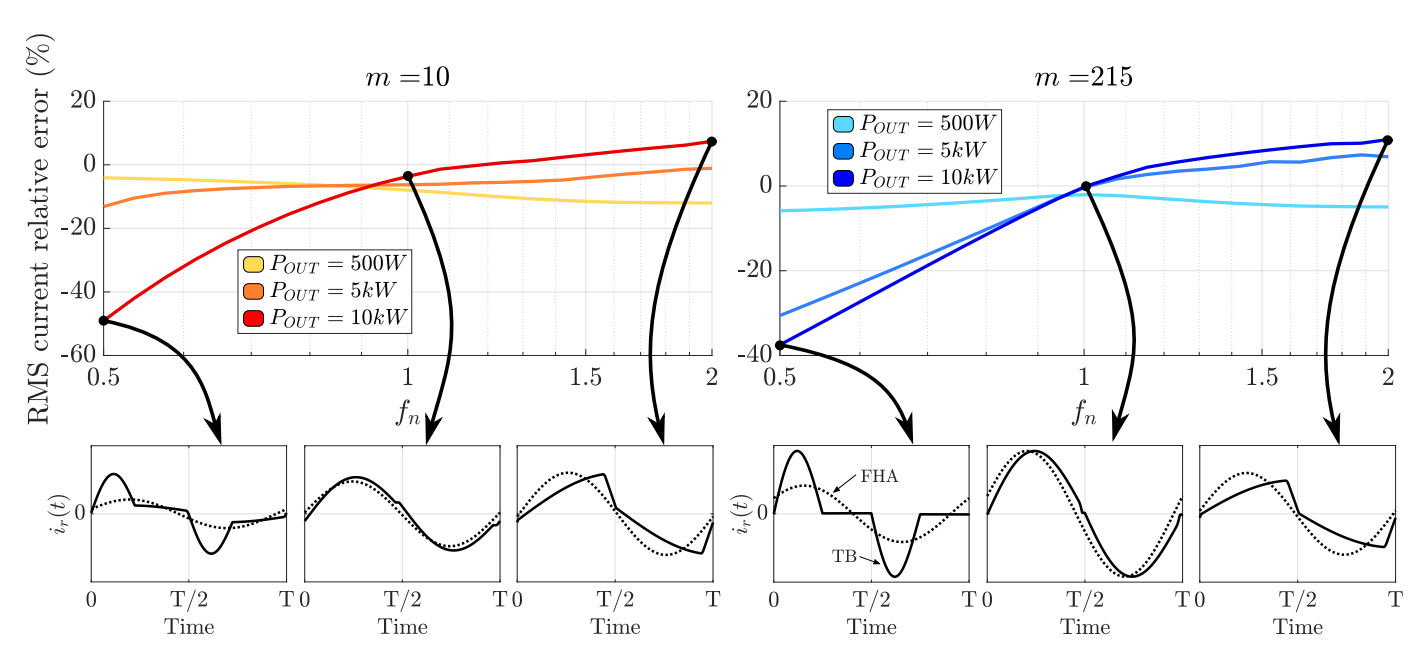

Figure 3.23: Comparison of rms current for FHA and TB models

\subsubsection{Series resistance and current distortion}

As explained in the voltage gain model, the addition of the series resistance has a damping effect on the resonance of the LLC network. The series quality factor $Q_{s}$ parameter is used to quantify this damping effect, as illustrated in Figure 3.24.

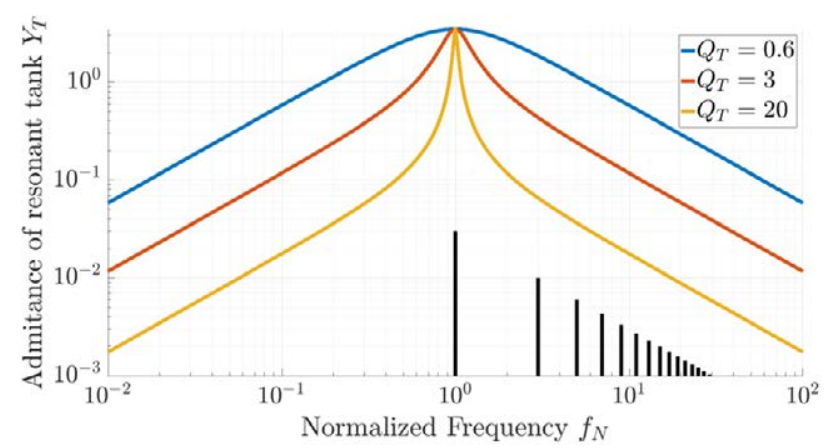

Figure 3.24: Resonance damping
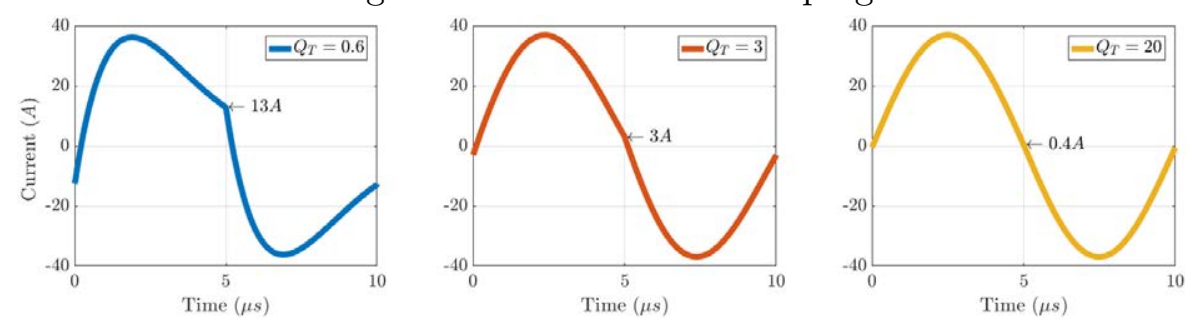

Figure 3.25: Current distortion 
With low values of $Q_{s}$, the higher harmonics are not filtered and therefore the current is distorted, as depicted in Figure 3.25. This distortion increases the turn-off current, which also can increase the switching losses by loss of ZCS behavior. However, this additional can be helpful in achieving a full ZVS. Therefore it is interesting to consider calculating it in the design process.

\subsubsection{Comparison between SR-TB and DI-TB current models}

In the first subsection, it was established that the FHA is not accurate as a model for the resonant current. Time-based simulation are required for accurate results. Two different time-based models can be used, the SR-TB and DI-TB, as explained in the previous sections. However, to model the instantaneous current during the transition, for ZVS analysis, the output capacitors of the MOSFET need to be modeled, as they resonate with the resonant network along the dead-time transition. The current models used are therefore modified to include this, as depicted in Figure 3.26 and Figure 3.27.

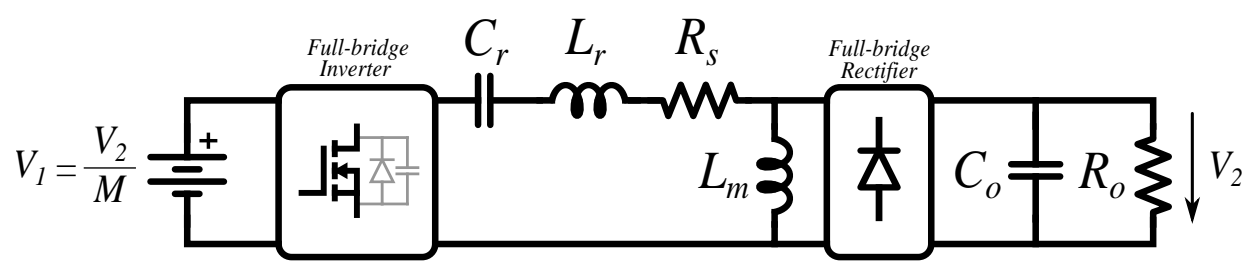

Figure 3.26: SR-TB cambiar a puente de mosfets en primary

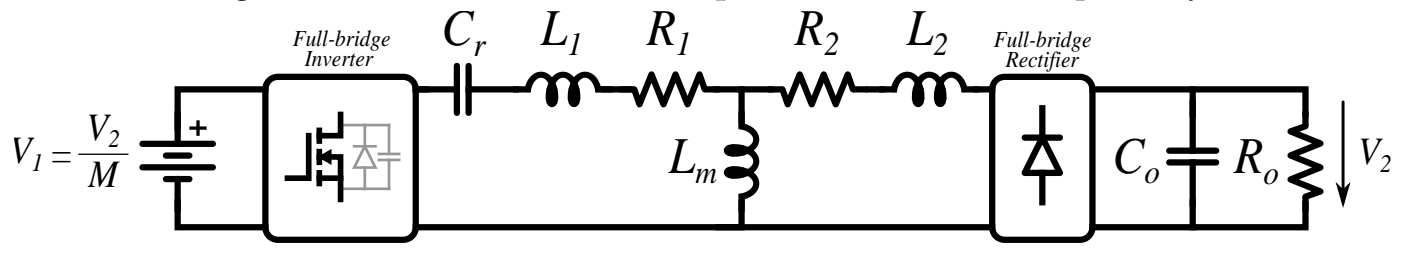

Figure 3.27: DI-TB cambiar a puente de mosfets en primary

Figure 3.28 shows the comparison of the currents during the dead-time transition of the RS-TB and DI-TB models.

It can be noted that the models only show mismatch at low inductance ratio and operating at resonance and below resonance operation. In the context of ZVS analysis, the average charge during the dead-time transition is needed to estimate if the ZVS is complete or not. In the following section, ZVS analysis is carried out 

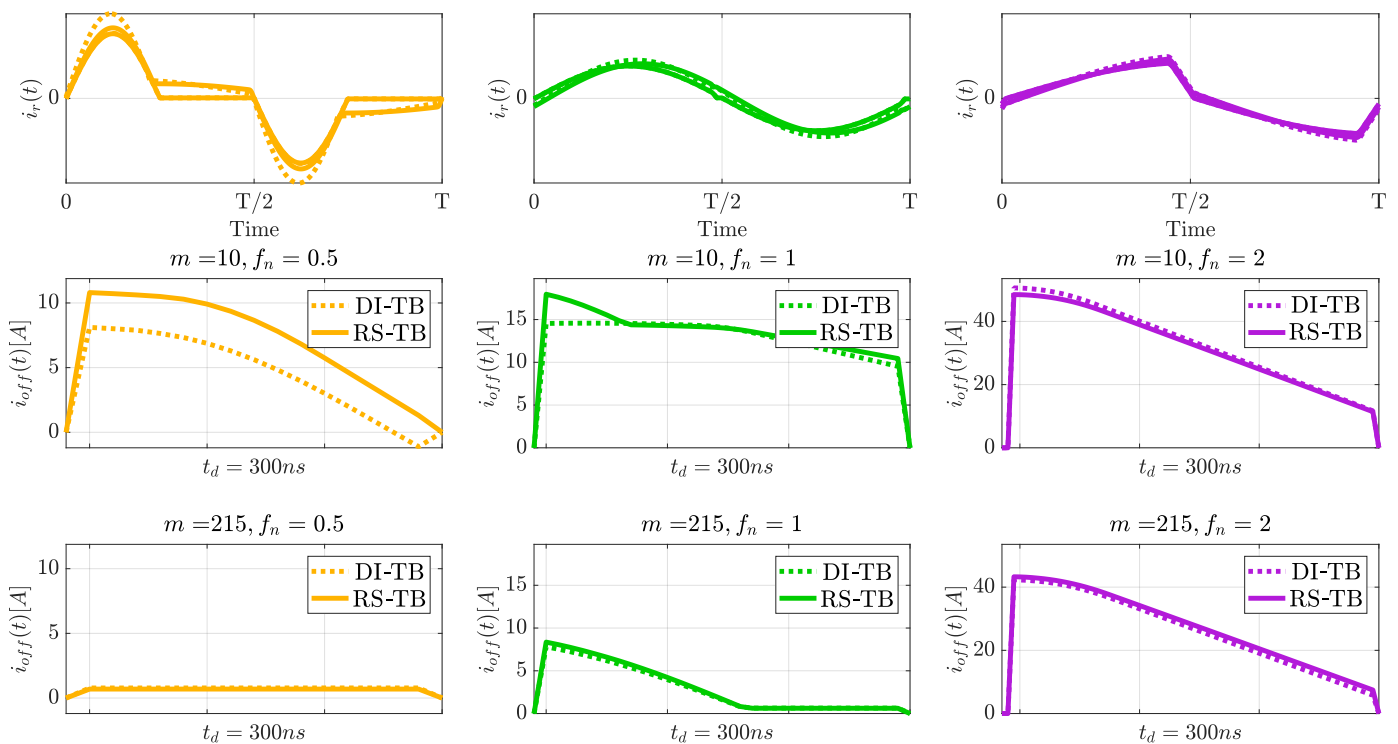

Figure 3.28: Instantaneous resonant current comparison for RS-TB and DI-TB models, at $m=10.5$ and $m=215$ at $10 \mathrm{~kW}$

using the DI-TB current model with the MOSFET bridge, with output capacitance $C_{\text {oss }}$ accurately modeled.

\subsection{Chapter summary}

In this chapter, the LLC converter operation was recalled with the different frequency operation modes. The efficiency of the LLC was estimated, and it was verified that the maximum efficiency is achieved at resonant frequency. For this reason, the operation at resonant frequency is desired for unregulated LLC converters. Because unregulated converters do not control their output voltage, accurate models for the gain are required for design purposes. Two different analytical FHA models were proposed in this chapter: the series resistance FHA (SR-FHA) and the distributed impedance FHA (DI-FHA). They were compared with their time-based simulation equivalents SR-TB and DI-TB. The proposed modified FHA models are accurate operating close to the resonant frequency, where the unregulated LLC converter operates. The accuracy of the SR-FHA model is high enough for low inductance ratio $m$, while the DI-FHA show better results for the low inductance ratio designs. 
Chapter 4

\section{Zero Voltage Switching Analysis}

\section{in LLC Converters and}

Auxiliary Circuits

In this chapter, the ZVS transition will be analyzed in detail and highlighting the particularities related to LLC converters. LLC converters are known in the literature to have both Zero Current Switching (ZCS) or Zero Voltage Switching (ZVS) capabilities $[19,20]$.

In Figure 4.1, the LLC converter voltage gain $M$ over the normalized frequency $f_{n}$ is illustrated. The Zero current switching (ZCS) and zero voltage switching (ZVS)

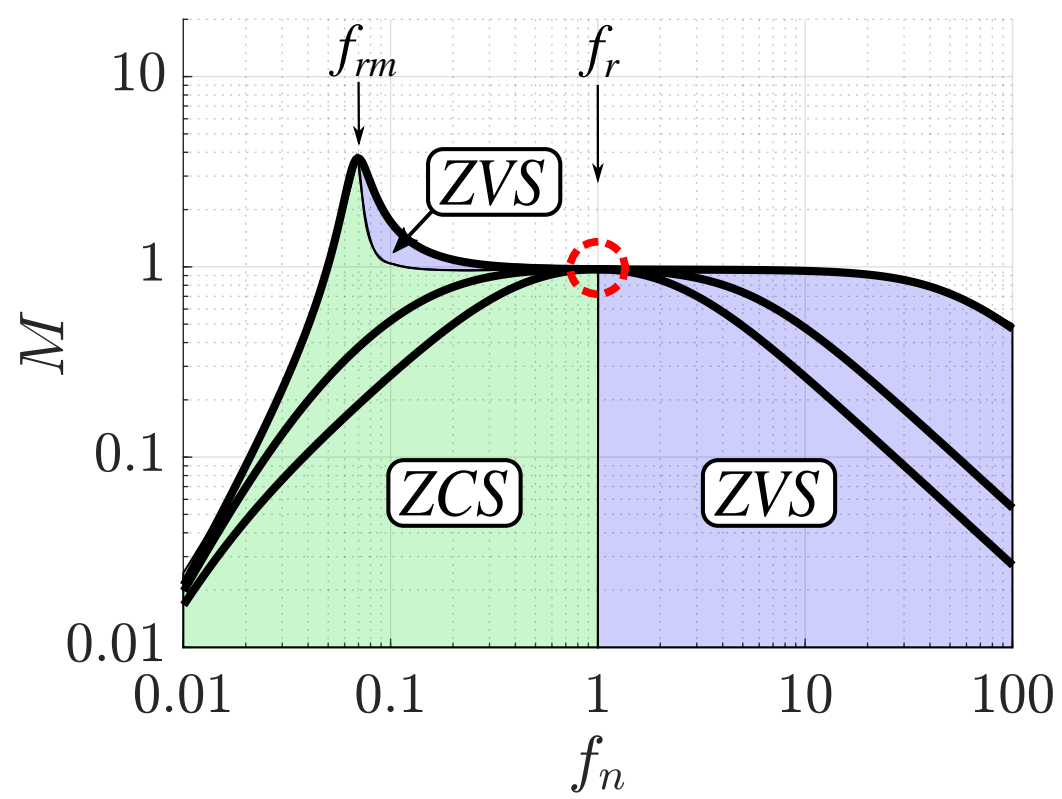

Figure 4.1: LLC converter voltage gain $M$ over the normalized frequency $f_{n}$ with the ZVS and ZCS operating regions 
regions are shown. In above resonance operation, ZVS is achieved because of the inductive behavior of the resonant network. Below resonance, the resonant network has capacitive behavior load quality factors of $Q=0.18$ and higher. However, for low load quality factor $(Q<0.05)$ the parallel inductor will be dominant and then ZVS is possible for the frequency range in between the series resonant frequency $f_{r}$ and the parallel resonant frequency $f_{r m}$, which is defined as follows:

$$
f_{r m}=\frac{1}{2 \pi \sqrt{L_{m} C_{r}}}
$$

In unregulated LLC converters operating at resonant frequency $\left(f_{n}=1\right)$, the operation is located at the intersection between the ZVS and ZCS regions. It is possible to be in the ZVS region with not enough inductive current to achieve a full ZVS transition. This is called in the literature imcomplete ZVS (i-ZVS) [21].

In the conventional analysis of the state of the art, the full ZVS condition is based on the value turn-off current. However, this method has its limitations when the turn-off current is not constant, like in LLC converters. In this chapter, a more accurate charge-based method is presented, base on the total charge delivered by the turn-off current to the MOSFET capacitances during the dead-time. Along this section, the electric charge $(Q)$ is going to be used. However, the letter $Q$ is already used for the quality factor, in the context of LLC converters. Therefore, the lower-case $q$ is going to be used for electrical charges instead for the sake of clarity and to avoid confusion.

Finally, as seen in the previous section, the most efficient LLC designs have low inductance ratio and therefore will have small turn-off current at resonant frequency. These designs will have incomplete ZVS. In order to cope with this issue, auxiliary circuits can be used to improve the ZVS capabilities of these LLC converters without compromising their designs in terms of efficiency. Four different auxiliary ZVS circuit solutions will be analyzed and compared in terms of power losses, volume, and complexity.

\subsection{ZVS Basics}

In power converters, Zero Voltage Switching (ZVS) is a type of soft-switching, achieved when a transistor is turned-on with zero voltage. As it is known in the 
state of the art, this reduces the power losses as well as the emitted noise by avoiding high voltage spikes and high voltage derivatives. In MOSFET devices, this voltage is the Drain-Source voltage $V_{D S}$. Between these terminals, a parasitic capacitance is located, called output capacitance $C_{\text {oss }}$, as illustrated in Figure 4.2. Additionally, a parasitic diode is also present because of the semiconductor unions used to create the MOSFET structure.

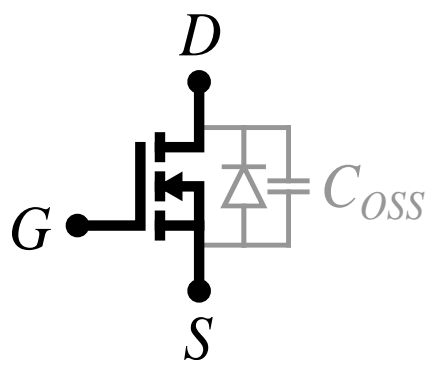

Figure 4.2: MOSFET with parasitic diode and $C_{O S S}$ capacitance

A typical MOSFET structure in power converter is the totem pole structure, also called leg, in the context of bridge structures, as depicted in Figure 4.3.

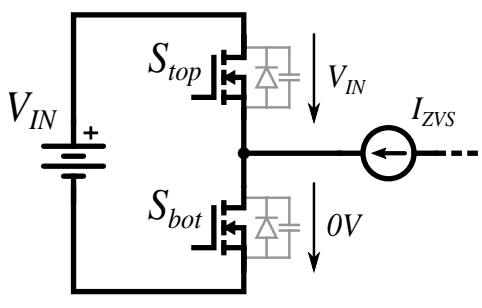

a)

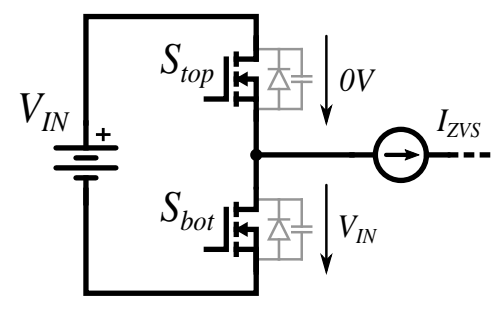

b)

Figure 4.3: MOSFET totem pole structure: a) Low-side turn-off, high-side turn-on b) High-side turn-off, Low-side turn-on

There are two possible states: the low-side turn-off and high-side turn-on transition, depicted in Figure 4.3 a); and the high-side turn-off and low-side turn-on transition, as illustrated in Figure $4.3 \mathrm{~b}$ ). The voltage drops of the on devices are neglected and equal to $0 \mathrm{~V}$. In both figures, the current in the correct direction to achieve ZVS is shown. This current moves the electrical charges from the charged capacitor to the discharged one. When the charge transfer has ended, the diode of 


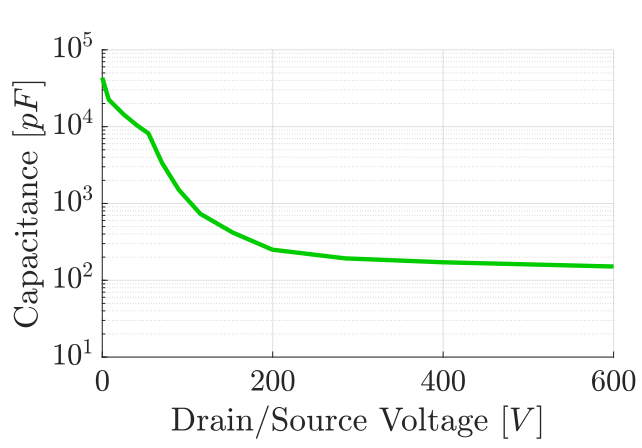

Figure 4.4: Output capacitance $C_{\text {oss }}$ of a Coolmos MOSFET device IPW65R037C6 in function of $V_{d s}$

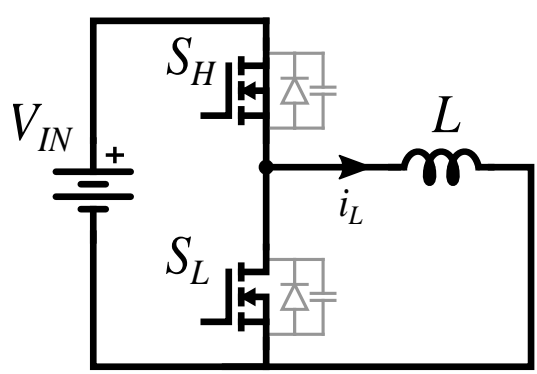

Figure 4.6: Transistor leg with a single inductor, ZVS transition model

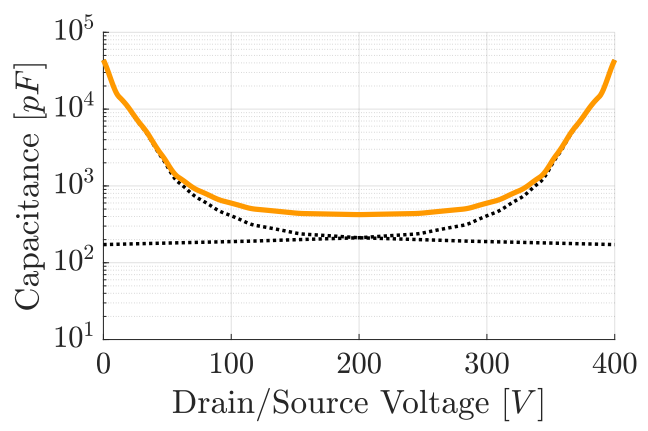

Figure 4.5: Equivalent output capacitance of a transistor leg with IPW65R037C6 devices, as depicted in Figure 4.6.

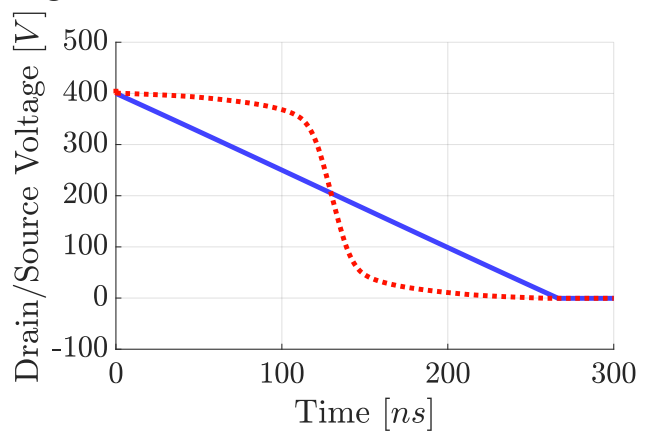

Figure 4.7: Discharge of the output capacitance with variable Capacitance (red dotted line) and equivalent Capacitance models (blue solid line)

the discharged capacitor will start conducting, and this device can be turn-on with zero voltage.

If the charge stored in the $C_{o s s}$ capacitor has not been completely transferred to the opposite capacitor and this transistor turns on, the energy will be lost in the transistor channel, generating losses over time for each switching cycle.

It is a known fact, that the output capacitance $C_{\text {oss }}$ of power transistors has a non-linear behavior as a function of $V_{d s}$, as shown in Figure 4.4 .

Considering a transistor totem pole structure with a single inductor connected to the middle point, as illustrated in Figure 4.6, the total capacitance as function of the Drain/Source Voltage of the low-side capacitor because the one depicted in Figure 4.5. The discharge of this capacitance with a constant current is illustrated 
in Figure 4.7. This discharge has a low slope at the beginning and at the end of the discharge, where the voltage is either close to zero or close to $V_{I N}$ and the equivalent capacitance is high. If calculating an equivalent capacitance based on charge balance, as explained in [21], the value is the following:

$$
C_{e q}=\frac{q_{o s s}}{\Delta V_{D S}}=\frac{q_{o s s}}{V_{I N}-0}=\frac{1}{V_{I N}-0} \int_{0}^{V_{I N}} C_{o s s}\left(v_{d s}\right) d v_{d s}
$$

With this value, the total discharge of the equivalent capacitor and the real variable capacitor take the same time, as depicted in Figure 4.7. Although the current shape is different, the equivalent model will be used for the remainder of the section. The variable capacitance can be used in detailed simulations, but they would be more time-consuming. The equivalent capacitance is as accurate in terms of the required time to achieve ZVS. Therefore it can be used to reduce the simulation time, and reduce the complexity of the analytical equations.

\subsection{ZVS transition analysis: conventional method and limitations for LLC converters}

In the literature, ZVS analysis is typically done assuming a constant current during the dead-time transition [21-23] and particularly for LLC converters [22, 23]. In recent years, some corrections have been made to estimate the ZVS range [24, 25], but they do not mention the variable turn-off current. The assumption that the turn-off current is valid in single inductors circuits, as illustrated in Figure 4.8, and when the energy of the inductor is high enough for the current to be constant.

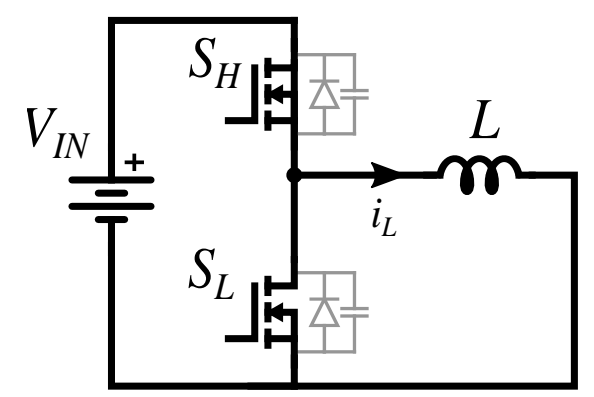

Figure 4.8: Single inductor 
Chapter 4. Zero Voltage Switching Analysis in LLC Converters and Auxiliary Circuits

Typically, during the switching transition, the inductor current is at the maximum, and therefore the energy stored in the inductor is also the maximum possible. The inductor and the two $C_{\text {oss }}$ capacitors form a resonant circuit. However, if the energy stored in the inductor is higher than the energy stored in the capacitor, the inductor current can be assumed constant. Therefore, the inductor can be replaced with a current source in the analysis along the dead-time transition. In [21], the energy balance equation is written in terms of the total charge stored by the output capacitors $q_{\text {oss }}$, as follows:

$$
\frac{1}{2} L I^{2} \gg q_{\text {oss }} \cdot V_{I N}
$$

where $q_{\text {oss }}$ is defined as the total charge of all the devices contributing in the ZVS transition, of a transistor leg:

$$
q_{\text {oss }}=2 \cdot N_{P A R} \cdot q_{\text {ossSingle }}\left(V_{I N}\right)
$$

Where $N_{P A R}$ is the number of parallel devices and $q_{\text {ossSingle }}$ is the charge stored in the output capacitor of a single device.

In LLC converters, there is a resonant network with two inductors and one capacitor, as depicted in Figure 4.9.

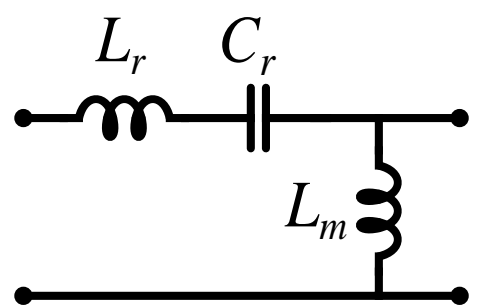

Figure 4.9: LLC resonant network

The energy stored in $L_{m}$ and $L_{r}$ will be different, depending on the design or the operating conditions. Also, the resonant capacitor $C_{r}$ will stored some energy, that will affect the behavior of the current in the inductors, this will also be dependent on the operating conditions. Hence, the full ZVS condition cannot be but written as a simple equation, as in 4.3 and the current cannot be considered constant. Therefore, a charge-based method is proposed in the next section to cope with this issue. 


\subsection{Charge-based ZVS analysis for LLC converters}

As explained in the previous section, the more accurate current gain model to be used for LLC converters with integrated transformer and parasitics, is the distributed model, as depicted in Figure 4.10

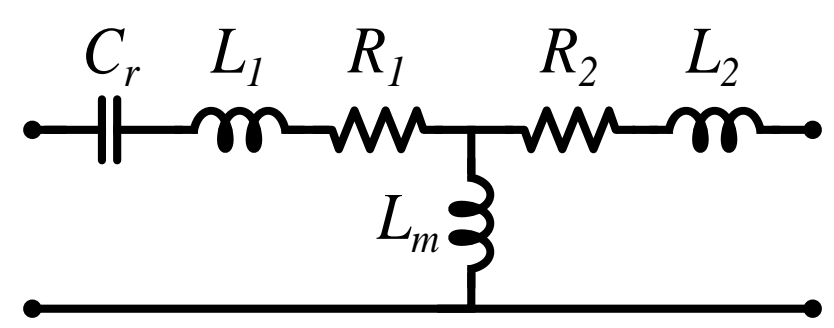

Figure 4.10: Distributed LLC model resonant network

The resonant current of the LLC converter does not remain constant during the dead-time transition. The shape of the resonant current is highly dependent on the LLC parameters, as shown in Figure 4.11, where the resonant current during the dead-time transition is depicted, for a range of frequencies $\left(0.5<f_{n}<2\right)$ and two different inductance ratios $(m=10.5$ and $m=215)$. Consequently, a charge based analysis is required to estimate the complete ZVS condition.

The total charge delivered by the LLC resonant network is defined by the following equation:

$$
q_{i}=\int_{0}^{t_{d}} i_{o f f}(t) d t
$$

To account for the variable current over the transition, the charge ratio $k_{q}$ can be defined as follows:

$$
k_{q}=\frac{q_{i}}{q_{i c o n s t}}=\frac{\int_{0}^{t_{d}} i_{o f f}(t) d t}{I_{o f f} t_{d}}
$$

With this charge ratio $k_{q}$, equation 4.5 can be rewritten:

$$
q_{i}=k_{q} I_{o f f} t_{d}
$$



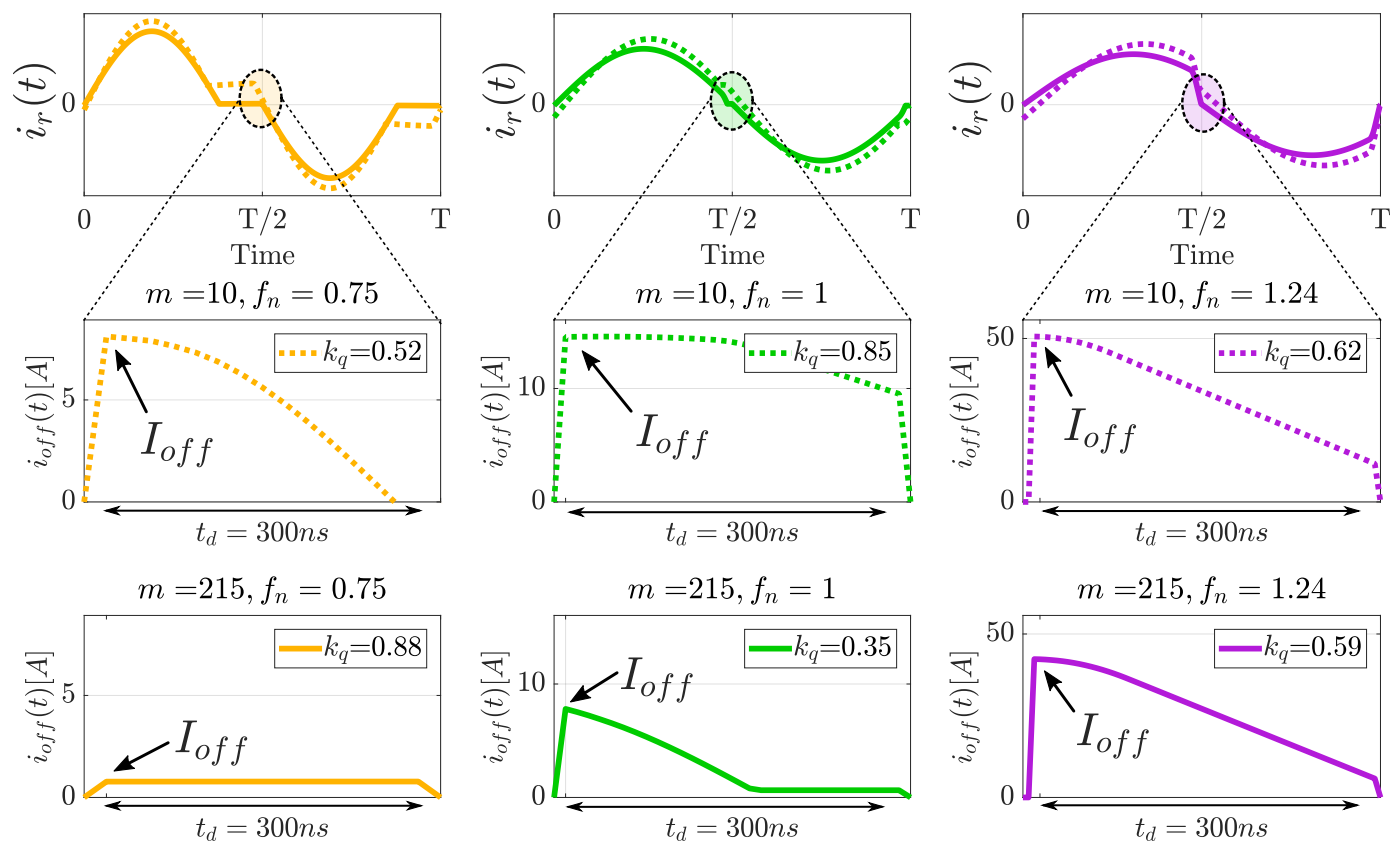

Figure 4.11: LLC converter current during the transition below resonance (left), at resonance (center) and above resonance (right), for two different inductance ratios: $m=10.5$ (center row) and $m=215$ (bottom row)

To achieve a complete ZVS transition, the charge delivered by the resonant network $q_{i}$ must be higher than the energy stored in all the output capacitances of the bridge transistors. This condition can be written as:

$$
q_{i}=k_{q} I_{o f f} t_{d} \geq q_{o s s T o t a l}
$$

Using this equation, the LLC converter can be designed to achieve complete ZVS. Additionally, this condition can be used to design the auxiliary circuits to achieve the same results. 


\subsection{ZVS auxiliary circuits: analysis, design and comparison}

\subsubsection{Auxiliary circuits classification}

As explained in the state of the art section, the auxiliary circuits are a common solution to increase the ZVS range of power converters, especially in full-bridge topologies [26-32]. Auxiliary circuits in Full-bridge converters can be classified in two different categories:

- Two circuits solutions (single leg)

- Single circuit solutions (double leg)

Figure 4.12 illustrates the two circuit structure. This structure is needed when using non-symmetrical modulations, where either the duty cycle or the phase shift of each leg is different. As a consequence, the switching transition of the legs occurs at a different moment, therefore peak current of the auxiliary circuit is required at a different moment. With two independent circuits this issue can be solved.

In Figure 4.13, the single auxiliary structure is depicted. This structure connects a single circuit between each leg of the full-bridge structure. Although some single circuit solutions can be used for asymmetrical modulations [29], this structure is more commonly used in symmetrical modulations, where the switching transition of each leg occurs at the same point in time. In a symmetrical modulation,when switches $S_{1}$ and $S_{4}$ are on, switch $S_{2}$ and $S_{3}$ are off. For this reason, leg $A$ has a high-side turn-off and low-side turn-off, while leg B has a low-side turn-off and high-side turn-on. Therefore, the current required for the ZVS transition has a reversed polarity and a single circuit can be used to achieve this, as shown in Figure 4.13.

Another useful way to classify the auxiliary circuits is by the type of components used. There are two categories:

- Passive circuits

- Active circuits

In passive circuit, inductors and capacitor are used, while active circuits also consists of diodes and transistors. The goal of introducing active components is to reduce the RMS current of the inductor, while achieving the same peak current during the ZVS transition. Though, with these additional components, the control 


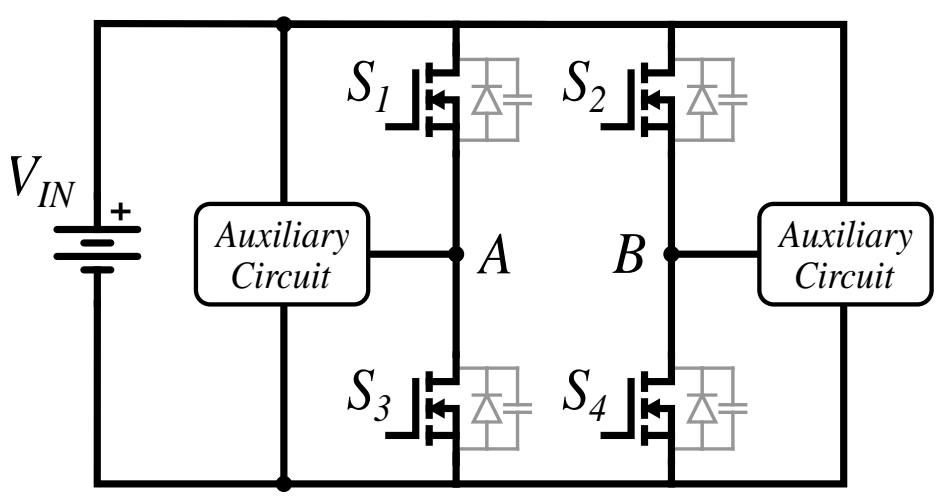

Figure 4.12: Two auxiliary circuit structure for Full-bridge: Between nodes A and $\mathrm{B}$ the rest of the full-bridge is connected

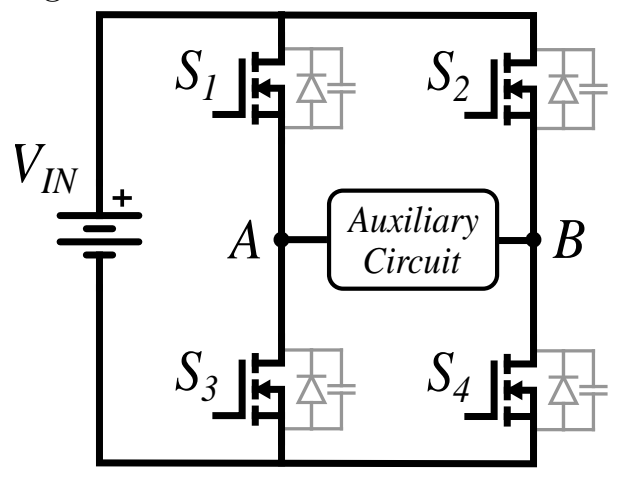

Figure 4.13: Single "leg to leg" auxiliary circuit structure for Full-bridge: Between nodes $\mathrm{A}$ and $\mathrm{B}$ the rest of the full-bridge is connected

complexity increases and power losses can be higher. However, a trade-off between reduction of volume and increase in power losses can be achieved, and will be explained in the following sections.

\subsubsection{Design of auxiliary circuits}

Multiple auxiliary circuit solutions are available in the state of the art to increase the ZVS range of full-bridge converters. To select the most adequate solution a comparison of different auxiliary circuit topologies is required. As they are composed of different components, their design will be different. Nevertheless, the goal of all the ZVS auxiliary circuit is the same: supply the correct amount of current during the dead-time transition. The four different auxiliary circuit structures, depicted in Figure 4.14, are going to be compared in terms of power losses, volume and 


\subsection{ZVS auxiliary circuits: analysis, design and comparison}

complexity. All the auxiliary circuits are designed for a $10 \mathrm{~kW}$ LLC converters, the specifications can be found in chapter 6. For switching devices Coolmos Silicon devices are used.

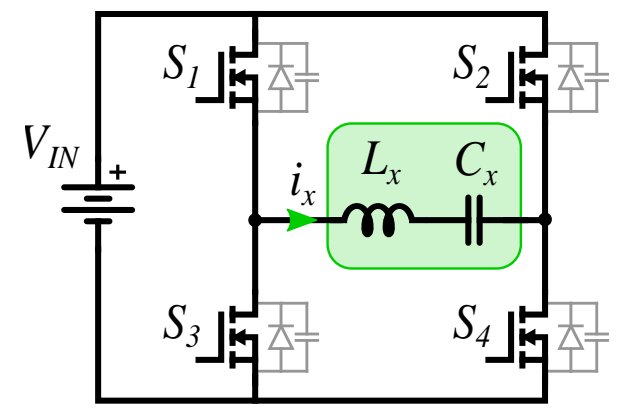

a)

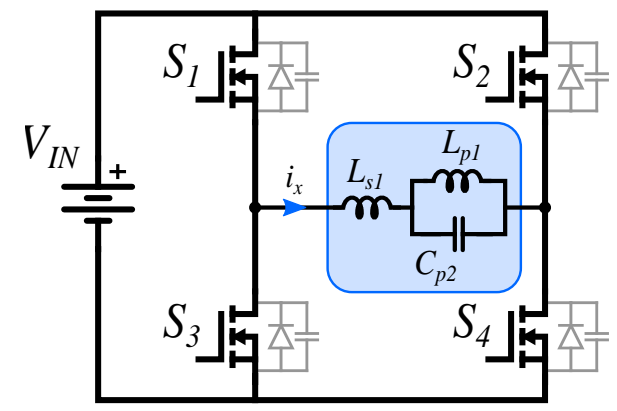

c)

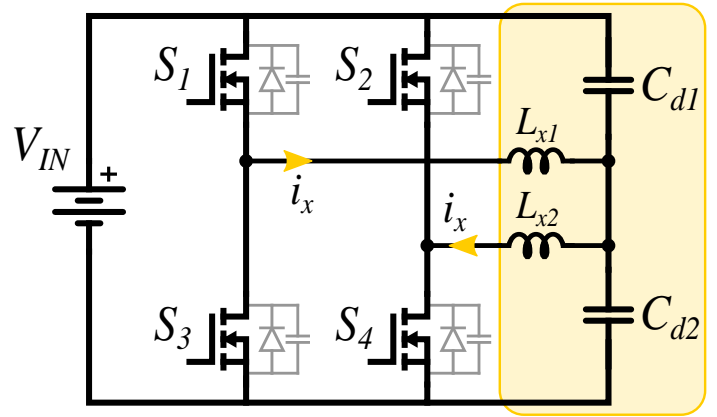

b)

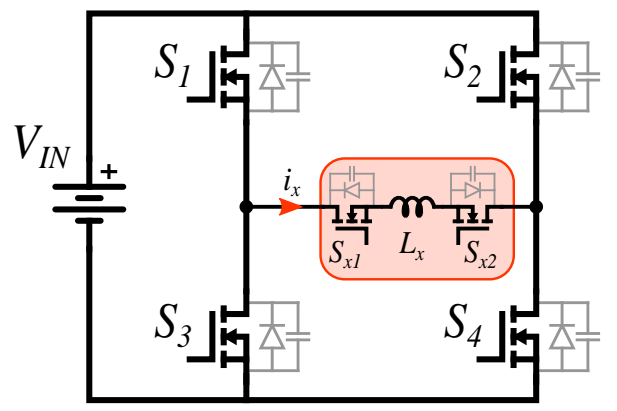

d)

Figure 4.14: Auxiliary circuits, A: Single inductor passive circuit, B: two inductors with auxiliary capacitor leg circuit, C: LCL resonant circuit, D: Single inductor active circuit

The design of the auxiliary circuits is going to be explained in the following subsections. For the sake of simplicity, an additional normalized parameter is going to be defined. It will be defined similar to the inductance ratio $m$ of the LLC converter. The auxiliary inductance ratio is denoted:

$$
m_{x}=\frac{L_{x}+L_{r}}{L_{r}}
$$

With this parameter, it is easy to compare different LLC converter designs with and without auxiliary circuits in terms of complete ZVS. Considering the specifications of the $10 \mathrm{~kW}$ prototype, the value of current to reach to achieve a 
full ZVS transition is $I_{Z V S}=15 A$, which means a value of auxiliary inductance of $L_{x}=66 / m u H$

\subsubsection{Single inductor passive circuit}

This auxiliary circuit, proposed in [33], has the advantage of low component count, with only one inductor and DC blocking capacitor. It consist of a single circuit solution connected between the middle points of the full-bridge, as illustrated in Figure 4.18

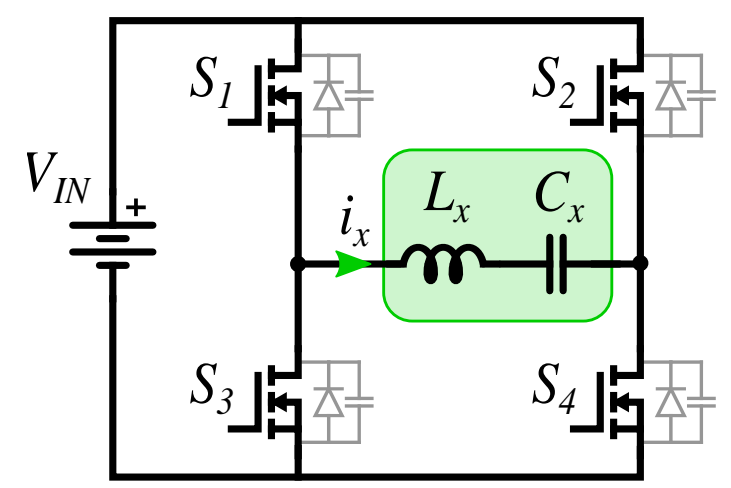

Figure 4.15: Single inductor passive circuit

To provide the necessary current for the ZVS transition, the behavior of this circuit needs to be inductive. This means that at the switching frequency the inductive reactance needs to be dominant over the capacitor reactance. In terms of the resonant frequency of the auxiliary resonant tank created by the two components, the condition is the following:

$$
\frac{1}{2 \pi \sqrt{L_{x} C_{x}}} \ll f_{s}
$$

In the case of the LLC converter operating at resonant frequency, the condition can be written as:

$$
\frac{1}{2 \pi \sqrt{L_{x} C_{x}}} \ll \frac{1}{2 \pi \sqrt{L_{r} C_{r}}}
$$

Simplifying this condition, and using equation 4.9 we can obtain the relationship between the auxiliary capacitor and the resonant capacitor. 


\subsection{ZVS auxiliary circuits: analysis, design and comparison}

$$
C_{x} \gg \frac{C_{r}}{\left(m_{x}-1\right)}
$$

In practice a value of 20 times bigger can be used to avoid the resonance between the auxiliary inductor $L_{x}$ and the auxiliary capacitor $C_{x}$.

Selecting the values of $L_{x}$ and $C_{x}$ accordingly, the auxiliary capacitor impedance $\left(1 / \omega C_{x}\right)$ is negligible in comparison to the auxiliary inductance impedance $\left(\omega L_{x}\right)$. Therefore, the voltage drop in the capacitor is negligible and the voltage applied to the inductor is equal to the square voltage of the input bridge, as depicted in Figure 4.16.
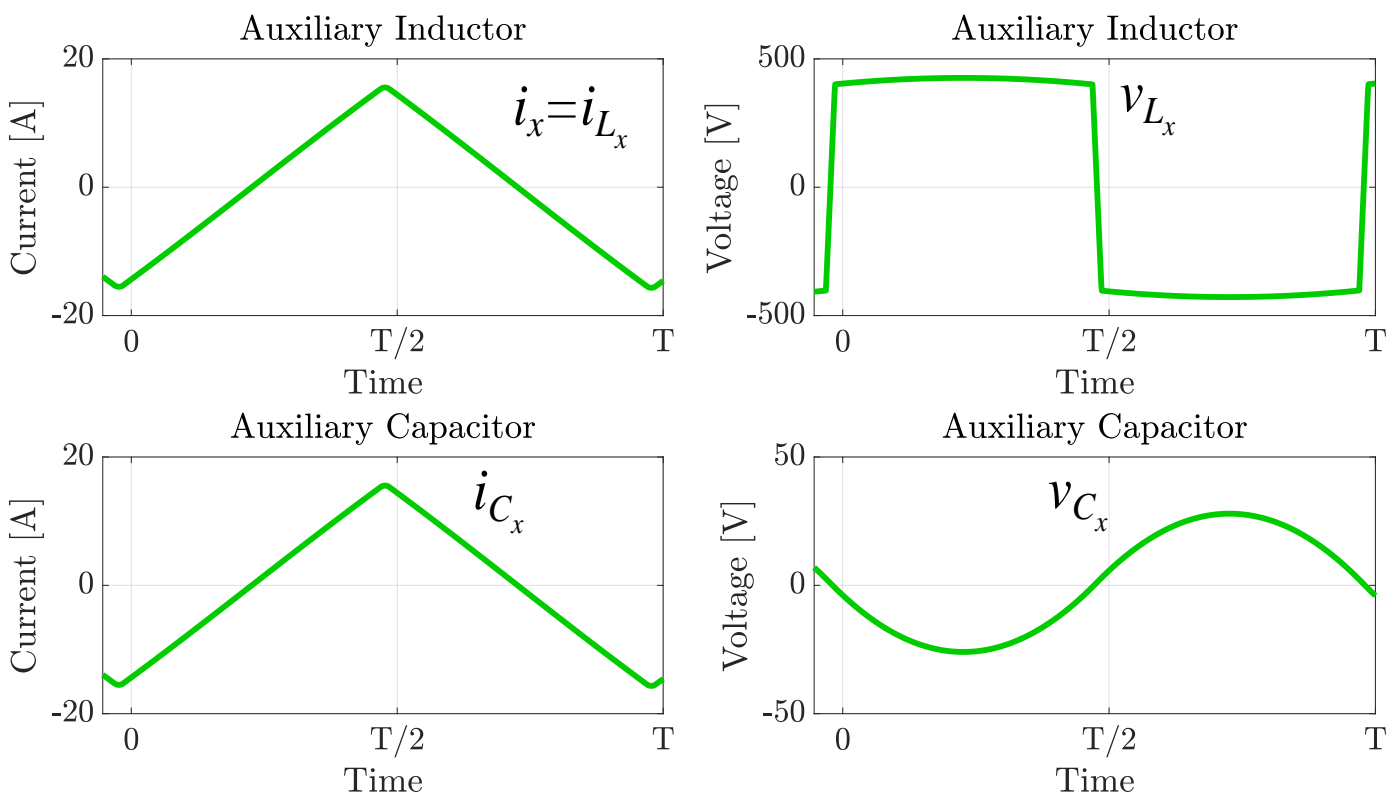

Figure 4.16: Single inductor passive circuit waveforms

With this square voltage applied to the auxiliary inductor, the current is triangular, as shown in Figure 4.16. The triangular inductive peak current of the auxiliary inductor can be calculated as follows:

$$
I_{x}=\max \left(i_{x}(t)\right)=\frac{V_{I N}}{4 L_{x} f_{s}}=\frac{\pi n V_{O U T}}{2\left(m_{x}-1\right) Z_{r} f_{n} M}
$$

As explained in the previous section, to estimate the complete ZVS transition, the inductive charge delivered by the auxiliary circuit and is needed: 


$$
q_{i}=q_{i x}+q_{i r}=\left(I_{x}+k_{q} I_{o f f}\right) t_{d}
$$

This charge is the sum of the charge delivered by the LLC circuit and the auxiliary circuit charge. The charge ratio coefficient $k_{q}$ can be estimated by simulation. Using equations $4.9,4.13$ and 4.14 , we can derive the minimum auxiliary inductance ratio condition to achieve complete ZVS:

$$
m_{x} \leq 1+\frac{\pi n V_{\text {OUT }}}{2\left(\frac{q_{o s s}}{t_{d}}-k_{q} I_{r}\right) Z_{r} f_{n} M}
$$

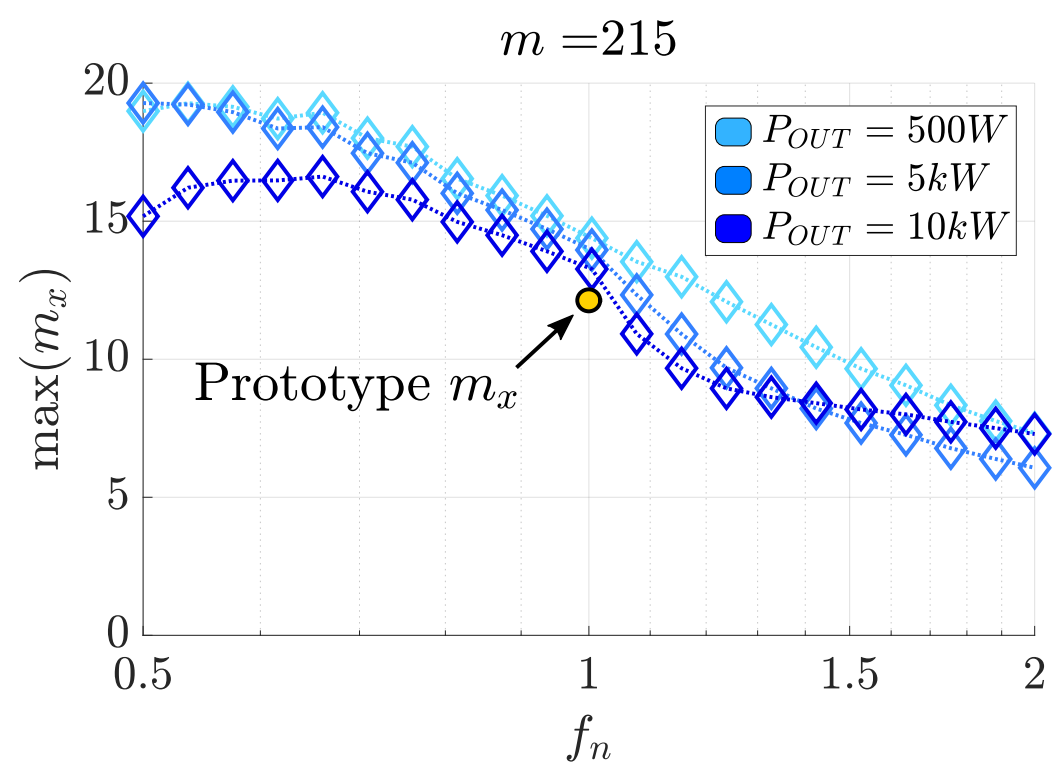

Figure 4.17: Maximum auxiliary inductance ratio $m_{x}$ for different at different frequencies and output powers

As this minimum value depends on the charge ratio $k_{q}$, it will have different values at different operation points for the LLC converter, as depicted in Figure 4.17.

\subsubsection{Two inductors with auxiliary capacitor leg circuit}

This circuit was analyzed in [28]. In this solution, the inductor is divided in two and connected to the middle point of auxiliary capacitor leg, as depicted in Figure 4.18. 


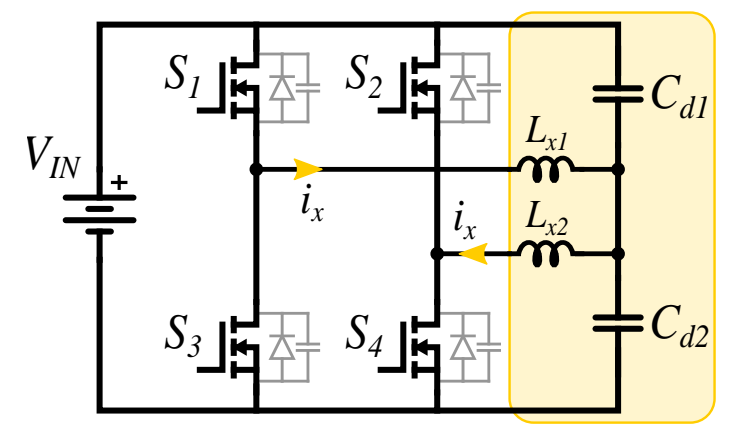

Figure 4.18: Two inductors with auxiliary capacitor leg circuit

This capacitor leg, provides a stable voltage divider with $V_{I N} / 2$, similar to the capacitor leg of a half-bridge. These capacitor also act as DC blocking capacitors. The waveforms of voltage and currents are depicted in Figure 4.19.
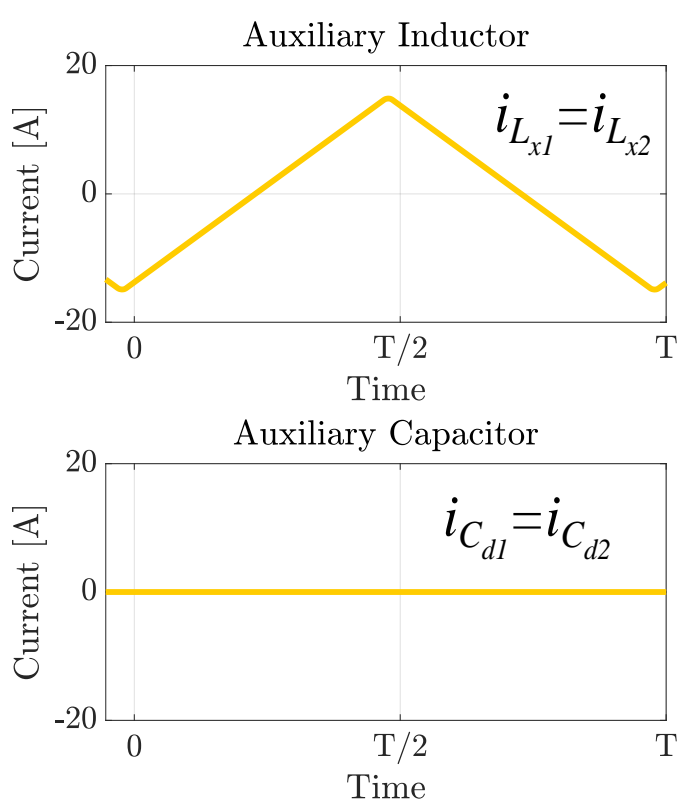

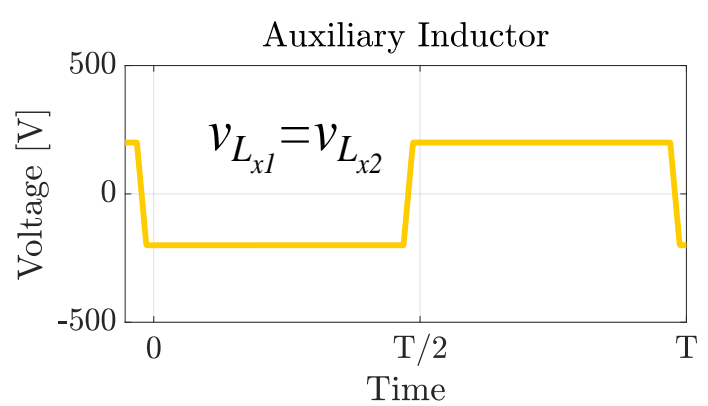

Auxiliary Capacitor

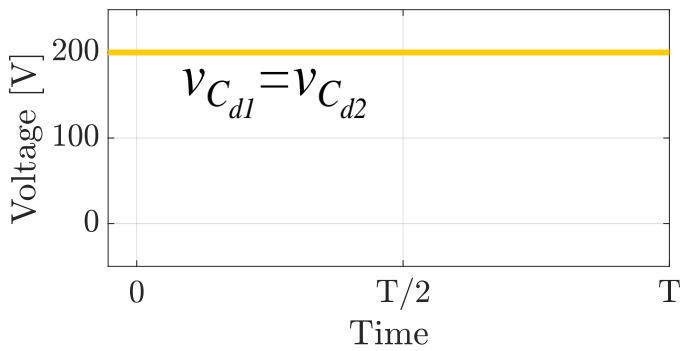

Figure 4.19: Two inductors with auxiliary capacitor leg circuit waveforms

The amplitude of the square voltage applied to each inductor $L_{x 1}$ and $L_{x 2}$ is $V_{I N} / 2$ the inductance needed to reach the same peak current as the circuit in the previous section is:

$$
L_{x 1}=L_{x 2}=L_{x} / 2
$$


Additionally, the two inductors are connected to the same capacitor leg circuit and no current is flowing through the capacitors as the two inductor share the same current with different sign. However, these capacitors need to be designed to avoid resonance at the switching frequency, because, during the start-up transient current will flow through the capacitor leg and resonance can occur between these capacitors and the auxiliary inductors.

\subsubsection{LCL resonant single circuit}

This LCL resonant circuit was proposed and analyzed in [29], in its single circuit configuration, and details on the design can be found in the reference. The two circuit configuration analysis can be found in [30] and [31]. In this configuration, the auxiliary inductor is again split in two different inductors. These inductors have half the inductance than the single inductor solution. Additionally a capacitor is connected in parallel with one of the inductors, as in Figure 4.20.

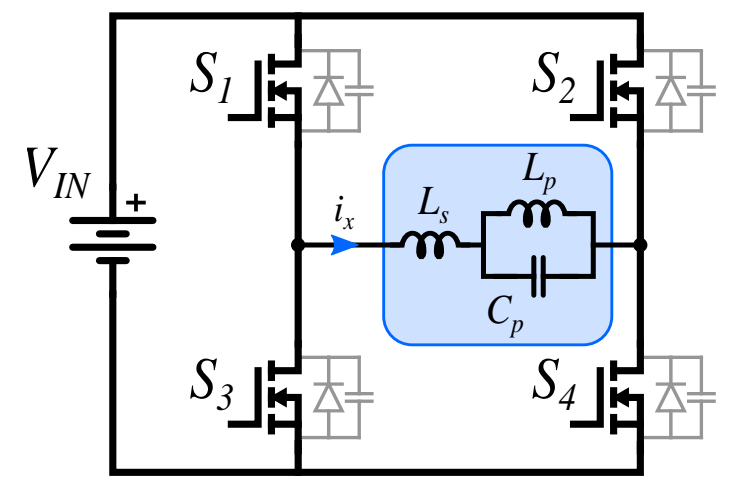

Figure 4.20: LCL resonant auxiliary circuit

Details on the design of the auxiliary circuit components are available in [29-31]. Following the design procedure of the publication, we obtain $L_{s}=L_{p}=66 \mu \mathrm{H}$ a value of $C_{p}=36 n F$. With these values a resonant distortion in the auxiliary current is achieved, as illustrated in Figure 4.21.

With this current shape, the RMS current through the inductor $L_{s}$ is reduced from $9.2 A$ to $6.8 A$, and the RMS current through $L_{p}$ increases from $9.2 A$ to $11.5 A$. However, this circuit reduces also the RMS current flowing through the full-bridge devices. 

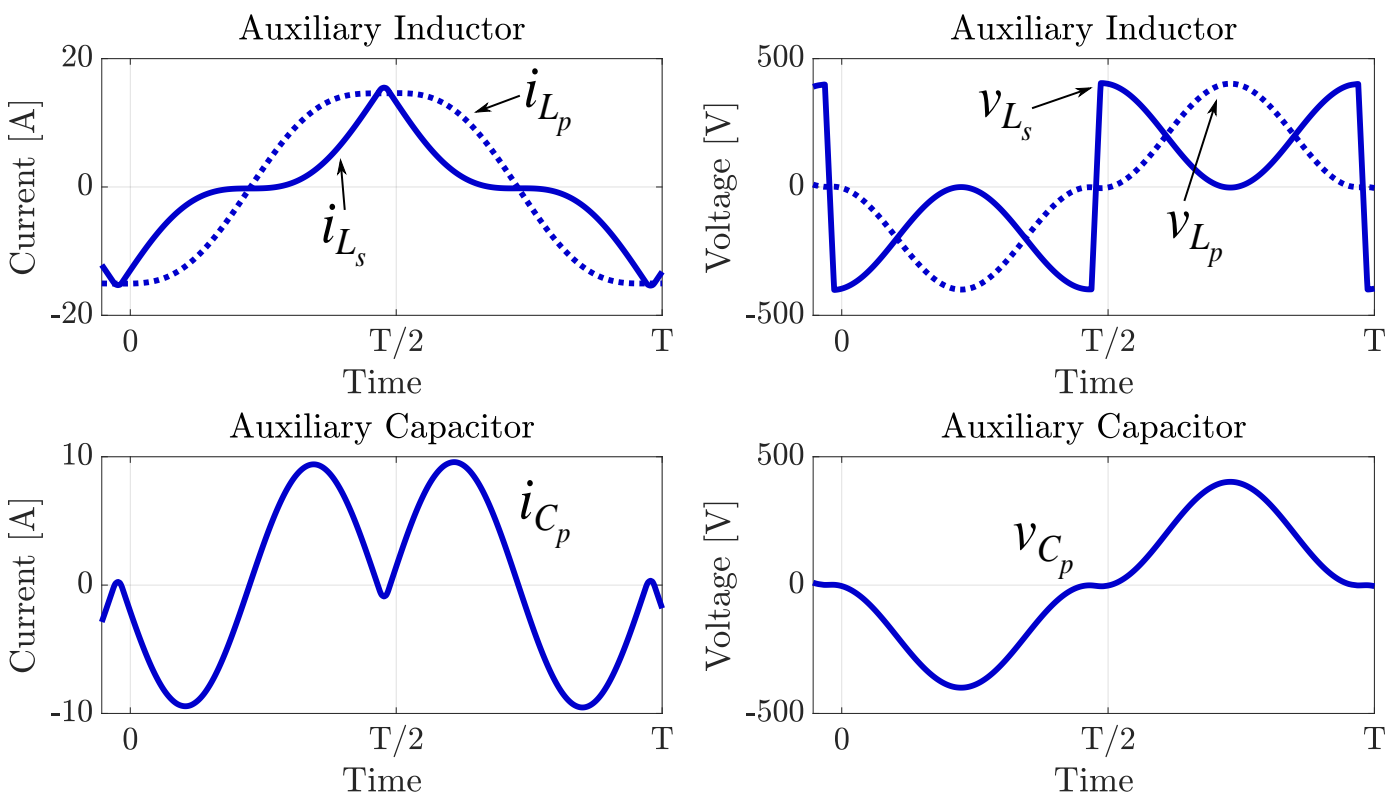

Figure 4.21: LCL resonant circuit waveforms

\subsubsection{Single inductor active circuit}

This auxiliary circuit is similar to the single inductor passive solution. However, the DC Blocking capacitor is substituted by two switches, creating a bidirectional switching structure, as shown in Figure 4.22.

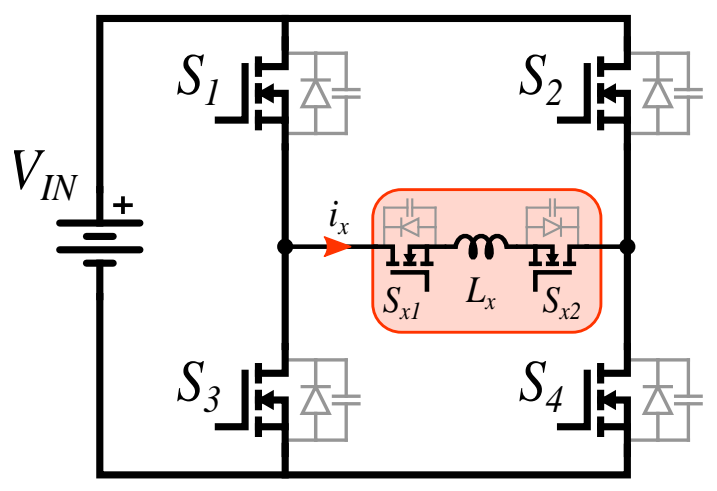

Figure 4.22: Single inductor active auxiliary circuit

The purpose of the switches is to decrease the RMS current, as illustrated in Figure 4.23 . 

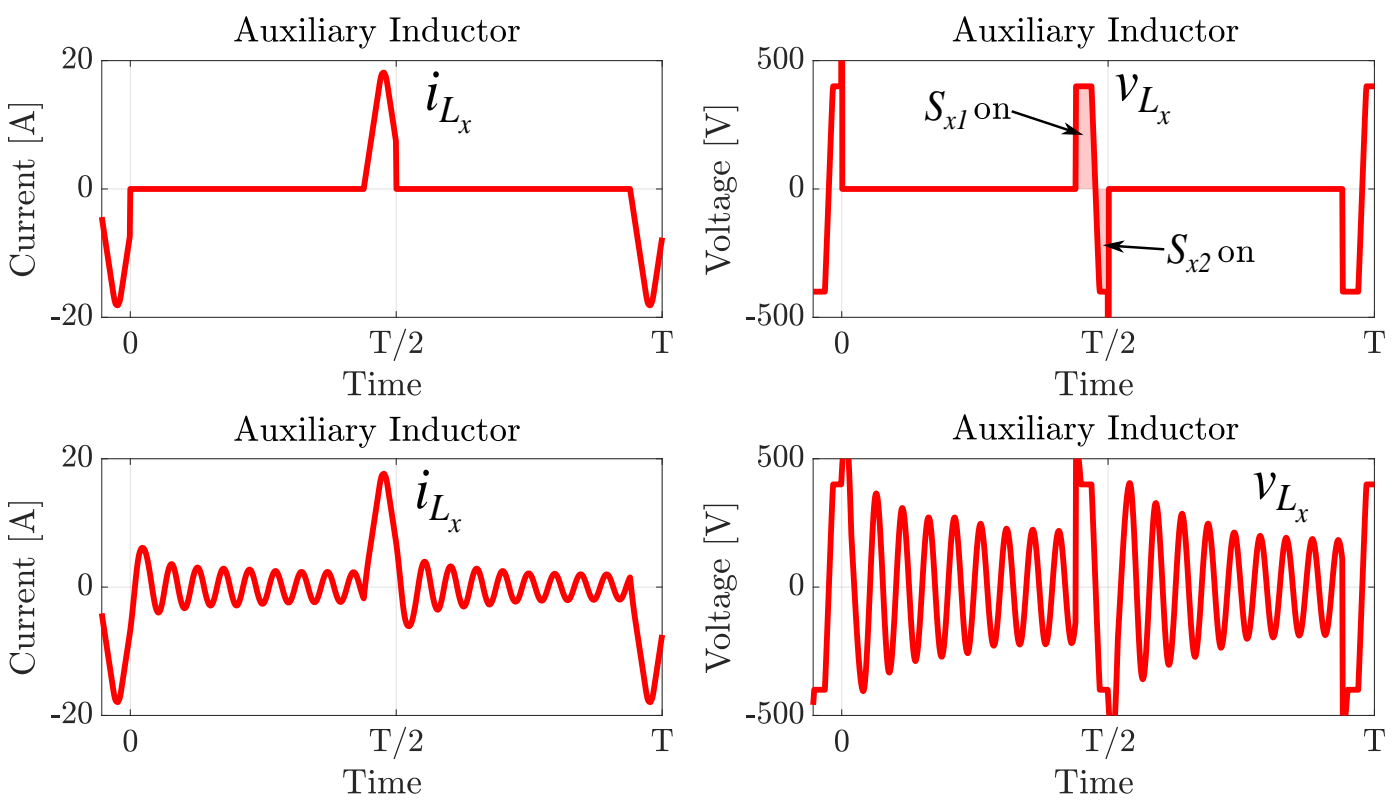

Figure 4.23: Single inductor active auxiliary circuit: simulated waveforms

The DC blocking capacitor is not needed, as the inductor operates in discontinuous conduction mode. The value of the inductance is reduced by a factor of 10 , because the peak current remains the same, the inductor energy is reduced by the same factor.

However, if the $C_{\text {oss }}$ of the switches used for these solutions are considered, the waveform is deformed by resonance between the $C_{o s s}$ and the inductor, as depicted in Figure 4.23. This does not add significantly to the power losses. However, it increases the emitted noise, which can be critical in some sensitive applications, like aircraft power conversion.

\subsubsection{Comparison of ZVS auxiliary circuits}

The four auxiliary circuits presented in the last section can be compared in terms of power losses, volume and complexity. All of the auxiliary circuit are designed for a $10 \mathrm{~kW}$ LLC converter using Silicon MOSFET technology. The specifications of a prototype with these characteristics is presented in Chapter 6

Figure ?? and Figure ?? show the power loss and volume breakdown of the four different auxiliary circuit solutions. 


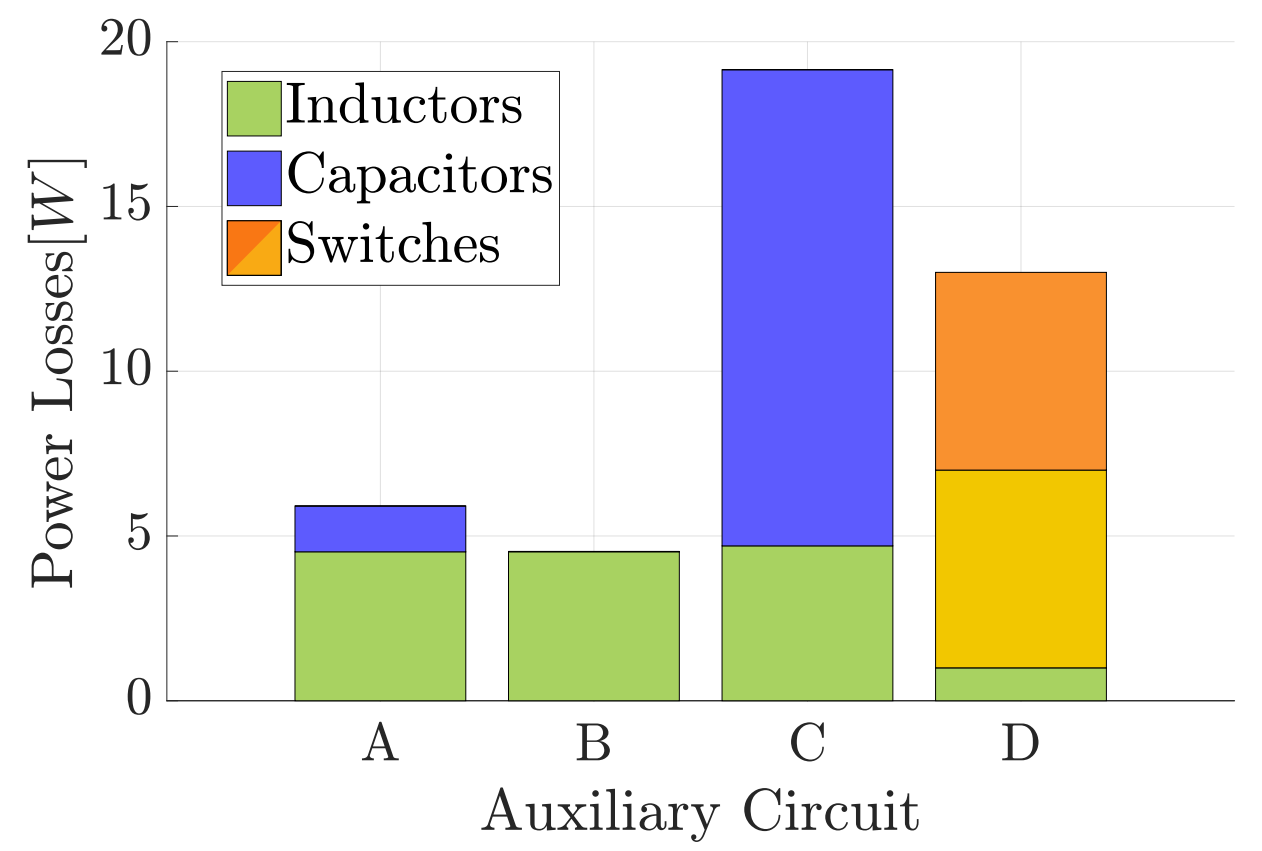

Figure 4.24: Comparison of power losses for the four different auxiliary circuit designs. The losses of the switches are dividided into switching losses and conduction losses

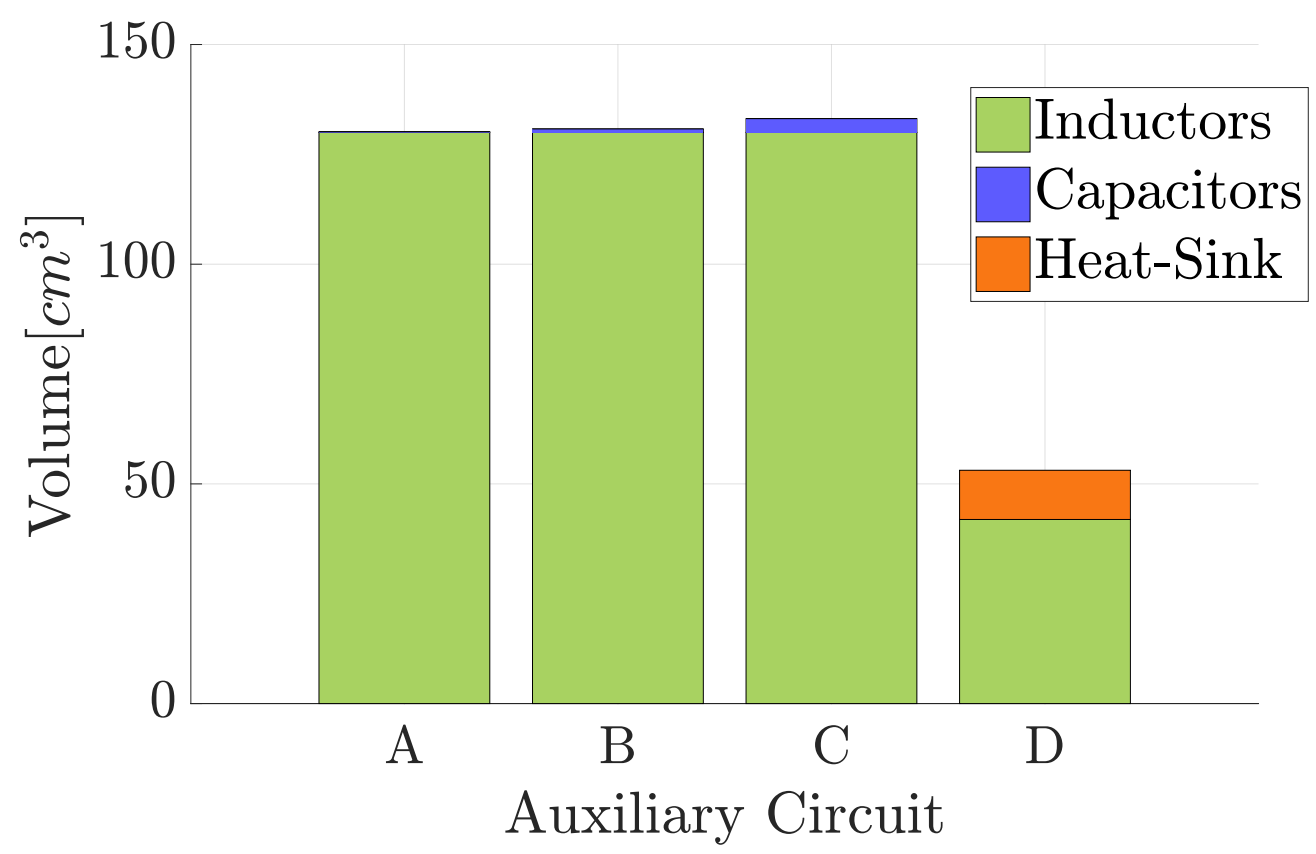

Figure 4.25: Comparison of Volume for the four different auxiliary circuit designs 
Chapter 4. Zero Voltage Switching Analysis in LLC Converters and Auxiliary Circuits

Table 4.1: Auxiliary capacitors comparison

\begin{tabular}{cccc}
\hline & Circuit A & Circuit B & Circuit C \\
\hline \hline Number of Capacitors & 1 & 2 & 1 \\
\hline Capacitance & $740 n F$ & $370 n F$ & $36 n F$ \\
\hline Maximum Voltage & $28 \mathrm{~V}$ & $200 \mathrm{~V}$ & $400 \mathrm{~V}$ \\
\hline Energy & $0.29 \mathrm{~mJ}$ & $7.4 m \mathrm{~J}$ & $2.88 \mathrm{~mJ}$ \\
\hline RMS Current & $9.2 \mathrm{~A}$ & $\sim 0 \mathrm{~A}$ & $6.5 \mathrm{~A}$ \\
\hline
\end{tabular}

It can be noted that the solutions $\mathrm{A}, \mathrm{B}$ and $\mathrm{C}$ are similar. As explained before the two inductors of solutions $\mathrm{B}$ and $\mathrm{C}$ have an inductance value of $L_{x} / 2$, which is equivalent to a single $L_{x}$ inductor, since their maximum current is the same. In the case of the circuit D solution, there is a trade-off between losses and volume. The volume and losses of the inductor from solution D is reduced are greatly reduces. However, this circuit requires two auxiliary switches and it produces additional losses.

The auxiliary capacitors volume and losses were not considered for the comparison. Using multilayer ceramic capacitor (MLCC) technology, the volume and losses are negligible. All the auxiliary capacitors are in the range of $36 \mathrm{nH}$ to $740 \mathrm{nH}$ and their maximum voltages are between $28 \mathrm{~V}$ to $400 \mathrm{~V}$. In this range, Film capacitors and MLLC technologies overlap. However, multilayer ceramic capacitors have less volume and better characteristics [34].

Table 4.1, shows a comparison of the capacitors characteristic for circuit design $\mathrm{A}, \mathrm{B}$ and $\mathrm{C}$. There is a trade-off between the RMS current and the maximum energy stored. In the design A, the capacitor has the minimum energy, while the RMS current is the highest. Losses will limit this design, and it may need multiple parallel capacitors. However, design B has the highest energy, two orders of magnitude higher than $\mathrm{A}$, while the current and therefore losses are negligible in comparison. This design will be limited by the maximum capacitor energy and can be oversized even when the losses are zero. The capacitor design of circuit $\mathrm{C}$ has moderately high energy and high RMS current. However, these differences in the auxiliary capacitor design will only affect the overall losses and volume if using a worst technology for the range, like film technology, while using MLCC it will be negligible.

The auxiliary circuits modify the current through the input bridge in order to achieve full ZVS during the transition. However, the current is also modified 


\subsection{ZVS auxiliary circuits: analysis, design and comparison}
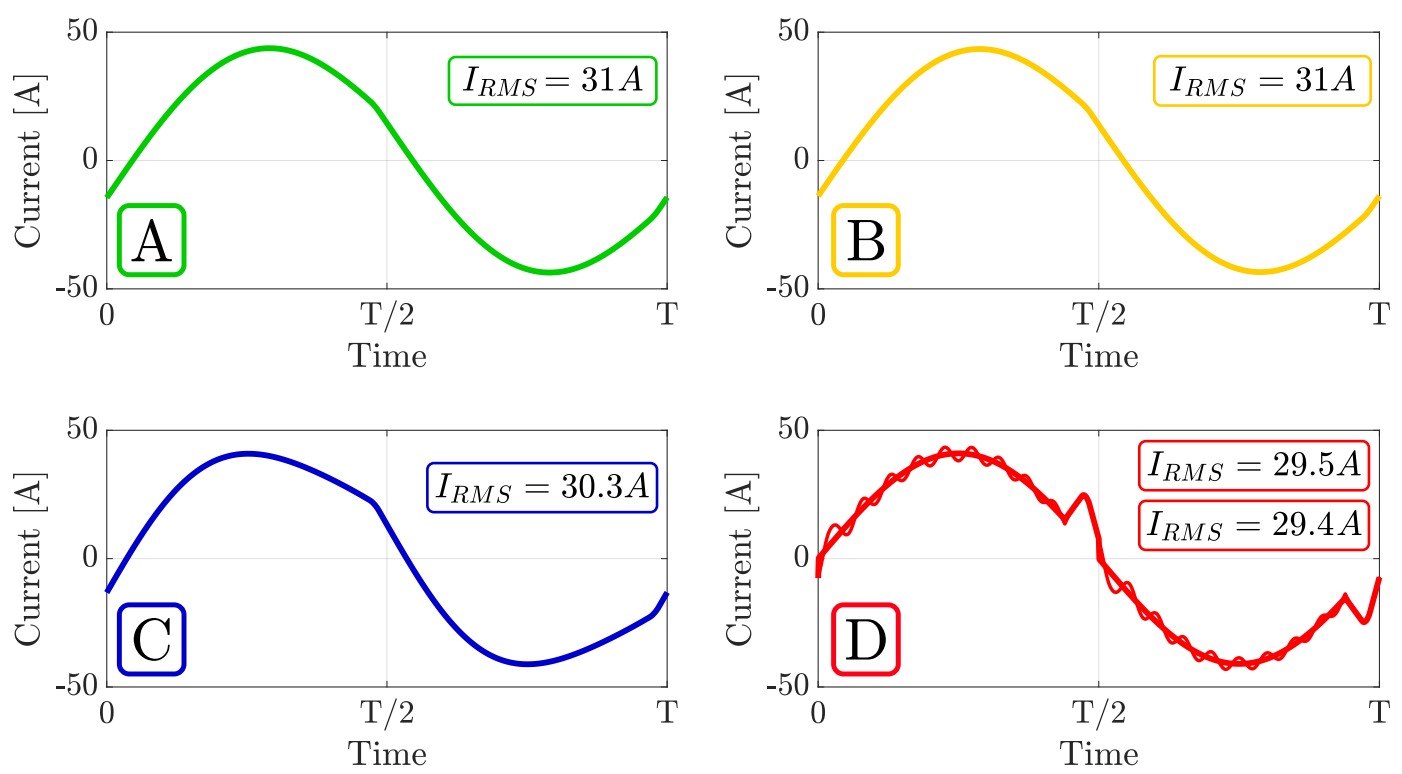

Figure 4.26: Comparison of MOSFET currents with the different auxiliary circuit solutions

throughout all the switching cycle. This will affect the conduction losses of primary devices.

Figure 4.26 illustrates the resonant current with the additional current of each auxiliary circuit.

The unmodified resonant current has a RMS value of $28 \mathrm{~V}$. With the addition of the auxiliary current, the resonant current is distorted and the RMS increases, as depicted in Figure 4.26 .

Figure ?? can then be updated with the extra losses generated in the primary devices.

The minimum total power losses are achieved by the auxiliary circuit type $\mathrm{C}$ (LCL resonant circuit) and the maximum losses by the type D (single inductor active circuit). The power losses in the active devices for the type $\mathrm{D}$ circuit were estimated using Silicon technology. Nevertheless, by using GaN or SiC devices, its performance can significantly be improved.

The volume and power losses of each auxiliary circuit were presented. Nevertheless, it is interesting to also compare the circuits in terms of complexity. Table 4.2 highlights this comparison. 


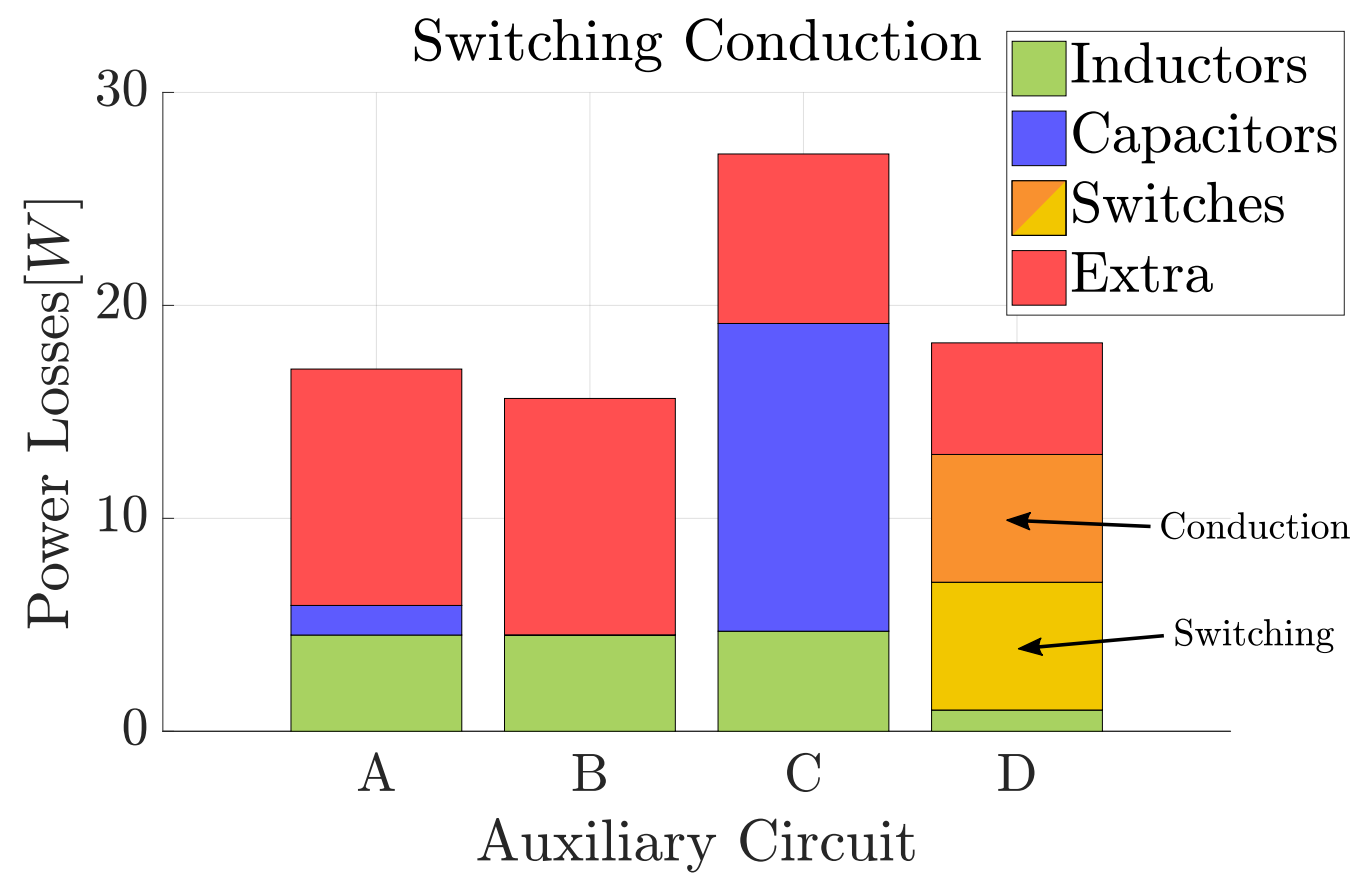

Figure 4.27: Comparison of power losses for each auxiliary circuit design with extra primary bridge conduction losses, because of the current distortion from Figure 4.26

Table 4.2: Auxiliary circuits complexity comparison

\begin{tabular}{ccccc}
\hline & Circuit A, & Circuit B & Circuit C & Circuit D \\
\hline \hline Component count & 2 & 4 & 3 & 3 \\
\hline Control required & No & No & No & Yes \\
\hline Sensitivity & Low & Low & High & High \\
\hline Design complexity & Low & Low & High & Moderate \\
\hline Reliability & High & High & High & Moderate \\
\hline
\end{tabular}

The component count introduces complexity by increasing the number of connections between components, this can also add considerable parasitics. The auxiliary circuit $\mathrm{C}$, has one of the best overall performance and volume. However, its design is complex and the value of the resonant capacitor $C_{p}$ is very sensitive to small changes, as it can change the behavior of the circuit. Low variability capacitors need to be used. Circuits A and B have less complexity, and their auxiliary capacitor can be selected to have a capacitance as high as possible to avoid the effects of capacitance variability. 


\subsection{Chapter summary}

The reliability of a converter can be critical in some applications. Ensuring full ZVS in the whole range can improve the reliability of a converter by reducing the switching noise and reducing the high $d v / d t$ related issues. Passive auxiliary circuit can achieve that with a high reliability, while active auxiliary circuits are dependent on control signals and external signals that can be lost. Therefore the reliability of active circuit can be lower than their passive equivalents.

\subsection{Chapter summary}

In this chapter, the ZVS transition analysis was reviewed. The traditional approach of considering only the turn-off current to determine the ZVS condition is not enough for topologies where the current during the transition is not constant, like in LLC converters. An charge-based method is proposed to consider the effect of the variable transition current, as a contribution of this thesis. Using this method, several ZVS auxiliary circuits are analyzed and compared. The design of these circuits is specific to LLC converters. However, the auxiliary circuits are valid for all full-bridge topologies. LLC converters are known to have a ZVS capabilities over wide ranges. Nevertheless, optimal LLC design with high parallel inductance and low circulating current have difficulties achieving complete ZVS. The auxiliary circuit can help improve the range of complete ZVS transition to the full load range. The single inductor ZVS circuit is a contribution of this thesis, the comparison with LLC designs without auxiliary circuits will be analyzed in detail in the next chapter. 



\section{Design and Optimization}

In this chapter, the design and optimization of the LLC full-bridge with full ZVS range will be presented. First, the complexity of the problem is addressed and the original contributions of the thesis are highlighted. Then, the models for power loss, volume and temperature estimation will be reviewed. Subsequently, the overall design of the LLC will be presented, focusing on the LLC parameters and the design of the transistors and the transformer. Finally, the multi-objective optimization will be performed, using the Pareto front concept to analyze the results.

\subsection{Problem statement: Multiobjective-optimization}

Power converters are complex systems involving multiple design parameters that can be optimized. The power losses $\left(P_{\text {loss }}\right)$ and volume $(\mathrm{Vol})$ are two parameters to be minimized in power converters. Equivalently, the efficiency $\left(\eta=\frac{P_{o}}{P_{o}+P_{\text {loss }}}\right)$ and the power density $\left(\frac{P_{o}}{V o l}\right)$ can also be used, in that case the parameters needs to be maximized. The power density and efficiency of converters are usually negatively correlated. This means that if one parameter increases the other one decreases; leading to a non-trivial multi-variable optimization problem, in which infinite optimal solutions are possible. All of the optimal solutions of a multi-objective optimization form what is called a Pareto front [35], which is the boundary of the all optimal solutions, as depicted in Figure 5.1.

A trade-off between the two variables of Figure 5.1 is required to select the desired design. Some restriction can be applied to the solutions to narrow the solution optimal solution space, as illustrated in Figure 5.1. These restrictions can be for example the operating temperature, the saturation of the magnetic components or costs. 


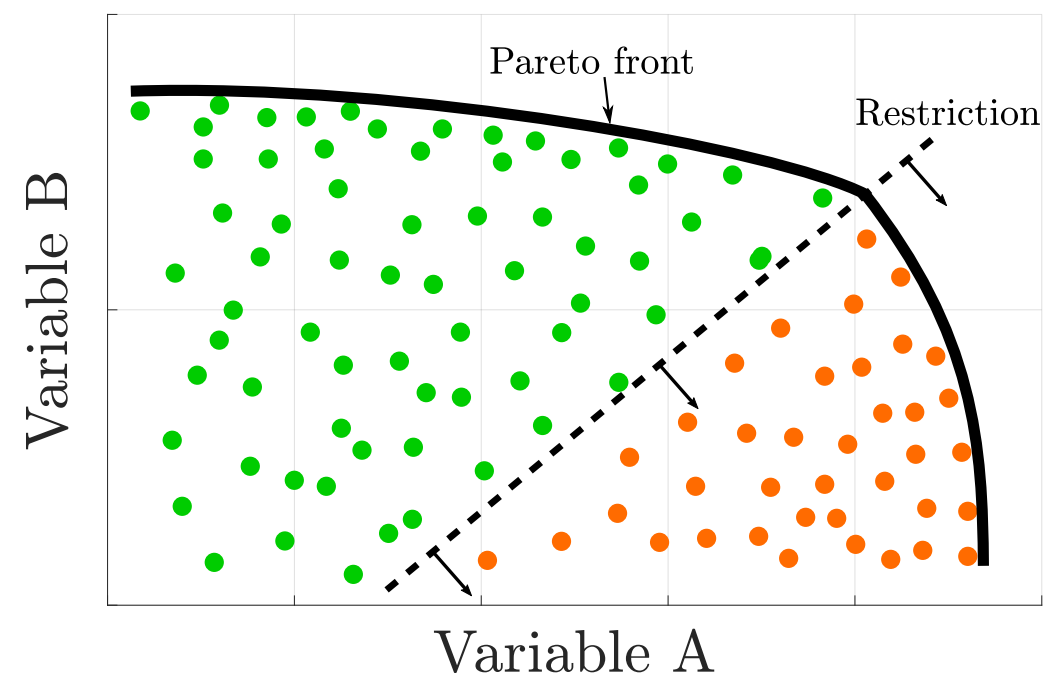

Figure 5.1: Pareto front data calculation algorithm

The quality of the solution to the Pareto front analysis will depend on the quality of the models used to estimated all the intermediary variables to calculate the total efficiency and power density. Models from the state of the art are going to be used to estimate the power losses of the different components, there is no original contribution in these models. To verify the feasibility of the solution in terms of operating temperature, a thermal model specific to planar transformer is proposed as a secondary contribution of this work.

Finally, the optimization results will depend on the technology used for different components. The transistor technology, the transformer winding configuration and magnetic core materials are some of the different parameters that can be defined and that will change the results of the optimization algorithm. An assessments of the different technologies will be done in section 5.3.2, regarding the LLC topology.

\subsection{Modeling of losses, volume and temperatures}

In this section the models used to estimate the power losses, the volume and the temperature of components will be reviewed. These models will be used in the design and the multi-objective optimization sections. 


\subsection{Modeling of losses, volume and temperatures}

\subsubsection{Power loss models}

The estimation of losses in LLC converters can be divided into three main component types: transistors, magnetic components and capacitors. Each component has different loss models. In the following sections, the loss models from the state of the art will be reviewed.

\subsubsection{Transistor power loss model}

Independently of transistor technology, the power losses of switching devices are divided in two types: conduction losses and switching losses. The models used for the power loss estimation will be presented in the following sections

\section{Conduction losses:}

The following equation determines the conduction losses of a single MOSFET:

$$
P_{\text {Cond }}=R_{D S o n} \cdot I_{R M S}^{2}
$$

where $R_{D S o n}$ is the drain/source ON resistance and $I_{R M S}$ is the RMS current through the device.

However, the transistor drain/source ON resistance is affected by the temperature of the junction, as depicted in Figure 5.2.

Considering the effect of the temperature, the equation is modified as follows:

$$
P_{\text {Cond }}=R_{D S o n}(\theta) \cdot I_{R M S}^{2}
$$

Where $\theta$ is the junction temperature of the transistor. The temperature dependent $R_{D S o n}(\theta)$ can be curve fitted with a quadratic functions with great accuracy as depicted in Figure 5.2 Finally, to estimate the total conduction losses of a full-bridge structure with multiple devices in parallel. the following equation is used.

$$
P_{\text {cond }}=\frac{4 R_{D S o n}(\theta)}{N_{M O S}} \cdot I_{R M S}^{2}
$$

where $N_{M O S}$ is the number of devices in parallel in each switch position 


\section{Chapter 5. Design and Optimization}

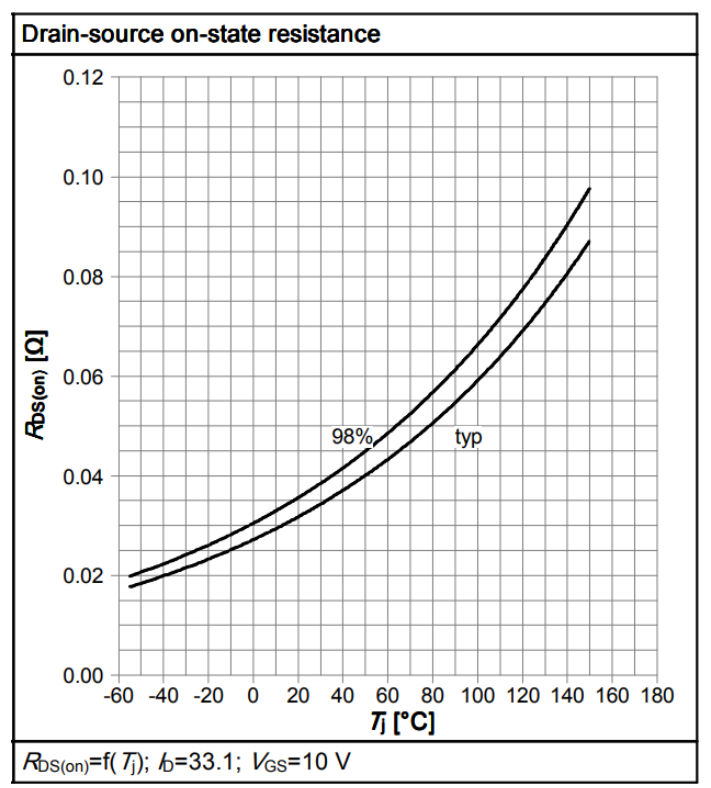

Figure 5.2: Temperature effect on Drain/Source resistance from Infineon Si MOSFET IPW65R037C6

\section{Switching losses:}

The switching losses, in the case of Si MOSFET, are estimated using a method explained in the application note [36]. To calculate the switching losses for SiC and GaN devices a quadratic approximation can be estimated from the data-sheet, as depicted in Figure 5.3. The equation for the switching losses is as follows:

$$
P_{S w}=N_{M O S} \cdot f_{s} \cdot V_{D S m a x}\left(I_{D O N} \frac{t_{r i}+t_{f u}}{2}+Q_{r r}+I_{D O F F} \frac{t_{r u}+t_{f i}}{2}\right)
$$

where $t_{r i}$ and $t_{f i}$ are the current rise and fall times. These parameters are usually given in the data-sheet explicitly. The times $t_{r u}$ and $t_{f u}$ are the voltage rise and fall times. These are not explicitly given in the data-sheet. However, they can be estimated using the following equations from [36]:

$$
t_{f u}=\frac{t_{f u 1}+t_{f u 2}}{2}
$$




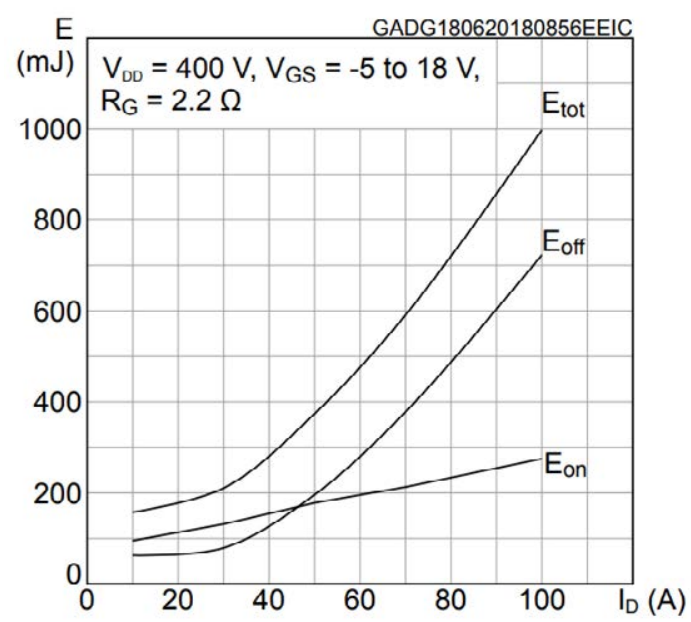

Figure 5.3: Switching loss estimation from data-sheet. Source SCTH9065G2V-7

$$
\begin{array}{r}
t_{f u 1}=\left(V_{D S}-R_{D S} \cdot I_{D o n}\right) \frac{C_{G D 1}}{I_{G o n}} \\
t_{f u 2}=\left(V_{D S}-R_{D S} \cdot I_{D o n}\right) \frac{C_{G D 2}}{I_{G o n}} \\
t_{r u}=\frac{t_{r u 1}+t_{r u 2}}{2} \\
t_{r u 1}=\left(V_{D S}-R_{D S} \cdot I_{D o n}\right) \frac{C_{G D 1}}{I_{G o f f}} \\
t_{r u 2}=\left(V_{D S}-R_{D S} \cdot I_{D o n}\right) \frac{C_{G D 2}}{I_{G o f f}}
\end{array}
$$

With these equations, the non-linearity of the Millers capacitance is considered with a two point approximation. Using this approach with arbitrarily high number of points an integral equation, as follows:

$$
t_{f u}=\frac{\int_{0}^{V_{D S}-R_{D S} \cdot I_{D o n}} C_{G D}\left(v_{d s}\right) d v_{d s}}{I_{G o n}}
$$

and, 


$$
t_{r u}=\frac{\int_{0}^{V_{D S}-R_{D S} \cdot I_{D o n}} C_{G D}\left(v_{d s}\right) d v_{d s}}{I_{G o f f}}
$$

If ZVS is not achieved an additional term is included in the switching losses. The energy stored in the $C_{\text {oss }}$ capacitor is lost each switching cycle and for each full-bridge leg.

$$
P_{\text {noZVS }}=Q_{o s s} \cdot f_{s}
$$

\subsubsection{Magnetic component losses}

The magnetic components losses are divided into core losses and winding losses. These two types of losses have very different mechanisms that are briefly reviewed as follows.

\section{Winding losses:}

The winding losses consist of the power losses created in the conductors of a magnetic component by Joule's first law. In order to calculate this losses the resistance of the windings needs to be accurately estimated. In low frequency magnetic component, the following equation can be used:

$$
P_{\text {Winding }} \text { Low Freq }=R_{D C} \cdot I_{R M S}^{2}
$$

At high frequency, the resistance of the magnetic component cannot be considered constant. Its value is increased by so called high frequency effects, mainly:

- Skin effect

- Proximity effect [37]

- Gap effect [38]

All of these high frequency effects can be summarized with one concept. The external or internal magnetic field $(\mathrm{H})$ created by the windings or other external sources create a a distribution of current that decreases the effective section of the wires, as depicted in Figure 5.4. By decreasing the effective section the resistance of the windings is increased. 


\subsection{Modeling of losses, volume and temperatures}

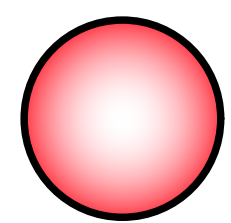

Skin effect

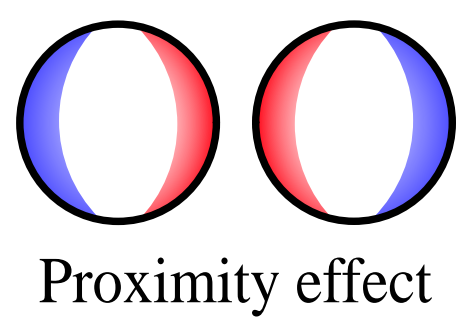

Proximity effect

Figure 5.4: High frequency effects: Skin effect and Proximity effect

Considering these high frequency effects the following equation can be used to estimate the conduction losses.

$$
P_{W \text { inding }}=R_{D C} \cdot I_{D C}^{2}+\sum_{i=1}^{\infty} R_{A C, i} \cdot I_{R M S, i}^{2}
$$

where $R_{D C}$ is the DC resistance of the windings, $I_{D C}$ is the DC current through the windings, $R_{A C, i}$ is the resistance the $i^{t} h$ harmonic and the $I_{R M S, i}$ is the RMS current of the $i^{t} h$ harmonic. In order to estimate the resistances at each harmonic finite element analysis (FEA) can be used. In the context of these work, the FEA tool ANSYS Pemag [39] will be used for this purpose.

In particular for the design of the transformer of LLC converters operating at resonant frequency, the equation 5.15 can be simplified. Because the operating frequency is constant at the first harmonic and the higher harmonics are negligible, the equation is then simplified as follows:

$$
P_{\text {Winding }}=R_{A C, f_{s}} \cdot I_{R M S, f_{s}}^{2}
$$

\section{Core losses:}

Core losses are due to two different phenomenons:

- Hysteresis [40]

- Eddy currents [37]

The hysteresis losses are related to the magnetization/demagnetization of the magnetic core, where a hysteresis loop is created in each cycle. This losses depend on the magnetic properties of the core material. Because magnetic materials are also conductors some Eddy currents are created perpendicular to the magnetic fields 


\section{Chapter 5. Design and Optimization}

created inside them. These are the Eddy current losses. They mostly depend on the electrical resistance of the core material. In order to estimate the sum of the core losses the Steinmetz equation can be used. It is an empirical equation with the following expression:

$$
P_{\text {Core }}=A_{e} \cdot l_{e} \cdot k_{S E} \cdot f^{\alpha} \cdot B^{\beta}
$$

Where, $A_{e}$ is the effective area of the core, $l_{e}$ is the effective length of the core, $f$ is the frequency applied to the magnetic core, $B$ is the peak flux density in the core, and $k_{S E}, \alpha$ and $\beta$ are the Steinmetz coefficients.

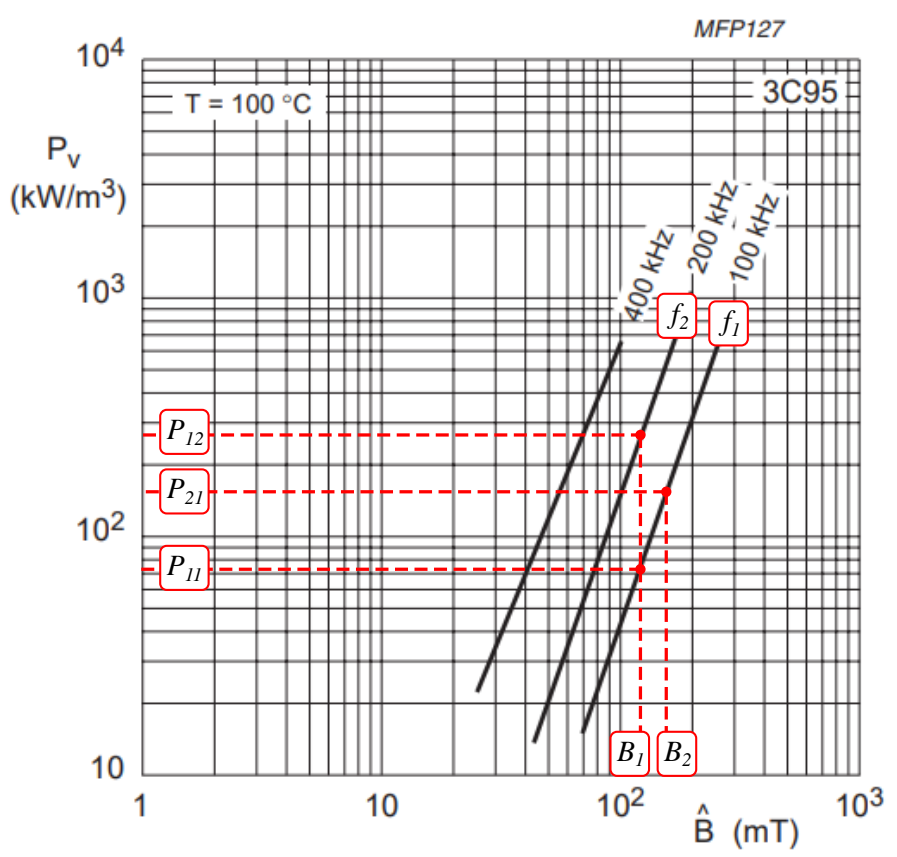

Figure 5.5: Power loss in function of flux density $B$ at different frequencies for material 3C95. Source: Ferroxcube [1]

The three Steinmetz coefficients can be estimated using three data points from the manufacturers data-sheet. In Figure 5.5, the volumetric power losses $P_{v}$ over the peak flux density $B$ of the material $3 C 95$ are depicted.

The Steinmetz empirical approach is valid for sinusoidal waveforms, from which the data is gathered to estimate the Steinmetz parameters. In the state of the art, there are several modifications on the regular Steinmetz equations, like the improved 


\subsection{Modeling of losses, volume and temperatures}

generalized Steinmetz equation (iGSE) [41]. This modified approach improves the accuracy of the power loss estimation for square voltage waveforms at different duty cycles. However, for $50 \%$ duty cycle square voltage waveform. The mismatch between the models is lower than $10 \%$. Therefore, in this work, the conventional Steinmetz equation will be used, for simplicity and speed of calculation, as some of the coefficients in the iGSE require numerical calculation instead of analytical.

\subsubsection{Capacitor Losses}

Capacitors are known to have different loss mechanisms as well, like dielectric loss and also by Joule effect. However, in high power topologies and in the ranges of a few hundred Volts, the dielectric losses can be neglected over the resistive losses.

Real capacitor presents parasitic elements like the equivalent series resistance (ESR) or the equivalent series inductance (ESL), as depicted in Figure 5.6.

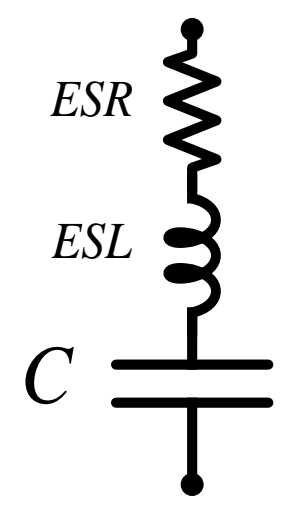

Figure 5.6: Capacitor model with parasitic ESL and ESR

The following equation can be used to calculate the resistive losses of capacitors.

$$
P_{E S R}=\frac{E S R}{N_{C a p}} \cdot I_{r m s, C a p}^{2}
$$

Where the $I_{r m s, C a p}$ is the RMS current flowing through the capacitor, $N_{C a p}$ is the number of parallel capacitors used, and $E S R$ is the equivalent series resistance of the capacitor, that can be found in the manufacturers data-sheet. The ESL does not affect the power losses of the capacitor. Nevertheless it affects the voltage ripple.

The ESL of the capacitor typically has a negligible effect on the ripple, in the case of filter capacitors. However, in the case of a resonant capacitor, the ESL has 


\section{Chapter 5. Design and Optimization}

to be considered as it becomes part of the resonant tank and can influence the value of the resonant frequency.

\subsubsection{Volume estimation}

The power density converters has been increasing in recent decades [3]. To calculate the power density of a design a good estimation of the total volume of components is required. Typically the volume of a converter is dominated by the magnetic components. In high power converters, heat-sinks are also a big part of the total volume of the converter, as high amounts of losses need to be dissipated in order to reduce the operating temperatures of all components. In the following subsections, the volume estimation methods are going to be review for magnetic components, heat-sinks and capacitors.

\subsubsection{Magnetic component volume}

As explained previously, the magnetic component volume is dominant in power converters. The magnetic component consist usually of two main parts: the core and the windings.

The magnetic core volume is defined by two parameters given in the manufacturers data-sheet, the effective area $A_{e}$ and the effective length $l_{e}$ :

$$
V_{e}=A_{e} \cdot l_{e}
$$

The winding volume can be estimated similarly, with the following equation

$$
\operatorname{Vol}_{C u}=A_{C u} \cdot l_{C u}
$$

Where $A_{C u}$ is the window area and the $l_{C u}$ is the average turn length of the wires.

The total volume of the whole magnetic component can be then defined as:

$$
V o l_{T o t}=A_{e} \cdot l_{e}+A_{C u} \cdot l_{C u}
$$




\subsection{Modeling of losses, volume and temperatures}

However, this only accounts for the solid volume. The volume of the box containing the whole transformer can be considered, as depicted in Figure 5.7. Considering this, the equation is modified as follows:

$$
\operatorname{Vol}_{T o t}=K_{b o x}\left(A_{e} \cdot l_{e}+A_{C u} \cdot l_{C u}\right)
$$

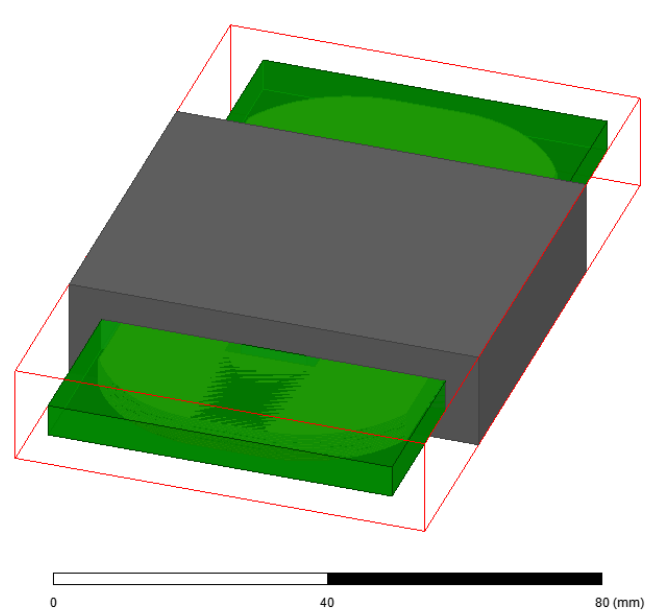

Figure 5.7: Planar transformer

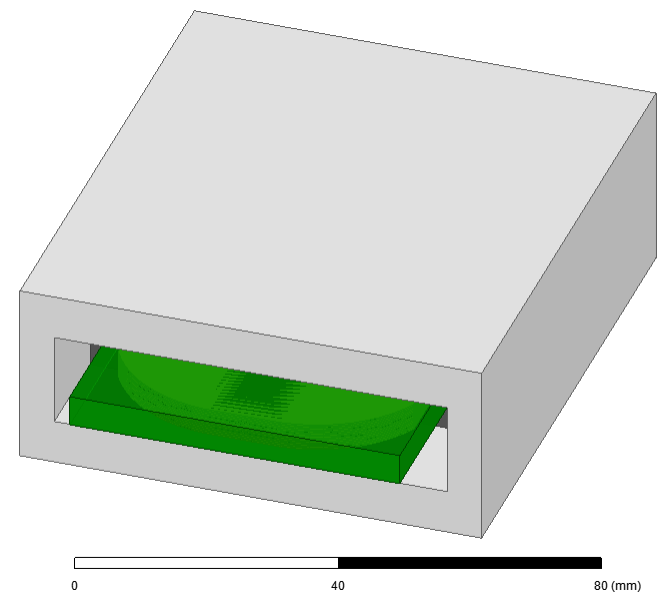

Figure 5.8: Planar transformer with heat-sink

The planar transformer can be built with an surrounding heat-sink to better dissipate the heat generated by the power losses, as illustrated in Figure 5.8. Considering this, to calculate the total volume of the boxed that contains the transformer and its heat-sink, a new coefficient is required:

$$
V o l_{T o t}=K_{(\text {Trafo+HS }) \text { Box }} \cdot\left(A_{e} \cdot l_{e}+A_{C u} \cdot l_{C u}\right)
$$

A value of $K_{(\text {Trafo+HS Box }}=3.41$ will be considered, for the calculations used in the results of section 5.4.2.1.

\subsubsection{Heat-sink Estimation}

The volume of the transistors is negligible in comparison with the magnetic components. However, their losses are considerably higher, as depicted in the pie chart of Figure 5.9 (Primary and secondary bridges) 


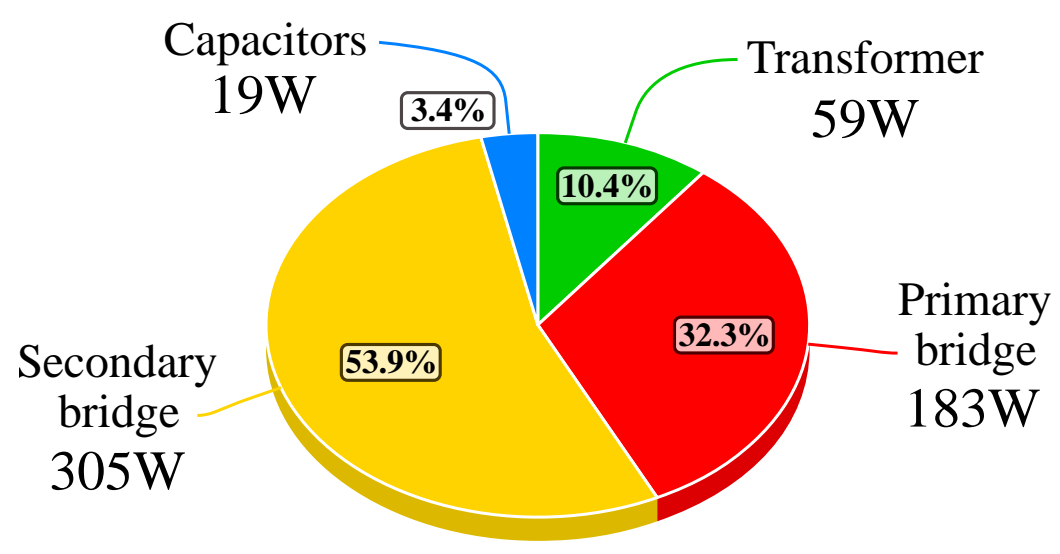

Figure 5.9: Prototype breakdown of power losses

These power losses need a cooling system in order to maintain the junction temperature within safe operating values. In high power converters, the volume of this heat-sink is not negligible. In order to estimate the volume of the heat-sink, it is possible to use the "cooling system performance index", proposed in [42]. This index is shown in the following equation:

$$
C S P I\left[\frac{W}{K \cdot d m^{3}}\right]=\frac{1}{R_{t h, S-a}\left[\frac{K}{W}\right] V_{C S}\left[d m^{3}\right]}
$$

A value of $C S P I=17.7\left[\frac{W}{K \cdot d m^{3}}\right]$ will be selected to account for an air cooled aluminum heat-sink.

\subsubsection{Capacitor volume}

The volume of capacitors can be estimated using the dimensions given by the manufacturer from the data-sheet. In Figure 5.10 and Figure 5.11 are depicted the dimensions for Film capacitors and ceramic capacitors respectively.

Using ceramic capacitors, the volume is usually negligible in comparison to other components. While using film capacitors the total volume will be higher and usually will be considered. 


\section{领TDK}

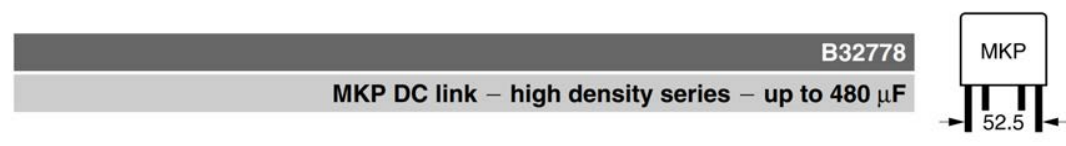

Ordering codes and packing units (lead spacing $52.5 \mathrm{~mm}, \mathrm{P}_{1}=\mathbf{2 0 . 3} \mathrm{mm}$ )

\begin{tabular}{|c|c|c|c|c|c|c|c|c|}
\hline$\overline{\mathrm{C}_{\mathrm{R}}{ }^{1)}}$ & $\begin{array}{l}\text { Max. dimensions } \\
\mathrm{w} \times \mathrm{h} \times \mathrm{l}\end{array}$ & $\begin{array}{l}\text { Ordering code } \\
\text { (composition see } \\
\text { below) }\end{array}$ & $\begin{array}{l}I_{\text {RMS,max }}{ }^{2)} \\
70^{\circ} \mathrm{C} \\
10 \mathrm{kHz} \\
\text { A }\end{array}$ & $\begin{array}{l}\mathrm{ESR}_{\mathrm{typ}} \\
70^{\circ} \mathrm{C} \\
10 \mathrm{kHz} \\
\mathrm{m} \Omega\end{array}$ & $\begin{array}{l}\mathrm{ESL}_{\text {typ }}{ }^{3)} \\
70^{\circ} \mathrm{C} \\
10 \mathrm{kHz} \\
\mathrm{nH}\end{array}$ & $\begin{array}{l}\tan \delta \\
1 \mathrm{kHz} \\
10^{-3}\end{array}$ & $\begin{array}{l}\tan \delta \\
10 \mathrm{kHz} \\
10^{-3}\end{array}$ & $\begin{array}{l}\text { pcs. } \\
\text { MOQ }\end{array}$ \\
\hline \multicolumn{9}{|c|}{$\mathrm{V}_{\mathrm{R}, 70^{\circ} \mathrm{C}}=800 \mathrm{VDC}, \mathrm{V}_{\mathrm{op}, 85^{\circ} \mathrm{C}}=700 \mathrm{VDC}$} \\
\hline 30 & $43.0 \times 24.0 \times 57.5$ & B32778T8306K000 & 14.5 & 9.8 & 14.0 & 3.2 & 30.2 & 420 \\
\hline 45 & $30.0 \times 45.0 \times 57.5$ & B32778G8456+000 & 19.5 & 6.6 & 14.0 & 3.2 & 30.9 & 280 \\
\hline 50 & $30.0 \times 45.0 \times 57.5$ & B32778G8506+000 & 20.0 & 6.3 & 13.0 & 3.2 & 30.9 & 280 \\
\hline 55 & $35.0 \times 50.0 \times 57.5$ & B32778G8556+000 & 23.0 & 5.6 & 14.0 & 3.2 & 31.1 & 108 \\
\hline 60 & $35.0 \times 50.0 \times 57.5$ & B32778G8606+000 & 23.5 & 5.1 & 15.0 & 3.3 & 31.2 & 108 \\
\hline 80 & $130.0 \times 24.0 \times 57.5$ & B32778J8806K000 & 37.5 & 3.6 & 4.0 & 3.2 & 30.2 & 80 \\
\hline 90 & $45.0 \times 57.0 \times 57.5$ & B32778G8906+000 & 32.5 & 3.5 & 17.0 & 3.3 & 32.2 & 140 \\
\hline 100 & $60.0 \times 45.0 \times 57.5$ & B32778G8107+000 & 34.5 & 3.2 & 19.0 & 3.3 & 31.9 & 200 \\
\hline 270 & $130.0 \times 58.0 \times 57.5$ & B32778J8277K000 & 70.5 & 1.2 & 6.0 & 3.5 & 32.4 & 40 \\
\hline
\end{tabular}

Figure 5.10: Film capacitor data-sheet: Volume estimation

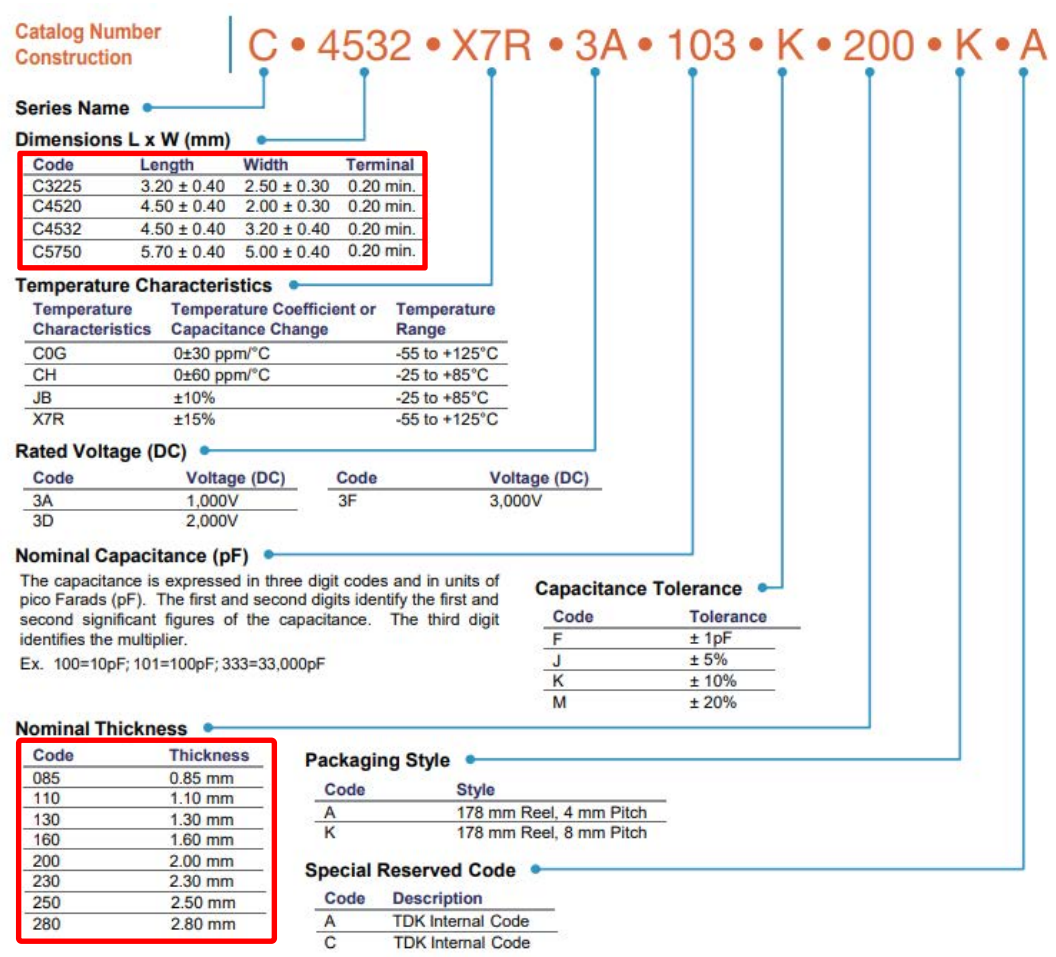

Figure 5.11: Multilayer ceramic capacitor data-sheet: Volume estimation 


\subsubsection{Thermal modeling of magnetic components}

As the power density of a converter increases, the capability to dissipate the power losses is reduced, with less volume and area to transfer the heat generated. The thermal behavior is then critical design parameter to optimize the power density of a converter.

\subsubsection{Simple thermal model with single resistance}

The accurate modeling of the thermal resistance of a magnetic components requires complex simulations with finite elements analysis (FEA). However, using the electrical equivalent approach, the equations are more manageable. The simplest electrical equivalent model that can be derived is depicted in Figure 5.12. This model consists on a single thermal impedance to consider the whole magnetic component as a single entity. The temperature of the component is calculated as:

$$
\Delta \theta=\left(\theta-\theta_{a m b}\right)=R^{t h} \cdot P
$$

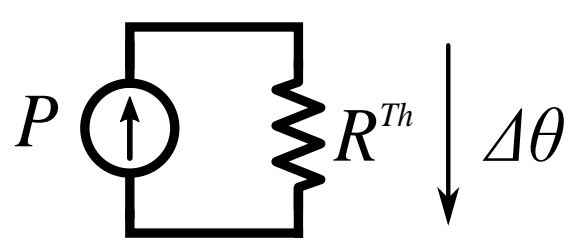

Figure 5.12: Simple thermal electric equivalent model

However, magnetic components consist two distinct parts: the magnetic core and the windings, that usually present different thermal behavior.

\subsubsection{Decoupled $\mathrm{Fe} / \mathrm{Cu}$ thermal model}

Considering the different behaviors of the core material $(\mathrm{Fe})$ and the winding $(\mathrm{Cu})$, a decoupled model can be created separating the temperature increment for each component. The core and the windings are generally built with different materials and shapes. Therefore they present different thermal behavior and will have a different maximum operating temperature. The decoupled model include these differences, as depicted in Figure 5.13. 


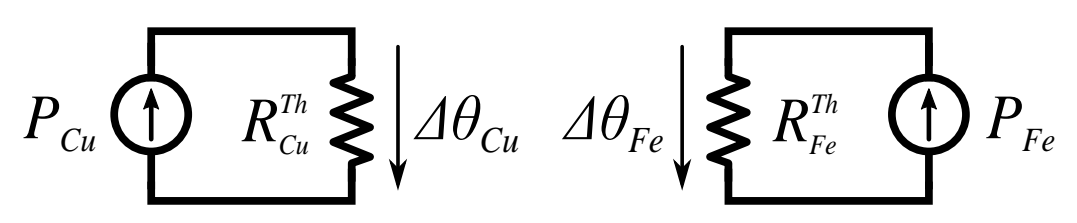

Figure 5.13: Decoupled thermal electric equivalent model

$$
\left(\begin{array}{c}
\Delta \theta_{C u} \\
\Delta \theta_{F e}
\end{array}\right)=\left(\begin{array}{cc}
R_{C u}^{T h} & 0 \\
0 & R_{F e}^{T h}
\end{array}\right) \cdot\left(\begin{array}{l}
P_{C u} \\
P_{F e}
\end{array}\right)
$$

The equations for this model are detailed in matrix form in (5.26). However, these models neglect the influence of the core and the windings between each other. The heat generated in one part will also affect the other because of their adjacency. This temperature behaviour coupling is required to analyze correctly extreme designs cases with dominant core losses or dominant winding losses. In these extreme designs, the decoupled model will lead to a considerable underestimation of the temperature of the component.

\subsubsection{Coupled thermal model}

In order to consider the thermal coupling between the temperature both core and windings, the coupled model can be introduced, as depicted in Figure 5.14. This thermal model is an original contribution. It was developed in collaboration with G. Salinas. A generalized coupled model, considering multiple elements can be found in the PhD thesis of G. Salinas, "Thermal modeling of high-frequency magnetics for power electronics by Finite Element Analysis".

The equation for this model, presented in equation (??), have non-zero terms outside the main diagonal, showing the coupling between the temperatures and losses of the core and windings. This model requires 4 different parameters and 2 different FEA simulation are enough to estimate the parameters. The first simulation will only have losses in the core and zero losses in the winding, while the second will have zero loses in the core and power losses in the windings. The estimation of the four resistances are the following: 


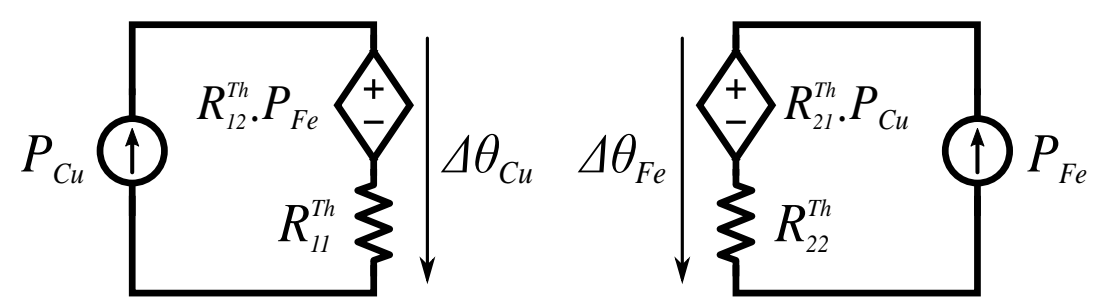

Figure 5.14: Coupled thermal electric equivalent model

$$
\left(\begin{array}{c}
\Delta \theta_{C u} \\
\Delta \theta_{F e}
\end{array}\right)=\left(\begin{array}{ll}
R_{11}^{T h} & R_{12}^{T h} \\
R_{21}^{T h} & R_{22}^{T h}
\end{array}\right) \cdot\left(\begin{array}{l}
P_{C u} \\
P_{F e}
\end{array}\right)
$$

Table 5.1: Transformer design parameters

\begin{tabular}{cccc}
\hline & A & B & C \\
\hline \hline Effective Area $\left(\mathrm{mm}^{2}\right)$ & 813 & 511 & 222 \\
\hline Volume $\left(\mathrm{mm}^{3}\right)$ & 105,242 & 52,442 & 15,017 \\
\hline Total Volume $\left(\mathrm{mm}^{3}\right)$ & 105,242 & 104,885 & 105,119 \\
\hline
\end{tabular}

$$
\begin{aligned}
& R_{11}^{T h}=\frac{\left.\Delta \theta_{C u}\right|_{P_{F e}=0}}{P_{C u}} \\
& R_{22}^{T h}=\frac{\left.\Delta \theta_{F e}\right|_{P_{C u}=0}}{P_{F e}} \\
& R_{12}^{T h}=\frac{\left.\Delta \theta_{C u}\right|_{P_{C u}=0}}{P_{F e}} \\
& R_{21}^{T h}=\frac{\left.\Delta \theta_{F e}\right|_{P_{F e}=0}}{P_{C u}}
\end{aligned}
$$

These parameters can be estimated for different transformer sizes. In particular for planar transformers, like the ones depicted in Figure 5.15, Figure 5.16 and Figure 5.17. The values of effective area of the core and total volume are of these three designs are summarized in Table 5.1

Figure 5.18 shows the FEA simulated values, where it can be noted that the thermal resistance increases with smaller core sizes. A two parameter exponential function can be used to approximate this simulated values. The equations for the four thermal resistances for the thermal resistance matrix are as follows: 


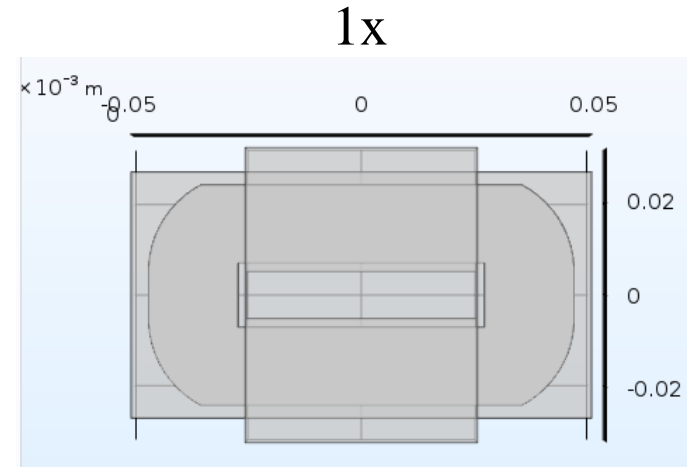

Figure 5.15: Transformer design A

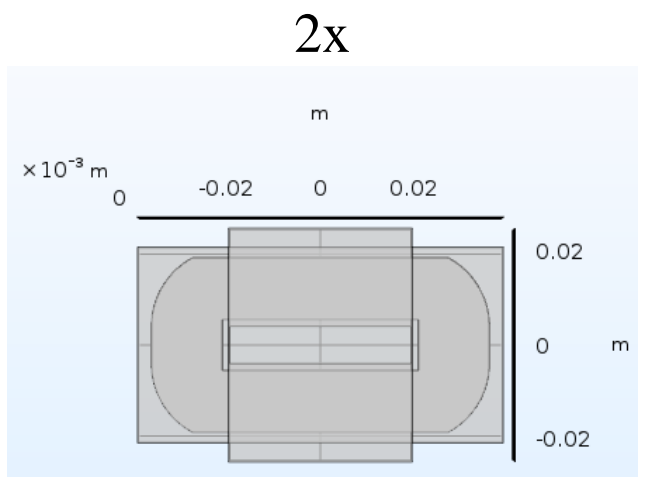

Figure 5.16: Transformer design B

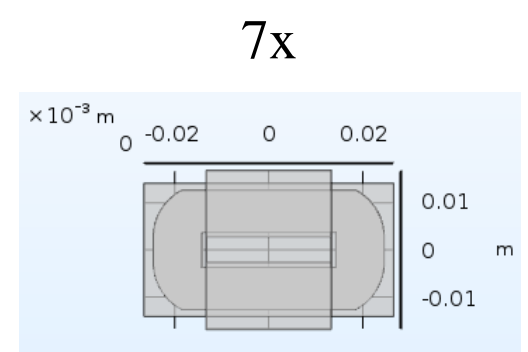

Figure 5.17: Transformer design C

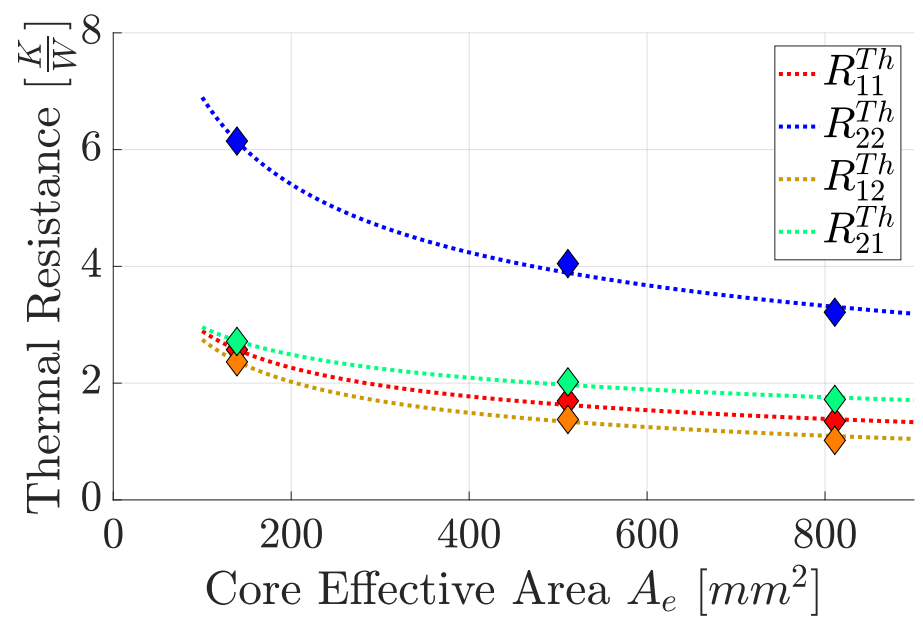

Figure 5.18: Thermal Resistance: FEA calculations (diamonds), Curve Fitting from equations 5.325 .335 .345 .35 (dotted line) 


$$
\begin{aligned}
& R_{11}^{T h}\left(A_{e}\right)=0.272 \cdot\left(A_{e}\right)^{-0.351} \\
& R_{22}^{T h}\left(A_{e}\right)=0.112 \cdot\left(A_{e}\right)^{-353} \\
& R_{12}^{T h}\left(A_{e}\right)=0.296 \cdot\left(A_{e}\right)^{-0.25} \\
& R_{21}^{T h}\left(A_{e}\right)=0.0477 \cdot\left(A_{e}\right)^{-0.44}
\end{aligned}
$$

With this approximations, the thermal behavior of different transformer sizes will be considered for the design and optimization in the following sections.

\subsubsection{Maximum core temperature: Thermal runaway issue}

The theoretical maximum temperature for magnetic materials is the Curie temperature, at which the material looses its magnetic properties. However, in practice, the maximum operating temperature is limited by power losses. At a certain critical temperature, the power losses can be higher than the heat dissipation capability of the core, creating a unstable increase of temperature called thermal runaway [43]. This phenomenon is consequence of the non-linear dependence of core losses on temperature.

In Figure 5.19, the effect of four different thermal resistances in the operating temperature of 3C95 ferrite from Ferroxcube is depicted. With the thermal resistance $R_{1}$, the operating temperature is low $\left(54^{\circ} C\right)$, however, the power losses are not optimal. With the resistance $R_{2}$, the minimum power losses are achieved at approximately $79^{\circ} \mathrm{C}$, this is the optimal operating temperature. With $R_{3}$, the maximum operating temperature is achieved. This operation point is not desirable, as small deviations on temperature and losses will incur in thermal runaway. Using a thermal resistance higher than $R_{3}$, thermal runaway will occur, like with resistance $R_{4}$. A good design restriction is to not allow designs with temperatures higher than the minimum power loss temperature. In the case of the material 3C95 from Ferroxcube, this temperature is around $100^{\circ} \mathrm{C}$, as illustrated in Figure 5.19. 


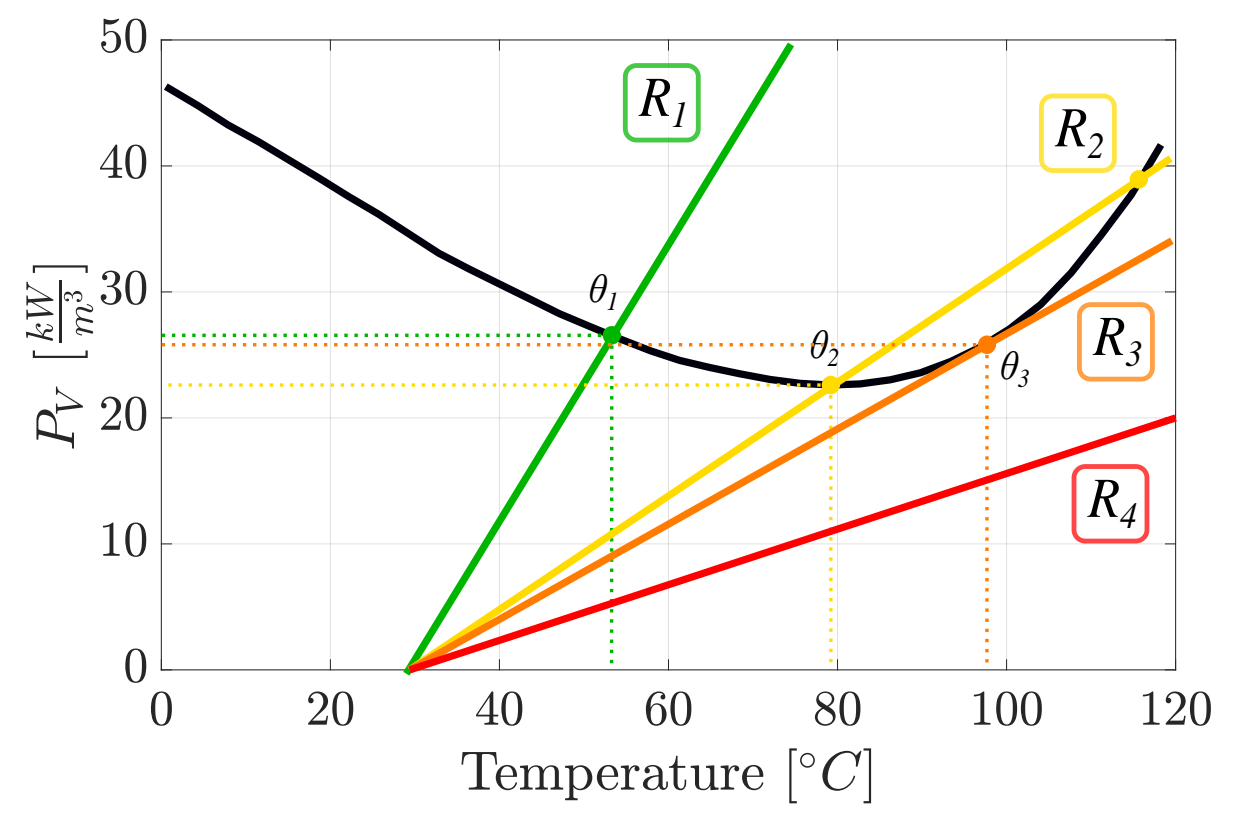

Figure 5.19: Thermal runaway effect

\subsubsection{Maximum winding temperature}

In the case of winding temperature and the influence on power losses, no thermal runaway effect is present. There is a natural balancing of the power losses in parallel conductors. As the temperature increases in a conductor, so does its resistance. This decreases the share of the total current flowing through that conductor. Therefore, decreasing the power losses and decreasing the temperature. A natural negative feedback loop is created with power losses and temperature so that the current is balanced between all conductors and thermal equilibrium is reached. As explained previously, the resistance of a conductor material used in windings (traditionally Copper and Aluminum) increases with temperature, following this equation:

$$
R_{w}(\theta)=R_{w}\left(20^{\circ} C\right) \cdot\left(1+\alpha\left(\theta-20^{\circ} C\right)\right)
$$

Where $R_{w}\left(20^{\circ} C\right)$ is the conductor resistance at $20^{\circ} C, \theta$ is the temperature of the conductor and $\alpha$ is the temperature coefficient of the conductor material. For Copper windings the value is $\alpha=4.04 \cdot 10^{-3}\left[\frac{1}{{ }^{o} C}\right]$. 


\section{Chapter 5. Design and Optimization}

Electrical insulators safe operating temperatures are quite high, ranging from $200^{\circ} \mathrm{C}$ to $400^{\circ} \mathrm{C}$. Because of the coupling between the windings and core temperatures, good designs will not allow winding temperatures much higher than the maximum temperature allowed for the core $\left(100^{\circ} \mathrm{C}\right)$ The thermal limit for the windings is generally much higher than for magnetic materials. The constraint is the increase in electrical resistance with increasing temperatures. However, the practical maximum temperature limit can be set up by the isolation material properties.

Additionally, if the temperature in the windings is much higher than the temperature in the core, the core temperature will be increased, by the adjacency of both parts.

\subsection{Design of LLC operating at resonant frequency with high conversion ratio and high output current}

In this section, the design guidelines of the different parameters and components for an LLC operating at resonant frequency will be presented. Further concerns about the high output current and high voltage ratio converters will be included, as it is the focus of this work.

\subsubsection{Parameter design}

The three main parameters of the LLC converter are the two inductors and single capacitor that give its name: $L_{r}, L_{m}$ and $C_{r}$. These form a resonant network, as depicted in Figure 5.20.

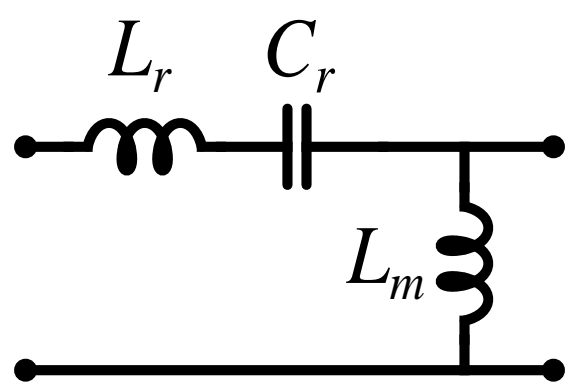

Figure 5.20: LLC resonant network 


\subsection{Design of LLC operating at resonant frequency with high conversion ratio and high output current}

In order to analyze the influence of these parameters, it is convenient to use three other related parameters:

- The resonant frequency:

$$
f_{r}=\frac{1}{2 \pi \sqrt{L_{r} C_{r}}}
$$

- The resonant characteristic impedance

$$
Z_{r}=\sqrt{\frac{L_{r}}{C_{r}}}
$$

- And the inductance ratio

$$
m=\frac{L_{m}+L_{r}}{L_{r}}
$$

With these three equations, the resonant components $L_{r}, L_{m}$ and $C_{r}$ are defined as follows:

$$
\begin{gathered}
L_{r}=\frac{Z_{r}}{2 \pi f_{r}} \\
C_{r}=\frac{1}{2 \pi f_{r} Z_{r}} \\
L_{m}=(m-1) \frac{Z_{r}}{2 \pi f_{r}}
\end{gathered}
$$

In order to optimize the volume of the components of the resonant network, it is necessary to analyze the maximum energy of the two conductors and the capacitor. To simplify the equations and analysis, an infinite inductance ratio will be assumed to analyze the energy of the series $L_{r}$ and $C r$. This means that the circulating current will be neglected. The influence of the parallel inductor will be added later to the analysis.

\subsubsection{Series inductor energy optimization}

The expression for the maximum energy of the series inductor $L_{r}$ is:

$$
E_{L_{r}}=\frac{1}{2} L_{r} I_{\max 1}^{2}
$$




\section{Chapter 5. Design and Optimization}

Where $I_{\max 1}$ is the peak current of the resonant current in primary side. While operating at resonant frequency and with infinite inductance ratio $m$, the resonant current can be assumed a perfect sine wave. Its maximum value is defined as follows:

$$
I_{\max 1}=\frac{\pi}{2} \cdot \frac{P_{o}}{n V_{o}}
$$

Using equations 5.43 and 5.44 , maximum energy can be rewritten as:

$$
E_{L_{r}}=\frac{\pi}{16} \cdot \frac{P_{o}^{2}}{n^{2} V_{o}^{2}} \cdot \frac{Z_{r}}{f_{r}}
$$

To minimize the energy of the series inductor, the equivalent impedance needs to be minimized and the resonant frequency maximized. In the design of LLC converters at the resonant frequency, the resonant frequency $f_{r}$ is equal to the switching frequency $f_{s}$. To select the switching frequency, the trade-off between conduction losses and switching losses needs to be considered, as explained in previously. The switching frequency will also have an effect on the transformer volume. In theory, high frequencies will lead to a lower volume of the transformer. However, there will be a frequency limit for a given core material, because each core material has a different optimal frequency.

Once the frequency is selected, considering the core material of the transformer and the trade-off between conduction losses and switching losses of the chosen transistor technology, the only way to minimize the energy of the resonant inductor is to reduce the equivalent impedance of the tank. This means to reduce the value of inductance $L_{r}$ as much as possible. In isolated LLC converters, the minimum achievable inductance is the leakage inductance of the transformer plus the parasitic inductances of the connections and PCB traces. Additionally, transformers with low leakage have lower high-frequency effects. This decreases the AC resistance and therefore reduces the winding losses, thus leading to better optimized transformer designs.

\subsubsection{Parallel inductance design}

The parallel inductance is the element that distinguishes a regular series resonant converter from an LLC converter. This parallel inductance affects the regulation 


\subsection{Design of LLC operating at resonant frequency with high conversion ratio and high output current}

range and the boosting behavior at low frequencies in conventional LLC converters, as depicted in Figure 5.21.

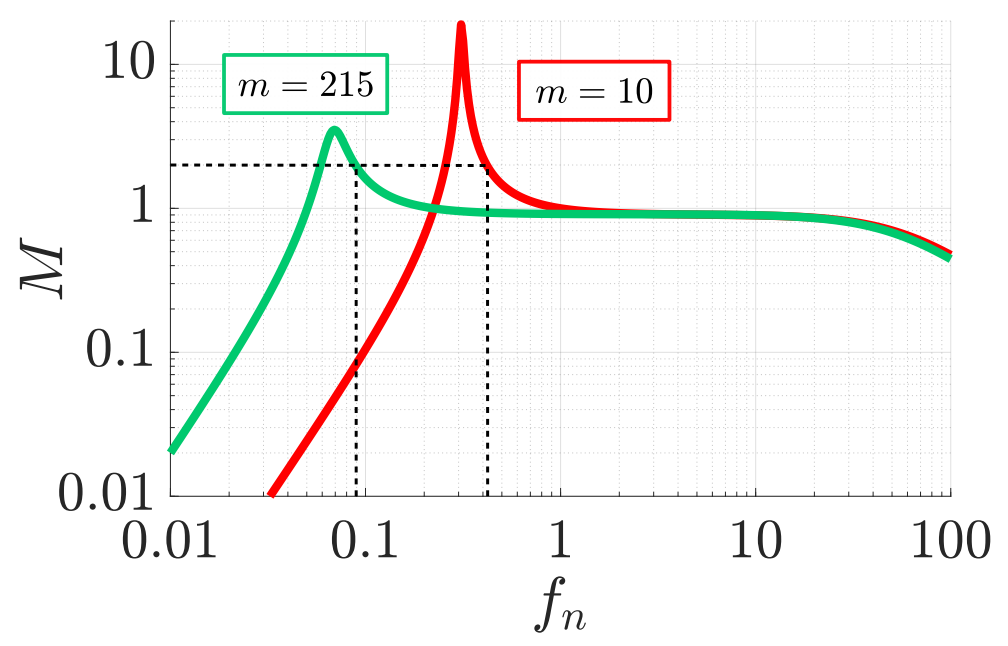

Figure 5.21: Voltage gain for different inductance ratios

However, in an LLC converter operating at resonant frequency, the desired voltage gain is $M=1$ and the frequency is fixed at the resonance $f_{n}=1$. Nevertheless, there is an advantage of having the parallel inductor in comparison to series resonant converters, as it provides the necessary inductive current during the ZVS transition, as explained in the previous chapter. The parallel inductor voltage is determined by the secondary bridge voltage, as depicted in Figure 5.22.

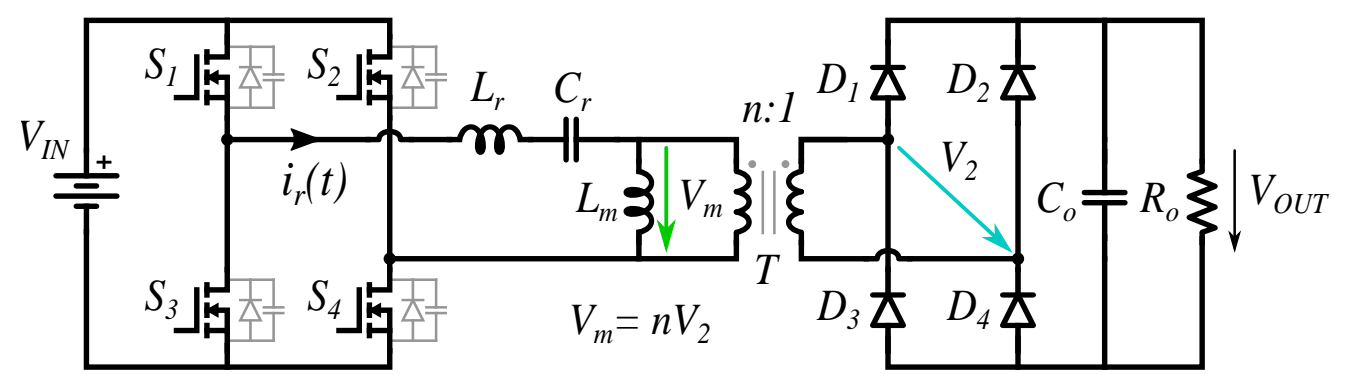

Figure 5.22: LLC full-bridge converter: Parallel inductor voltage

If the output capacitor filter is designed accordingly, the secondary bridge voltage will be a square voltage waveform. With this voltage applied to the parallel inductor, the current will result in a triangular waveform, as depicted in Figure 5.23. 


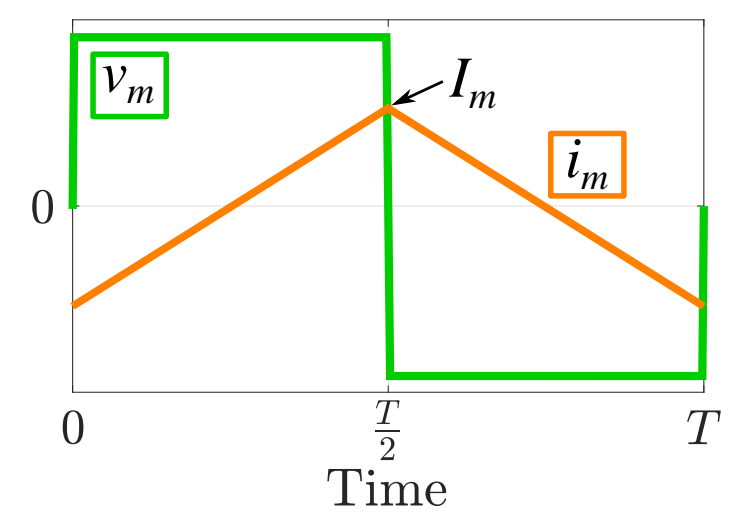

Figure 5.23: Parallel inductor $L_{m}$ : Voltage and current

The peak value of this current is determined by the following equation:

$$
I_{L_{m}}=\frac{V_{I N}}{4 L_{m} f_{s}}
$$

As explained in Chapter 4, the current required to achieve a full ZVS transition is:

$$
I_{L_{m}}=\frac{q_{o s s}}{k_{q} t_{d}}
$$

Using the last two equations the value for the required parallel inductance is:

$$
L_{m}=\frac{k_{q} t_{d} V_{I N}}{4 f_{s} q_{o s s}}
$$

However, as explained before a current distortion effect can be caused by a low quality factor of the series resonant tank $Q_{s}$, this will increase the turn-off current requiring a higher parallel inductance for the same current. Considering this, the parallel inductance is:

$$
L_{m}=\frac{V_{I N}}{4 f_{s}\left(\frac{q_{o s s}}{k_{q} t_{d}}-\Delta I_{Q_{s}}\right)}
$$

Where $\Delta I_{Q_{s}}$ is the additional turn off current created by the distortion related to the series quality factor $Q_{s}$.

However, to achieve high values of current and achieve a full ZVS transition, low values of $L_{m}$ are required. Gapped transformers are usually needed to reach these magnetizing inductance values. This issue can be solved by using an auxiliary circuit, as explained in Chapter 4. 


\subsection{Design of LLC operating at resonant frequency with high}

conversion ratio and high output current

Table 5.2: Transistor technology comparison

\begin{tabular}{cccc}
\hline Device & $\begin{array}{c}\text { Si } \\
\text { IPW65R037C6 }\end{array}$ & $\begin{array}{c}\text { SiC } \\
\text { SCTH90N65G2V-7 }\end{array}$ & $\begin{array}{c}\text { GaN } \\
\text { GS66516T }\end{array}$ \\
\hline \hline$R_{d s}\left(25^{\circ} C\right)$ & $37 m \Omega$ & $18 m \Omega$ & $25 m \Omega$ \\
$R_{d s}\left(100^{\circ} C\right)$ & $66 m \Omega$ & $22 m \Omega$ & $49 m \Omega$ \\
$q_{\text {oss }}(400 V)$ & $645 n C$ & $230 n C$ & $100 n C$ \\
$R_{t h J C}$ & $0.25 \frac{{ }^{\circ} C}{W}$ & $0.45 \frac{{ }^{\circ} C}{W}$ & $0.3 \frac{{ }^{\circ} C}{W}$ \\
$R_{t h J A-H S}$ & $1.2 \frac{{ }^{o} C}{W}$ & $1.4 \frac{{ }^{o}}{W}$ & $2.5 \frac{{ }^{\circ} C}{W}$ \\
Package & TO- 247 & TO- 247 & $G a N_{P X}{ }^{\circledR}$ \\
\hline
\end{tabular}

\subsubsection{Transistor design}

The LLC converter consist of an inverter structure, a resonant network and a rectifier structure, as depicted in Figure 5.24.

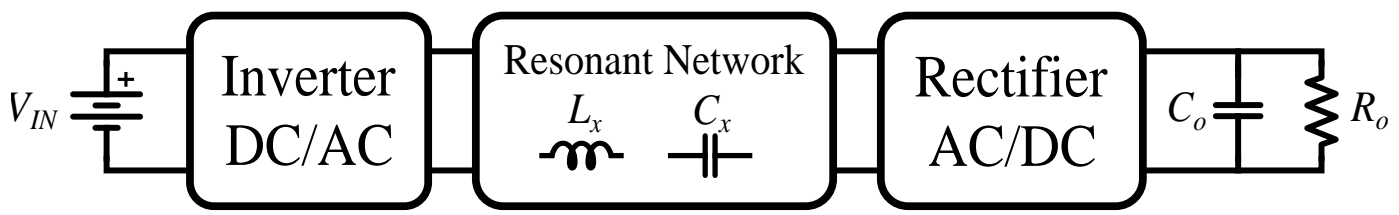

Figure 5.24: LLC full-bridge converter: Parallel inductor voltage

Different combinations of inverter and rectifiers are possible. However, in the context of this thesis that relates to high conversion ratio and high output current LLC converters, the structures for both inverter and rectifier are going to be full-bridge. Transistor have to be selected for both. The primary side is the high-voltage/low-current side and the secondary side is the low-voltage/high-current

\subsubsection{Primary high-voltage transistor design}

In the primary bridge of a high conversion ratio LLC converter, the voltage applied is high $(400 \mathrm{~V})$. A derating of $60 \%$ is applied in order to withstand voltage spikes and overshoots. Devices with $650 \mathrm{~V}$ can be selected to have a safe margin. Three different types of devices are available: Silicon ( $\mathrm{Si}$ ) Metal oxide field effect transitor (MOSFET), Silicon Carbide ( $\mathrm{SiC})$ MOSFET and Gallium Nitride (GaN) High electron mobility transistor (HEMT). 


\section{Chapter 5. Design and Optimization}

Every device is rated at $650 \mathrm{~V}$, even the $\mathrm{SiC}$ transistor. While $\mathrm{SiC}$ technology is more common at $1200 \mathrm{~V}$, recent improvements in the technology have allowed lower breakdown voltage $\mathrm{SiC}$ devices, with optimized drain/source resistance. The best device for conduction losses is the $\mathrm{SiC}$ device with the lower drain/source resistance. It presents also the least resistance increment with temperature. However, the thermal resistivity of the junction to case is the worst. The GaN transistor is the best device in terms of output capacitance charge $\left(q_{\text {oss }}\right)$, it requires the least amount of current to achieve a full ZVS transition, as depicted in Figure 5.25.

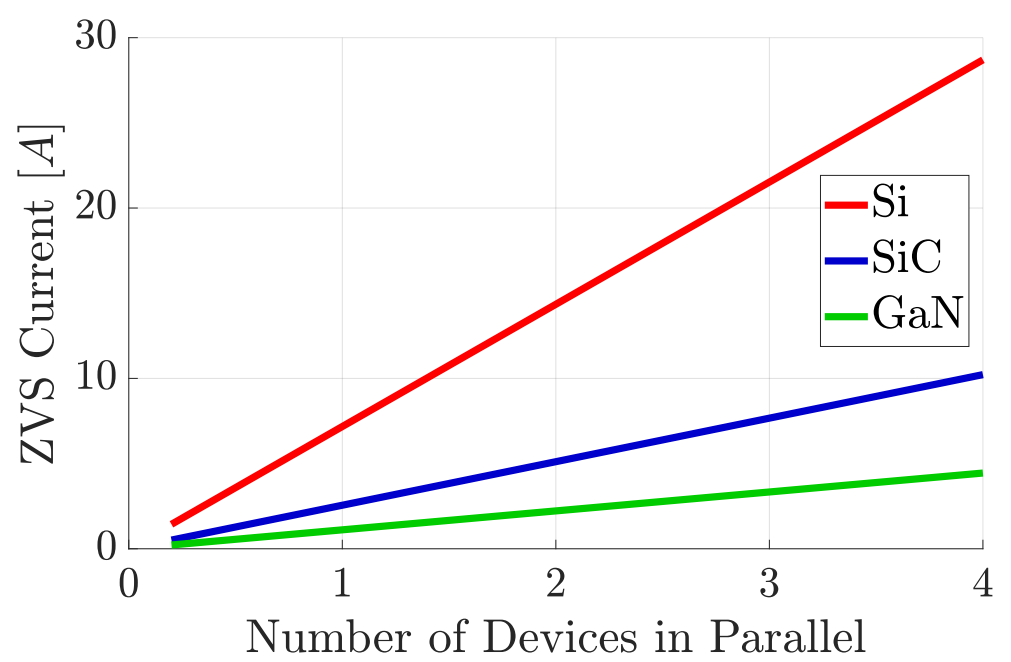

Figure 5.25: ZVS current

Using multiple transistors in parallel the capacitances are added and the $q_{\text {oss }}$ increases. This increases the current required to achieve the full ZVS transition, increasing the switching losses. However, with multiple devices in parallel, the equivalent resistance decreases and the conduction losses are reduced. This power loss trade-off between conduction and switching is shown in Figure 5.27. To calculate the power losses of each technology, the devices in Table 5.2 are used. The power losses of a $10 \mathrm{~kW}$ LLC converter are used to calculate the losses. The switching losses are estimated with the currents of Figure 5.25, to achieve full ZVS. The optimum number of devices can be found in this graph. The optimum value for GaN technology is 2 devices in parallel, while with $\mathrm{SiC}$ technology the optimum is at 1 device and between 1 and 2 for Si technology. 
5.3. Design of LLC operating at resonant frequency with high conversion ratio and high output current

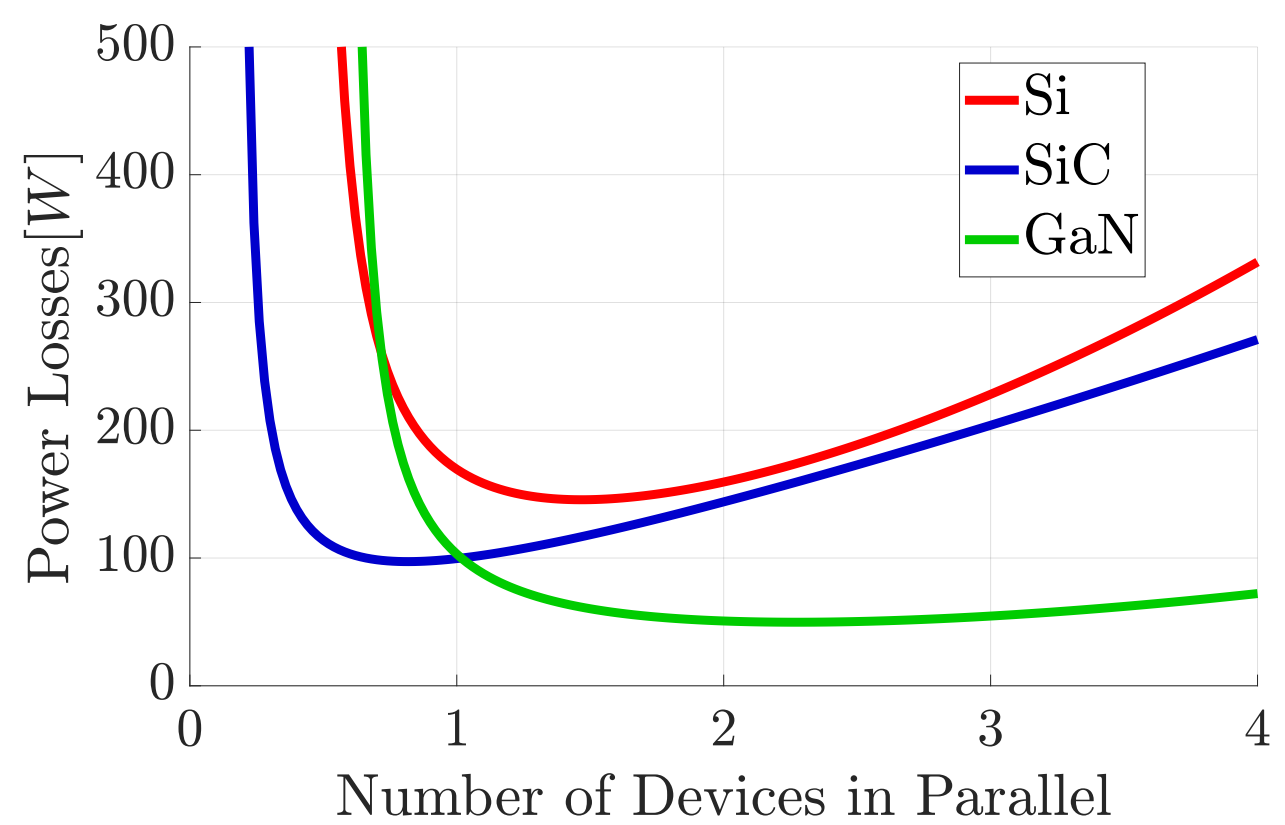

Figure 5.26: Power Losses of different technologies

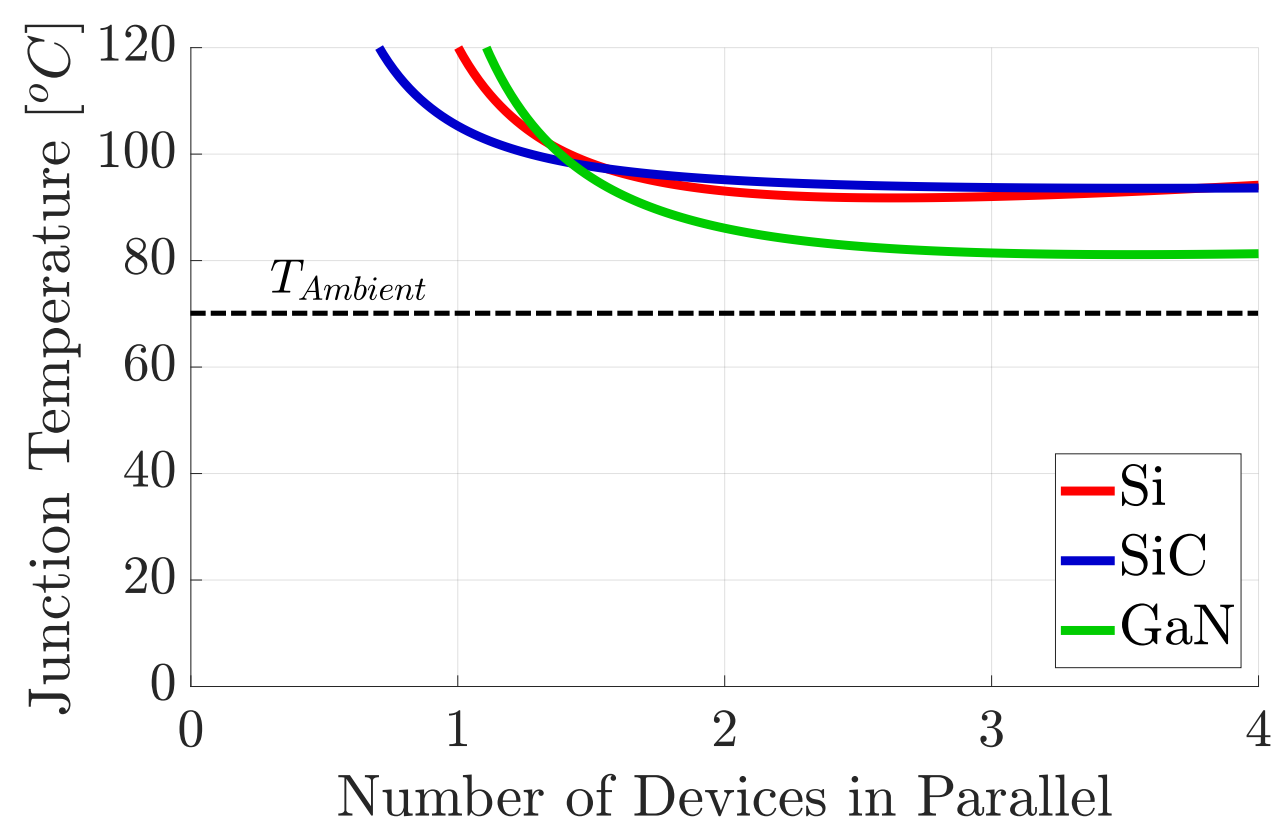

Figure 5.27: Junction Temperature of the different transistor technologies. 


\section{Chapter 5. Design and Optimization}

The operating temperatures of the junction for multiple devices in parallel are shown in Figure 5.27, using the thermal resistances in Table 5.2.

\subsubsection{Magnetic component design}

The design of magnetic component is heavily influenced by the type of magnetic core material and shape used, and also by the winding configuration.

\subsubsection{Magnetic core material selection}

The core material selection is highly influenced by the operating frequency selection. The performance of the different materials is different [44].

In recent decades, the tendency in power converter design is to push the frequency as high as possible. A key benefit of increasing the frequency is to decrease the size of the magnetics. However, there are three fundamental limits to the increase in frequency in power converter: the transistor switching losses, the core losses and the high frequency effects that increase the winding losses. In the case of the transistor losses limit, the trade-off between the conduction losses and switching losses is the limit to the frequency. Recent improvement in devices and new materials like $\mathrm{SiC}$ and GaN are pushing the limits of high frequency in power conversion [45]. However, in high power conversion, the conduction losses are high and the trade-off with the switching losses limits the frequencies to values around hundreds of kilohertz for converters with output powers around tens of kilowatts.

In the case of magnetic materials, high power conversion ferrites are typically, low frequencies ferrites, ranging from $50 \mathrm{kHz}$ to $200 \mathrm{kHz}$ [1]. The selected material to design the transformer and the auxiliary inductor of the $10 \mathrm{~kW}$ is the $3 C 95$ ferrite from Ferroxcube. The range of frequencies selected to analyze is between $100 \mathrm{kHz}$ and $140 \mathrm{kHz}$.

\subsubsection{Magnetic core shape selection}

Traditional high power transformer core shapes are typically E-cores, U-cores or POT cores. However, the use of planar magnetics are widespread both in academia and industry. They are being used to achieve high power density in power converters. Models and theoretical analysis as well as practical publications are 


\subsection{Design of LLC operating at resonant frequency with high conversion ratio and high output current}

[46, 47]. An overview of planar magnetic technology can be found in [48], where the advantages and disadvantages are summarized. The advantages are:

- Low profile

- High power density and good thermal characteristic

- Easy of manufacturability and cost reduction

- Good repeatability

- Modularity

- Easy interleaving winding configuration

- Predictable parasitic

In the context of optimized isolated LLC converters, where the leakage is used as the series resonant inductor, the good repeatability and easy interleaving of the planar magnetics are key to a successful and optimized design. Nevertheless, planar magnetic components are not devoid of disadvantages:

- Large footprint

- Low copper fill factor

- Limited number of turns

- High parasitic capacitance

In high current applications the low copper fill factor can be an issue, but this can be solved by using multiple transformers in parallel or even in series/parallel configurations. This will be explained in section 5.3.4. The high parasitic capacitance, if high, can also influence the resonance of an LLC converter, so it needs to be accurately estimated to prevent any effect in the resonance. Additionally, some methods in the state of the art can be used to reduce this parasitic element [49].

\subsubsection{Winding structure selection}

The windings magnetic component can be arranged in different configurations and different wire types. In high frequency components, the conventional round wires are undesirable. The high frequency effects create high copper losses and designs that are far from the optimum. To reduce the effect of these high frequency effects, discussed previously, Litz wires or foil conductors can be used.

The Litz wire is a type wire where multiple isolated strands are twisted in bundles. There are multiple bundle levels and multiple twisting patterns in order to reduce the high frequency effects by allowing the multiple strands to travel 


\section{Chapter 5. Design and Optimization}

throughout the whole section of the wire and use the complete copper area more efficiently. This type of wire has benefits in high frequency design. However, the packing factor is also reduced, as the twisting of bundles and the individual isolation occupies a lot of window area, reducing the effect copper area. In high power transformers, where big Litz wires, or multiple parallels are needed to withstand the current, the manufacturing process can damage the isolation of each strand, when soldering all the cables to a terminal connection.

Foil conductor have better window utilization than Litz wires. They are easier to interleave and are simpler to construct [50]. It is also simpler to estimate the parasitic effects of foil conductors than Litz wires. Also the repeat ability of foil winding is better. This is critical in LLC converters, where the leakage inductance is used as the series resonant inductance.

\subsubsection{Design and optimization of magnetic components}

Considering a given core and winding technology, in the case of this work the planar E core and foil conductors, the design space can be reduced and therefore the optimization of the number of turns can be realized. In magnetic component design, there is a trade-off between the core losses and the winding losses. Considering the number of turns of the secondary side of the LLC converter depicted in Figure 5.28.

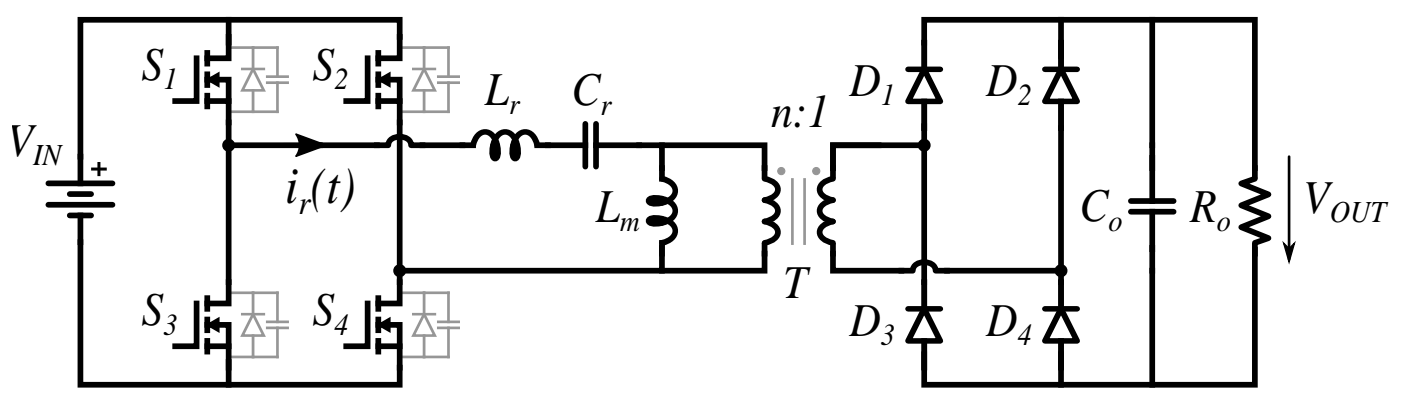

Figure 5.28: LLC converter with high conversion ratio and high output power

In secondary side, the number of turns is lower and the current is higher. The trade-off between the core losses and the winding losses are depicted in Figure 5.29, for the specifications of Table 5.3 


\subsection{Design of LLC operating at resonant frequency with high conversion ratio and high output current}

Table 5.3: LLC converter specifications for high voltage ratio and high output current

\begin{tabular}{cccc}
\hline Input Voltage & Output Voltage & Output Power & Output Current \\
\hline \hline $400 \mathrm{~V}$ & $28 \mathrm{~V}$ & $10 \mathrm{~kW}$ & $360 \mathrm{~A}$ \\
\hline
\end{tabular}

The winding losses $P_{C u}$ increase with the number of turns, as the resistance increases with the length of wires and therefore the number of turns. Also, with a high number of turns, less window area can be used for parallel wires to decrease the resistance. This creates a increase of losses that is quadratic with the number of turns. Additionally, the core losses decrease with the secondary number of turns, this can be seen from the Steinmetz equation combined with the flux density expression. The Steinmetz equation is as follows:

$$
P_{\text {Core }}=A_{e} \cdot l_{e} \cdot k_{S E} \cdot f^{\alpha} \cdot B^{\beta}
$$

And the peak flux density is:

$$
B=\frac{d \cdot V_{O}}{2 \cdot f_{s} \cdot n_{2}}
$$

Combining these two equations, we obtain:

$$
P_{\text {Core }}=A_{e} \cdot l_{e} \cdot k_{S E} \cdot f^{\alpha} \cdot\left(\frac{d \cdot V_{O}}{2 \cdot f_{s} \cdot n_{2}}\right)^{\beta}
$$

Where it can be observe that the core losses are proportional to $n_{2}^{-\beta}$. This can be seen grpahicaly in Figure 5.29.

In order to find the secondary number of turns at which the minimum losses are reached, the derivative of the total losses is required to be zero, as follows:

$$
\frac{d P_{t o t}}{d n_{2}}=\frac{d P_{F e}}{d n_{2}}+\frac{d P_{C u}}{d n_{2}}=0
$$

The condition can be rewritten as:

$$
\frac{d P_{F e}}{d n_{2}}=-\frac{d P_{C u}}{d n_{2}}
$$

Differentiating the Steinmetz equation and the winding losses, we obtain: 


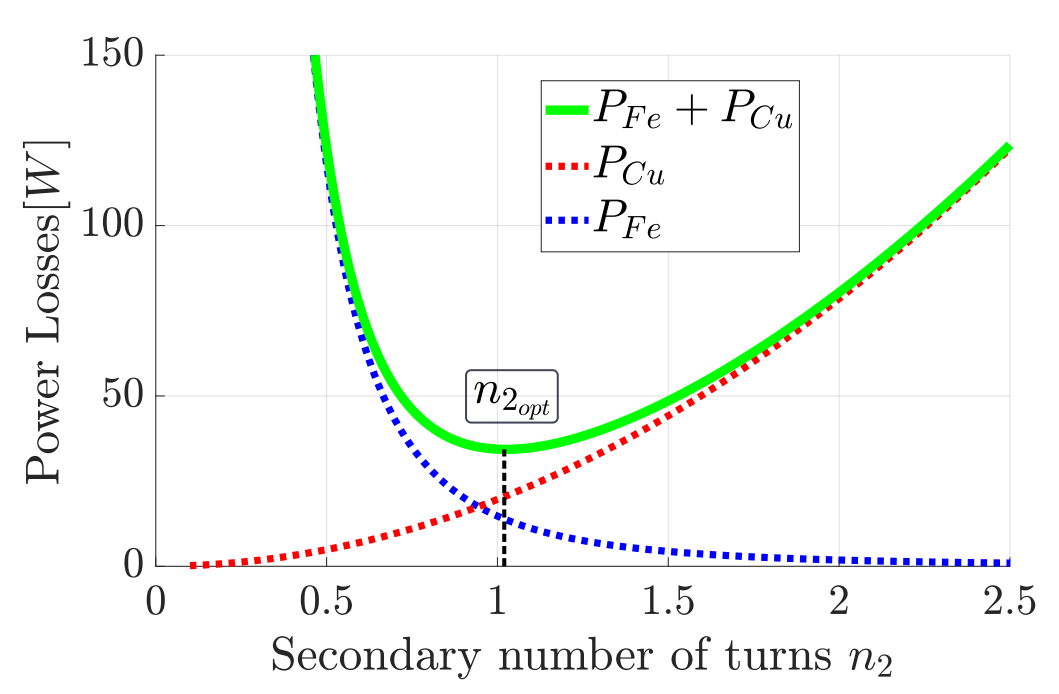

Figure 5.29: Core/winding power loss trade-of in function of the transformer secondary number of turns

$$
\frac{d P_{F e}}{d n_{2}}=-\beta n_{2}^{(-\beta-1)} \cdot k_{S E} \cdot A_{e}^{1-\beta} \cdot l_{e} f^{\alpha-\beta}\left(V_{o} / 4\right)^{\beta}
$$

and,

$$
\frac{d P_{C u}}{d n_{2}}=2 \cdot n_{2} \cdot \rho_{a c-e q} \cdot \frac{l_{C u}}{A_{C u}} \cdot I_{R M S 2}^{2}
$$

where $\rho_{a c-e q}$ is the equivalent resistivity of a given winding configuration.

$A_{C u}$ and $l_{C u}$ are the window area and the mean length of the wires. $l_{e}$ is the equivalent length of the magnetic path. For a given core shape, the values of these three geometrical paramaters can be scaled with the effective area $A_{e}$ with the following relationships:

$$
\begin{gathered}
l_{e}=3.08 \cdot A_{e}^{\frac{1}{2}} \\
A_{C u}=0.1541 \cdot A_{e} \\
l_{C u}=9.4886 \cdot A_{e}^{\frac{1}{2}}
\end{gathered}
$$




\subsection{Design of LLC operating at resonant frequency with high conversion ratio and high output current}

Substituting $A_{C u}$ and $l_{C u}$ in (5.56) and combining it with (5.55), we obtain the expression for the optimal number of turns in function of the core effective area $A_{C u}$.

$$
n_{2_{O P T}}=\left(0.123 \frac{\beta \cdot k_{S E} \cdot V_{o}^{\beta} \cdot f^{(\alpha-\beta)}}{2 \rho_{a c} I_{R M S}^{2}}\right)^{\frac{1}{\beta+2}} \cdot A_{e}^{\frac{2-\beta}{\beta+2}}
$$

It can be noted that the RMS current is in the denominator. This means that for increasing current and increasing output power, the optimal number of turns decreases. Figure 5.31 illustrate the optimal number of turns calculated with equation (5.60).

Combining the estimation of power losses with the thermal models explained in section 5.2.3, a thermal limit can be considered, as illustrated in Figure 5.30. Selecting a maximum differential temperature of 120 for the windings and 60 for the core, the minimum size of the core in terms of effective are can be calculated, as shown in Figure 5.30.

It can be observed in Figure 5.31 that considering the thermal limit the value of the optimal number of turns can be rounded down or up to $n_{2}=1$. With this knowledge, the conventional method of iterations to locate the optimum number of turns is avoided and the design time and complexity is reduced.

\subsubsection{Series-Parallel Configuration}

The Series-Parallel configuration has been used previously in the literature in LLC converters in [51]. This configurations has advantages in terms of the natural current sharing between the secondary bridges and also the current stresses are shared between them. This is helpful in high secondary current applications, where splitting the high current into different output bridges is required to spread losses and reduce the temperature of the secondary devices.

This LLC series/parallel configuration is close to LLC matrix configuration approach ??. However, the difference is that a single transformer component is not to integrate the different series/parallel transformers. In high power and high output current converters, it is actually more interesting to split the transformer into different components in order to increase the heat dissipation capabilities.

The series parallel configuration can be generalized to any number of series parallel transformers and output bridges, as depicted in Figure 5.33. 


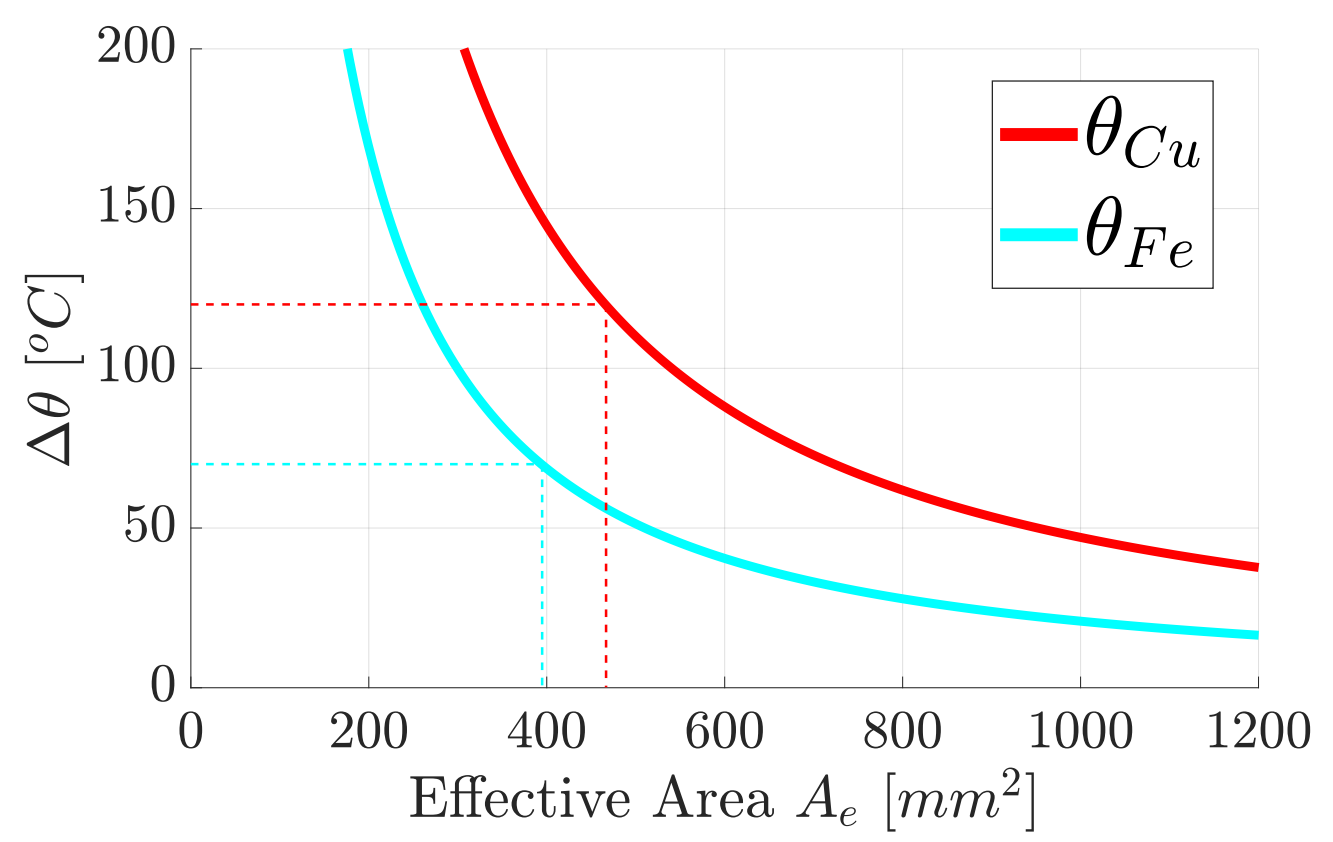

Figure 5.30: Core and winding temperatures in function of different transformer sizes, scaled with the effective area

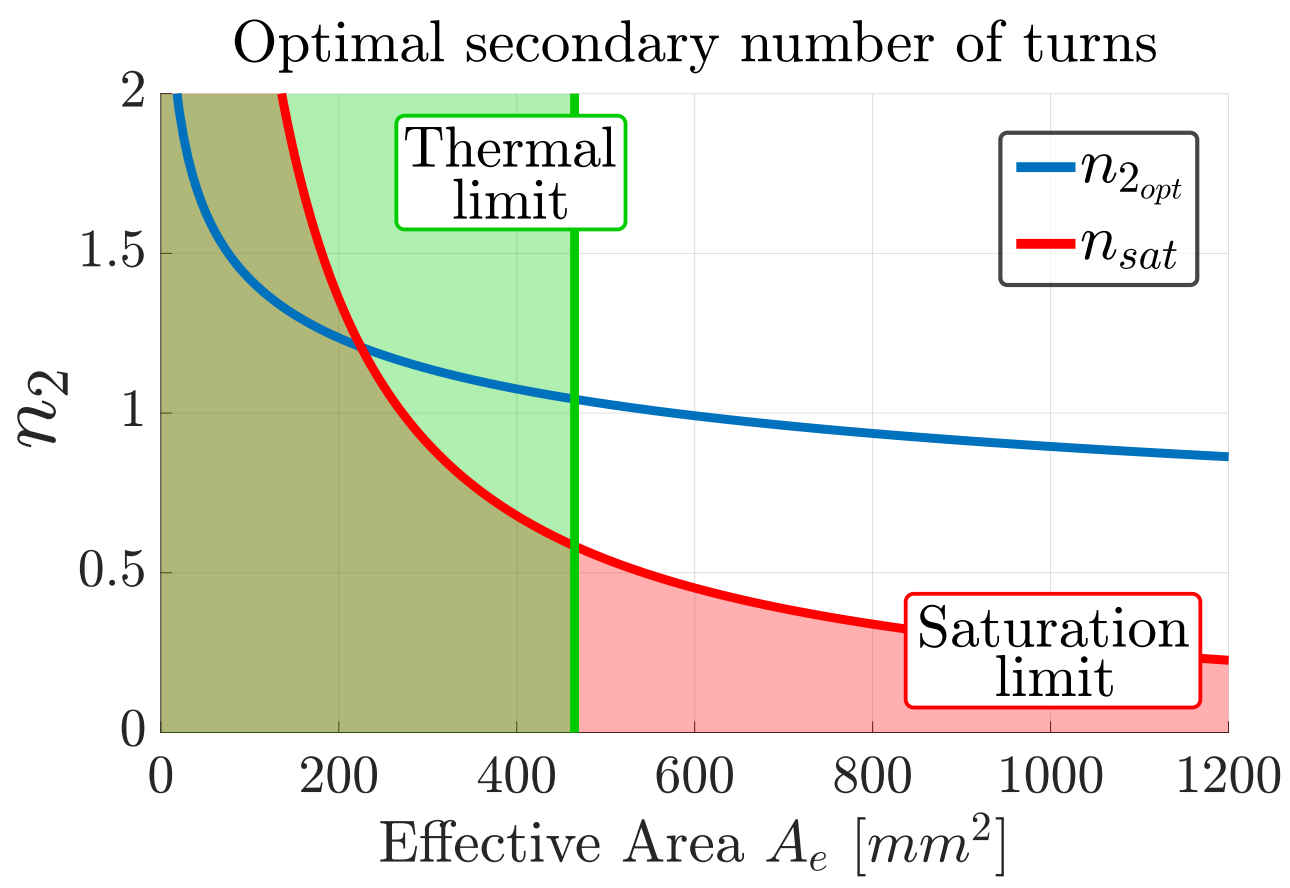

Figure 5.31: Optimal secondary number of turns for different transformer sizes, scaled with the effective area 
5.3. Design of LLC operating at resonant frequency with high conversion ratio and high output current
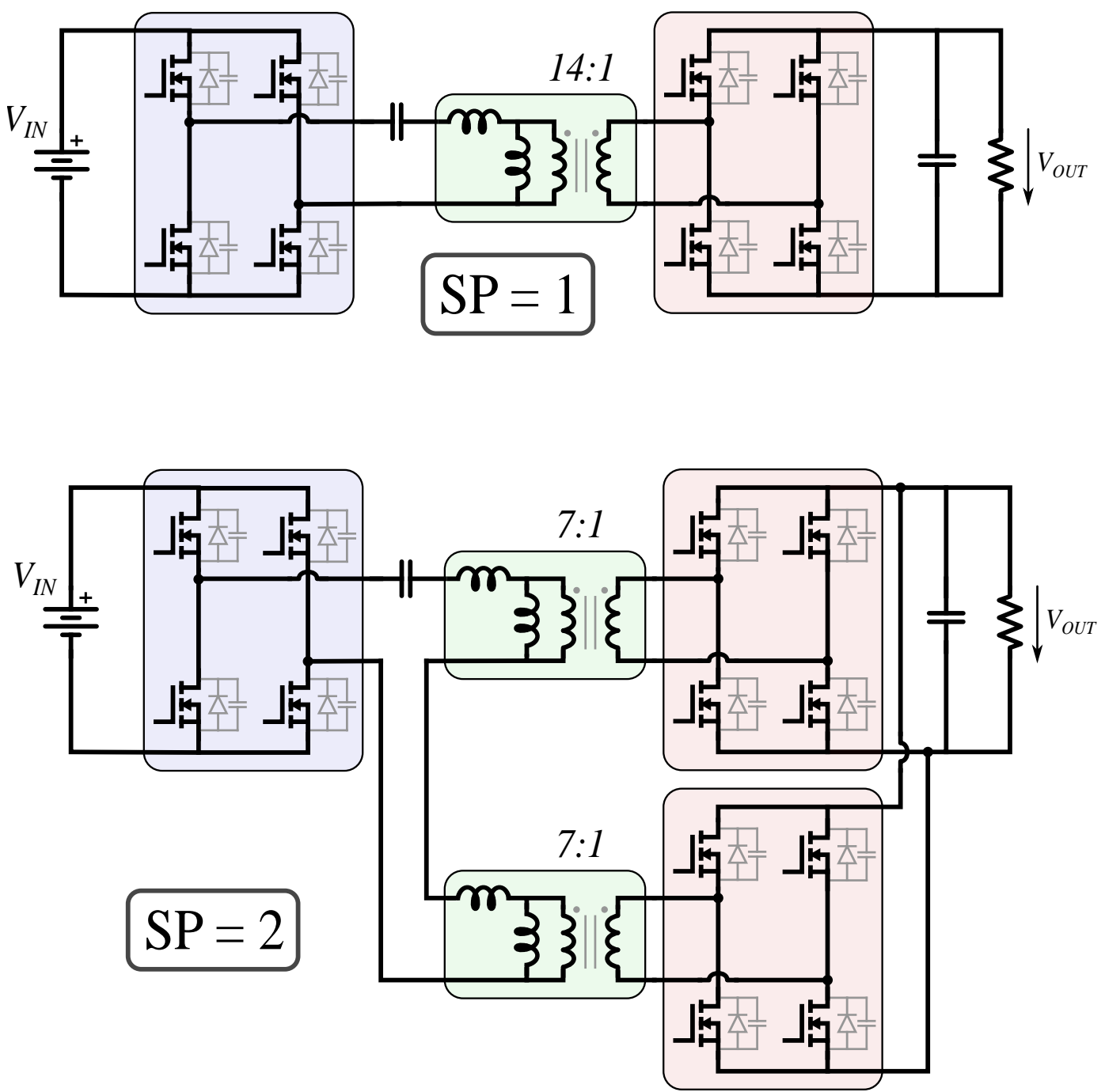

Figure 5.32: Series/parallel configuration, $\mathrm{SP}=1$ and $\mathrm{SP}=2$ 


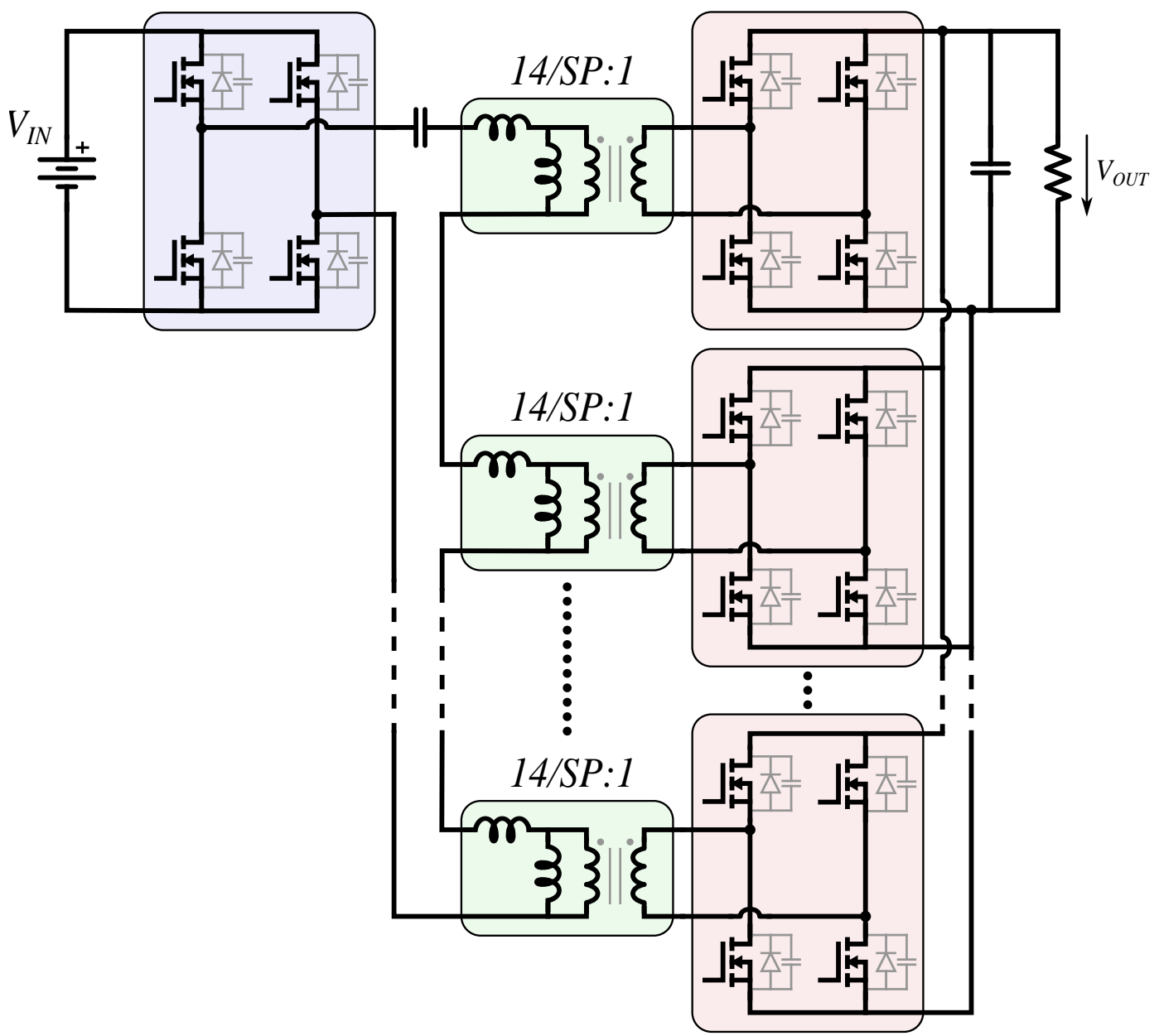

Figure 5.33: Series/parallel configuration arbitrary number of series parallel $S P \in \mathbb{N}]$ 


\subsection{Multi-objective optimization: Pareto front analysis}

Increasing the value of series/parallel number $(S P)$, the turns ratio is divided. High turns ratio transformers designs are more complex and interleaving is harder to achieve, which leads to lower efficiency and more power losses to dissipate. The generalized series/parallel structure helps with this issue, as the multiple series/parallel transformer have their turns ratio reduced, as depicted in Figure 5.33. Additionally, as explained in section 5.2.3, the thermal resistance of a magnetic component is reduced when dividing it into multiple smaller components.

\subsection{Multi-objective optimization: Pareto front analysis}

In this section, the multi-objetive optimization data calculation algorithm will be presented and the results will be analyzed.

\subsubsection{Data calculation algorithm for LLC converters operating at resonant frequency}

For the multi-objetive optimization of the LLC converters operating at resonant frequency, the data has to be calculated and analyzed using the Pareto front analysis. To gather all the data, the models from section 5.2 will be used. A sweep of every input is iterated until getting the complete design solutions set. These input parameters are the design parameters of each component in the topology: transistors, magnetic components, capacitors, etc. However, magnetics are by far the most complex component in terms of quantity of parameters but also of the model complexity. The different design parameters include, the core material and shape, the winding material and configuration, the turns ratio, the voltage, the output power, the presence of gap, among others. A reduction in the number of transformer parameters will significantly reduce the calculation time.

To reduce the complexity of the data calculation algorithm, the design space of the transformers can be narrowed. As explained in section 5.3.3.2, planar transformer offer benefits in terms of thermal behavior and can lead to designs with high power density. Because of the range of frequencies (from $100 \mathrm{kHz}$ to $140 \mathrm{kHz}$ ) the material considered will be Ferrite, specifically 3C95 from Ferroxcube [1]. This material has a flat power loss curve as a function of temperature. Therefore, its range of stable operating temperature is increased. 


\section{Chapter 5. Design and Optimization}

The core shape selected will be the planar E-core. All geometrical properties will be scaled and related with the effective area $A_{e}$. With this method, a single sweep of $A_{e}$ will define multiple transformer sizes. Three different dimensionless coefficients will be used to scale the values the effective length $\left(l_{e}\right)$, the window area $\left(A_{C u}\right)$ and the winding mean length $\left(l_{C u}\right)$ :

$$
\begin{gathered}
k_{e}=\frac{l_{e}^{2}}{A_{e}} \\
k=\frac{A_{C u}}{A_{e}} \\
k_{C u}=\frac{l_{C u}^{2}}{A_{C u}}
\end{gathered}
$$

With these coefficients the expression for $l_{e}, l_{C u}$ and $A_{C u}$ are:

$$
\begin{gathered}
l_{e}=k_{e}^{\frac{1}{2}} \cdot A_{e}^{\frac{1}{2}} \\
A_{C u}=k \cdot A_{e} \\
l_{C u}=\left(k_{C u} \cdot k\right)^{\frac{1}{2}} \cdot A_{e}^{\frac{1}{2}}
\end{gathered}
$$

With these coefficients the value for the total volume can be calculated as follows:

$$
V o l=l_{e} \cdot A_{e}+l_{C u} \cdot A_{C u}=\left(k_{e}^{\frac{1}{2}}+k_{C u}^{\frac{1}{2}} \cdot k^{\frac{3}{2}}\right) \cdot A_{e}^{\frac{3}{2}}
$$

For planar core shapes with foil windings, these coefficients can be derived from the geometrical information contained in the manufacturers data-sheet:

$$
\begin{gathered}
k_{e}=9.5 \\
k=0.1541 \\
k_{C u}=584
\end{gathered}
$$




\subsection{Multi-objective optimization: Pareto front analysis}

The expression for the volume is then:

$$
V o l=4.54 \cdot A_{e}^{\frac{3}{2}}
$$

Reducing the geometrical parameters of the core shape to only the effective area Ae and that the optimum for the secondary number of turns is $n_{2}=1$, as explained in section 5.3.3.4. The rest of the parameters that influence the transformer design are the switching frequency $f_{s}$, the gap length $l_{g}$ and the series-parallel configuration number $S P$. In addition to the transformer parameters, the number of parallel primary and secondary transistors per switch $N_{m o s}$ and $N_{m o s 2}$ are added as sweep parameters. Finally, the transistor technology is the last parameter to be swept, using $\mathrm{Si}, \mathrm{SiC}$ and GaN devices.

The flowchart of the data gathering algorithm is depicted in Figure 5.34. The first calculation is the peak flux density $B$. If the transformer saturates, the design is not valid, and therefore, new inputs from the sweep are required. Next, the turn-off $I_{O f f}$ current is calculated, taking into account the distortion effects of the series tank quality factor $Q_{s}$, as explained in section 3.4.1. With the turn-off current, it can be determined if the ZVS condition is met. If the condition is not met, an auxiliary circuit can be calculated. Once the power losses are calculated, the last restriction can be applied. A temperature differential limit is set for the winding temperature differential $\Delta \theta_{C u}$ and the core temperature differential $\Delta \theta_{F e}$.

When all the data is gathered, it can be classified into different categories depending on the inputs, to draw the Pareto fronts for the different input parameters.

\subsubsection{Multi-objective optimization results and conclusions}

In this section, the results of the multi-objective optimization will be presented.

\subsubsection{1 $\rho / \eta$ Pareto results}

In this section, the results of the Pareto analysis for the power density $(\rho)$ and efficiency $(\eta)$ will be shown for the LLC converter operating at resonant frequency at $10 \mathrm{~kW}$ output power and with $400 \mathrm{~V}$ input voltage and $28 \mathrm{~V}$ output voltage. To create a fair comparison, the same type and amount of secondary devices will be used for all the series/parallel configurations. 


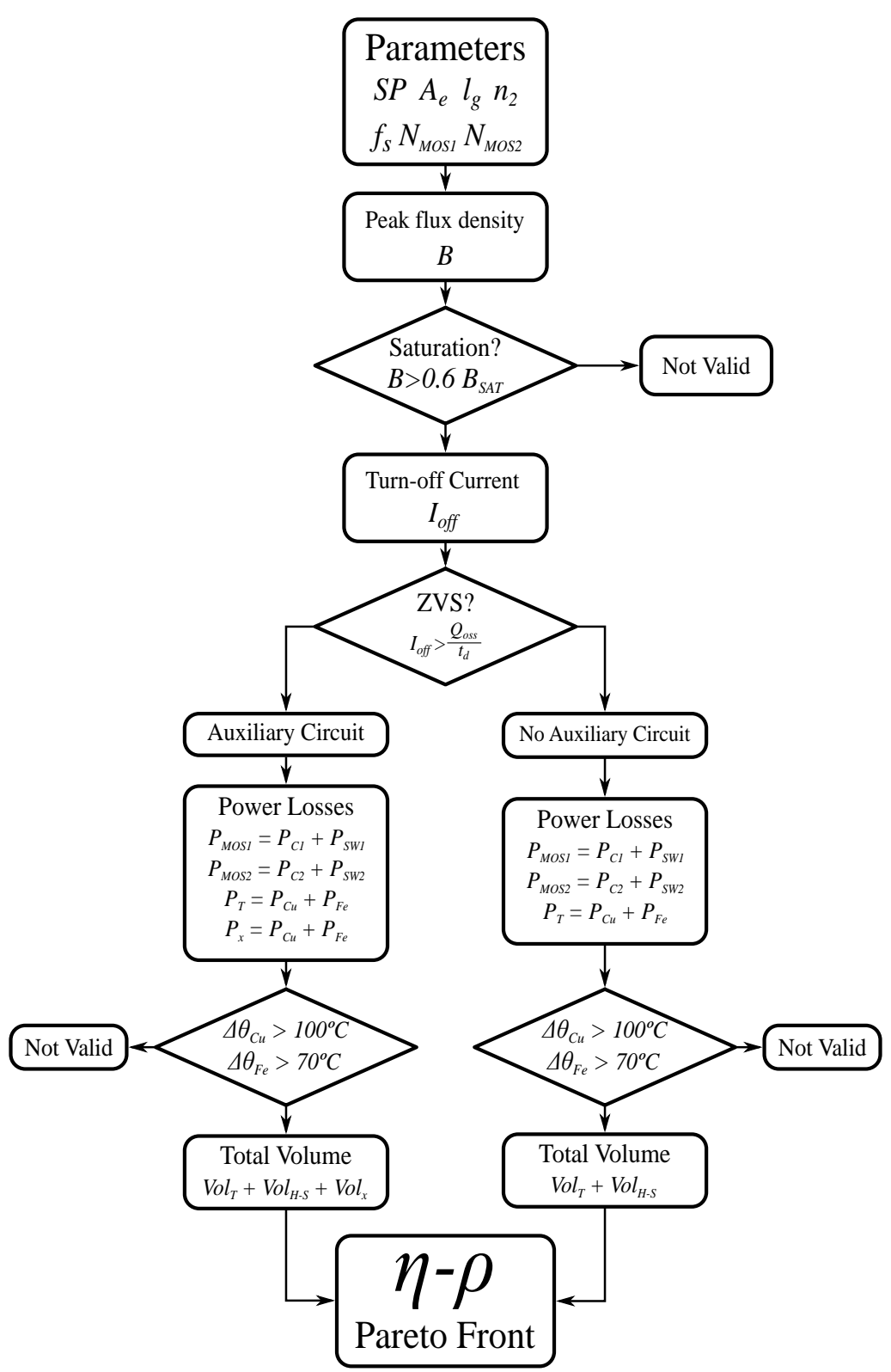

Figure 5.34: Pareto front data calculation algorithm 


\subsection{Multi-objective optimization: Pareto front analysis}

Figures 5.35, 5.36 and 5.37 illustrates the results of the pareto fronts analysis for the $S P=1, S P=2$ and $S P=7$ series/parallel configurations. Different transistor technologies are used for the primary devices ( $\mathrm{Si}, \mathrm{SiC}$ and $\mathrm{GaN}$ ) and also different magnetic component configurations: Forward type transformers, gapped transformers. All the designs solutions achieve a full ZVS transition, for this auxiliary circuits are used in some forward type transformer designs to add the required ZVS current.

For the case of the conventional single phase LLC converter $(\mathrm{SP}=1)$, the results of Figure 5.35 show that there are no solutions for the forward type transformers without auxiliary circuit., for neither of the transistor technologies. Forward type transformers have typically high magnetizing inductances. The only possible way to achieve a smaller magnetizing inductance is with a smaller core size, but at this power level $(10 \mathrm{~kW})$, small size cores will not be able to dissipate the heat generated by their power losses. The forward type transformer design with auxiliary circuit show an improvement in power density and efficiency over the gapped transformer solutions. Gapped transformer have more copper losses due to the high frequency effects generated by the fields created by the gap. Bigger cores are required in this type of designs in order to handle the higher losses.

Figure 5.36 shows the result of the multi-objective optimization algorithm for the $S P=2$ case, in which two series/parallel transformer connected to two output transistor bridges. As explained previously, dividing the transformer into two different components helps with heat management, which makes viable smaller transformer size designs. This is shown by the overall increase in peak power density, doubling from $7 \mathrm{~kW} / \mathrm{dm}^{3}$ to $14 \mathrm{~kW} / \mathrm{dm}^{3}$ in the Si technology case, red Pareto front in Figure 5.36. As it was the case in the $S P=1$ case, the auxiliary circuit plus the forward type transformer designs have improved efficiency and power density over the gapped transformer designs, for the Si technology. However, in the case of the $\mathrm{SiC}$ and $\mathrm{GaN}$ technologies, forward type designs without auxiliary circuit are viable. Since the output capacitance charge qoss of these devices is lower than Si devices, the magnetizing inductance necessary is high enough so that no auxiliary circuit is required.

Finally, Figure 5.37 depicts the same results for the $S P=7$ case. As was the case for the previous case, the power density is increased with more series/parallel 


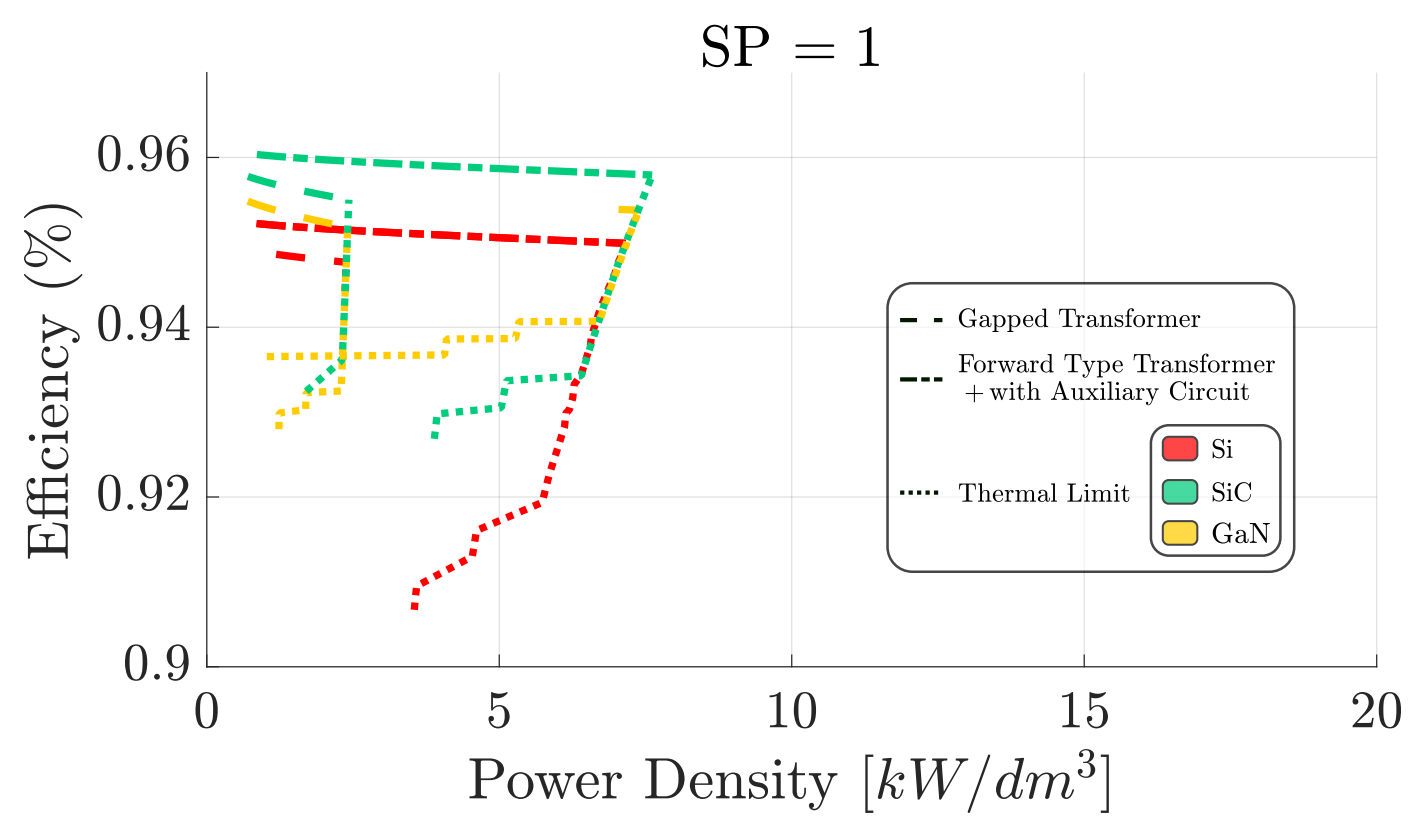

Figure 5.35: Pareto results for different transistor technologies and Series/Parallel configurations

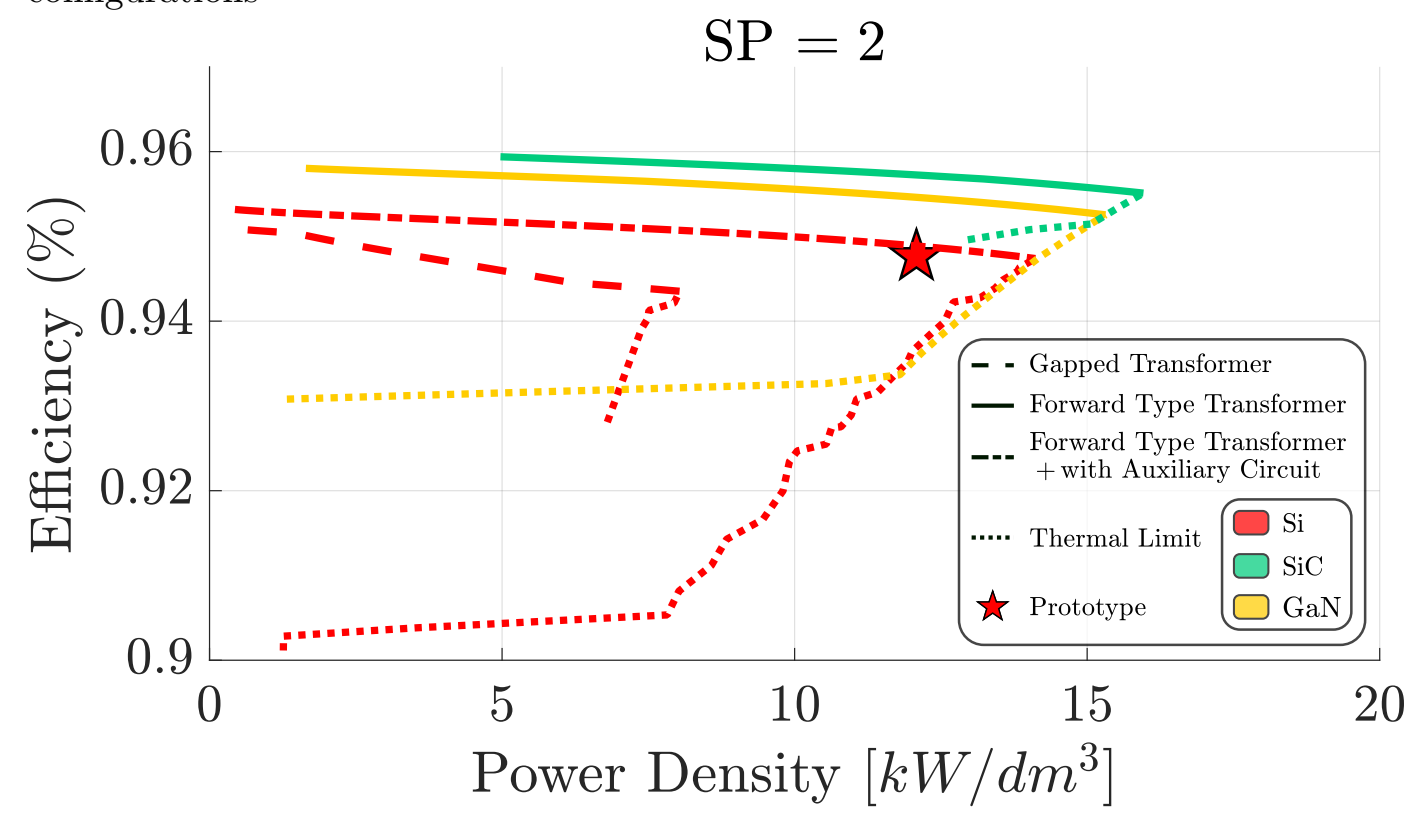

Figure 5.36: Pareto results for different transistor technologies and Series/Parallel configurations 


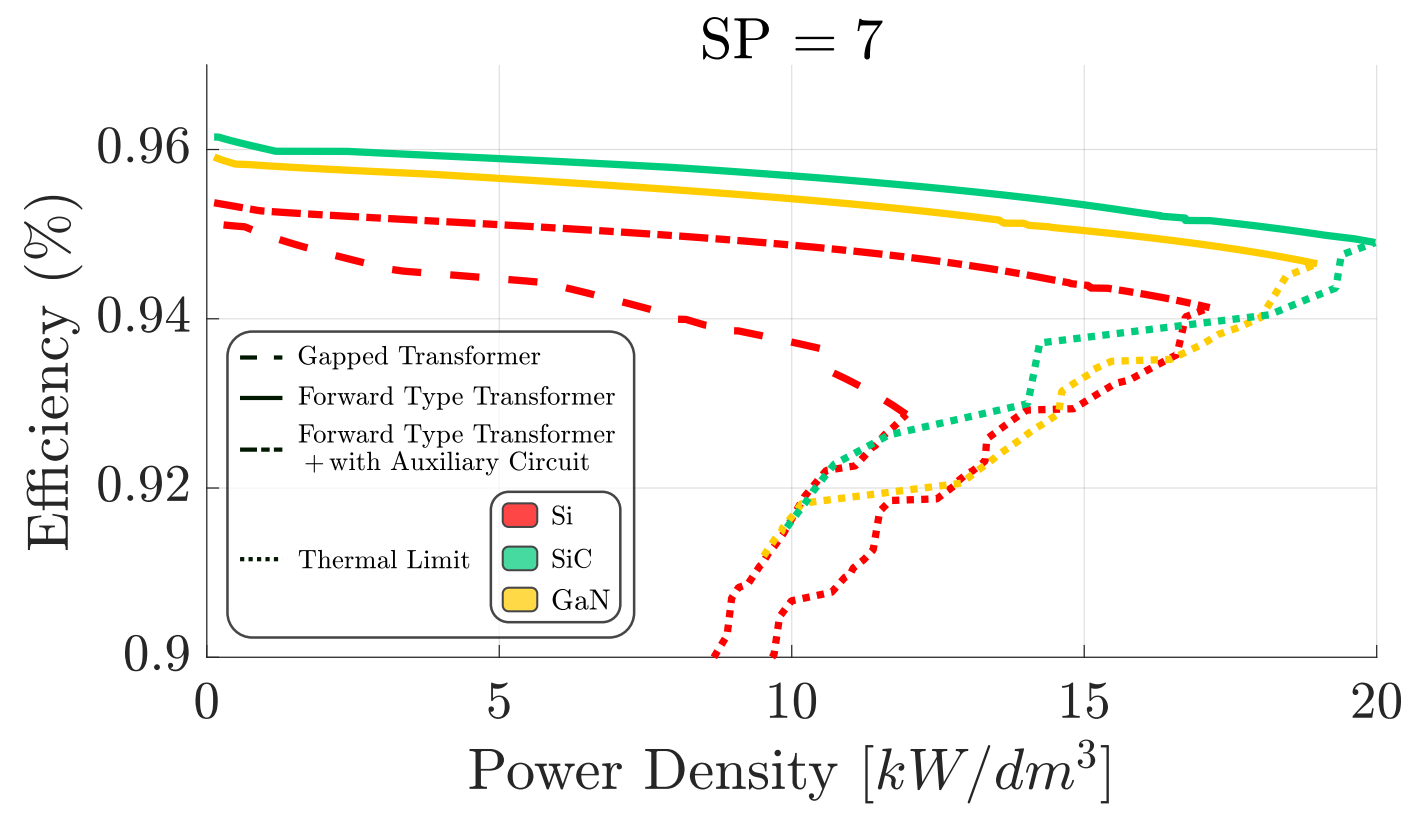

Figure 5.37: Pareto results for different transistor technologies and Series/Parallel configurations

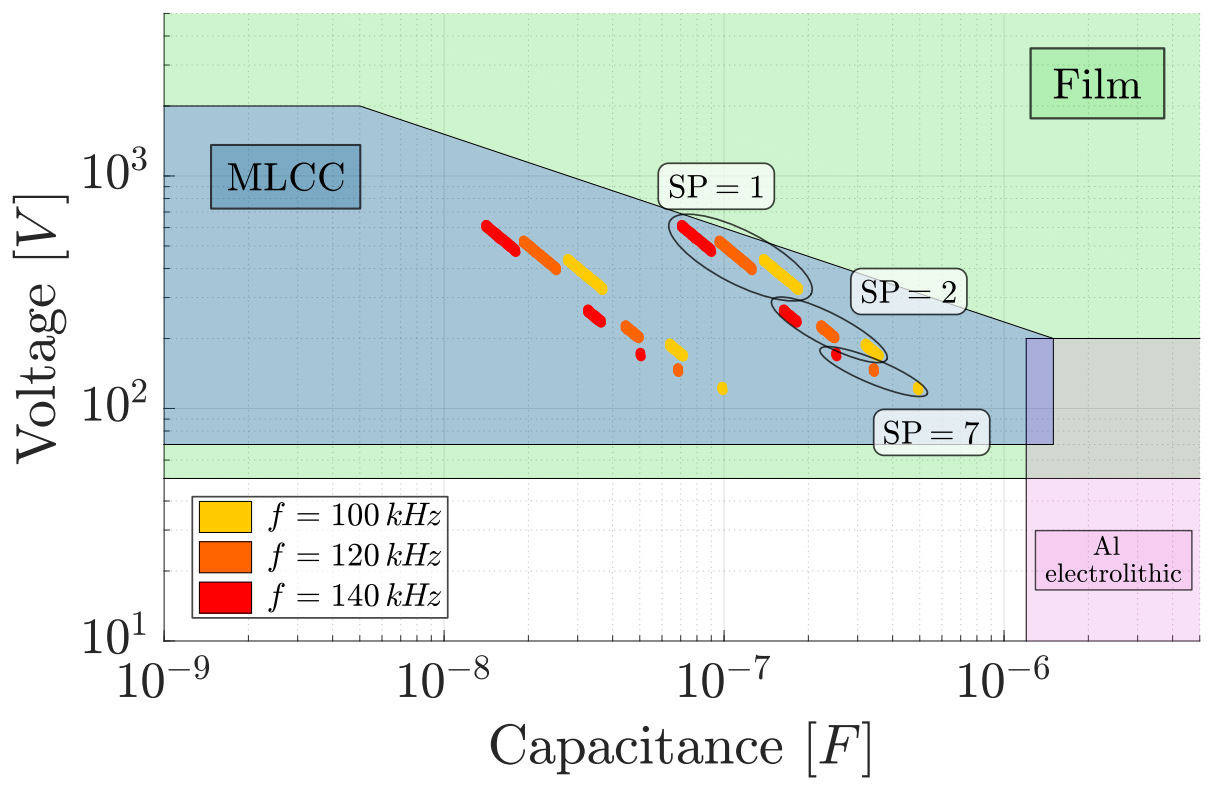

Figure 5.38: Capacitor design space results 


\section{Chapter 5. Design and Optimization}

transformer being added. The peak power density for $\mathrm{Si}$ designs increases to $17 \mathrm{~kW} / \mathrm{dm}^{3}$, with reduced efficiency $(94 \%)$ in the peak power density point.

The prototype built for this work was designed and built in 2015, when GaN and $\mathrm{SiC}$ devices were proven and mature. In recent years these wide bandgap devices have been proven and are mature enough [45].

\subsubsection{Resonant Capacitor range results}

Figure 5.38 shows the range of resonant capacitance values in the voltage-capacitance plane. The values are within the overlap area between the film capacitor technology and the multi-layer ceramic capacitor (MLCC). In case of overlap between the technologies, the recommended technology is the MLCC, as stated by [34].

Additionally, the resonant capacitor is connected in series and therefore carries the full resonant current. The design of this capacitor will include multiple capacitors in parallel. Considering a design with 5 SMD capacitors, the values of capacitances are the ones shown in Figure 5.38. They are still in the MLCC/film overlap area.

\subsection{Chapter summary}

Multi-objective optimization and Pareto front analysis are necessary tools to design and optimize power converters. Their accuracy is dependent on the quality of the models used. In this chapter, the models used to estimate the power loss, volume, and operating temperature of the components of an LLC converter operating at resonant frequency were presented. Details on the LLC parameters design were discussed, analyzing the energy of the series resonant inductor and capacitor, as well as the parallel inductance. The series/parallel configuration was reviewed and applied to the LLC converter with a generalized approach with multiple transformers. In the state of the art only the version with two series/parallel transformers was used in [51]. This modification of the conventional single transformer approach was compared in terms of efficiency and power density. It was proven to improve both the power density and efficiency by the merits of spreading the power losses and improving the heat dissipation capabilities. The multi-objective optimization algorithm also showed that auxiliary circuits are required in Si designs to improve the efficiency and power density while achieved full ZVS transition. 


\subsection{Chapter summary}

However, an auxiliary circuit is not required for high values of series/parallel number $S P$ and wide bandgap devices ( $\mathrm{SiC}$ and $\mathrm{GaN}$ ), because the current required to ensure full ZVS is lower than with Silicon transistors. 

Chapter 6

\section{Experimental validation}

In this chapter, a prototype is constructed and tested in order to validate experimentally the proposed models and to verify the proposed auxiliary circuit operation. The prototype is a $10 \mathrm{~kW}$ isolated DC/DC converter for aircraft applications. The performance of the converter is measured at different output powers. The behavior of the converter is shown with and without an auxiliary circuit to verify that the improvement in performance.

\subsection{Construction of prototype}

This prototype was built in the context of the AIR project [52], in collaboration with Indra Sistemas S.A. and Airbus companies. The project was a part of the European Cleansky initiative [53]. The goal of the project was to design and implement a $10 \mathrm{~kW}$ isolated rectifier to supply aircraft loads at $28 \mathrm{Vdc}$. As part of this European initiative, it follows the More electrical aircraft design philosophy.

\subsubsection{More electric aircraft philosophy}

In recent years, the modern aircraft design has been moving towards the More Electrical Aircraft (MEA) design philosophy [54-57]. Following this design philosophy, old mechanical, hydraulic and pneumatic systems are substituted by electric and electronic equivalents, that are less bulky and more efficient. With this efficiency increment and weight reduction, a great reduction in fuel consumption can be achieved. However, the electrical power level in the aircraft increases significantly. Therefore, new power supply solutions are needed.

Traditionally, aircraft rectifier units have been designed as passive solutions, as depicted in Figure 6.1. 
Chapter 6. Experimental validation

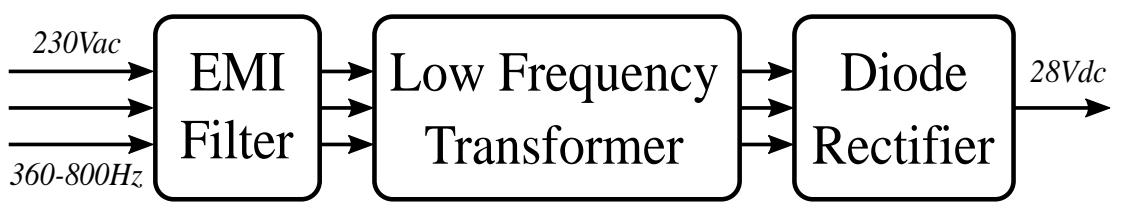

Figure 6.1: Aircraft isolated rectifier: Passive solution

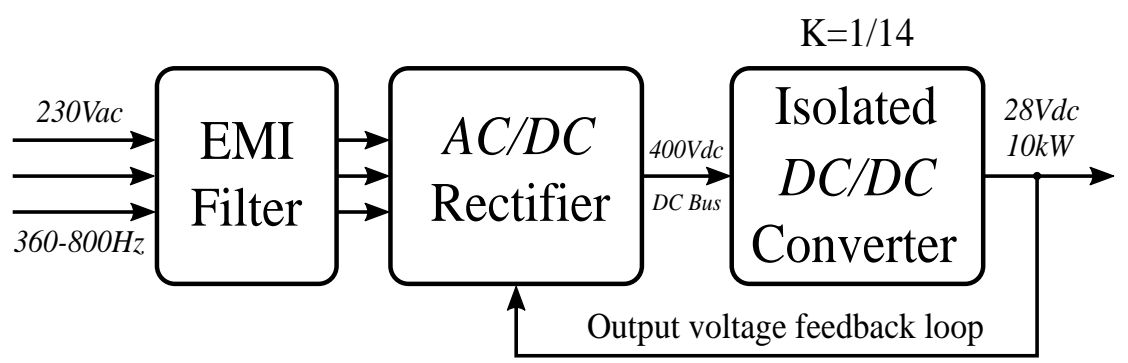

Figure 6.2: Aircraft isolated rectifier: Active solution

These passive solutions are very robust, as they consist only of passive components: inductors capacitors and transformers. The rectification of the $\mathrm{AC}$ power is carried out with diodes, so no control is required. However, the output voltage is not controlled.

New MEA rectifier unit designs are based on active solutions, as shown in Figure 6.2. These active systems usually consist of an EMI filter, an AC/DC rectifier and an isolated $\mathrm{DC} / \mathrm{DC}$ converter. One of the advantages of active solutions is the reduction of undesired harmonics in the $\mathrm{AC}$ grid, which will improve the life cycle of the AC generators, and can reduce the size of the input EMI filter. Additionally, active solutions will typically have higher efficiency and power density than passive solutions. Also, with the help of active switches, the frequency can be increased and the size and weight of magnetic components can be reduced. Nevertheless, these active solutions have also some drawbacks. The robustness of active solutions is reduced in comparison to their passive counterparts. Because they contain active switches with control circuits, the number of components is higher, which decreases the robustness. The robustness of the active systems can be improved by redundancy. However, this decreases the overall system power density.

The specifications of the isolated DC/DC converter are shown in Table 6.1. The input voltage is determined by the choice of input $\mathrm{AC} / \mathrm{DC}$ rectifier. With a Buck type rectifier with an $\mathrm{AC}$ input of $230 \mathrm{~V}_{a c}$, the bus voltage is rated at $400 \mathrm{~V}$. Using a 
Table 6.1: Isolated DC/DC specifications for AIR system

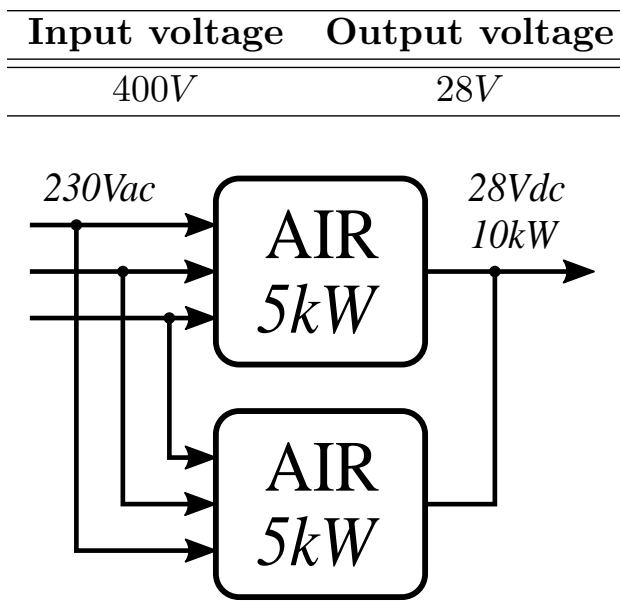

a)
Output power Output current

$10 \mathrm{~kW} \quad 360 \mathrm{~A}$

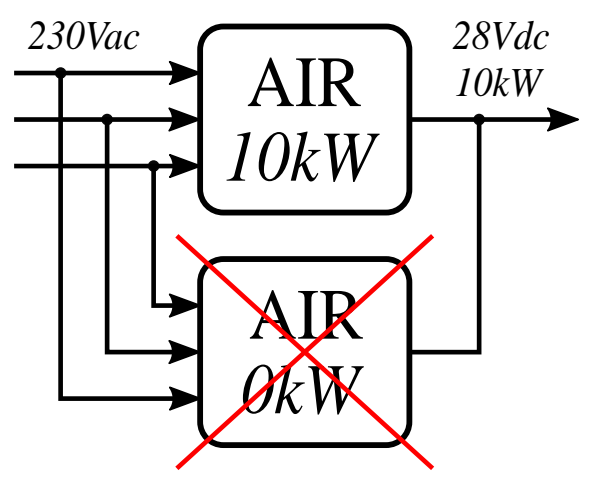

b)

Figure 6.3: System redundancy. a) Normal operation. b) Overload operation

Boost type rectifier, the $\mathrm{DC} / \mathrm{DC}$ converter input is then $800 \mathrm{~V}$. Using a Buck type rectifier the voltage is $400 \mathrm{~V}$ and using a boost type rectifier the voltage is $800 \mathrm{~V}$. The output voltage is $28 \mathrm{~V}$, which is the currents standard for DC power supply in aircraft loads. A new standard of $270 \mathrm{~V}$ is being discussed in MEA publications to decrease the weight of the copper wiring in the modern airplane by reducing the current at a higher voltage.

The maximum output power is $10 \mathrm{~kW}$. However, the nominal power of the system is $5 k W$, because this system is supposed to work in tandem, as depicted in Figure $6.3 \mathrm{a}$ ). In normal operation, the load is shared between the two units with $5 k W$ for each unit. In case of failure of one of the units, it can be isolated and the other one will deliver the full power, as depicted in Figure $6.3 \mathrm{~b}$ ). In this overload condition the power will be $10 \mathrm{~kW}$ for a single rectifier unit. Therefore, the system is required to withstand double the output power. However it must be optimized to operate at the nominal output power.

The prototype consists on three different parts: the input board, the transformers and the output board, as illustrated in Figure 6.4 and Figure 6.5 The auxiliary circuit is located on top the primary input board. A list of components for the prototype is shown in Table 6.2 . 
Table 6.2: List of prototype components

\begin{tabular}{cccc}
\hline Component & Reference & Type & Quantity \\
\hline \hline Input Capacitor & B32778G8606K & Film & 5 \\
Primary Transistors & IPW65R037C6 & Coolmos & 8 \\
Resonant Capacitor & C4532C0G2E473J320KA & Multilayer & 6 \\
C3225C0G2E103J160KA & Ceramic & 3 \\
Transformer & Planar E-core & Ferrite & 2 \\
$\quad$ Core & Copper Foil & 200 $\mu m$ & - \\
Transformer & & & \\
Winding & OPP10004S2L-03 & Optimos & 32 \\
Secondary & & Film & 12 \\
Transistors & B32774D4226J000 & Ferrite & 1 \\
Output & E65/32/27 & & \\
Capacitors & &
\end{tabular}




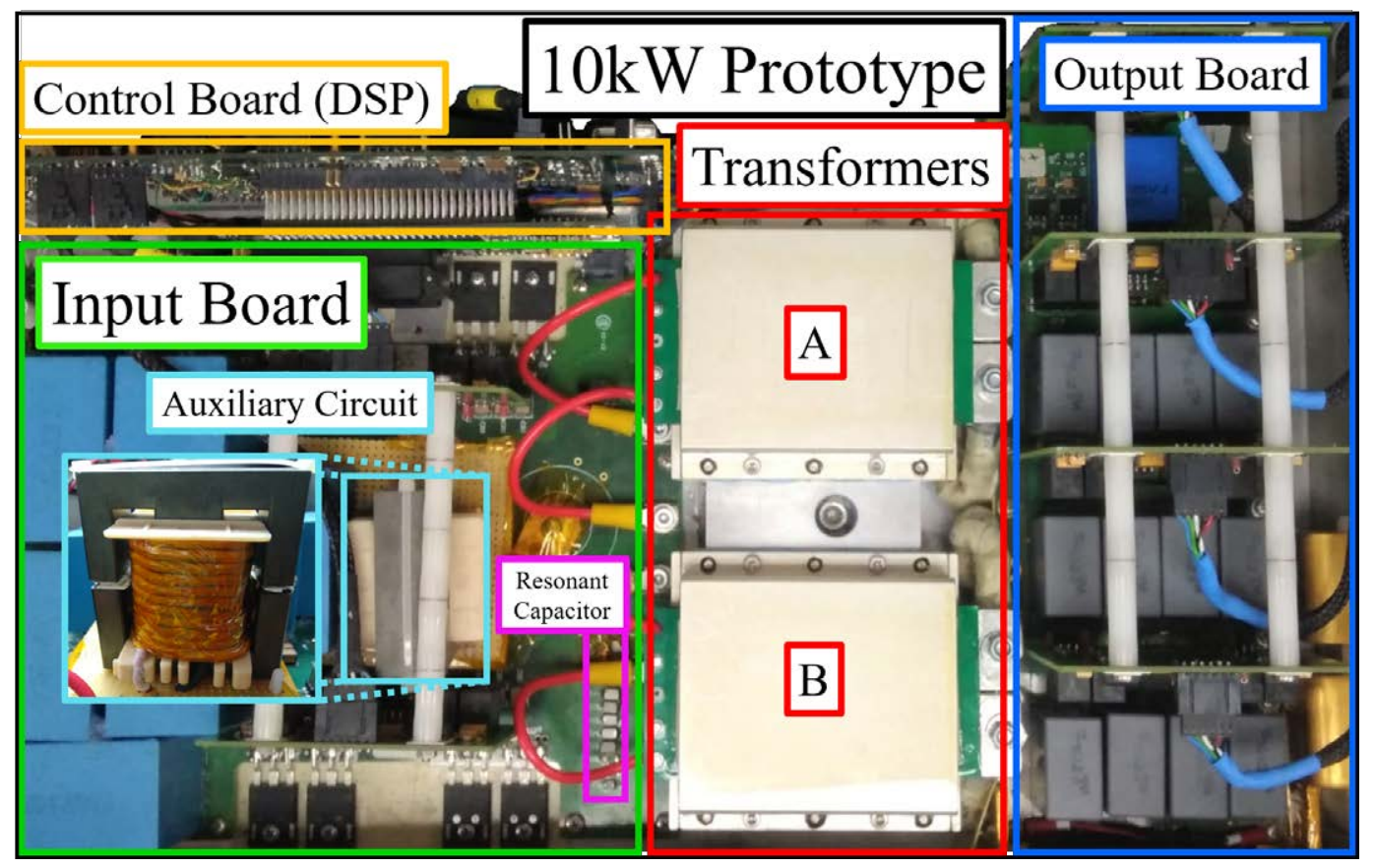

Figure 6.4: Prototype: $10 \mathrm{~kW}$ LLC converter operating at constant frequency with series parallel configuration

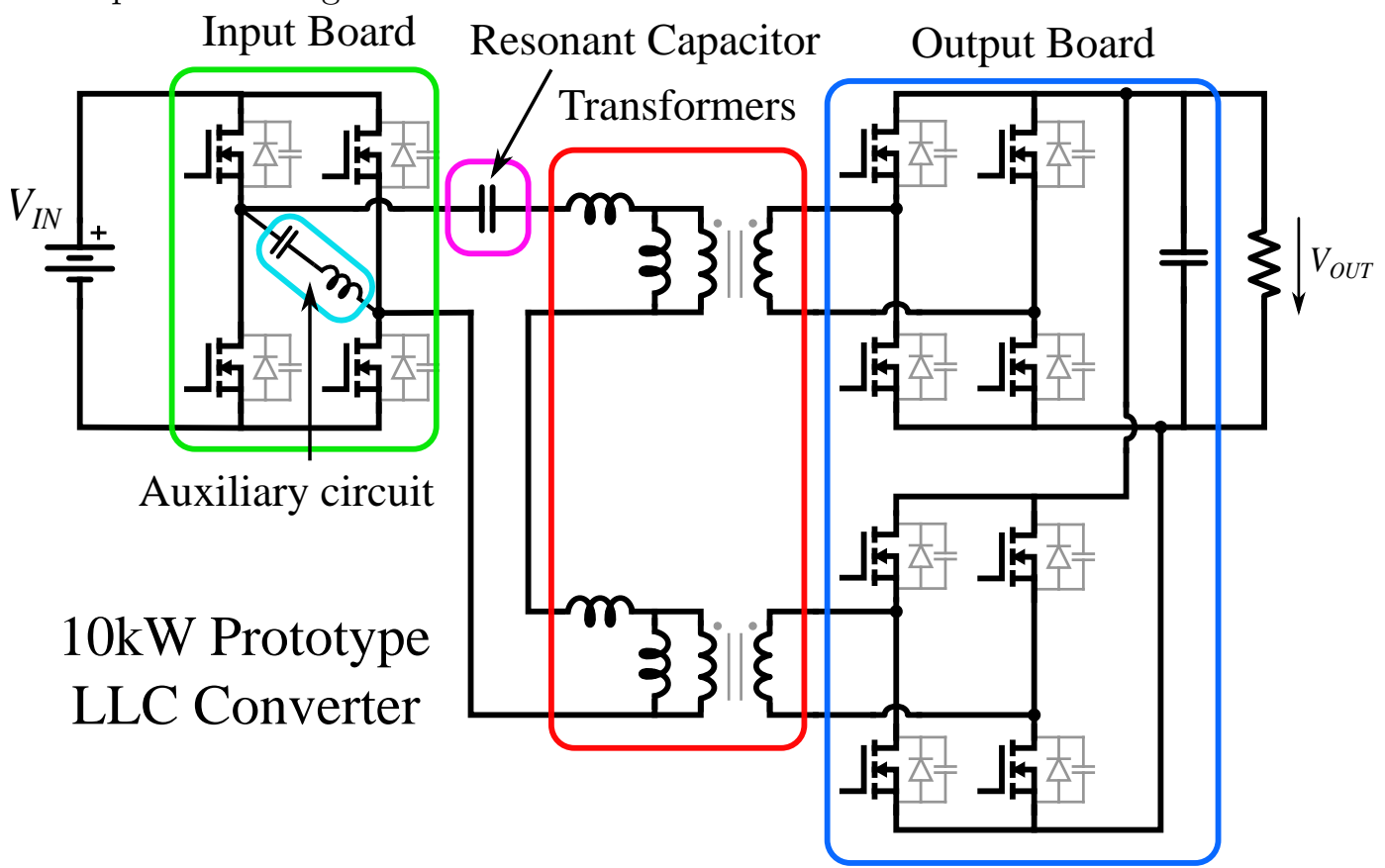

Figure 6.5: LLC converter operating at constant frequency with series parallel configuration 
Chapter 6. Experimental validation

In the following sections, some brief details of each components are going to be highlighted Possible improvement or modern substitute to improve the prototype will be proposed.

\subsubsection{Transistors}

This prototype was designed and built at the beginning of the year 2015 . In that year Gallium Nitride $(\mathrm{GaN})$ and Silicon Carbide $(\mathrm{SiC})$ were still emerging as competitors for traditional Silicon (Si) MOSFET. Both GaN and SiC devices have a clear improvement in switching losses over $\mathrm{Si}$ devices. However, in a soft-switched topology, like the LLC converter, this increase in performance is less visible. Additionally, the aircraft industry favors devices that have been proven with several thousand operating hours without issues, this is only true for $\mathrm{SiC}$ and $\mathrm{GaN}$ devices just recently [45]. For these reasons, the Silicon devices were chosen.

\subsubsection{Input bridge transistors}

The input bridge is the high voltage stage of the prototype. The nominal voltage is $400 \mathrm{~V}$. The devices are selected with a derating of $X \%$. Considering this, $650 \mathrm{~V}$ Coolmos $^{T M}$ generation $\mathrm{C} 6$ devices from Infineon were selected. These are Silicon MOSFET with a TO - 247 package. Two devices per switch are used, to dissipate a total of $19.25 \mathrm{~W}$ at the full load of $10 \mathrm{~kW}$.

As explained previously, these can be substituted with wide band-gap devices ( $\mathrm{GaN}$ or $\mathrm{SiC}$ ) to improve the prototype efficiency. However, new driving circuits will need to be designed. Keeping the Coolmos technology, they can be substituted by the new generation of $\mathrm{C} 7$ Coolmos.

\subsubsection{Output bridge transistors}

The output bridge has a voltage of $28 V_{d c}$, which is the standard in aviation for electrical loads. The transistors chosen are Optimos from Infineon 4 transitor per switch position and two independent bridge. The total number of equivalent parallel devices is 8 . This reduces significantly the conduction losses. The switching losses are reduced because ZCS is achieved and so is the reverse recovery, because of the softer turn-off slope. 


\subsection{Construction of prototype}

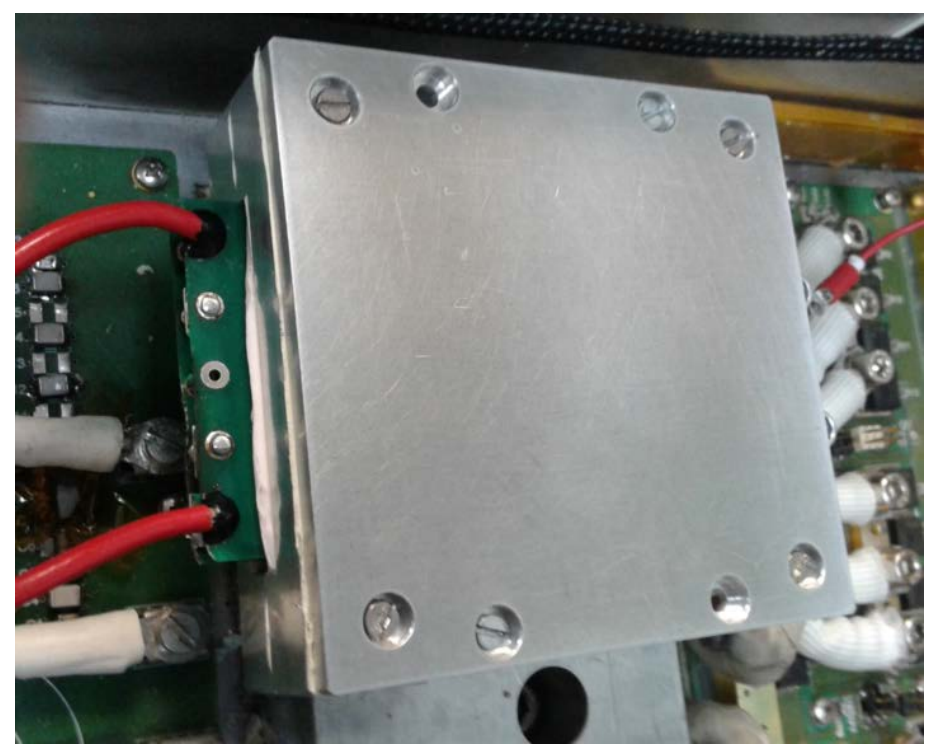

Figure 6.6: Transformer with heat-sink

\subsubsection{Magnetic components}

In order to have a trade-off between the switching losses and the conduction losses of the transistor the switching frequency was selected to be $100 \mathrm{kHz}$. At this frequency the optimum core material is ferrite. The ferrite material 3C95 [1] from Ferroxcube was chosen for all magnetic components of this prototype: the transformers and the auxiliary inductor. This material has lower losses than predecessors but also a flatter core loss vs. temperature curve, minimizing the thermal runaway effect. A improved version of the flat loss material is already available, the 3C97 material.

\subsubsection{Transformer}

The planar technology was used to design both transformers of the series/parallel configuration. The planar E-core E64/32/20 and a copper foil winding structure were used for this component. A heat-sink covering the whole planar component was installed to help with the heat dissipation and reduce the operating temperature, as depicted in Figure 6.6. 


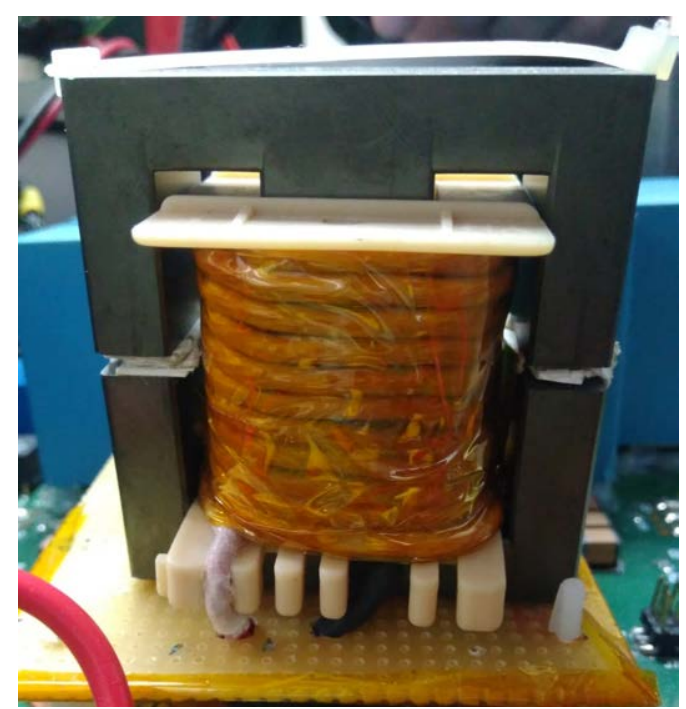

Figure 6.7: Auxiliary inductor

\subsubsection{Auxiliary circuit}

The auxiliary inductor is designed with a commercial ferrite E-core E65/32/27. The number of turns is 20 and with a gap of $6.37 \mathrm{~mm}$ the value of the inductance is $66 \mu \mathrm{H}$. With this value of inductance a ratio of $m=12.5$ is achieved.

The inductor is depicted in Figure 6.7.

Litz wire technology is used for the windings, to reduce the undesirable high frequency effects.

The capacitor selected for the prototype is not a MLCC, as proposed in section 4.4.3. An over-sized design of the film capacitor technology was selected for robustness. The same capacitor technology as the input capacitor was used.

\subsubsection{Capacitors}

In airborne converter, the use of electrolytic capacitor is forbidden. Their failure mode is typically short circuit and involves explosive behavior, which is not desirable in aircraft environments, where critical systems are in close proximity because of space issues. Electrolytic capacitors have also faster degrading rates because of out-gassing, especially in the extreme environments of an aircraft. Therefore, the two technologies used for the prototype are: film capacitors and ceramic multilayer capacitors: Film capacitor have self healing capabilities and their failure mode is 


\subsection{Construction of prototype}

in open circuit, which adds to the robustness of the system. Multilayer ceramic capacitors MLCC have improved characteristics over the film capacitors in their overlap regions, as explained in [34]. However, multilayer capacitor are sensitive to changes in their capacitance with temperature, especially the X7R technology. For this reason, the much more stable C0G technology is used

\subsubsection{Resonant capacitor}

The resonant capacitor is designed to resonate with the leakage inductance of the two series parallel transformers. The total leakage inductance of primary side and all parasitics added are equal to $7 u H$. The resonant frequency is selected to be $100 \mathrm{kHz}$. Therefore, the resonant capacitor is $349 \mathrm{nF}$. The multi-layer ceramic capacitor technology is used. COG material is used to avoid the issue of capacitance stability with temperature.

The peak RMS current that the capacitors withstand is $31 A$. In order to handle this current several capacitor are placed in parallel. Seven capacitors with $47 n F$ and two capacitors with $10 n F$ are used for a total of $349 n F$. With this value the resonant frequency is $101 \mathrm{kHz}$

\subsubsection{Input and output capacitors}

The film capacitor technology is used for both input and output capacitors. The input capacitor design is limited by the total ripple desired in the DC bus. However, the output capacitor design is limited by losses.

\subsubsection{Heat-sink}

A forced air cooled Aluminum heat-sink was selected to dissipate the power losses of the primary and secondary bridge MOSFET , as well as the transformer power losses. The Aluminum material is used instead of copper for two main reasons: Aluminum is lighter than Copper, which is desirable for aircraft applications, in which volume is a greatly restricted by specification. Additionally, Aluminum forms a protective oxide while copper oxides do not offer such protective behavior, this is specially critical in aircraft systems, where the environmental conditions can be harsh. 
Chapter 6. Experimental validation

Table 6.3: Prototype normalized parameters

\begin{tabular}{cccccccc}
\hline$Q(500 W)$ & $Q(5 k W)$ & $Q(10 k W)$ & $Q_{S}$ & $m$ & $m_{x}$ & $f_{n}$ & $f_{n x}$ \\
\hline \hline 0.02 & 0.18 & 0.36 & 7.5 & 215 & 12.5 & 0.99 & 0.023 \\
\hline
\end{tabular}

Table 6.4: Prototype parameters

\begin{tabular}{cccccccc}
\hline$L_{r}$ & $C_{r}$ & $L_{m}$ & $L_{x}$ & $C_{x}$ & $R_{s}$ & $f_{r}$ & $f_{s}$ \\
\hline \hline $7.11 \mu H$ & $349 n F$ & $2 \times 750 \mu H$ & $60 \mu F$ & $602 m \Omega$ & $102 k H z$ & $101 k H z$ & 0.023 \\
\hline
\end{tabular}

\subsubsection{Drivers}

The MOSFET driver circuits are all isolated. To drive the high-side transistor of the full-bridge leg isolation is required in order to correctly reference the driving signal to the middle point, which has a pulsating voltage. The UCC21520 driver chip from texas instrument is used, which includes two isolated outputs.

\subsubsection{Control board}

To generate the transistors PWM signals, a digital controller is used. The selected processor is the TMS320F28379D Dual-Core Delfino from Texas instruments [58]. A control board is built with additional circuitry to implement hardware protections in the form of logical NAND gates.

Two ADC converters from the TMS320F28379D are used to measure the input voltage and output voltage. Additionally, over-voltage and under-voltage protections are implemented to test the converter while protecting the integrity of the converter.

The transistors PWM signals are implement with a 300ns hardware delay between them, to allow time for the ZVS transition to be completed.

\subsection{Experimental results}

In this section, the experimental results of the prototype will be reviewed. The prototype parameters can be found in Table 6.3 and Table 6.4.

A breakdown of the volume in Figure 6.8. The total Volume of the prototype is $4.2 \mathrm{dm}^{2}$. Two thirds of the prototype volume consists of the heat-sink for primary and secondary transistors. There is still room for improvement in terms of power density, as this is only a demonstrator prototype. 


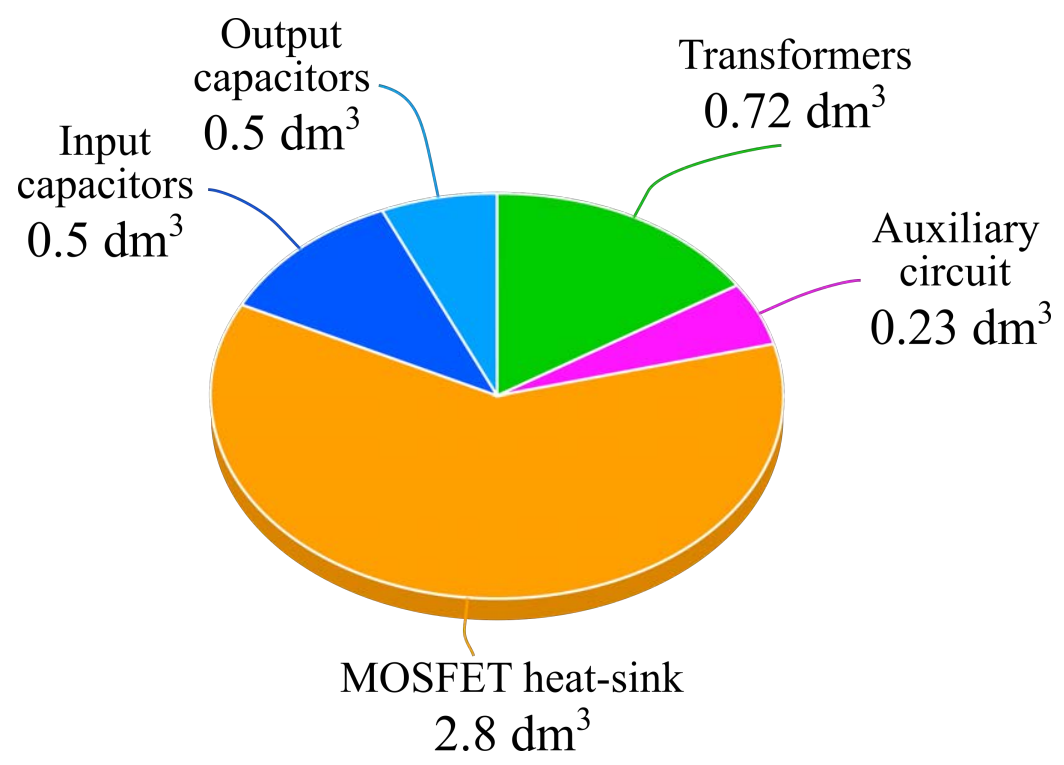

Figure 6.8: Volume breakdown of the prototype

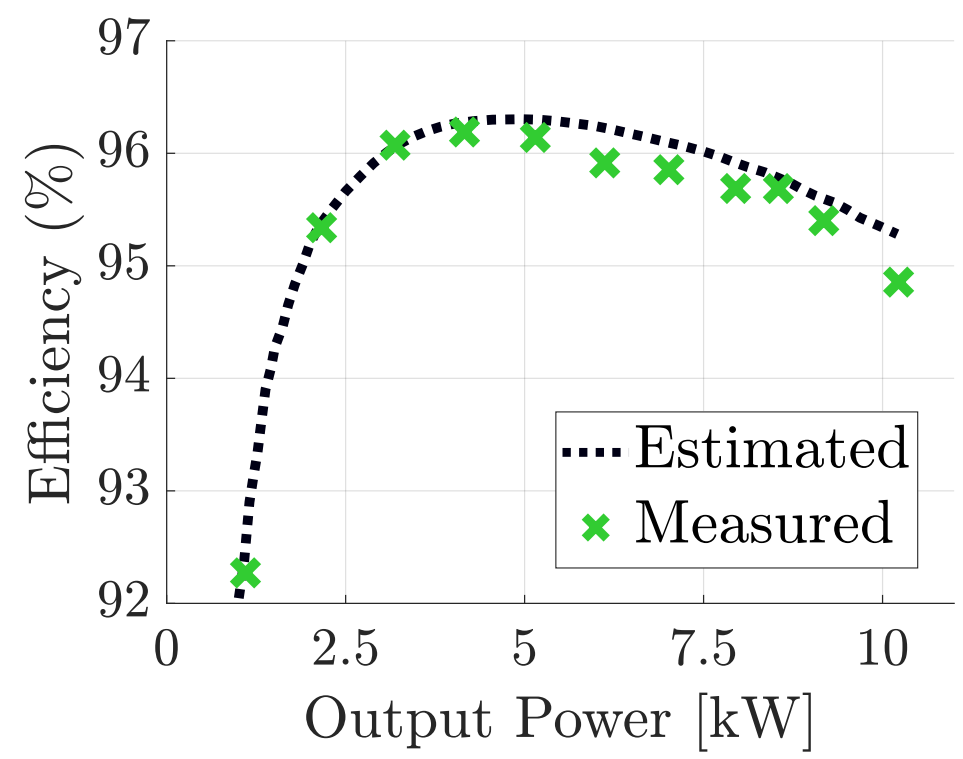

Figure 6.9: Experimental results: Efficiency at different output powers with auxiliary circuit 


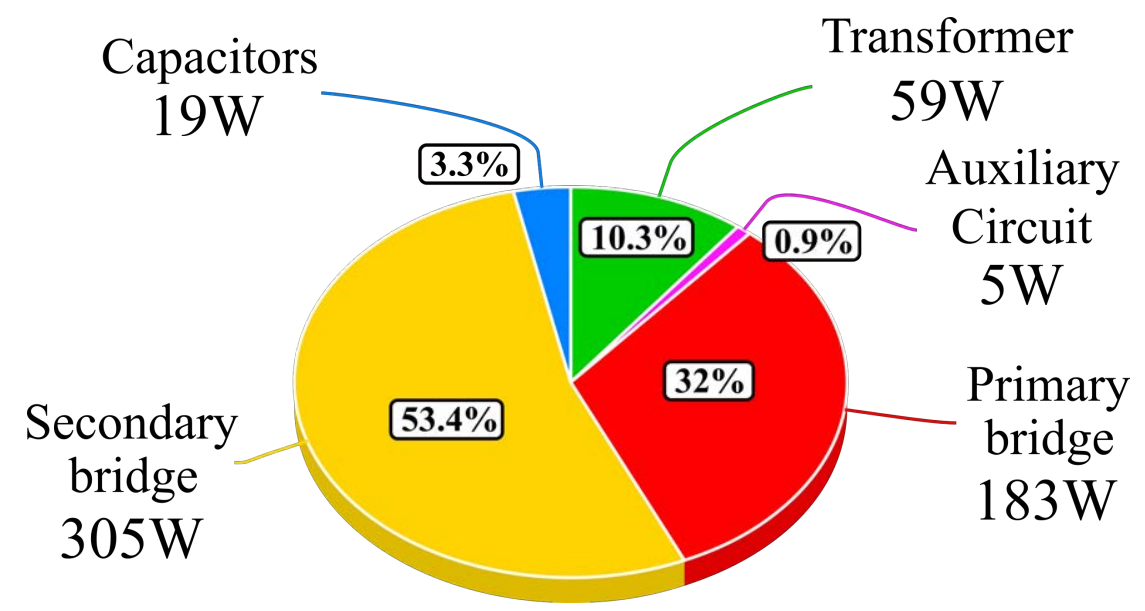

Figure 6.10: Prototype breakdown of power losses

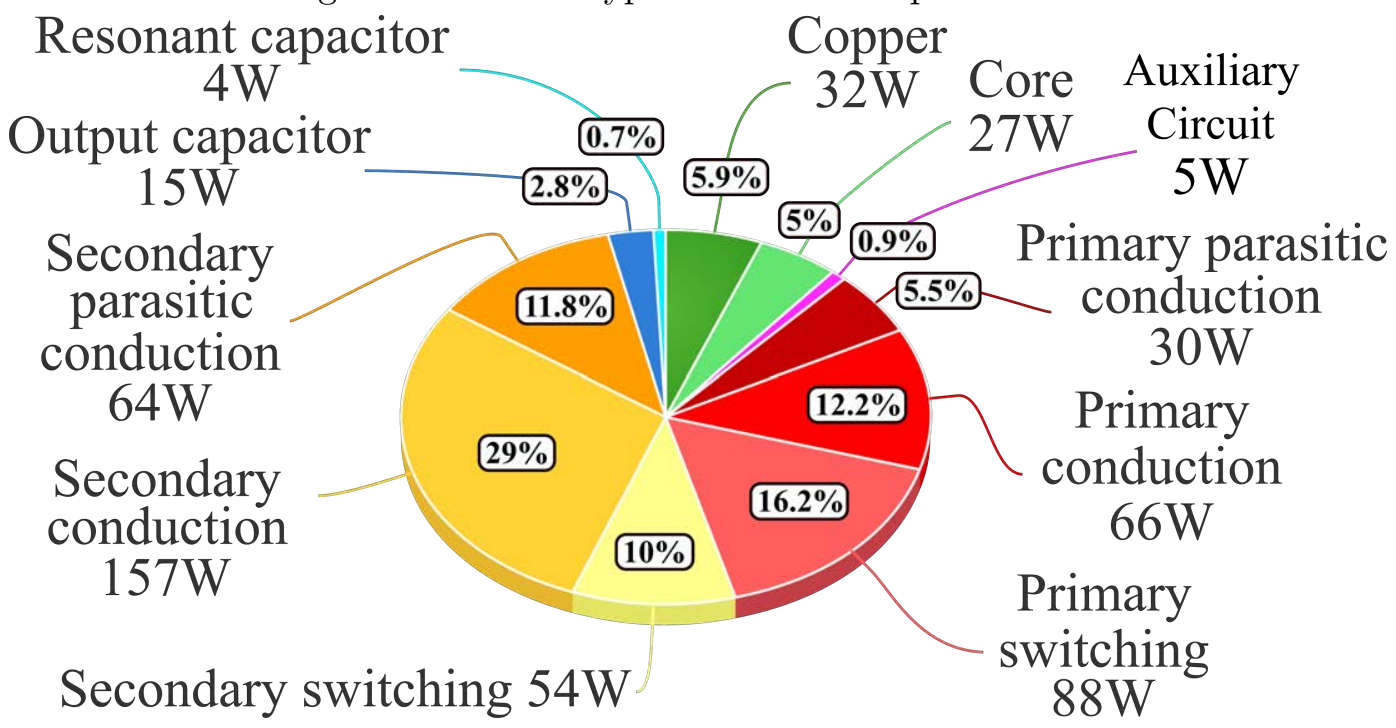

Figure 6.11: Prototype detailed breakdown of power losses 


\subsection{Experimental results}

The efficiency of the converter between $1 k W$ and $10 k W$ is depicted in Figure 6.9. The peak efficiency is achieved at $4 k W$ with $96.37 \%$ efficiency. At the nominal power of $5 \mathrm{~kW}$ the efficiency is $96.2 \%$, and at the overload condition of $10 \mathrm{~kW}$ the efficiency drop to $94.96 \%$. At the overload condition the measured efficiency has a higher mismatch with the estimated values. This is caused by an the temperature increase with higher power, this in turn, increases the parasitic resistance of all prototype internal wires and connections.

The breakdown of power loss is presented in Figure 6.10 and Figure 6.11 in more detail. It can be noted that the transistor lossses, including primary and secondary devices are dominant. In particular, the secondary bridge has high current $(400 A)$ and therefore the losses are over $50 \%$ of the total prototype power losses. It can also be noted that $16 \%$ of the total power losses is generated because of the parasitic resistance of the connections of both primary and secondary side, including the transformer connection to the primary and secondary power boards.

\subsubsection{Voltage gain verification}

The voltage gain was measured at different loads and compared with the proposed series resistance SR-FHA model from section 3.3.2 in Chapter 3 of this work. This series resistance model (SR-FHA) is used instead of the distributed impedance model (DI-FHA) because the inductance ratio of the converter is high $(m=215)$ and, as explained in Chapter 3, in high inductance ratio LLC converters, the SR-FHA model is accurate. The comparison between model and the measured values is shown in Figure 6.12.

There is a good match between the estimated value of the SR-FHA analytical equation and the measured value. However, close to the maximum output power $(10 k W)$ the mismatch increases. The source of this error is the incorrect approximation of the resistances of the parasitics. With high power, the temperature of the internal wires and connections increases and therefore the parasitic approximation done is not valid. This can be corrected by measuring the temperature. 


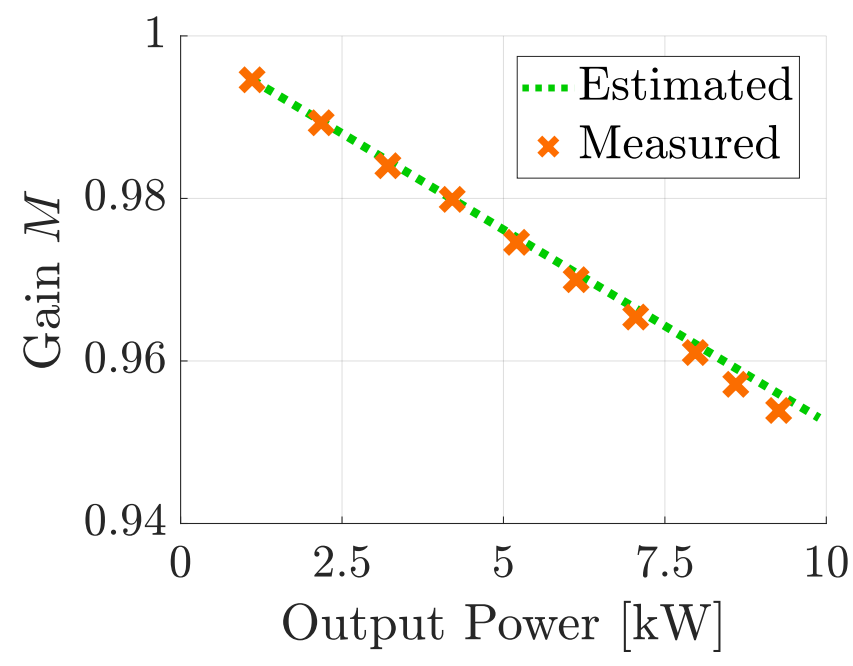

Figure 6.12: Voltage Gain Estimation and experimental results

\subsubsection{ZVS transition experimental results and auxiliary circuit}

To validate the auxiliary circuit operation the ZVS transition has to be observed in detailed. Two currents and two voltages are measured: the resonant tank current $i_{r}$, the auxiliary current $i_{x}$, the drain-source voltage $v_{d s}$ and gate-source voltages $v_{g s}$ of a low side transistor of the input bridge, as depicted in Figure 6.13. The additional current $i_{M}$ is inferred by mathematical calculation using the oscilloscope mathematical channel. The measurement of this current is not possible as the current probe does not fit in the connection.

The charge coefficient $k_{q}$ is calculated at three different output powers $(500 W, 5 k W, 10 k W)$. This charge coefficient is the ratio between the real charge of the turn-off current during the transition and a hypothetical constant turn-off current with the same initial value, as explained in section ??. The results are $k_{q}=0.91, k_{q}=0.66$ and $k_{q}=0.51$

Additionally, it is also interesting to analyze the behavior of the converter without auxiliary circuit, to verify that improvement in efficiency and noise of the auxiliary circuit. In Figure 6.17, the behavior of the converter without auxiliary circuit is shown at $5 k W$. Figure 6.18 , shows a zoom of the voltage transition at the same power of $5 \mathrm{~kW}$. 


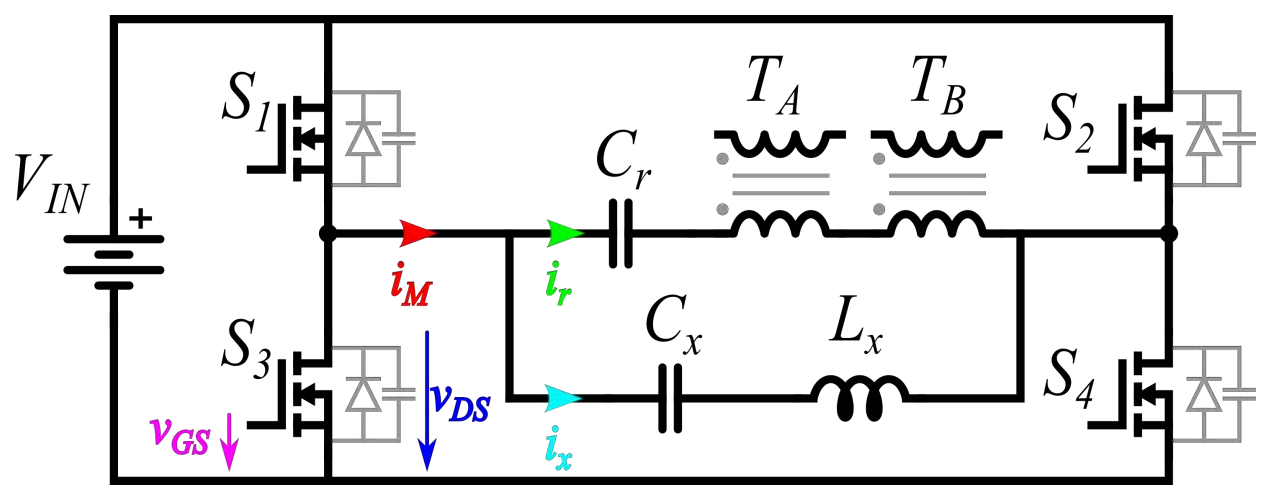

Figure 6.13: ZVS transition experimental measurement set-up

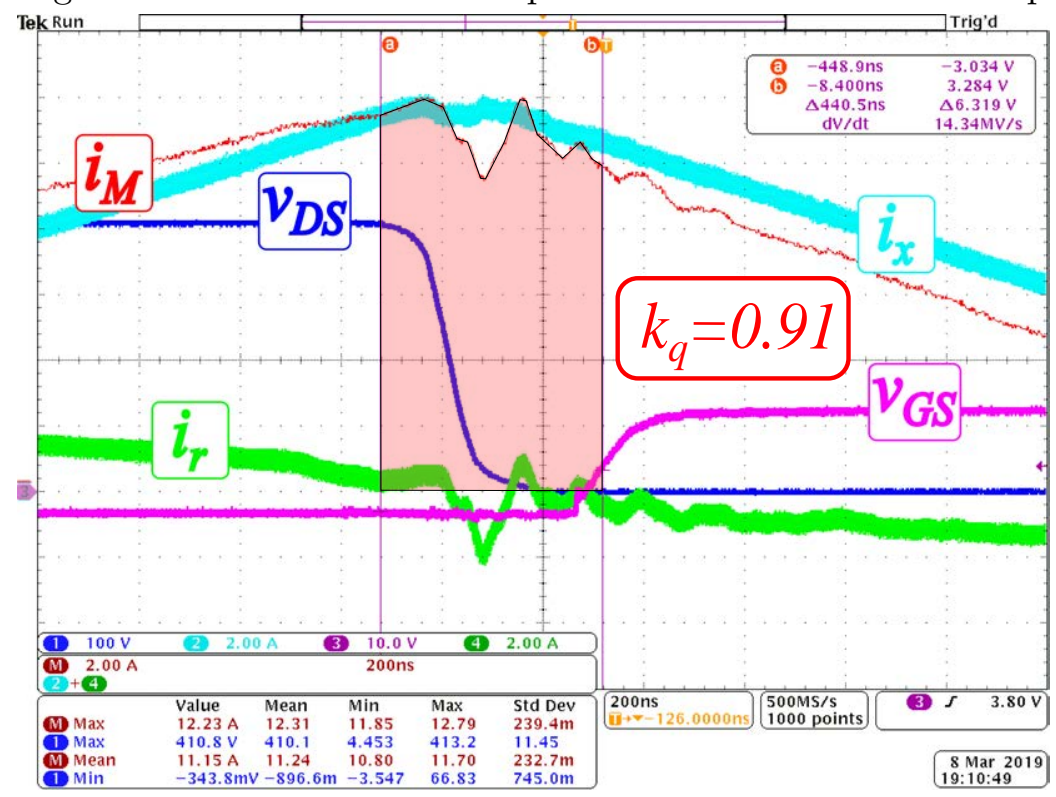

Figure 6.14: ZVS transition experimental results of the $m=215$ LLC converter with auxiliary circuit at $500 \mathrm{~W}$. Low-side MOSFET Drain/source voltage (Ch1 in blue, $100 \mathrm{~V} /$ div), auxiliary circuit current (Ch2 in cyan, 5A/div), low-side MOSFET Gate/Source voltage (Ch3 in magenta, 25V/div), resonant current (Ch4 in green, $5 A /$ div $)$ 


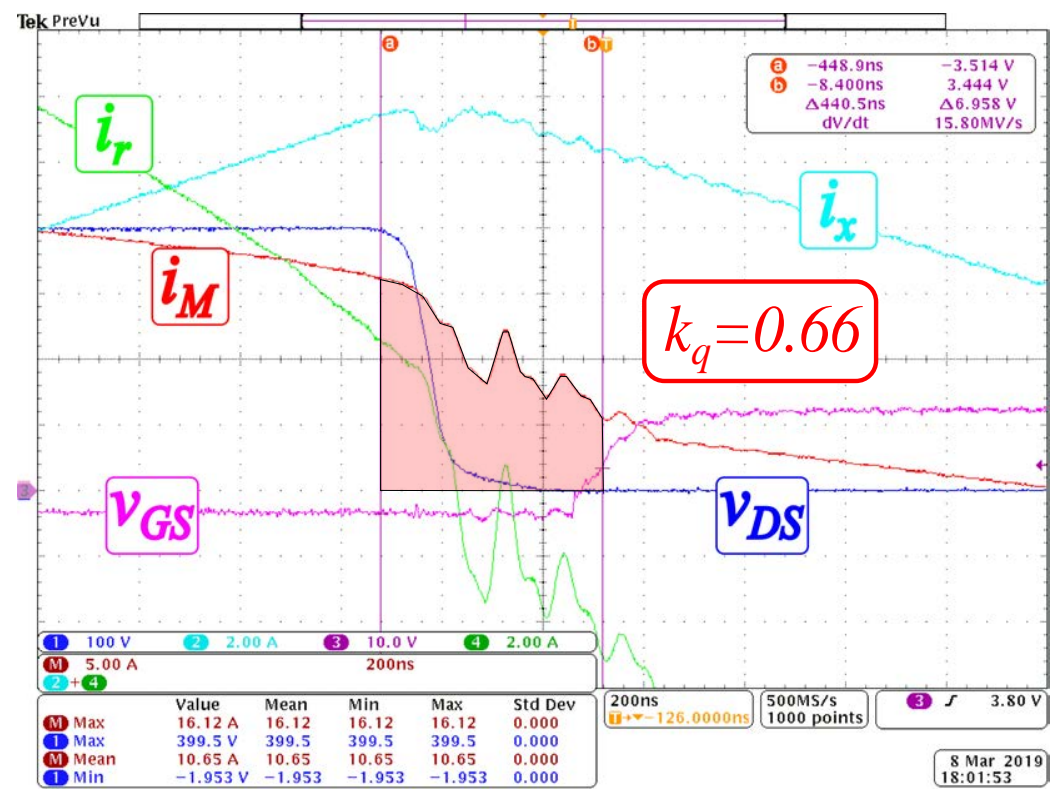

Figure 6.15: ZVS transition experimental results of the $m=215$ LLC converter with auxiliary circuit at $5 \mathrm{~kW}$. Low-side MOSFET Drain/source voltage (Ch1 in blue, $100 \mathrm{~V} /$ div ), auxiliary circuit current (Ch2 in cyan, $5 \mathrm{~A} / \mathrm{div}$ ), low-side MOSFET Gate/Source voltage (Ch3 in magenta, $25 \mathrm{~V} / \mathrm{div})$, resonant current (Ch4 in green, $5 A / d i v)$

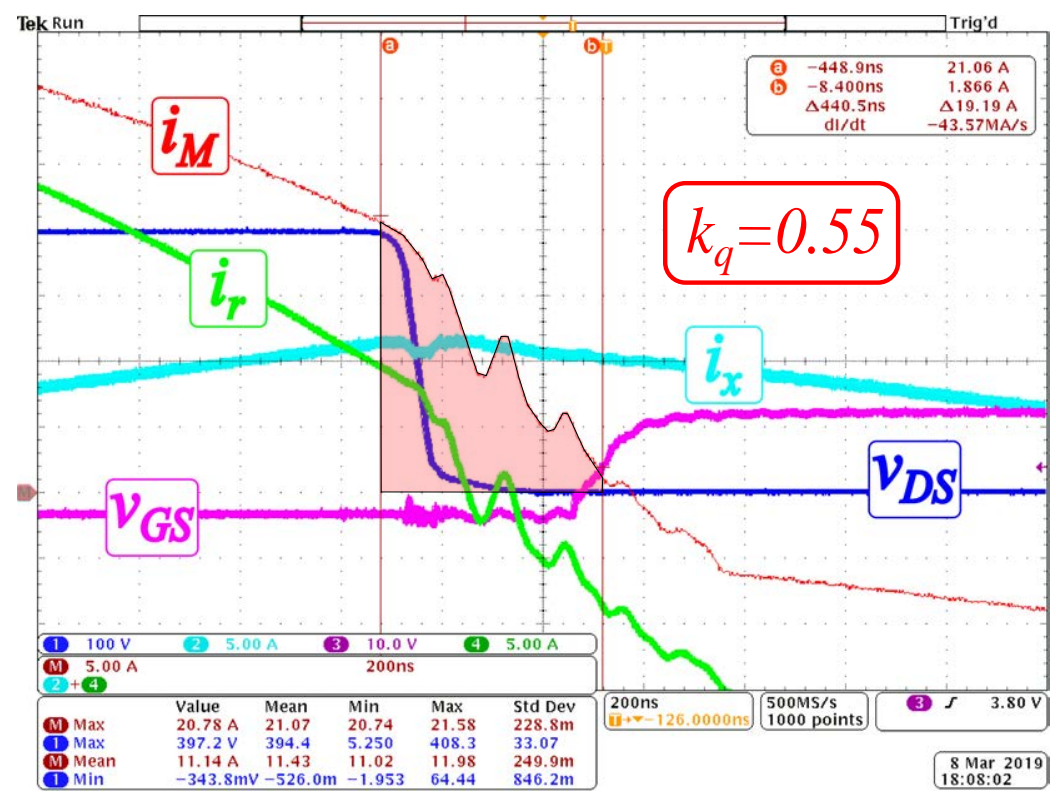

Figure 6.16: ZVS transition experimental results of the $m=215$ LLC converter with auxiliary circuit at $10 \mathrm{~kW}$. Low-side MOSFET Drain/source voltage (Ch1 in blue, $100 \mathrm{~V} / \mathrm{div}$ ), auxiliary circuit current (Ch2 in cyan, $5 \mathrm{~A} / \mathrm{div}$ ), low-side MOSFET Gate/Source voltage (Ch3 in magenta, $25 \mathrm{~V} /$ div), resonant current (Ch4 in green, 54 (S) 


\subsection{Experimental results}

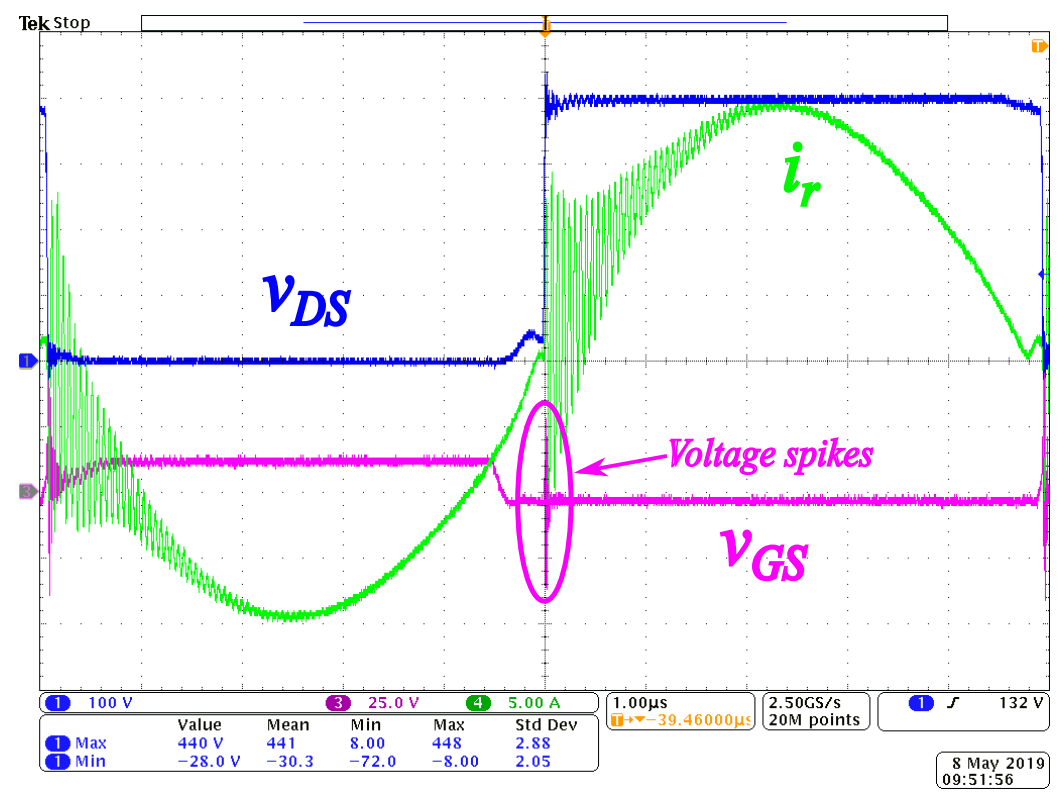

Figure 6.17: ZVS transition experimental results of the $m=215$ LLC converter without auxiliary circuit at $5 k W$. Low-side MOSFET Drain/source voltage (Ch1 in blue, $100 \mathrm{~V} /$ div), Low-side MOSFET Gate/Source voltage (Ch3 in magenta, $25 \mathrm{~V} /$ div), Resonant current (Ch4 in green, $5 \mathrm{~A} / \mathrm{div}$ )

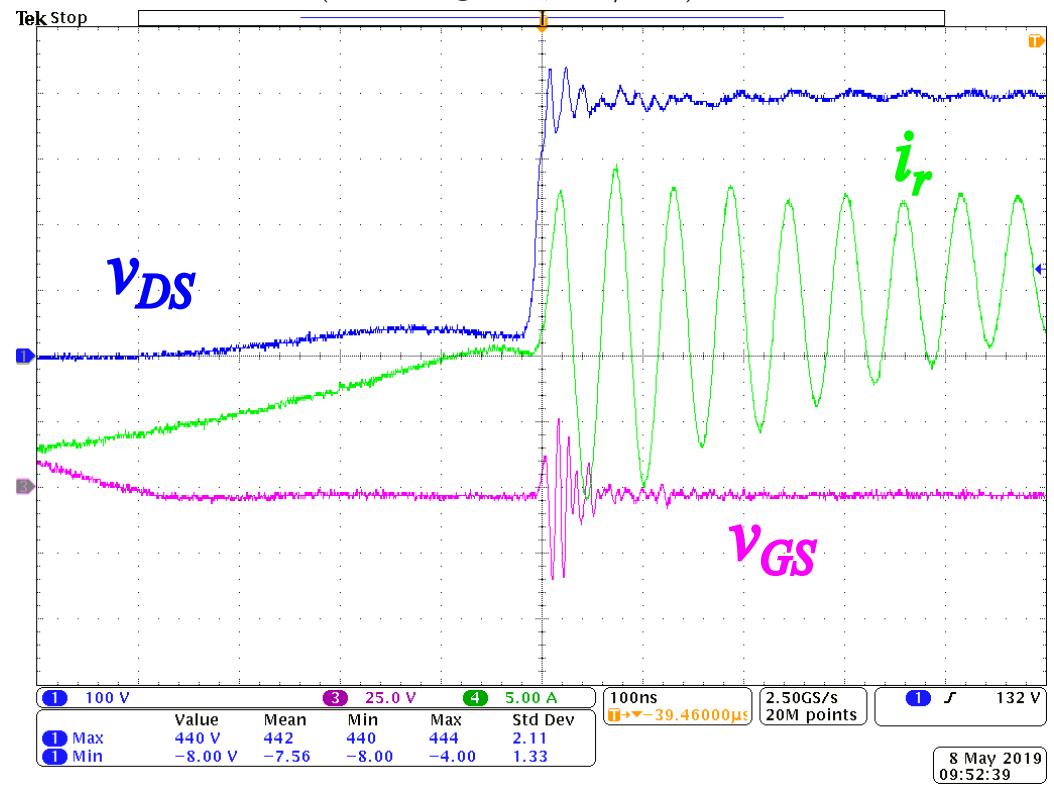

Figure 6.18: Experimental results of $m=215$ LLC converter without auxiliary circuit at $5 \mathrm{~kW}$. Low-side MOSFET Drain/source voltage (Ch1 in blue, 100V/div), Low-side MOSFET Gate/Source voltage (Ch3 in magenta, 25V/div), Resonant current (Ch4 in green, $5 \mathrm{~A} / \mathrm{div}$ ) 
Chapter 6. Experimental validation

Without the auxiliary circuit, the magnetizing current of the forward type transformer is not enough to achieve a full ZVS transition. The charge/discharge of the $C_{o s s}$ of the transistors is incomplete, as illustrated in Figure 6.18, where a zoom of the transition is shown. A voltage spike of $430 \mathrm{~V}$ of maximum voltage on the Drain/Source voltage appears because of the incomplete ZVS hard switching. This voltage spike is not high enough to break the devices. However, because of the high voltage derivative and the noise generated, a resonance is created in the series tank current $i_{r}$, shown in green in Figure 6.18. This generates additional conduction losses in the transistors and the primary of the transformer. This reduces the efficiency, as it will be seen in the next section.

Additionally, a spike in the Gate/Source signal is induced because of the previously mentioned noise. This voltage increases with the output power. At higher powers it can turn on the transistor and create a short-circuit, that will damage the primary devices.

\subsubsection{Performance at different loads}

Experimental waveforms are shown at the nominal load $(5 k W)$ in Figure 6.20, and at the maximum load $(10 \mathrm{~kW})$ are shown in Figure 6.21. The two secondary resonant currents currents are shown with inverted polarity to check the current sharing balance. At $10 \mathrm{~kW}$, the maximum mismatch between the two tranformer secondary current is less than $5 \%$.

As explained in the ZVS section, the auxiliary circuit purpose is to improve the efficiency by increasing the range of ZVS. The comparison of efficiency of the prototype with and without auxiliary circuit is shown in Figure 6.19. The efficiency is improved by 3 percentage points at $5 k W$ and by 20 percentage points at $1 k W$. The incomplete ZVS related losses are constant with different output powers, so the improvement is higher at lower output powers. The experimental results without auxiliary circuit are stopped at the nominal power of $5 k W$ to ensure the safe operation of the converter, as the voltage spikes in the gate source voltage increase with the output power. Operation at $10 \mathrm{~kW}$ without auxiliary circuit is not verified, however the estimated efficiency is still less than with the auxiliary circuit. 


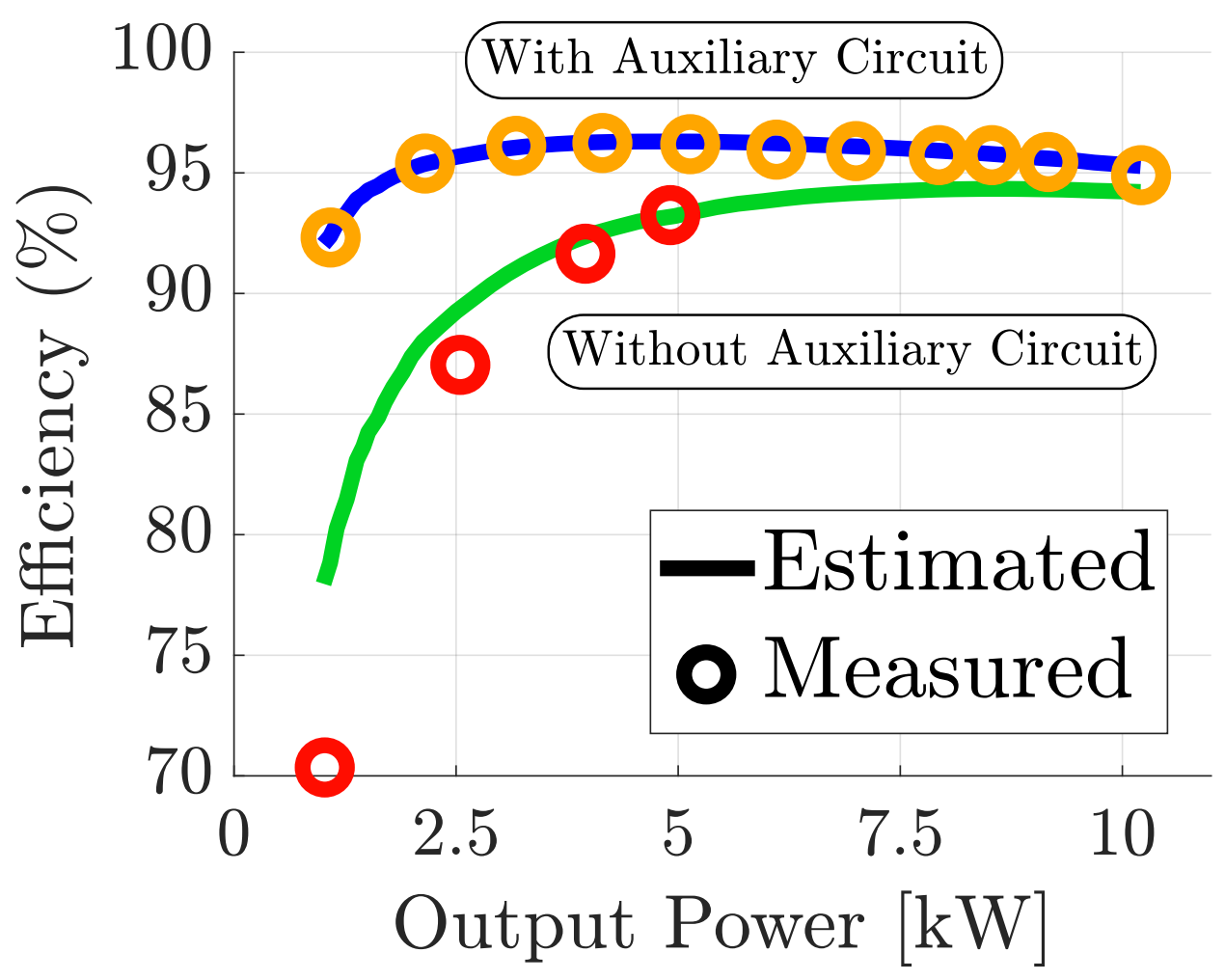

Figure 6.19: Experimental results: Comparison of efficiency at different output powers with and without auxiliary circuit 


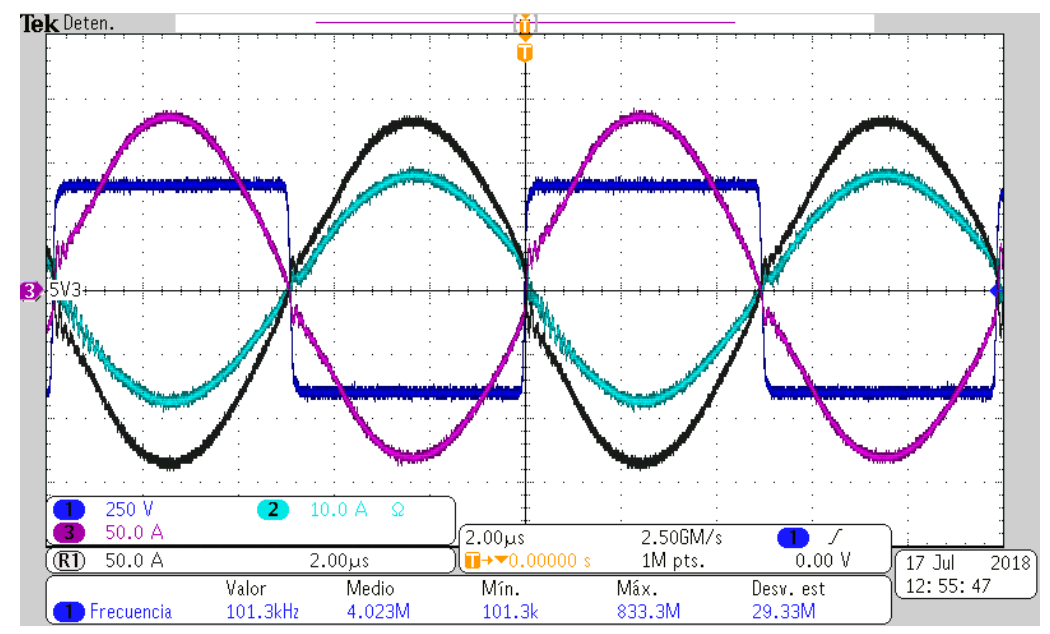

Figure 6.20: Experimental results at $5 k W$, with auxiliary circuit . Input bridge voltage, between middle points (Ch1 in blue, 250V/div), input resonant current (Ch2 in cyan, 10A/div), Secondary resonant current A (Ch3 in magenta, 10A/div), Secondary resonant current B (R1 in black, 10A/div)

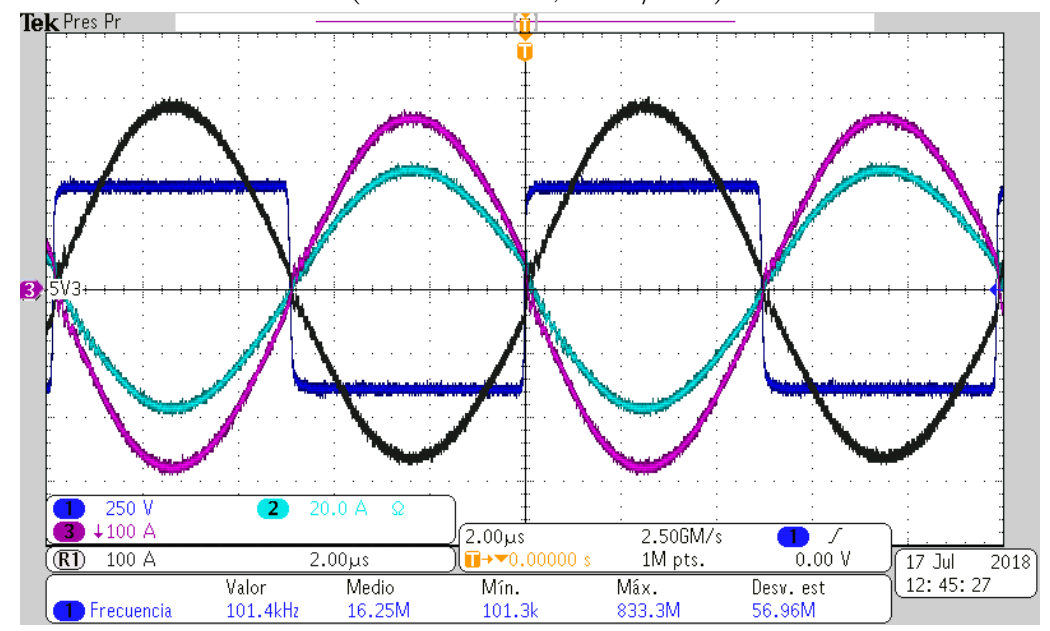

Figure 6.21: Experimental results at $10 \mathrm{~kW}$, with auxiliary circuit . Input bridge voltage, between middle points (Ch1 in blue, $250 \mathrm{~V} / \mathrm{div}$ ), input resonant current (Ch2 in cyan, 10A/div), Secondary resonant current A (Ch3 in magenta, 10A/div), Secondary resonant current B (R1 in black, 10A/div) 


\subsubsection{Experimental results: conclusions}

The experimental results show that the LLC converter operating at constant frequency is an adequate solution for high power conversion. The efficiency is higher than $95 \%$ in the range of $2.5 \mathrm{~kW}$ to $9.5 \mathrm{~kW}$. The full ZVS transition is achieved with the addition of the auxiliary circuit. The efficiency is also improved with the auxiliary circuit by eliminating the non-ZVS related power losses. The current sharing between the two transformers is verified without current measurement or control loop. 

Chapter 7

\section{Conclusion and future work}

\subsection{Conclusion and contributions}

The LLC converter is already a proven topology of the state of the art for high power application where high power density requirements. The soft switching nature of the topology allows for reduced losses even at high frequency, where the size of the magnetic components can also be reduced.

This work concludes that the maximum efficiency of the LLC converter is achieved in operation at resonant frequency. For this reason, the LLC converter operating at resonant frequency is adequate for DC transformer operation. It can operate at resonant frequency without regulation because the voltage gain is almost constant at $M=1$.

However, the parasitics need to be considered in the voltage gain analysis, in particular for unregulated LLC topologies operating at resonant frequency, to accurately account for the small variations in the voltage. The conventional first harmonic approximation (FHA) is not accurate enough to consider this effect. The first original contribution of this work is the analysis and comparison of voltage gain models for the LLC converter and their ranges of accuracy at different operating modes of the LLC converter. Both analytical FHA based models and simulated models were compared. Two modified FHA models were considered: the SR-FHA with added series resistance and the DI-FHA with added resistance and distributed impedance, and also their time based (TB) simulated models counterparts, SR-TB and DI-TB.

In operation close to resonant frequency, the analytical models are as accurate as the time-based ones. While the SR-FHA is accurate only for low inductance ratio $m$, the DI-FHA remains accurate even for low inductance values, were the gain is greatly influenced by the distribution of the impedances. In operation below and 
above resonant frequency the analytical models are increasingly less accurate, the farther the switching frequency is from the resonant frequency. In those cases, the time-based simulated models the only accurate models. Nevertheless, the simulated models are time consuming.

A full ZVS transition is desired in most power converters, as it reduces the switching losses and the issues related with high voltage derivatives and emitted noise. LLC converters are capable of achieving a full ZVS transition over the full load range by selecting the correct frequency of operation. However, in LLC operating at resonant frequency this is not possible. The use of gapped transformers is typically required to increase the magnetizing circulating current needed to achieve the full ZVS transition. These gapped transformers decrease the power density and efficiency of the converter. In order to maintain the benefits of ZVS while using a forward type transformer an auxiliary circuit can be used. With the auxiliary circuit the necessary inductive energy can be generated outside the transformer. This improves the transformer design, decoupling the issue of ZVS and the transformer design. The second original contribution of this thesis is the analysis of different ZVS auxiliary circuit and a proposed ZVS auxiliary circuit with a single inductor passive solution.

The single inductor active solution (Circuit D) achieves the lowest additional volume but at the cost of additional losses, especially when using Si devices. The LCL resonant single inductor solution (Circuit C) has the highest losses and therefore is not a good candidate for high power converters. The best solution overall is the double inductor solution (Circuit B) with the lowest volume and the lowest power losses, because the auxiliary capacitor do not carry current. The proposed single inductor solution with series capacitor only $10 \%$ more losses than the optimal solution: the double inductor solution. Nevertheless, the proposed single inductor circuit is a more simple solution with less components and requires only a two connections, reducing the parasitics on the input board of the converter. When comparing the total volume of the gapped transformer solution and the forward type transformer with additional ZVS auxiliary circuit (Circuit A) the losses are reduced by $42 \%$ from $87 \mathrm{~W}$ to $49.8 \mathrm{~W}$ and the volume is reduced by $33 \%$ from $0.74 d m^{3}$ to $0.49 \mathrm{dm}^{3}$. 


\subsection{Future work}

The design and optimization of a high voltage ratio and high output LLC converter operating at frequency is a complex problem. As the third and final original contribution of this work, a multi-objetive optimization methodology was presented using models from the state of the art and considering different technologies for the transistors, magnetics, capacitors; and different series/parallel configurations for the transformers. Accurate thermal models are also considered in the multi-objective optimization methodology. Thermal models are critical to achieve the highest power density, as the volume and thermal resistance are inversely correlated. Therefore, to push the limits of the thermal behaviour of components, accurate thermal models are required. As conclusion, the series/parallel configuration helps to increase the efficiency and power density of the overall converter, by spreading the losses and allowing an optimized transformer design.

Finally, a $10 \mathrm{~kW}$ prototype was designed and built to experimentally verify the proposed models and the auxiliary circuit. The prototype uses a series/parallel configuration with two transformers. This prototype achieves a maximum efficiency of $96.37 \%$ at $4 k W$, and an efficiency of $94.96 \%$ at the maximum power of $10 k W$ and its total volume is $4.55 \mathrm{dm}^{3}$.

\subsection{Future work}

To complete the scope of the research work carried out with this Thesis, several task can be done as future work.

- Consider integrated magnetic for the design and optimization: A proven state of the art topology for LLC converters is the matrix transformer solution, in which multiple series/parallel transformer can be integrated in a single component, canceling fluxes and therefore reducing the core volume required. Matrix converter solutions have been developed in the range of $1 \mathrm{~kW}$. To consider this topology in the range of $10 \mathrm{~kW}$, the thermal behaviour of the matrix transformers at this output power needs to be explored. AS the matrix component volume is reduced, there is a challenge to keep the component temperature low while increasing the power density. 
- Including additional parasitics in the modified FHA models, like the parasitic capacitance of transformers: Planar transformer were used in the prototype of this work. The planar technology has improved thermal behavior and improved performances over regular configurations for high frequency power transformers. However, a drawback of this technology is the increased parasitic capacitances of planar components. It is possible for these parasitics to influence in the voltage gain analysis of LLC converters, especially in high voltage gain and high output current applications.

- Consider multilevel inverter topologies for the multi-objective optimization: In high voltage gain application, multilevel inverter topologies can help reduce the breakdown voltage of the devices and improve their characteristics. Additionally the turns ratio of the transformer can be reduced, helping with the interleaving and reducing the winding losses by reducing the high frequency effects.

- Including the transient behavior in the ZVS auxiliary circuit comparison: The transient behaviour of the different auxiliary circuits was not considered in this work. The design of the components can be modified by the transient behavior as some over-voltages or over-currents may need to be withstood during these transients.

- Including costs and reliability in the pareto analysis: An interesting addition to the multi-objective optimization is the addition of cost. The use of new transistor technologies can improve the efficiency of the converter. However, their cost is also higher. The series/parallel configuration has been shown to improve the power density and efficiency of the LLC converter. However, with increased number of components, complexity, the cost and reliability of the system can be worsen.

\subsection{Diffusion of the results}

The following papers have been published during the research work carried out along the developmental of this thesis: 


\section{Journal papers}

1. Y. E. Bouvier, D. Serrano, U. Borović, G. Moreno, M. Vasić, J. A. Oliver, P. Alou, J. A. Cobos, J. Carmena, "ZVS Auxiliary Circuit for a $10 \mathrm{~kW}$ Unregulated LLC Full-Bridge Operating at Resonant Frequency for Aircraft Application," Energies, vol. 12, no. 10, p. 1850, May 2019.

\section{Conference papers}

1. Y. E. Bouvier, U. Borović, Vasić, J. A. Oliver, P. Alou, J. A. Cobos, F. Arévalo, J. C. García-Tembleque, J. Carmena, "DC/DC fixed frequency resonant LLC full-bridge converter with series-parallel transformers for $10 \mathrm{~kW}$ high efficiency aircraft application," 2017 IEEE Energy Conversion Congress and Exposition (ECCE), Cincinnati, OH, 2017, pp. 3788-3795.

2. Y. Bouvier, M. Vasić, P. Alou, J. A. Oliver, O. García, J. A. Cobos, "45kW Full Bridge Converter with Discontinuous Primary Current for High Efficiency Airborne Application" Seminario Anual de Automática, Eletrónica Industrial e Instrumentación (SAAEI), Jun. 2014.

3. C. Li Y. E. Bouvier, A. Berrios, P. Alou, J. A. Oliver and J. A. Cobos, "Revisiting "Partial Power Architectures" from the "Differential Power" Perspective," 2019 20th Workshop on Control and Modeling for Power Electronics (COMPEL), Toronto, ON, Canada, 2019, pp. 1-8.

4. U. Borović, S. Zhao, M. Silva, Y. E. Bouvier, M. Vasić, J. A. Oliver, P. Alou, J. A. Cobos, F. Arevalo, J. GarciaTembleque, J. Carmena, C. Garcia and P. Pejović "Comparison of Three-phase Active Rectifier Solutions for Avionic Applications: Impact of the Avionic Standard DO-160 F and Failure Modes" IEEE Energy Conversion Congress and Exposition (ECCE), Milwaukee, WI, 2016, pp. 1-8.

5. U. Borović, S. Zhao, M. Silva, Y. E. Bouvier, M. Vasić, J. A. Oliver, P. Alou, J. A. Cobos, P. Pejović, "Comparison of three-phase active rectifiers for aircraft application" Seminario Anual de Automática, Eletrónica Industrial e Instrumentación (SAAEI), Jul. 2015. 



\section{Bibliography}

[1] Ferroxcube. Ferroxcube 3c95/97 materials. https://www.ferroxcube.com/ en-global/download/download/94, 2019. (Cited on pages $\mathrm{xx}, 68,88,97$ and 113.)

[2] Directorate-General for Research and Innovation. Electrification of the transport system - studies and reports, 2017. (Cited on page 1.)

[3] J. W. Kolar, U. Drofenik, J. Biela, M. L. Heldwein, H. Ertl, T. Friedli, and S. D. Round. Pwm converter power density barriers. In 2007 Power Conversion Conference - Nagoya, pages P-9-P-29, April 2007. (Cited on pages 1 and 70.)

[4] Vorpérian Vatché. Analysis of resonant converters. PhD thesis, California Institure of Technology, Pasadena California, 1984. (Cited on page 10.)

[5] V. Vorperian and S. Cuk. A complete dc analysis of the series resonant converter. In 1982 IEEE Power Electronics Specialists conference, pages 85-100, June 1982. (Cited on page 10.)

[6] S. Sooksatra and C. Q. Lee. Non-resonant coupled parallel resonant converter. In Proceedings of the 32nd Midwest Symposium on Circuits and Systems, , pages 781-784 vol.2, Aug 1989. (Cited on page 10.)

[7] R. R. Robson and D. J. Hancock. A 10-kw series resonant converter design, transistor characterization, and base-drive optimization. In 1982 IEEE Power Electronics Specialists conference, pages 33-44, June 1982. (Cited on page 10.)

[8] R. P. Severns. Topologies for three-element resonant converters. IEEE Transactions on Power Electronics, 7(1):89-98, Jan 1992. (Cited on page 10.)

[9] Bo Yang, F. C. Lee, A. J. Zhang, and Guisong Huang. Llc resonant converter for front end dc/dc conversion. In APEC. Seventeenth Annual IEEE Applied Power Electronics Conference and Exposition (Cat. No.02CH37335), volume 2, pages 1108-1112 vol.2, March 2002. (Cited on page 10.)

[10] R. W. Erickson, A. F. Hernandez, A. F. Witulski, and R. Xu. A nonlinear resonant switch. In 20th Annual IEEE Power Electronics Specialists Conference, pages 43-50 vol.1, June 1989. (Cited on page 15.)

[11] X. Fang, H. Hu, Z. J. Shen, and I. Batarseh. Operation mode analysis and peak gain approximation of the llc resonant converter. IEEE Transactions on Power Electronics, 27(4):1985-1995, April 2012. (Cited on page 20.) 
[12] X. Fang, H. Hu, F. Chen, U. Somani, E. Auadisian, J. Shen, and I. Batarseh. Efficiency-oriented optimal design of the llc resonant converter based on peak gain placement. IEEE Transactions on Power Electronics, 28(5):2285-2296, May 2013. (Cited on page 20.)

[13] W. Feng, P. Mattavelli, and F. C. Lee. Pulsewidth locked loop (pwll) for automatic resonant frequency tracking in llc dc-dc transformer (llc-dcx). IEEE Transactions on Power Electronics, 28(4):1862-1869, April 2013. (Cited on page 23.)

[14] X. Wu, H. Chen, and Z. Qian. 1-mhz llc resonant dc transformer (dcx) with regulating capability. IEEE Transactions on Industrial Electronics, 63(5):2904-2912, May 2016. (Cited on page 23.)

[15] B. Lee, M. Kim, C. Kim, K. Park, and G. Moon. Analysis of llc resonant converter considering effects of parasitic components. In INTELEC 2009 - 31st International Telecommunications Energy Conference, pages 1-6, Oct 2009. (Cited on page 24.)

[16] X. Fang, H. Hu, L. Chen, A. Amirahmadi, J. Shen, and I. Batarseh. Operation analysis and numerical approximation for the llc dc-dc converter. In 2012 Twenty-Seventh Annual IEEE Applied Power Electronics Conference and Exposition (APEC), pages 870-876, Feb 2012. (Cited on page 24.)

[17] H. Chen and X. Wu. Analysis on the influence of the secondary parasitic capacitance to zvs transient in llc resonant converter. In 2014 IEEE Energy Conversion Congress and Exposition (ECCE), pages 4755-4760, Sep. 2014. (Cited on page 24.)

[18] R. L. Steigerwald. A comparison of half-bridge resonant converter topologies. In 1987 2nd IEEE Applied Power Electronics Conference and Exposition, pages 135-144, March 1987. (Cited on page 24.)

[19] R. Beiranvand, B. Rashidian, M. R. Zolghadri, and S. M. Hossein Alavi. A design procedure for optimizing the llc resonant converter as a wide output range voltage source. IEEE Transactions on Power Electronics, 27(8):3749-3763, Aug 2012. (Cited on page 37.)

[20] Christian Oeder and Thomas Duerbaum. ZVS investigation of llc converters based on FHA assumptions. In 2013 Twenty-Eighth Annual IEEE Applied Power Electronics Conference and Exposition (APEC), pages 2643-2648. IEEE, mar 2013. (Cited on page 37.)

[21] M. Kasper, R. M. Burkart, G. Deboy, and J. W. Kolar. Zvs of power mosfets revisited. IEEE Transactions on Power Electronics, 31(12):8063-8067, Dec 2016. (Cited on pages 38, 41 and 42.) 


\section{Bibliography}

[22] U. Kundu, K. Yenduri, and P. Sensarma. Accurate zvs analysis for magnetic design and efficiency improvement of full-bridge llc resonant converter. IEEE Transactions on Power Electronics, 32(3):1703-1706, March 2017. (Cited on page 41.)

[23] R. Ren, B. Liu, E. A. Jones, F. Wang, Z. Zhang, and D. Costinett. Accurate zvs boundary in high switching frequency llc converter. In 2016 IEEE Energy Conversion Congress and Exposition (ECCE), pages 1-6, Sep. 2016. (Cited on page 41.)

[24] D. Zhou, X. Zhang, X. Liu, Y. Wang, D. Xu, and H. Tian. Design of llc converter parameters based on zvs characteristic analysis. In 2018 21st International Conference on Electrical Machines and Systems (ICEMS), pages 2251-2255, Oct 2018. (Cited on page 41.)

[25] W. Qin, L. Zhang, and X. Wu. Re-examination of zvs condition for mhz llc converter operating at resonant frequency. In 2018 IEEE International Power Electronics and Application Conference and Exposition (PEAC), pages 1-4, Nov 2018. (Cited on page 41.)

[26] M. Borage, S. Tiwari, S. Bhardwaj, and S. Kotaiah. A full-bridge dc-dc converter withzero-voltage-switching overthe entire conversion range. IEEE Transactions on Power Electronics, 23(4):1743-1750, July 2008. (Cited on page 45.)

[27] A. F. Jabbar, M. Mansor, and N. A. Rahim. Pulse-width control scheme for fixed-frequency zvs dc-dc converter with active auxiliary circuit. In 2013 IEEE Conference on Clean Energy and Technology (CEAT), pages 124-127, Nov 2013. (Cited on page 45.)

[28] P. K. Jain, Wen Kang, H. Soin, and Youhao Xi. Analysis and design considerations of a load and line independent zero voltage switching full bridge $\mathrm{dc} / \mathrm{dc}$ converter topology. IEEE Transactions on Power Electronics, 17(5):649-657, Sep. 2002. (Cited on pages 45 and 50.)

[29] A. Safaee, P. Jain, and A. Bakhshai. A zvs pulsewidth modulation full-bridge converter with a low-rms-current resonant auxiliary circuit. IEEE Transactions on Power Electronics, 31(6):4031-4047, June 2016. (Cited on pages 45 and 52.)

[30] A. Safaee, P. Jain, and A. Bakhshai. A low-rms-current passive auxiliary circuit for zvs operation of full bridge converters. In 2014 IEEE Energy Conversion Congress and Exposition (ECCE), pages 5065-5070, Sep. 2014. (Cited on pages 45 and 52.)

[31] A. Safaee, P. K. Jain, and A. Bakhshai. An adaptive zvs full-bridge dc-dc converter with reduced conduction losses and frequency variation range. IEEE 
Transactions on Power Electronics, 30(8):4107-4118, Aug 2015. (Cited on pages 45 and 52.)

[32] H. Sugimura, H. Muraoka, K. Soushin, M. Matsuda, and M. Nakaoka. Dual mode zvs-pwm high frequency load resonant inverter with auxiliary edge resonant snubber for super heated steamer. In IECON'03. 29th Annual Conference of the IEEE Industrial Electronics Society (IEEE Cat. No.03CH37468), volume 2, pages 1679-1684 Vol.2, Nov 2003. (Cited on page 45.)

[33] Yann E. Bouvier, Diego Serrano, Uroš Borović, Gonzalo Moreno, Miroslav Vasić, Jesús A. Oliver, Pedro Alou, José A. Cobos, and Jorge Carmena. Zvs auxiliary circuit for a $10 \mathrm{kw}$ unregulated llc full-bridge operating at resonant frequency for aircraft application. Energies, 12(10):1850, May 2019. (Cited on page 48.)

[34] TDK. MLCC (Multilayer Ceramic Chip Capacitor) C0G Guide for Resonance Circuit Vol.1 - Multilayer Ceramic Chip Capacitors . (Cited on pages 56, 104 and 115.)

[35] J. W. Kolar, J. Biela, S. Waffler, T. Friedli, and U. Badstuebner. Performance trends and limitations of power electronic systems. In 2010 6th International Conference on Integrated Power Electronics Systems, pages 1-20, March 2010. (Cited on page 61.)

[36] Dusan Graovac, Marco Purschel, and Kiep Andreas. MOSFET Power Losses Calculation Using the Data- Sheet Parameters. 2006. (Cited on page 64.)

[37] P. L. Dowell. Effects of eddy currents in transformer windings. Proceedings of the Institution of Electrical Engineers, 113(8):1387-1394, August 1966. (Cited on pages 66 and 67.)

[38] F. A. Holguín, R. Prieto, R. Asensi, and J. A. Cobos. Power losses calculations in windings of gapped magnetic components. In 2014 IEEE Applied Power Electronics Conference and Exposition - APEC 2014, pages 2605-2506, March 2014. (Cited on page 66.)

[39] ANSYS PEmag. https://www.ansys.com. (Cited on page 67.)

[40] I. Bianchi and M. F. da Silva. Two simple techniques for hysteresis power losses measurement. In 2007 IEEE Instrumentation Measurement Technology Conference IMTC 2007, pages 1-3, May 2007. (Cited on page 67.)

[41] Jieli Li, T. Abdallah, and C.R. Sullivan. Improved calculation of core loss with nonsinusoidal waveforms. In Conference Record of the 2001 IEEE Industry Applications Conference. 36th IAS Annual Meeting (Cat. No.01CH37248), volume 4, pages 2203-2210. IEEE. (Cited on page 69.) 


\section{Bibliography}

[42] Uwe Drofenik, Gerold Laimer, and Johann Kolar. Theoretical converter power density limits for forced convection cooling. pages 608-619., 06 2005. (Cited on page 72.)

[43] F. Farahmand, F.P. Dawson, and J.D. Lavers. Critical Temperature for Thermal Runaway in a Magnetic Material. IEEE Transactions on Magnetics, 44(11):4513-4516, nov 2008. (Cited on page 78.)

[44] W. G. Hurley, T. Merkin, and M. Duffy. The performance factor for magnetic materials revisited: The effect of core losses on the selection of core size in transformers. IEEE Power Electronics Magazine, 5(3):26-34, Sep. 2018. (Cited on page 88 .)

[45] B. Artl. Wide band gap devices are mature, July 2019. (Cited on pages 88, 104 and 112.)

[46] C. Fei, F. C. Lee, and Q. Li. High-efficiency high-power-density llc converter with an integrated planar matrix transformer for high-output current applications. IEEE Transactions on Industrial Electronics, 64(11):9072-9082, Nov 2017. (Cited on page 89.)

[47] J. Lu, S. Stegen, and D. Butler. High frequency and high power density transformers for $\mathrm{dc} / \mathrm{dc}$ converter used in solar pv system. In The 2nd International Symposium on Power Electronics for Distributed Generation Systems, pages 481-484, June 2010. (Cited on page 89.)

[48] Z. Ouyang and M. A. E. Andersen. Overview of planar magnetic technology - fundamental properties. IEEE Transactions on Power Electronics, 29(9):4888-4900, Sep. 2014. (Cited on page 89.)

[49] M. A. Saket, N. Shafiei, and M. Ordonez. Planar transformer winding technique for reduced capacitance in llc power converters. In 2016 IEEE Energy Conversion Congress and Exposition (ECCE), pages 1-6, Sep. 2016. (Cited on page 89.)

[50] A. Khan, D. Waheed, M. B. Siddiqui, M. S. Anwer, S. W. Hussain, and I. A. Makda. Design and comparative analysis of litz and copper foil transformers for high frequency applications. In 2018 20th European Conference on Power Electronics and Applications (EPE'18 ECCE Europe), pages P.1-P.10, Sep. 2018. (Cited on page 90.)

[51] B. R. Lin, P. L. Chen, and C. L. Huang. Analysis of LLC converter with series-parallel connection. In 2010 5th IEEE Conference on Industrial Electronics and Applications, pages 346-351. IEEE, jun 2010. (Cited on pages 93 and 104.)

[52] AIR: Active and Isolated Rectifier - indra. (Cited on page 107.) 


\section{Bibliography}

[53] Clean Sky - European initiative. (Cited on page 107.)

[54] K. Emadi and M. Ehsani. Aircraft power systems: technology, state of the art, and future trends. IEEE Aerospace and Electronic Systems Magazine, 15(1):28-32, 2000. (Cited on page 107.)

[55] J.A. Rosero, J.A. Ortega, E. Aldabas, and L. Romeral. Moving towards a more electric aircraft. IEEE Aerospace and Electronic Systems Magazine, 22(3):3-9, mar 2007. (Cited on page 107.)

[56] Xin Zhao, Josep M. Guerrero, and Xiaohua Wu. Review of aircraft electric power systems and architectures. In 2014 IEEE International Energy Conference (ENERGYCON), pages 949-953. IEEE, may 2014. (Cited on page 107.)

[57] R.I. Jones. The More Electric Aircraft: the past and the future? In IEE Colloquium. Electrical Machines and Systems for the More Electric Aircraft, volume 1999, pages 1-1. IEE, 1999. (Cited on page 107.)

[58] Texas Instrument. TMS320F28379D Delfino ${ }^{T M}$ 32-bit MCU with 800 MIPS, 2xCPU, 2xCLA, FPU, TMU, 1024 KB Flash, CLB, EMIF, 16b ADC - TI.com. (Cited on page 116.) 